\title{
Demographic, Spatial, And Epigenetic Response Of The Louisiana Waterthrush (Parkesia Motacilla) To Shale Gas Development
}

\author{
Mack W. Frantz \\ West Virginia University, mwfrantz@mix.wvu.edu
}

Follow this and additional works at: https://researchrepository.wvu.edu/etd

Part of the Ornithology Commons

\section{Recommended Citation \\ Frantz, Mack W., "Demographic, Spatial, And Epigenetic Response Of The Louisiana Waterthrush (Parkesia Motacilla) To Shale Gas Development" (2019). Graduate Theses, Dissertations, and Problem Reports. 3920. \\ https://researchrepository.wvu.edu/etd/3920}

This Dissertation is protected by copyright and/or related rights. It has been brought to you by the The Research Repository @ WVU with permission from the rights-holder(s). You are free to use this Dissertation in any way that is permitted by the copyright and related rights legislation that applies to your use. For other uses you must obtain permission from the rights-holder(s) directly, unless additional rights are indicated by a Creative Commons license in the record and/ or on the work itself. This Dissertation has been accepted for inclusion in WVU Graduate Theses, Dissertations, and Problem Reports collection by an authorized administrator of The Research Repository @ WVU. For more information, please contact researchrepository@mail.wvu.edu. 


\title{
DEMOGRAPHIC, SPATIAL, AND EPIGENETIC RESPONSE OF THE LOUISIANA WATERTHRUSH (PARKESIA MOTACILLA) TO SHALE GAS DEVELOPMENT
}

\author{
Mack W. Frantz \\ Dissertation submitted to the \\ Davis College of Agriculture, Natural Resources, and Design at \\ West Virginia University \\ in partial fulfillment of the requirements for the degree of \\ Doctor of Philosophy in \\ Forest Resource Science
}

Petra Wood, Ph.D., Chair

Steve Latta, Ph.D.

Mike Strager, Ph.D.

Amy Welsh, Ph.D.

Stuart Welsh, Ph.D.

Wildlife and Fisheries Resources Program

Division of Forestry and Natural Resources

\section{Morgantown, West Virginia 2019}

Keywords: aquatic-terrestrial, bioindicator species, demographic, disturbance, DNA methylation, energy impacts, epigenetic, foraging, forested watershed, habitat quality, headwater stream, heavy metals, hydraulic fracturing, macroinvertebrate, Marcellus-Utica, site fidelity, spatial, survival, territory, unconventional shale gas 


\title{
ABSTRACT \\ DEMOGRAPHIC, SPATIAL, AND EPIGENETIC RESPONSE OF THE LOUISIANA WATERTHRUSH (PARKESIA MOTACILLA) TO SHALE GAS DEVELOPMENT
}

\begin{abstract}
Mack W. Frantz
My study centered on a bioindicator songbird, the Louisiana Waterthrush (Parkesia motacilla), hereafter waterthrush, an organism that co-occurs in both forested and aquatic habitat across the aquatic-terrestrial interface. This enabled the opportunity to quantify demographic, spatial, and epigenetic (i.e., DNA methylation) responses in a highly forested watershed of the Central Appalachians, the areas that have undergone the most rapid transformations over the last decade from unconventional shale gas development and activities. I organized my dissertation into 4 parts (Part 1: Introduction, Part 2: Louisiana Waterthrush Demography, Part 3: Spatial Assessment of Louisiana Waterthrush Foraging, Part 4: Louisiana Waterthrush Molecular Ecology) including 6 chapters that indicate multiple biotic and abiotic factors interacted with or were altered by shale gas development resulting in atypical, negative disturbances that drove a steep decline in a waterthrush population in West Virginia.

Part 1 includes Chapter 1 and is an introduction to my dissertation. I introduce the reader to the rationale for my study, the focal species, research objectives, and the study area. I also mention some limitations to my study that can be considered in any future research endeavors.

Part 2 comprises Chapters $2-3$ which are a comprehensive examination of demographic parameters over a six-year period (2009-2011, 2013-2015). In Chapter 2, I examined demographic response to shale gas development for nest abandonment, nest survival, nest productivity, a source-sink threshold, riparian habitat quality, and territory density and length. Nest productivity was lower in areas disturbed by shale gas where a source-sink threshold suggested these areas were more at risk of being sink habitat. Overall results suggest a decline in waterthrush site quality as shale gas development increased. In Chapter 3, I focused on first-year return rates (site fidelity), site fidelity factors, and apparent survival. I related natal fidelity and pairing rates to territory density, and also compared \# of breeding attempts between return and non-returning females with and without territory shale gas disturbance. The study identified
\end{abstract}


potential conflicts between factors that influence adult survival and site fidelity that may affect long-term population persistence.

Part 3 includes Chapters 4-5 and focuses on utilizing and accounting for spatial properties intrinsic to stream ecosystems to make informed decisions regarding waterthrush foraging. Chapter 4 was a follow-up to a waterthrush aquatic prey study at our site in 2011 that suggested shale gas development negatively affected waterthrush demography from alterations in their aquatic prey at a watershed scale. During 2013-2014, I quantified waterthrush demographic response and nest survival in relation to potential changes in its aquatic prey due to shale gas development. I utilized spatial generalized linear mixed models that accounted for both spatial and non-spatial sources of variability. I found waterthrush aquatic prey was negatively affected by shale gas development at the nest and territory level, and that there may be a disturbance threshold at which waterthrush can no longer adapt and respond negatively to changes in its aquatic prey. In Chapter 5, I used spatial stream network models (SSNMs) to explore relationships among the waterthrush, stream channel and monitoring data, and the aquatic prey of the waterthrush. I compared the spatial models to traditional regression models to see which ones performed best. We sampled aquatic prey in waterthrush territories and collected wetted perimeter stream channel and water chemistry data along a $50 \mathrm{~m}$ fixed point stream grid that mapped the foraging substrate or stream channel where waterthrush forage. By relating foraging observations and data collected to the stream grid, I was able to develop a foraging probability index that determined what conditions or variables create or affect ideal foraging locations. Spatial models outperformed traditional regression models and made a statistical difference in whether stream covariates of interest were considered relatable to waterthrush foraging. My study also indicated waterthrush forage in areas of higher biotic stream integrity.

Lastly, Part 4 includes Chapter 6 where I examined epigenetic modifications. These are alterations to genes without changing the gene sequence and can be thought of as an evolutionary "soft" inheritance of gene expression that can either be adaptive or maladaptive for the individual. DNA methylation is one type of epigenetic modification that may vary in response to environmental stressors. We examined the association between DNA methylation and demographic characteristics in addition to potential differential methylation from shale gas development. There was differential methylation for demographic characteristics as well as for adult males between shale gas undisturbed and disturbed areas. Barium ( $\mathrm{Ba})$ and strontium $(\mathrm{Sr})$ 
data were collected in 2013 feather samples where adult males had fewer methylated sites at higher concentrations of $\mathrm{Ba}$ and $\mathrm{Sr}$, while nestlings displayed no correlation of methylation to $\mathrm{Ba}$ and $\mathrm{Sr}$ concentrations. Females displayed increased methylation with increased $\mathrm{Ba}$ and $\mathrm{Sr}$, a trend reflected in adult female recaptures. Overall, results of our study suggest sex-specific influences of shale gas development on gene expression that may affect long-term population survival and fitness. 


\section{DEDICATION}

To my father, William C. Frantz (1949-2013).

Semper fidelis. 


\section{ACKNOWLEDGEMENTS}

There are many people that have been part of my journey since starting the Ph.D. program in 2012. Foremost, I would like to thank my graduate advisor Dr. Petra Wood for initially taking a chance on me to become her graduate student when I was working as a field technician for her Golden-winged Warbler (Vermivora chrysoptera) study, and at the time had not yet finished my Master's thesis. Her consideration, professionalism, and dedication to conservation are admirable traits that make for a great mentor and wildlife biologist. I thank her for her guidance throughout this process, and for trusting me when I started working full-time in a career position before finishing my dissertation. I appreciate Amy Welsh, Mike Strager, Stuart Welsh, and Steve Latta for serving on my graduate committee, and by doing so sharing their unique insights and experiences when reviewing this body of work. An additional thank you goes out to Amy for "adopting" me as one of her students for the epigenetic portion of the dissertation, sharing both knowledge and resources.

My time at WVU would not have been the same without the camaraderie and advice of fellow "Wood Lab" members, namely Ryan Davis, Jim Sheehan, Kyle Aldinger, Gretchen Nareff, Laura Farwell, and Eric Margenau. I thank Wild Genomics Lab members for the same shared experiences. A special thank you goes to Becky Nestor, Administrative Secretary Extraordinaire, who always went up and beyond to look after us graduate students. I thank Chris Rota, Donald Brown, George Merovich, and Adam Duerr for statistical guidance. I thank Donna Hartman, Eric Merriam, Eric Miller, and Andrew Watson for teaching me how to identify benthics under the scope, Greg Pond and George Merovich for their benthic assistance, and ultimately Brian Carlson for identifying my benthic samples.

Robert (Blake) Hepburn and Jack Toriello were the absolute best field technicians I could ever ask for during my first field season; no one can outdo their hard work or genuine coolness. I have full appreciation of the efforts of all field technicians and lab volunteers that have worked with me: Ashley Akers, Cody Bassett, Darin Blood, Tasso Cocoves, Jess Cosentino, Sara Crayton, Steve Daniels, Nick Glover, Jerry Kreiser, and Celeste Rosencrance. In particular, I thank Greg George, Doug Becker, Jim Sheehan and Jeremy Mizel for their initial waterthrush work before I came on the scene. I am grateful for housing arrangements at Lantz Farm and Nature Preserve provided jointly by Wheeling Jesuit University and West Virginia Division of Natural Resources (WVDNR), housing arrangements with Lantz Farm caretaker 
Don Sweaney the first year, then Connie and David Sivert thereafter, and for general support from Jordan Stackpole, Wildlife Manager of Lewis Wetzel Wildlife Management Area. Funding for this project was provided by the West Virginia Division of Natural Resources (WVDNR), U.S. Department of Energy National Energy Technology Laboratory, Appalachian Stewardship Foundation (ASF), West Virginia University (WVU), National Aviary, Eastern Bird Banding Association (EBBA), and First Catholic Slovak Ladies Association (FCSLA). This dissertation was also supported by the USDA National Institute of Food and Agriculture, Hatch project WVA00690.

I thank my wife Renee for her love and support throughout graduate school, both for my Master's thesis and Ph.D. dissertation. I cannot thank her enough for her encouragement just to keep pushing onward where every little bit of progress counts. I look forward to our married life together outside the confines of school! Finally, I am thankful to God knowing that I never need to be anxious about anything, but in every situation, by prayer and petition, with thanksgiving, present your requests to God. And the peace of God, which transcends all understanding, will guard your hearts and your minds in Christ Jesus (Philippians 4:6-7). 


\section{TABLE OF CONTENTS}

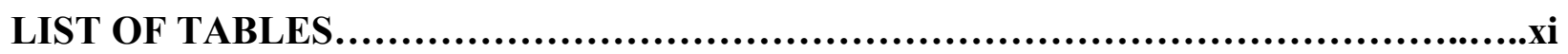

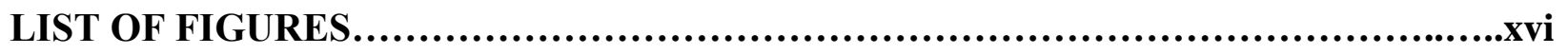

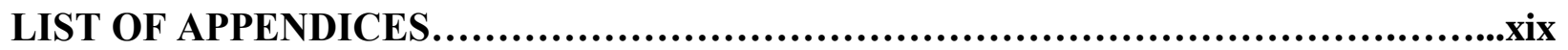

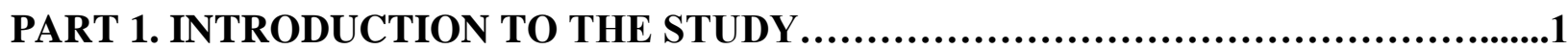

CHAPTER 1. INTRODUCTION........................................................

LITERATURE CITED ...............................................................

PART 2. LOUISIANA WATERTHRUSH DEMOGRAPHY .............................11

CHAPTER 2. DEMOGRAPHIC RESPONSE OF LOUISIANA WATERTHRUSH, A STREAM OBLIGATE SONGBIRD OF CONSERVATION CONCERN, TO SHALE GAS

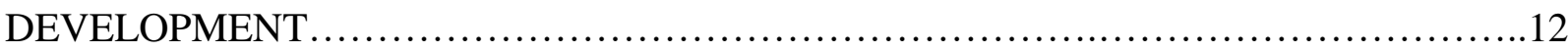

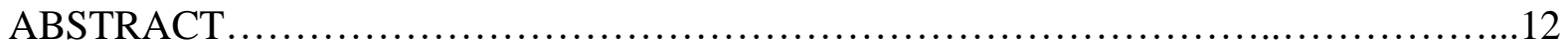

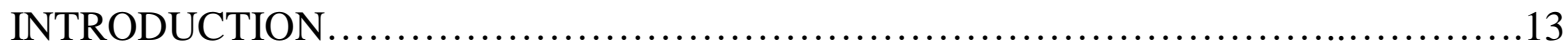

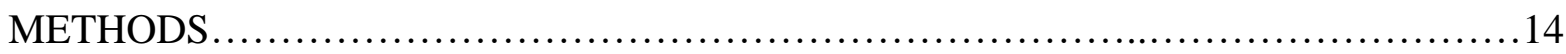

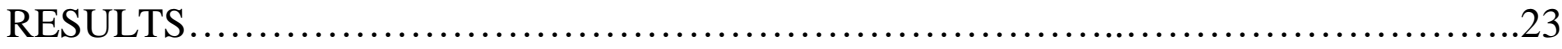

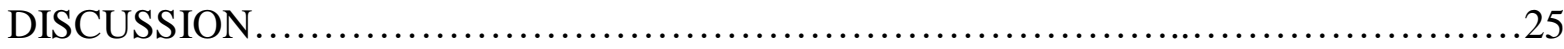

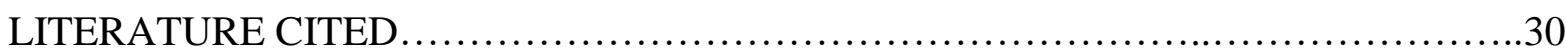

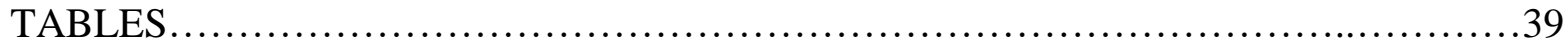

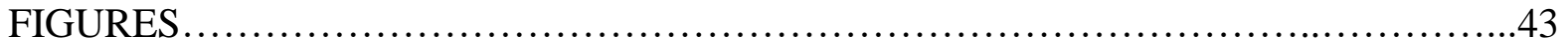

CHAPTER 3. LOUISIANA WATERTHRUSH (PARKESIA MOTACILLA) SURVIVAL AND SITE FIDELITY IN AN AREA UNDERGOING SHALE GAS

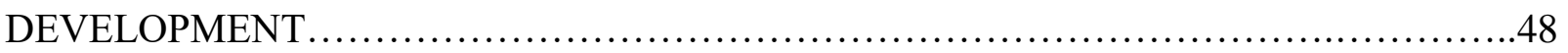

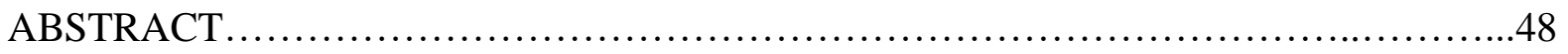

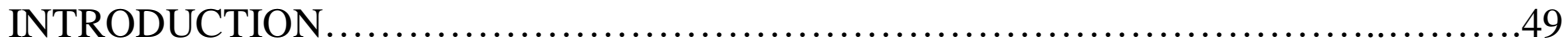

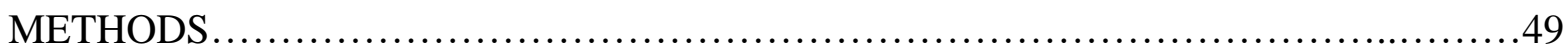

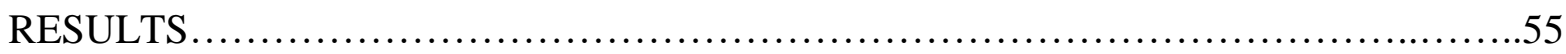

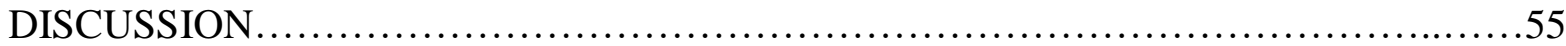

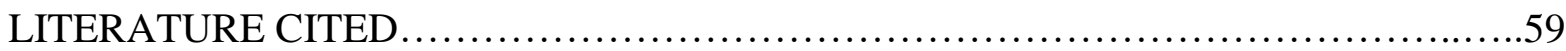




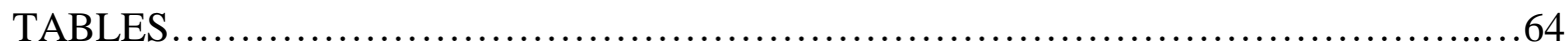

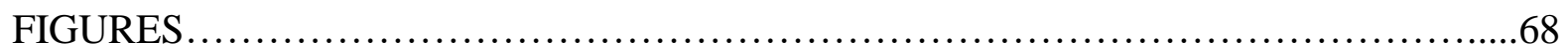

PART 3. SPATIAL ASSESSMENT OF LOUISIANA WATERTHRUSH FORAGING....71 CHAPTER 4. DEMOGRAPHIC CHARACTERISTICS OF AN AVIAN PREDATOR, LOUISIANA WATERTHRUSH (PARKESIA MOTACILLA), IN RESPONSE TO ITS AQUATIC PREY IN A CENTRAL APPALACHIAN USA WATERSHED IMPACTED BY SHALE GAS DEVELOPMENT......................................................... 72

ABSTRACT

CHAPTER 5. SPATIAL STREAM MODELING OF LOUISIANA WATERTHRUSH (PARKESIA MOTACILLA) FORAGING SUBSTRATE AND AQUATIC PREY IN A WATERSHED UNDERGOING SHALE GAS DEVELOPMENT .........................102

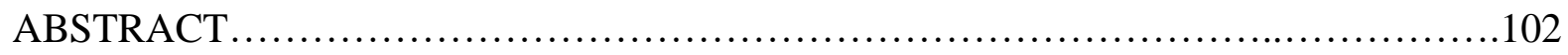

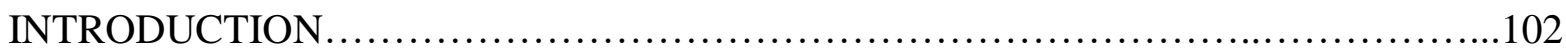

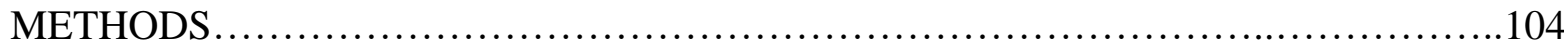

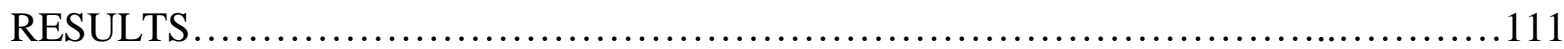

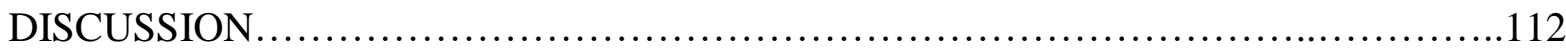

LITERATURE CITED ..............................................................

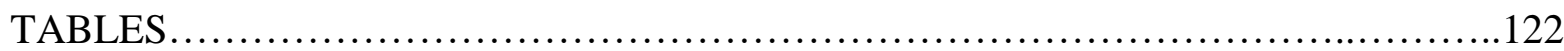

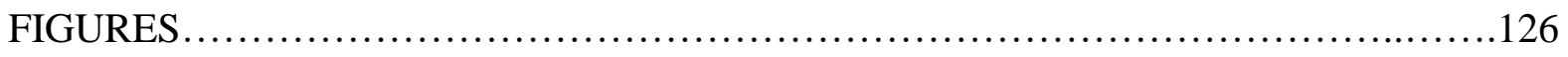


PART 4. LOUISIANA WATERTHRUSH MOLECULAR ECOLOGY.

.132

CHAPTER 6. EPIGENETIC RESPONSE OF LOUISIANA WATERTHRUSH (PARKESIA MOTACILLA) RELATED TO SHALE GAS DEVELOPMENT............................133

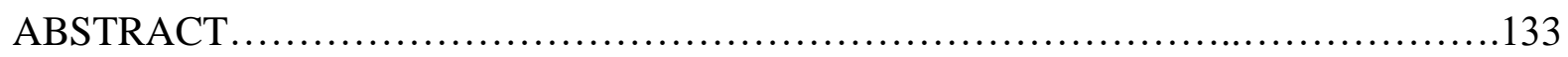

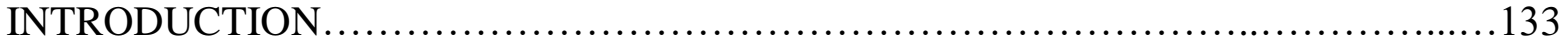

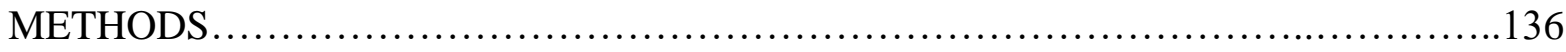

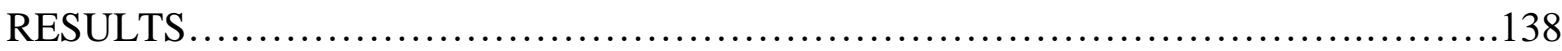

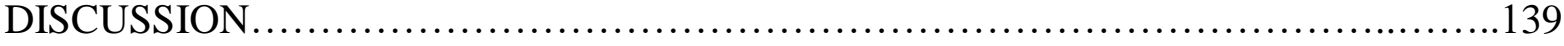

LITERATURE CITED ...................................................................

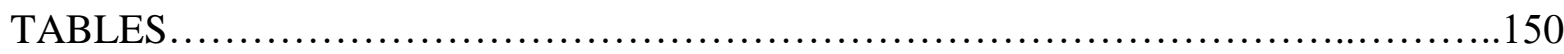

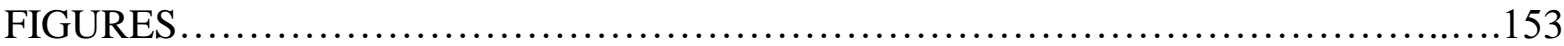

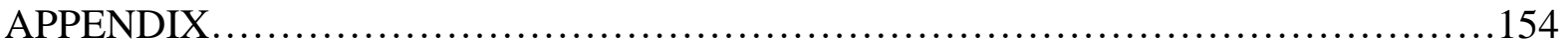




\section{LIST OF TABLES}

\section{CHAPTER 2. DEMOGRAPHIC RESPONSE OF LOUISIANA WATERTHRUSH, A STREAM OBLIGATE SONGBIRD OF CONSERVATION CONCERN, TO SHALE GAS DEVELOPMENT.

Table 1. Annual percent of each study stream's length that was disturbed by shale gas development or activity (StreamGas, SG; see Table 2) or potentially affected by runoff (StreamRunoff, SR) from shale gas well pads (not including pipeline or road disturbance). The

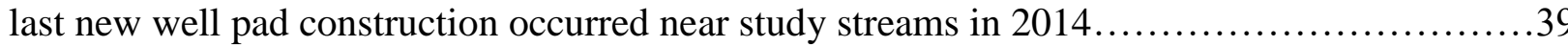

Table 2. Variables used in analyses evaluating the demographic response of Louisiana Waterthrush to shale gas development. Nest survival is daily survival rate (DSR) over a 29-day nesting period $\left(\mathrm{DSR}^{29}\right)$.

Table 3. Louisiana Waterthrush demography across six years in response to shale gas development at Lewis Wetzel Wildlife Management Area, WV. Population productivity is mean number of fledglings/successful nest/year multiplied by annual nest survival and average annual territory density/km of stream. Also shown are average annual EPA and habitat suitability index (HSI) scores \pm SE. A larger EPA or HSI score indicates better riparian habitat quality....

Table 4. AICc model results of 11 a priori nest survival models using Program MARK. See Table 2 for model notation. $\triangle \mathrm{AICc}=$ difference from the top model, $w_{\mathrm{i}}=$ Akaike weight, and $\mathrm{K}$ $=$ the number of parameters in each model ..........................................42

Table 5. Summary results for nest survival covariates $(n=7)$ from the top supported AICc models $(n=4)$ based on model-averaged regression coefficients, with unconditional standard error (SE) and 85\% confidence intervals. Significant covariates with non-overlapping confidence intervals are bolded.................................................................... 42

\section{CHAPTER 3. LOUISIANA WATERTHRUSH (PARKESIA MOTACILLA) SURVIVAL AND SITE FIDELITY IN AN AREA UNDERGOING SHALE GAS DEVELOPMENT}

Table 1. Annual percent apparent site fidelity (\# banded in previous year divided by \# resighted) for adult and nestling waterthrush. Annual adult male apparent survival $(\phi)$ and standard error (SE) from the year-only covariate model. Annual adult apparent survival was modeled for males only since female sample size was too small for a time-dependence parameter. Year interval represents a year +1 time interval for reporting apparent site fidelity and survival from the previous year. The study did not occur in 2012, so the 2011-2013 return rates are for individuals banded in 2011. Note only one female was banded in 2011 for the $0 \%$ female return rate from 2011-2013. Years where fidelity or survival could not be calculated are indicated with "-" either due to no newly banded waterthrush the previous year or because the study ended in $2015 \ldots . .64$

Table 2. A descriptive summary of site fidelity factors ( \pm standard error, SE) for adult male and female waterthrush that differed between returned vs. did not return birds (noted with *) and 
compared between shale gas disturbed and undisturbed territories. Productivity is the number of fledglings produced adjusted for nest survival in shale gas disturbed/undisturbed territories in the manner of Boves et al. (2015) and Frantz et al. (2018a). Higher EPA (range: 0-200) and HSI (range: 0-1) scores are indicative of better riparian habitat quality for waterthrush and their

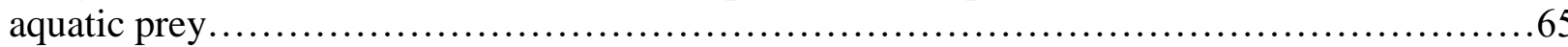

Table 3. Cormack-Jolly-Seber candidate models used to estimate male and female apparent survival $(\phi)$. AvgTerrGas was the average of shale gas territory disturbance across all years that an individual returned. AvgTerrRunoff was the average of potential hydraulic fracturing runoff in a territory across all years that an individual returned. The covariate year modeled time dependency (4 parameters). $\Delta \mathrm{AICc}=$ distance from the top model, $w_{i}=$ Akaike weight, $\mathrm{K}=$ the number of parameters in each model. The model term $\phi(\sim 1)$ indicates apparent survival was held constant. Model term $p(\sim 1)$ for encounter probability was held constant in every model. The constant model is $\phi(\sim 1) p(\sim 1)$. .

Table 4. Summary results for male and female apparent survival $(\phi)$ in the top supported models (i.e., models where $\triangle \mathrm{AICc}<2$ ). Male results are model-averaged regression coefficients while female results are unstandardized regression coefficients \pm standard error (SE). AvgTerrGas was the average of shale gas territory disturbance across all years that an individual returned. AvgTerrRunoff was the average potential hydraulic fracturing runoff in a territory across all years an individual returned. The covariate year modeled time dependency. Model supported covariates $(n=3)$ were not significant and had overlapping confidence intervals

\section{CHAPTER 4. DEMOGRAPHIC CHARACTERISTICS OF AN AVIAN PREDATOR, LOUISIANA WATERTHRUSH (PARKESIA MOTACILLA), IN RESPONSE TO ITS AQUATIC PREY IN A CENTRAL APPALACHIAN USA WATERSHED IMPACTED} BY SHALE GAS DEVELOPMENT.

Table 1. Louisiana Waterthrush annual demographic, riparian habitat quality, and shale gas disturbance metrics (mean \pm SE) at Lewis Wetzel Wildlife Management Area, WV at peak (2011) and later stages (2013-2014) of shale gas development. Our study associated waterthrush response to aquatic prey community changes in relation to shale gas disturbance. All metrics are a subset of those originally reported in Frantz et al. [28] excepting \% shale gas land cover which is cited from Farwell et al. [33]. Variable names are defined in Appendix Table 2..............91

Table 2. Association between waterthrush riparian habitat quality indices (i.e., EPA and HSI) and aquatic prey metrics in spatial generalized linear mixed models. In 2013, aquatic prey biomass and density increased with increasing EPA score, while in 2014 intolerant genera increased with increasing EPA score. No relationships were statistically significant in 2013 between HSI and aquatic prey, but in 2014 intolerant genera and WVSCI (approaching significance) increased with increasing HSI score. Results with ${ }^{\mathrm{P}}$ are from a Poisson model. $\mathrm{P}$ values of variables that are statistically significant are bolded. Variable names are defined in S1 Table 2. LRT $=$ likelihood ratio test $\chi 2$ statistic. $\beta=$ beta estimate of fixed effect..............92

Table 3. Association between waterthrush aquatic prey and shale gas disturbance metrics in spatial generalized linear mixed models. Results with ${ }^{\mathrm{P}}$ are from a Poisson model. In 2013, EPT 
richness increased with increasing TerrRunoff, but in 2014 EPT richness decreased with increasing TerrGas. In 2014, intolerant genera decreased with increasing TerrRunoff, TerrGas, and NestGas. $P$ values of variables that are statistically significant are bolded. Variable names are defined in S1 Table 2. LRT = likelihood ratio test $\chi 2$ statistic. $\beta=$ beta estimate of fixed

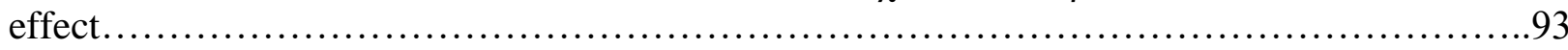

Table 4. Association between waterthrush demographic response (i.e., clutch size, number of fledglings, territory length and territory density) and its aquatic prey in spatial generalized linear mixed models. All tests for the relationships between clutch size, number of fledglings, and territory density with aquatic prey metrics were statistically non-significant. Territory length decreased with increasing aquatic prey density and number of intolerant genera in 2013. Results with ${ }^{\mathrm{P}}$ are from a Poisson model. $\mathrm{P}$ values of variables that are statistically significant are bolded. Variable names are defined in S1 Table 2. LRT $=$ likelihood ratio test $\chi 2$ statistic. $\beta=$ beta estimate of fixed effect

Table 5. Year 2013 and 2014 AICc model results of 7 a priori nest survival models with aquatic prey covariates using Program MARK. Of 7 a priori nest survival models, 6 different models were supported $(\triangle \mathrm{AICc}<2)$ in 2013 and 2014 with the null base model having the most weight in both years $(\mathrm{wi}=0.25,0.28) . \Delta \mathrm{AICc}=$ distance from the top model, and $w_{\mathrm{i}}=$ Akaike weight.

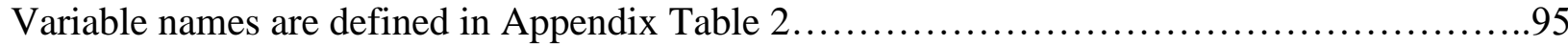

Table 6. Annual waterthrush nest survival covariates found in the top supported ( $\triangle \mathrm{AICc}<2, \mathrm{n}=$ $6)$ and unsupported $(n=1)$ AICc models based on regression coefficients, standard error $(\mathrm{SE})$, and $85 \%$ confidence intervals. In the null base model Rain had positive influence on daily survival rate (DSR) in 2013 and 2014, while TerrRunoff had negative influence on nest survival in 2014. Significant covariates with non-overlapping confidence intervals are bolded. Covariates included in every model to account for their influence (i.e., Rain, NestAge, TT, and TerrRunoff; [28]) have model-averaged regression coefficients and unconditional SEs. Variable names are defined in S1 Table 2............................................................... 96

\section{CHAPTER 5. SPATIAL STREAM MODELING OF LOUISIANA WATERTHRUSH (PARKESIA MOTACILLA) FORAGING SUBSTRATE AND AQUATIC PREY IN A} WATERSHED UNDERGOING SHALE GAS DEVELOPMENT.

Table 1. Initial non-spatial linear models (with nugget) to test the relationship between foraging score, water chemistry, macroinvertebrate metrics, shale gas land use and foraging probability index (FPI). Covariates with bolded $P$ values were significant at $\alpha=0.10 . \mathrm{R}^{2}$ is a generalized value of model fit and the partial sill (sill minus nugget) was included to assess variance of a covariate without the nugget effect...

Table 2. Initial spatial generalized linear models to test the relationship between foraging score, water chemistry, macroinvertebrate metrics, shale gas land use and foraging probability index (FPI). Covariates with bolded $P$ values were significant at $\alpha=0.10 . \mathrm{R}^{2}$ is a generalized value of model fit and the partial sill (sill minus nugget) was included to assess variance of a covariate without the nugget effect.... 
Table 3. Initial mixed autocovariance components (VAC) of the WVSCI and GLIMPSS spatial models. The nugget captures variability due to measurement error and/or spatial variability at less than the sampling distance. The range represents the distance at which the covariate is no longer spatially autocorrelated. The partial sill (sill minus nugget) assesses variance of a covariate without the nugget effect. Percent VAC is the percentage of residual variance accounted for by each autocovariance component. Based on higher partial sill values for Exponential TD, we added Mariah, Spherical, and Linear-with-sill TD to test before final selection of autocovariance components

Table 4. AIC model comparison for WVSCI and GLIMPSS spatial models with Exponential Euclidean, Exponential tail down (TD), Spherical TD, and Linear plus sill TD autocovariance components in comparison to the non-spatial model with less parameters. Lowest leave-one-out cross-validation root-mean-square-prediction error (RMSPE) and AIC value was used to assess which models to select for final model comparison.

Table 5. Final AIC model comparison for WVSCI \& GLIMPSS. Lowest leave-one-out crossvalidation root-mean-square-prediction error (RMSPE) and AIC value was used to select what model best explains foraging probability index (FPI).

Table 6. Final autocovariance components (VAC) of the WVSCI and GLIMPSS spatial models that best explain foraging probability index (FPI). The nugget captures variability due to measurement error and/or spatial variability at less than the sampling distance. The range represents the distance at which the covariate is no longer spatially autocorrelated. The partial sill (sill minus nugget) assesses variance of a covariate without the nugget effect. Percent VAC is the percentage of residual variance accounted for by each autocovariance component..........125

\section{CHAPTER 6. EPIGENTIC RESPONSE OF LOUISIANA WATERTHRUSH (PARKESIA MOTACILLA) RELATED TO SHALE GAS DEVELOPMENT........................133}

Table 1. Summary results of Analysis of Molecular Variance (AMOVA) performed on 100 methylation-sensitive amplified fragment-length polymorphism (MS-AFLP) restriction sites grouped by sex, adult female vs. nestling, age (second year [SY] vs. after second year [ASY]) and shale gas disturbance status (TerrGas), showing differential methylation $(P<0.10)$ on a population level........................................................... 150

Table 2. Summary results of Analysis of Molecular Variance (AMOVA) performed on 100 methylation-sensitive amplified fragment-length polymorphism (MS-AFLP) restriction sites grouped by adult male vs. nestling and shale gas disturbance status (TerrGas and TerrRunoff), indicating no differential methylation $(P>0.10)$ on a population level....................151

Table 3. A summary of recaptures $(n=9)$ that were sampled from year to year to evaluate the degree to which an individual's methylated state was subject to change. All Sites indicates the total number of methylated sites across all restriction sites $(\mathrm{n}=100)$, while Male vs. Female ( $\mathrm{n}$ $=39)$, Female vs. Nestling $(n=35)$, Male Age $(n=21)$, Female Age $(n=18)$, and TerrGas $(n=$ 10) indicates the total number of methylated sites across restriction sites determined to be differentially methylated. TerrGas Presence and TerrRunoff Presence are the presence (1) or 
absence $(0)$ of shale gas territory disturbance. The only nestling recapture was an adult female. Individuals with Strontium (Sr) and Barium (Ba) data from 2013 have Box-Cox transformed ppm values displayed as used in the Pearson correlations. NA $=$ the data is not available. Data that is not applicable is indicated with "_" because differential methylation was not tested...152 


\section{LIST OF FIGURES}

\section{CHAPTER 2. DEMOGRAPHIC RESPONSE OF LOUISIANA WATERTHRUSH, A STREAM OBLIGATE SONGBIRD OF CONSERVATION CONCERN, TO SHALE GAS DEVELOPMENT.

Figure 1. Our study area includes fourteen forested 1 st and 2 nd order headwater streams in the Lewis Wetzel Wildlife Management Area (WMA). It lies within the Marcellus-Utica shale basin, is within the core Louisiana Waterthrush (LOWA) range based on Breeding Bird Survey (BBS) data, and falls in the Appalachian Mountains Bird Conservation Region (BCR) in the eastern United States. LOWA Relative Abundance represents average waterthrush counts from nearby survey routes.

Figure 2. Examples of quantifying shale gas disturbances at the stream (A, B) and territory (C, D) scale and types of disturbance (E, F). A section of stream considered disturbed from frequent vehicular activity along a modified road (E). Sedimentation we traced upstream to its point of origin at an active shale gas well pad (F).

Figure 3. Four nest survival covariates that significantly influenced waterthrush daily survival rate (DSR). The binary response covariate NestGas also significantly influenced DSR (not depicted). See table 5 for model results and table 2 for covariate notation.

Figure 4. Average individual productivity (avg. \# fledglings/successful nest/male * nest survival) $\pm 95 \%$ CIs in areas undisturbed and disturbed by shale gas to a source-sink threshold (gray bracketed line) of 1.4 fledglings

Figure 5. EPA Index and Habitat Suitability Index (HSI) scores in relation to TerrGas (A, B, respectively)....

\section{CHAPTER 3. LOUISIANA WATERTHRUSH (PARKESIA MOTACILLA) SURVIVAL AND SITE FIDELITY IN AN AREA UNDERGOING SHALE GAS DEVELOPMENT}

Figure 1. A box and whisker plot of disturbance on headwater streams $(n=14)$ resulting from shale gas development over a 6 year period (2009-2011, 2013-2015) at Lewis Wetzel Wildlife Management Area (LWWMA) located in northwestern West Virginia.

Figure 2. Conditional inference trees showing significant splits in data structure for TerrGas (a), EPA (b), and HSI (c) in explaining adult male waterthrush site fidelity, and percent misclassification error rate represented in assigning individuals to that group.

Figure 3. A conditional inference tree showing a significant split in data structure for the number of breeding attempts in explaining adult female waterthrush site fidelity, and percent misclassification error rate represented in assigning individuals to that group ..................70 


\section{CHAPTER 4. DEMOGRAPHIC CHARACTERISTICS OF AN AVIAN PREDATOR, LOUISIANA WATERTHRUSH (PARKESIA MOTACILLA), IN RESPONSE TO ITS AQUATIC PREY IN A CENTRAL APPALACHIAN USA WATERSHED IMPACTED}

BY SHALE GAS DEVELOPMENT.

Figure 1. Location of study streams, benthic sampling locations, and stream reaches disturbed by shale gas development during 2013-2014 on the Lewis Wetzel Wildlife Management Area in northwestern West Virginia. The larger light green patches of non-shale gas disturbance are primarily timber harvests with partial canopy removal................................ 97

Figure 2. The average amount of shale gas related disturbance \pm standard error (SE) and range (black + and -$)$ on headwater streams $(n=14)$, in addition to statistically significant positive (green) and negative (red) demographic vs. aquatic prey responses over a six year period (20092011, 2013-2015) at Lewis Wetzel Wildlife Management Area (LWWMA) located in northwestern West Virginia. Nest survival results are not displayed. The bracketed line represents a hypothetical, conservative disturbance threshold $(\geq 25 \%)$ at which waterthrush demography may be more negatively affected based on the strongest and second strongest demographic responses to aquatic prey in 2011 and 2014. Variable names are defined in S1 Table 2 .

\section{CHAPTER 5. SPATIAL STREAM MODELING OF LOUISIANA WATERTHRUSH (PARKESIA MOTACILLA) FORAGING SUBSTRATE AND AQUATIC PREY IN A WATERSHED UNDERGOING SHALE GAS DEVELOPMENT.}

Figure 1. Study Area Map. Our study area, Lewis Wetzel Wildlife Management Area (LWWMA), lies within the Marcellus-Utica shale basin. We observed Louisiana Waterthrush foraging on fourteen 1 st and 2 nd order headwater streams and collected benthic macroinvertebrate samples during 2013-2014.

Figure 2. Foraging Probability Index by Stream. Overall foraging probability index (FPI, 0$100 \%$ ) on each stream during 2013-2014. FPI was derived from the number of foraging observations/total observations for a $60 \mathrm{~m}$ area surrounding each wetted perimeter grid point on the stream. FPI was a relative index that gauged where waterthrush were most likely to be found foraging. Note Carpenter Run (CARP) only had two foraging observations, limiting the ability to

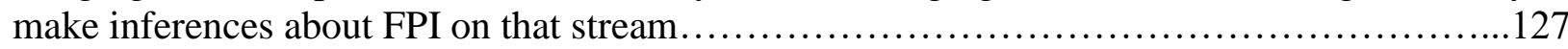

Figure 3. Foraging Probability Index Torgegram. An example of a torgegram for foraging probability index (FPI) which is a modified type of semivariogram. A torgegram displays semivariance (spatial autocorrelation) for samples on streams into flow-connected and unconnected structures to assist with model fitting. Diameters of circles are proportional to the number of pairs of points in each bin.

Figure 4. Model Performance. Leave one out cross validation predictions (LOOCV) and standard error (SE) against the observed data for the top WVSCI and GLIMPSS spatial models as one means of assessing model performance. 
Figure 5. Prediction Map. An example of prediction values mapped for WVSCI (solid circles) in relation to collected WVSCI data (open circles). The larger the solid circle, the more confidence in the prediction value (note most circles are small). Red values have a higher foraging probability index (FPI) than blue values..................................... 130

Figure 6. Foraging Probability Index Correlations. Post-hoc spearman rank correlation tests between foraging probability index (FPI) and WVSCI/GLIMPSS metrics (no. Ephemeroptera genera, no. Plecoptera genera, no. intolerant taxa tolerance value $<4$, and EPT richness). All tests were significant $(\mathrm{Rho}=0.24,0.20,0.23, \& 0.22$ respectively, $P<0.001)$

CHAPTER 6. EPIGENTIC RESPONSE OF LOUISIANA WATERTHRUSH (PARKESIA MOTACILLA) RELATED TO SHALE GAS DEVELOPMENT

Figure 1. The number of methylated restriction sites identified as differentially methylated for TerrGas $(\mathrm{n}=10)$ vs. strontium $\left(\mathrm{Sr} ; \mathrm{R}^{2}=-32, P=0.03\right)$ for adult males (top panel) and the number of methylated restriction sites across all restriction sites $(\mathrm{n}=100)$ vs. strontium $\left(\mathrm{Sr} ; \mathrm{R}^{2}=\right.$ $0.55, P=0.08$ ) for adult females (bottom panel) 


\section{LIST OF APPENDICES}

\section{CHAPTER 4. DEMOGRAPHIC CHARACTERISTICS OF AN AVIAN PREDATOR, LOUISIANA WATERTHRUSH (PARKESIA MOTACILLA), IN RESPONSE TO ITS AQUATIC PREY IN A CENTRAL APPALACHIAN USA WATERSHED IMPACTED}

BY SHALE GAS DEVELOPMENT.

Appendix Table 1. Annual shale gas disturbance activity at Lewis Wetzel Wildlife Management Area study streams in 2011, 2013, and 2014. Our research season for several ridgetop and stream research projects occurred relatively from April-July of each year, with time periods referring to this research season range. $\mathrm{R}=$ new ridgetop activity, $\mathrm{S}=$ new stream activity (streamside road activity or stream sedimentation), $\mathrm{W}=$ new well pad activity, $\mathrm{P}=$ parts considered disturbed from activity in previous years, $\mathrm{N}=$ no new activity. Superscripts $\mathrm{B}=$ Brief or intermittent activity period(s), E= Early in waterthrush breeding season, $\mathrm{L}=$ Late in waterthrush breeding season, and $\mathrm{C}=$ continuous activity.

As a result of previous and newly started ridgetop activity in 2010-2011 the whole downstream network of some streams became at risk for sedimentation and surface runoff for the remainder of the study. In 2013, construction started on a new compressor station located before reaching Snake North, meaning all headwater stream bases emptying into Buffalo Run north of this site was near heavy truck traffic from 2013-2014. In late 2013 (June-July), construction started on a new well pad at the base of Owl Run which was previously a homestead with all drilling completed by July-August 2014. Well pad construction started on the ridgetops above Olive Run in 2013 with wells not becoming active until 2014; otherwise the stream remained mostly undisturbed except for maintenance of a forested track for pump jack accessibility. Activity at Buffalo East and West Run was mainly concentrated at their confluence where an active shale gas pad was located, especially in 2013-2014 where disturbance was otherwise minimal. In 2013-2014, Wyatt and especially Sees Run were subject to sedimentation slips into the stream from compromised erosional control below well pads or access roads, especially during any rainfall event; Wyatt Run had a new unsodded pipeline connector that caused brief sedimentation early in the research season.

In 2014, activity at Slabcamp Run increased from the previous year from a well pad being redrilled but was commonly subject to streamside disturbance. Sees Run had increased sedimentation in 2014 from an active access road hillside partially collapsing and filling a stream valley. In summary, 2013 disturbances were just starting to occur but did not necessarily directly affect the streams during the time waterthrush were sampled in 2013, and in 2014 shale gas activity peaked again, particularly at Slabcamp Run, but did not achieve 2011 levels of activity

Appendix Table 2. Variables used to evaluate the demographic response and nest survival of Louisiana Waterthrush to aquatic prey and shale gas development. Nest survival is daily survival rate (DSR) over a 29-day nesting period. We evaluated Louisiana Waterthrush demographic response to aquatic prey and shale gas development using spatial generalized linear mixed

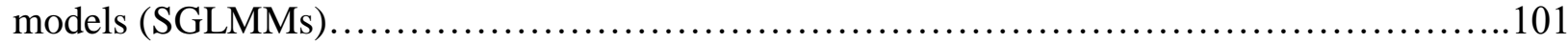




\section{CHAPTER 6. EPIGENTIC RESPONSE OF LOUISIANA WATERTHRUSH (PARKESIA MOTACILLA) RELATED TO SHALE GAS DEVELOPMENT.

Appendix Table 1. Summary results indicating differential methylation $(P<0.10)$ on a restriction site (i.e., locus) level after performing Analysis of Molecular Variance (AMOVA) grouped by sex (male, $n=107$ vs. female, $n=49)$, adult females $(n=49)$ vs. nestlings $(n=159)$, male age (second year [SY], $\mathrm{n}=14$ vs. after second year [ASY], $\mathrm{n}=87$ ), female age $(\mathrm{SY}, \mathrm{n}=13$ vs. ASY, $n=35)$, and TerrGas (undisturbed $n=46$, disturbed $n=49)$ for adult males $(n=$ 95)

Appendix Table 2. Proportion (\%) of differential methylation between male and female individual restriction sites $(n=39)$ that were statistically significant by sex (male, $n=107$ vs. female, $n=49)$, and the collective proportion of differential methylation among all $(n=100)$ and just the statistically significant restriction sites.

Appendix Table 3. Proportion (\%) of differential methylation between adult females vs. nestlings individual restriction sites $(n=35)$ that were statistically significant by adult females $(n=49)$ vs. nestlings $(\mathrm{n}=159)$, and the collective proportion of differential methylation among all $(\mathrm{n}=100)$ and just the statistically significant sites.

Appendix Table 4. Proportion (\%) of differential methylation between male age (second year [SY], $n=14$ vs. after second year [ASY], $n=87)$ individual restriction sites $(n=21)$ that were statistically significant by male age $(\mathrm{n}=101)$, and the collective proportion of differential methylation among all $(\mathrm{n}=100)$ and just the statistically significant sites.

Appendix Table 5. Proportion (\%) of differential methylation between female age (second year [SY], $\mathrm{n}=13$ vs. after second year [ASY], $\mathrm{n}=35)$ individual restriction sites $(\mathrm{n}=18)$ that were statistically significant by female age $(n=48)$, and the collective proportion of differential methylation among all $(\mathrm{n}=100)$ and just the statistically significant sites...

Appendix Table 6. Proportion (\%) of differential methylation between undisturbed $(\mathrm{n}=46)$ and disturbed $(n=49)$ shale gas territory (TerrGas) individual restriction sites $(n=18)$ that were statistically significant for adult males $(n=95)$, and the collective proportion of differential methylation among all $(n=100)$ and just the statistically significant restriction sites

Appendix Table 7. Results of BAYESCAN analysis on a restriction site (i.e., locus) level grouped by demographic parameter and shale gas disturbance status that was differentially methylated at a population level. $\mathrm{p}$ is the posterior probability for the selection model. $\log 10(\mathrm{PO})$ is the logarithm of Posterior Odds to base 10 for the selection model. The estimated alpha coefficient indicates the strength and direction of selection. The averaged $\mathrm{F}_{\text {st }}$ coefficient is calculated as the posterior mean. 


\section{PART 1. INTRODUCTION TO THE STUDY CHAPTER 1. INTRODUCTION}

\section{Rationale}

The rapid development of hydraulic fracturing techniques in the last decade have allowed the expansion of unconventional drilling activity and development, hereafter shale gas development, that overcome the low permeability of shale rock formations for hydrocarbon extraction (Arthur et al. 2008). The United States has twenty shale plays currently being developed (DOE 2009, EIA 2011), the Marcellus-Utica shale basin as one of the largest natural gas plays with substantial growth in gas production (EIA 2017a, EIA 2017b). While these techniques are being used globally (Boyer et al. 2011), the United States leads natural gas production and is becoming a net exporter (EIA 2015). The central Appalachian region is experiencing the quickest growth in shale gas development (MCOR 2016) since the underlying Marcellus-Utica shale is the most expansive basin and has the most potentially recoverable gas (DOE 2009).

Three-quarters of the Appalachian region categorized at highest potential risk from energy development, primarily shale gas, is forested (Dunscomb et al. 2014). As of 2015, over 140,000 ha of land had already been developed, with deciduous forest one of the major habitat types affected with high ecosystem service costs (Moran et al. 2017). West Virginia is one of two states (the other state Pennsylvania) with the highest probability for development (21\%; Dunscomb et al. 2014). From 2009-2012, the majority (73.3\%) of forest removed in West Virginia was the result of shale gas development (Widmann 2013), with about 1 ha of forest disturbed in addition to land cover disturbances associated with well and pipeline placement (Zinkhan 2016). Overall land cover disturbance due to Marcellus shale gas may be 3.6 ha per well pad (Zinkhan 2016), higher than shale gas footprints elsewhere (Entrekin et al. 2011, Drohan et al. 2012). By 2015, West Virginia had 20\% of $>15,000$ producing Marcellus wells (WVGES 2015) with 40,000 new wells projected by 2030 (DOE 2010).

Shale gas development tends to outpace the ability to create adequate management practices that avoid risks to aquatic and terrestrial wildlife communities and their habitat (Brittingham et al. 2014). Since West Virginia is highly forested (80\% of land cover; Gillespie 2012), forest loss and fragmentation from shale gas development has the potential to threaten Appalachian biodiversity (Kiviat 2013). In particular, species with specialized habitat needs that 
overlap these areas will be the most vulnerable (Brittingham et al. 2014). Only recently have we learned how shale gas development may positively and negatively influence Appalachian songbird communities (Barton et al. 2016, Farwell et al. 2016), predator-aquatic prey response (Wood et al. 2016), and how shale gas development may be associated with heavy metal bioaccumulation in songbirds (Latta et al. 2015). Even with recent insights, there has not been a mechanistic assessment of the interplay between shale gas disturbance and songbird demographic response (Northrup and Wittemyer 2013). Baseline data, such as population demography, are needed in both terrestrial and aquatic habitats of the Appalachian shale gas basin to detect and understand changes as they begin to occur (Brittingham et al. 2014). If multiple studies start to collect long-term baseline data, perhaps we can move beyond broad generalities in wildlife response to shale gas development and learn if a disturbance threshold exists that if exceeded has population-level consequences (Northrup and Wittemyer 2013; Becker et al. 2015).

There is a tendency for core forest disturbance from shale gas development to occur near forested headwater streams (Drohan et al. 2012). Proximity of shale gas development to water resources is of particular concern due to the potential for sedimentation runoff, reduced streamflow, contamination of surface waters (Entrekin et al. 2011), and alteration to the base of trophic food webs (Grant et al. 2016). Shale gas wells in the Marcellus shale region are commonly within 100-300 m of stream channels, and even closer for headwater drainage areas (Entrekin et al. 2011). Headwater streams are critical sources of water, sediment, organic matter, and nutrients for the rest of the stream system (Gomi et al. 2002), and therefore vital for ecological integrity (Freeman et al. 2007). Headwater streams, despite predominance of drainage area and total stream length, are largely overlooked for protection or regulation despite their potential effect on downstream reaches and aquatic life (MacDonald \& Coe 2007).

Consequently, biological communities and organisms that use resources downstream of shale gas development are at increased risk (Latta et al. 2015) and research of the highest priority (Souther et al. 2014), as indirect land use alterations to forest and water resources that may damage ecosystems represent the largest and most critical knowledge gap in scientific research (Costa et al. 2017). Using an organism that co-occurs in both forested and aquatic habitat across the aquatic-terrestrial interface (Gregory et al. 1991) may enable the most ideal scenario to quantify 
demographic, spatial, and epigenetic (i.e., DNA methylation) responses to shale gas development.

\section{Focal species}

The Louisiana Waterthrush (Parkesia motacilla), hereafter waterthrush, is a forested headwater stream specialist known for its ability to respond to changes in ecological conditions (Mattsson and Cooper 2006). The waterthrush is a species of conservation concern on the U.S. Fish and Wildlife Service National List (USFWS 2008) due to its specialized habitat. As biological indicators of biotic stream integrity (O'Connell et al. 2000, Mulvihill et al. 2008), waterthrush feed primarily on benthic macroinvertebrate aquatic prey (Mattsson et al., 2009) in well-developed riffle and pool areas (Prosser and Brooks 1998), forming linear territories along the stream reach (Mulvihill et al. 2008). Many of the forested stream ecosystems in which the waterthrush primarily breed have rapidly undergone unconventional shale gas development, particularly in the Marcellus-Utica shale region (Evans and Kiesecker 2014), where almost all of its core breeding range also overlaps this region (Sauer et al. 2014). Species with specialized terrestrial or aquatic habitat needs that overlap forested areas undergoing shale gas development may be the most vulnerable to disturbance (Brittingham et al. 2014). As such, the increased intensity of core forest disturbance where headwater streams (Drohan et al. 2012, Farwell et al. 2016) and this species co-occur make waterthrush an ideal organism to assess potential demographic, spatial, and epigenetic consequences from shale gas development.

\section{Objectives}

My overall objective was to determine the degree to which shale gas development on our study area may or may not affect waterthrush and its aquatic prey by demographical, spatial, and epigenetic mechanisms. Specific objectives and hypotheses are below.

1) Examine how shale gas development influenced demographic response of waterthrush during 2009-2011 and 2013-2015 by quantifying waterthrush nest survival, productivity, and nest abandonment, an overall source-sink threshold, riparian habitat quality, and territory density and length.

1a) I hypothesized that we would detect an inverse relationship between the amount of shale gas disturbance and demographic metrics despite the species' ability to compensate for resource loss (Mulvihill et al. 2008, Wood et al. 2016). 
1b) I hypothesized that productivity would differ between areas disturbed and undisturbed by shale gas development if source-sink dynamics (Pulliam 1988) exist in our local population.

2) Examine how shale gas development influenced first-year return rates (site fidelity), site fidelity factors, and annual survival of waterthrush during 2009-2011 and 2013-2015.

2a) I hypothesized apparent survival would decrease in concert with decreasing site fidelity.

3) After accounting for spatial and non-spatial sources of variability, examine how shale gas development influenced demographic response of waterthrush to aquatic prey changes in 20132014 as a follow-up to a 2011 aquatic prey study.

3a) I hypothesized that clutch size, number of fledglings, and territory density would have a positive association with aquatic prey metrics.

3b) Annual territory length increased as territory densities decreased (Frantz et al. 2018, Chapter 2), so we expected smaller territories to be indicative of higher quality aquatic prey and stream quality (e.g., Mulvihill et al. 2008).

3c) Nest survival was minimally affected by aquatic prey in 2011 (Wood et al. 2016) but I hypothesized that any stream impairment effects on the aquatic prey would affect nest survival.

3d) In evaluation of riparian quality indices we use to gauge waterthrush habitat (i.e., US EPA Rapid Bioassessment Protocol, EPA; Habitat Suitability Index, HSI), I hypothesized that aquatic prey would be positively linked with riparian quality habitat scores where higher scores indicate areas of higher aquatic stream health.

3e) In the same manner as waterthrush demographic response to shale gas development, I hypothesized an inverse relationship between aquatic prey metrics and the amount of shale gas disturbance or potential runoff in a territory or at a nest.

4) Using spatial stream network models, explore relationships between observed areas of waterthrush foraging and a) water chemistry, b) a waterthrush foraging score based on stream channel data, c) shale gas land use based on reach contributing area (i.e. catchment area), and d) multi-metric indices of biotic stream integrity at the family and genus level.

5) a) Examine how shale gas development may influence DNA methylation variation, hereafter differential methylation, of waterthrush between shale gas undisturbed and disturbed areas at the 
territory scale, b) determine if differential methylation of DNA fragments or loci, hereafter restriction sites, varied by sex and age, c) identify differentially methylated restriction sites that were potentially under selection, d) correlate methylated restriction sites to barium (Ba) and strontium ( $\mathrm{Sr}$ ) heavy metal concentrations bioaccumulated in waterthrush feathers, and e) evaluate the degree to which an individual's methylated state was subject to change across years in individuals that returned over more than one breeding season (i.e., recaptures).

5a) Females can have a higher body condition index (BCI) than males even when there are no differences in territory quality (Latta et al. 2016). As such, I hypothesized differential methylation between males and females, as well as for males to have a stronger response to shale gas development since females tolerate a wider range of territory quality (Latta et al. 2016).

5b) I hypothesized older adults to have fewer methylated restriction sites than younger adults because decreased methylation is correlated with age in birds (De Paoli-Iseppi et al. 2019). Similarly, I expected nestlings to be differentially methylated from adults. 5c) Presuming nestlings are less exposed to stress during the hatching to fledging stage than adults during the breeding season, I hypothesized a weak response to shale gas development between shale gas disturbed and undisturbed areas if differential methylation can correlate to a gradient of stress (Sun et al. 2018).

5d). Finally, I hypothesized that $\mathrm{Ba}$ and $\mathrm{Sr}$ heavy metal concentrations are inversely correlated to the number of methylated restriction sites since contaminants interfere with methyl transfer (Hala et al. 2014).

\section{Study Area}

We studied waterthrush along $58.1 \mathrm{~km}$ of $1 \mathrm{st}$ - and 2 nd-order forested headwater stream tributaries $(n=14)$ at Lewis Wetzel Wildlife Management Area (LWWMA) located in northwestern West Virginia $\left(39.490216^{\circ} \mathrm{N},-80.650713^{\circ} \mathrm{W}\right)$. The study area lies within the Permian Hills subdivision of the Western Allegheny Plateau Ecoregion, an area of deeply dissected topography and relatively continuous Appalachian Oak and Mixed-Mesophytic Forest (Woods et al. 1999) with elevations of 221-480 m. The study area overlays the Marcellus-Utica shale region, covers 6521 ha (Farwell et al. 2016), and occurs where waterthrush reach their highest densities within the central Appalachians (Sauer et al., 2014). In 2008, LWWMA was $95.3 \%$ forested with only $0.4 \%$ shale gas land cover, the first shale gas well development starting 
in 2007 (Farwell et al. 2016). Shale gas at our study area and within the surrounding region since then has rapidly increased (WVGES 2015). By the end of the study in 2015, LWWMA was $90.8 \%$ forested with $2.4 \%$ shale gas land cover, where $83.1 \%$ of shale gas development resulted in direct forest loss (Farwell et al. 2016).

\section{Limitations of the study}

Since the first shale gas development began at LWWMA in 2007 (Farwell et al. 2016), ideally we would have collected "baseline" waterthrush demographic data before any shale gas development began. However, because shale gas development was only $0.4 \%$ land cover in 2008, we started our study early in development and presume the high territory densities in the beginning of the study (2009-2010) were typical of the study area before development activities. West Virginia University researchers were scouting LWWMA ridgetops and valleys in 2008 as part of Cerulean Warbler (Setophaga cerulea), raptor ecology, and avian community research endeavors, and also were exploring streams with the idea of starting a pilot waterthrush study the following year. Anecdotal evidence from graduate students and field technicians I spoke with who were there in both 2008 and 2009 suggest very similar stream occupancy by waterthrush.

No waterthrush data were collected in 2012. The peak of shale gas development occurred in 2011, and by 2013 shale gas development had abated and was no longer site-wide but concentrated in certain areas. We saw some of the most apparent differences in demography from 2011 to 2013. Ideally if we had collected data in 2012, we would have seen a transitional stage between the high and low demographic values as the trends suggest. Having data for the year 2012 would have improved our survival estimates, as well as if adult females were banded sooner in the project to avoid having dissimilar encounter histories.

Finally, our study occurred on one wildlife management area (WMA) or technically only one watershed consisting of many subwatersheds, which may limit broad inferences beyond our study area boundaries. Regardless of the debatable semantics of what constitutes a genuine replicate vs. pseudoreplicate in ecology (Davies and Gray 2015), I am confident I have taken careful consideration of all aspects of our study design and data collected to provide credible science. Fortunately, since we had multiple undisturbed and disturbed streams at LWWMA at varying degrees of disturbance, I was able to account for and separate out any site-level (stream) effects from shale gas disturbance effects in my analyses, among any other sources of variability, when necessary. 


\section{LITERATURE CITED}

Arthur, D. J, B. Langhus, and D. Alleman. (2008). An overview of modern shale gas development in the United States. ALL Consulting. 18 pp.

Barton, E. P., S. E. Pabian, and M. C. Brittingham. (2016). Bird community response to Marcellus shale gas development. Journal of Wildlife Management 80:1301-1313.

Becker, D. A., P. B. Wood, M. P. Strager, and C. Mazzarella. (2015). Impacts of mountaintop mining on terrestrial ecosystem integrity: identifying landscape thresholds for avian species in the central Appalachians, United States. Landscape Ecology 30:339-356.

Brittingham, M. C., K. O. Maloney, A. M. Farag, D. D. Harper, and Z. H. Bowen. (2014). Ecological risks of shale oil and gas development to wildlife, aquatic resources and their habitats. Environmental Science and Technology 48:11034-11047.

Boyer, C., B. Clark, V. Jochen, R. Lewis, and C. K. Miller. (2011). Shale gas: A global resource. Oilfield Review 23:28-39.

Costa, D., J. Jesus, D. Branco, A. Danko, and A. Fiúza. (2017). Extensive review of shale gas environmental impacts from scientific literature (2010-2015). Environmental Science and Pollution Research 24:14579.

Davies, G. M., and A. Gray. (2015). Don't let spurious accusations of pseduoreplication limit our ability to learn from natural experiments (and other messy kinds of ecological monitoring). Ecology and Evolution 5:5295-5304.

De Paoli-Iseppi, R., B. E. Deagle, A. M. Polanowski, C. R. McMahon, J. L. Dickinson, M. A. Hindell, and S. N. Jarman. (2019). Age estimation in a long-lived seabird (Ardenna tenuirostris) using DNA methylation-based biomarkers. Molecular Ecology Resources 1-15. 10.111/17550998.12981.

DOE (Department of Energy). (2009). Modern shale gas development in the United States: A primer. Office of Fossil Energy and National Energy Technology Laboratory, U.S. Department of Energy, Washington, D.C. http://energy.gov/sites/prod/files/2013/03/f0/ShaleGasPrimer_Online_4-2009.pdf.

DOE (Department of Energy). (2010). Projecting the economic impact of Marcellus shale gas development in West Virginia: A preliminary analysis using publicly available data. Office of Fossil Energy and National Energy Technology Laboratory, U.S. Department of Energy, Washington, D.C. http://www.netl.doe.gov/energyanalyses/pubs/WVMarcellusEconomics3.pdf.

Drohan, P. J., M. Brittingham, J. Bishop, and K. Yoder. (2012). Early trends in landcover change and forest fragmentation due to shale gas development in Pennsylvania: A potential outcome for the Northcentral Appalachians. Environmental Management 49:1061-1075. 
Dunscomb, J. K., J. S. Evans, J. M. Strager, M. P. Strager, and J. M. Kiesecker. (2014). Assessing future energy development across the Appalachian Landscape Conservation Cooperative. The Nature Conservancy, Charlottesville, VA. 48 pp with appendices. Appalachian Landscape Conservation Cooperative Grant \#2012-02.

EIA (Energy Information Administration). (2011). Review of emerging resources: U.S. shale gas and shale oil plays. U.S. Department of Energy, Washington, D.C.

https://www.eia.gov/analysis/studies/usshalegas/pdf/usshaleplays.pdf.

EIA (Energy Information Administration). (2015). Annual energy outlook 2015 with projections to 2040. U.S. Department of Energy, Washington, D.C.

https://www.eia.gov/forecasts/aeo/pdf/0383(2015).pdf.

EIA (Energy Information Administration). (2017a). Marcellus shale play: geology review. U.S. Department of Energy, Washington, D.C. https://www.eia.gov/maps/pdf/MarcellusPlayUpdate_Jan2017.pdf.

EIA (Energy Information Administration). (2017b). Utica shale play: geology review. U.S. Department of Energy, Washington, D.C. https://www.eia.gov/maps/pdf/UticaShalePlayReport_April2017.pdf.

Entrekin, S., M. Evans-White, B. Johnson, and E. Hagenbuch. (2011). Rapid expansion of natural gas development poses a threat to surface waters. Frontiers in Ecology and the Environment 9:503-511.

Evans, J. S., and J. M. Kiesecker. (2014). Shale gas, wind and water: Assessing the potential cumulative impacts of energy development on ecosystem services within the Marcellus play. PLoS ONE 9:e89210.

Farwell, L. S., P. B. Wood, J. Sheehan, and G. A. George. (2016). Shale gas development effects on the songbird community in a central Appalachian forest. Biological Conservation 201:78-91.

Frantz, M. W., P. B. Wood, J. Sheehan, and G. George. (2018). Demographic Response of a migratory songbird of conservation concern to shale gas development. The Condor: Ornithological Applications 120:265-282.

Freeman, M. C., C. M. Pringle, and C. R. Jackson. (2007). Hydrologic connectivity and the contribution of stream headwaters to ecological integrity at regional scales. Journal of the American Water Resources Association 43:5-14.

Gillespie, W. H. (2012). Reforestation. e-WV: The West Virginia Encyclopedia. Accessed 14 April 2017. [Online]. https://www.wvencyclopedia.org/articles/49.

Gomi, T., R. C. Sidle, and J. S. Richardson. (2002). Understanding processes and downstream linkages of headwater systems. Bioscience 52:905-916. 
Grant, C. J., A. K. Lutz, A.D. Kulig, and M. R. Stanton. (2016). Fracked ecology: response of aquatic trophic structure and mercury biomagnification dynamics in the Marcellus shale formation. Ecotoxicology 25:1739-1750.

Gregory, S. V., F. J. Swanson, W. A. McKee, and K. W. Cummins. (1991). An ecosystem perspective of riparian zones. BioScience 41:540-551.

Hala, D., D. B. Huggett, and W. W. Burggren. (2014). Environmental stressors and the epigenome. Drug Discovery Today Technologies 12:e3-e8.

Kiviat, E. (2013). Risks to biodiversity from hydraulic fracturing for natural gas in the Marcellus and Utica shales. Annals of the New York Academy of Sciences 1286:1-14.

Latta, S. C., L. C. Marshall, M. W. Frantz, and J. Toms. (2015). Evidence from two shale regions that a riparian songbird accumulates metals associated with hydraulic fracturing. Ecosphere 6:144.

Latta, S. C., Cabezas, S., Mejia, D. A., Paulino, M. M., Almonte, H., Miller-Butterworth, C. M., and G. R. Bortolotti. (2016). Carry-over effects provide linkages across the annual cycle of a Neotropical migratory bird, the Louisiana Waterthrush Parkesia motacilla. Ibis 158:395-406.

MacDonald, L. H., and D. Coe. (2007). Influence of headwater streams on downstream reaches in forested areas. Forest Science 53:148-168.

Mattsson, B. J., and R. J. Cooper. (2006). Louisiana waterthrushes (Seiurus motacilla) and habitat assessment as cost-effective indicators of instream biotic integrity. Freshwater Biology 51:1941-1958.

Mattsson, B. J., T. L. Master, R. S. Mulvihill, and W. D. Robsinson. (2009). Louisiana Waterthrush (Parkesia motacilla). The birds of North America (P. G. Rodewald, Editor). Ithaca: Cornell Lab of Ornithology. https://birdsna-org.bnaproxy.birds.cornell.edu/Species Account/bna/species/louwat.

MCOR (Marcellus Center for Outreach and Research). (2016). Tri-state unconventional shale wells (PA, WV, OH). http://www.marcellus.psu.edu/resources/maps.php (Last updated December 31, 2015. Accessed Mar.15, 2016).

Moran, M. D., N. T. Taylor, T. F. Mullins, S. S. Sardar, and M. R. McClung. (2017). Land-use and ecosystem service costs of unconventional US oil and gas development. Frontiers in Ecology and the Environment 15:237-242.

Mulvihill, R. S., F. L. Newell, and S. C. Latta. (2008). Effects of acidification on the breeding ecology of a stream-dependent songbird, the Louisiana Waterthrush (Seiurus motacilla). Freshwater Biology 53:2158-2169. 
Northrup, J. M., and G. Wittemyer. (2013). Characterising the impacts of emerging energy development on wildlife, with an eye towards mitigation. Ecology Letters 16:112-125.

O'Connell, T. J., L. E. Jackson, and R. P. Brooks. (2000). Bird guilds as indicators of ecological condition in the central Appalachians. Ecological Applications 10:1706-1721.

Pulliam, H. R. (1988). Sources, sinks, and population regulation. The American Naturalist 132:652-661.

Sauer, J. R., J. E. Hines, J. E. Fallon, K. L. Pardieck, D. J. Ziolkowski, and W. A. Link. (2014). The North American Breeding Bird Survey, Results and Analysis 1966-2013 version 01.30.2015. USGS Patuxent Wildlife Research Center, Laurel, Maryland http://www. mbr-pwrc.usgs.gov/bbs/.

Souther, S., M. W. Tingley, V. D. Popescu, D. T. S. Hayman, M. E. Ryan, T. A. Graves, B. Harth, and K. Terrell. (2014). Biotic impacts of energy development from shale: research priorities and knowledge gaps. Frontiers in Ecology and the Environment 12:330-338.

Sun, L., X. Miao, J. Cui, J. Deng, X. Wang, Y. Wang, Y. Zhang, S. Gao, and K. Yang. (2018). Genome-wide high-resolution mapping of DNA methylation identifies epigenetic variation across different salt stress in Maize (Zea mays L.). Euphytica 214:25.

USFWS (United States Fish and Wildlife Service). (2008). Birds of conservation concern 2008. United States Department of Interior, Fish and Wildlife Service, Division of Migratory Bird Management, Arlington, Virginia. http://www.fws.gov/migratorybirds.

Widmann, R. H. (2013). West Virginia's forest resources, 2012. Res. Note NRS-192. U.S. Department of Agriculture, Forest Service, Northern Research Station, Newtown Square, PA.

Wood, P., M. Frantz, and D. Becker. (2016). Louisiana Waterthrush and benthic macroinvertebrate response to shale gas development. Journal of Fish and Wildlife Management 7: 423-433.

Woods, A. J., J. M. Omernik, and D. D. Brown. (1999). Level III and IV ecoregions of Delaware, Maryland, Pennsylvania, Virginia, and West Virginia, U.S. U.S. Environmental Protection Agency, National Health and Environmental Effects Research Laboratory, Corvallis, OR. ftp://ftp.epa.gov/wed/ecoregions/reg3/reg3_eco_desc.doc.

WVGES (West Virginia Geological and Economic Survey). (2015). WV Marcellus shale wells: completed, permitted, and cancelled episodes.

http://www.wvgs.wvnet.edu/www/datastat/devshales.htm.

Zinkhan, F. C. (2016). Site characteristics associated with conventional and unconventional petroleum development in West Virginia. MS Thesis. West Virginia University, Morgantown, WV. 
PART 2. LOUISIANA WATERTHRUSH ECOLOGY

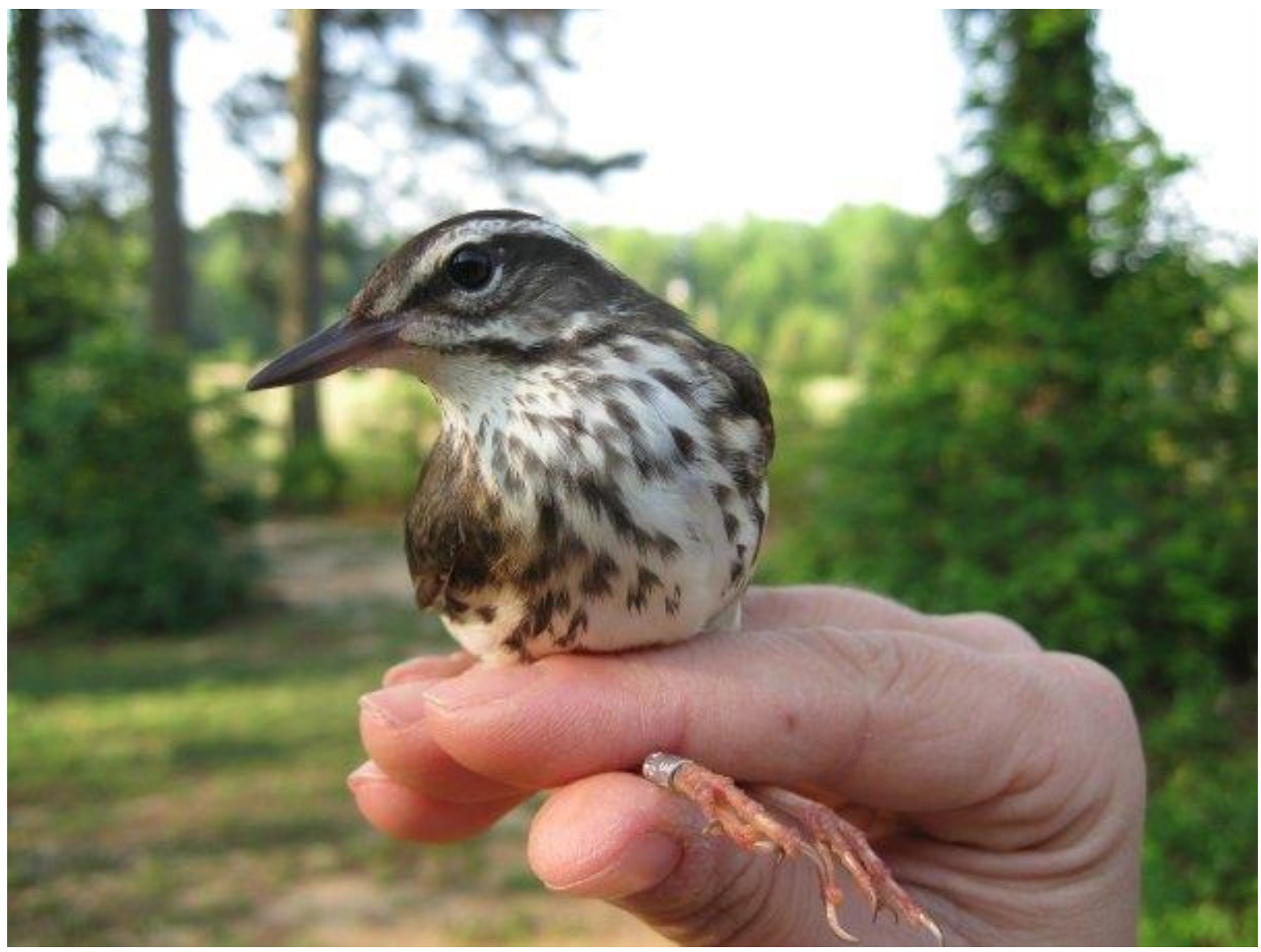




\title{
CHAPTER 2. DEMOGRAPHIC RESPONSE OF LOUISIANA WATERTHRUSH, A STREAM OBLIGATE SONGBIRD OF CONSERVATION CONCERN, TO SHALE GAS DEVELOPMENT
}

Chapter 2 was published in the peer-reviewed journal Condor: Ornithological Applications. The dissertation version includes an additional analysis on nest abandonment.

\section{Citation:}

Frantz, M. W., P. B. Wood, J. Sheehan, and G. George. 2018. Demographic response of a migratory songbird of conservation concern to shale gas development. The Condor:

Ornithological Applications 120:265-282. 10.1650/condor-17-130.1.

\begin{abstract}
Shale gas development continues to outpace implementation of best management practices for wildlife affected by development. We examined how shale gas development influenced demographic response of Louisiana Waterthrush (Parkesia motacilla) during 2009-2011 and 2013-2015 in a predominately forested landscape in West Virginia. Forest cover across the study area decreased from $95.3 \%$ in 2008 to $90.8 \%$ in 2015 while area affected by shale gas development increased from $0.4 \%$ to $2.4 \%$. We quantified nest survival, abandonment, and productivity, a source-sink threshold, riparian habitat quality, and territory density and length by monitoring $58.1 \mathrm{~km}$ of forested headwater streams ( $n=14$ streams). Across years, we saw annual variability in nest survival with a general declining trend over time. Of 11 a priori models to explain nest survival ( $n=280$ nests), four models that had temporal, habitat, and shale gas covariates were supported and two of these models accounted for most of the variation in daily survival rate. Once accounting for temporal effects (rainfall, nest age, time within season), shale gas development had negative effects on nest survival. There was a weak, non-significant association between nest abandonment or percent failed attempts and shale gas disturbance. Population-level nest productivity declined, and individual-level productivity was lower in areas disturbed by shale gas, and a source-sink threshold suggested these areas are more at risk for being sink habitat. Riparian habitat quality scores, as measured by an US Environmental Protection Agency index and a waterthrush Habitat Suitability Index, differed by year and were negatively related to the amount of each territory disturbed by shale gas development. Territory density was not related to the amount of shale gas disturbance on streams, but decreased over time as territory lengths increased. Overall, our results suggest a decline in waterthrush site quality as shale gas development increased, despite relatively small site-wide forest loss.
\end{abstract}


Keywords: unconventional shale gas, hydraulic fracturing, energy impacts, Marcellus-Utica, bioindicator species, headwater stream, Parkesia motacilla, waterthrush

\section{INTRODUCTION}

The United States has twenty shale formations containing unconventional natural gas deposits that are being developed using new horizontal drilling and hydraulic fracturing techniques (DOE 2009, EIA 2011). The central Appalachian region is experiencing the most rapid growth in unconventional drilling activity and development, hereafter shale gas development, (MCOR 2016) since the underlying Marcellus-Utica shale is the most expansive basin with the most potentially recoverable gas (DOE 2009). The state of West Virginia alone had 20\% of >15,000 producing Marcellus wells by 2015 (WVGES 2015) with 40,000 new wells projected by 2030 (DOE 2010). Within the Appalachian region, nearly $75 \%$ of close to 3.1 million forested hectares are at highest potential risk from energy development, primarily shale gas (Dunscomb et al. 2014). West Virginia is one of two states with the highest probability for development (21\%; Dunscomb et al. 2014), and species with specialized habitat needs that overlap these forested areas will be the most vulnerable (Brittingham et al. 2014).

Recent studies have examined how shale gas development may positively and negatively influence Appalachian songbird communities (Barton et al. 2016, Farwell et al. 2016), how predators and their aquatic prey respond (Wood et al. 2016), and how shale gas development may be associated with bioaccumulated contaminants (Latta et al. 2015). However, there has not been a mechanistic assessment of the interplay between shale gas disturbance and songbird demographic response (Northrup and Wittemyer 2013). Baseline demographic data are needed in both terrestrial and aquatic habitats of the Appalachian shale gas basin to detect and understand changes as they begin to occur (Brittingham et al. 2014).

The proximity of shale gas development to water resources is of particular concern due to the potential for sedimentation runoff, reduced streamflow, and contamination of surface waters (Entrekin et al. 2011). Therefore biological communities and organisms that use water resources downstream are at increased risk from shale gas activities near surface waters (Latta et al. 2015). The Louisiana Waterthrush (Parkesia motacilla), hereafter waterthrush, is a habitat specialist and 
species of conservation concern (USFWS 2008), that breeds along forested headwater streams and feeds primarily on benthic macroinvertebrates (Mattsson et al. 2009). Waterthrushes are well-established biological indicators of aquatic stream integrity (O’Connell et al. 2000, Mulvihill et al. 2008) and reach some of their highest abundances in the Marcellus shale region (Sauer et al. 2017). As such, the increased intensity of core forest disturbance where headwater streams and this species co-occur make waterthrush an ideal organism to assess potential demographic consequences from shale gas development (Drohan et al. 2012, Farwell et al. 2016). As a bioindicator species, we hypothesized that we would detect an inverse relationship between the amount of shale gas disturbance and demographic metrics despite the species' ability to compensate for resource loss (Mulvihill et al. 2008, Wood et al. 2016). Identifying how variability in habitat quality contributes to population surpluses (source habitat; Pulliam 1988) or deficits (sink habitat) is key to long-term conservation planning in landscapes undergoing development (Kirol et al. 2015). If source-sink dynamics exist in our local population, we also hypothesized that productivity would differ between areas disturbed and undisturbed by shale gas development.

We examined how increased shale gas development influenced waterthrush demography during 2009-2011 and 2013-2015. We quantified waterthrush nest abandonment, survival, and productivity, an overall source-sink threshold, riparian habitat quality, and territory density and length. In addition to identifying demographic responses, our results should inform well siting guidelines for shale gas development to minimize risk to ecological resources.

\section{METHODS}

\section{Study Area}

We studied waterthrush demography along $58.1 \mathrm{~km}$ of 1 st- and 2nd-order forested headwater stream tributaries $(n=14)$ in the Lewis Wetzel Wildlife Management Area (LWWMA) in northwestern West Virginia $\left(39.490216^{\circ} \mathrm{N},-80.650713^{\circ} \mathrm{W}\right.$, Figure 1), an area that supports the highest waterthrush densities within the central Appalachians (Sauer et al., 2017). The study area lies within the Permian Hills subdivision of the Western Allegheny Plateau Ecoregion, an area of deeply dissected topography and relatively continuous Appalachian Oak and Mixed-Mesophytic Forest (Woods et al. 1999) with elevations of 221-480 m that overlays the Marcellus-Utica shale region. In 2008, LWWMA was $95.3 \%$ forested and had $0.4 \%$ shale gas land cover; the first shale gas well development began in 2007 (Farwell et al. 2016). Shale gas 
development in our study area and within the surrounding region since then has rapidly increased (WVGES 2015). In 2015, LWWMA was $90.8 \%$ forested and $2.4 \%$ in shale gas development land cover, with $83.1 \%$ of shale gas development resulting in direct forest loss (Farwell et al. 2016).

During our study, gas well development activities included building of conventional (shallower formations) and Marcellus well pads, forest clearing for yet unbuilt well pads, the expansion of existing road and pipeline infrastructure, and the construction of new infrastructure. Early in the study (2009-2010), the majority of Marcellus wells and their water holding ponds were located along the main stem of Buffalo Run, where the majority of our headwater study streams empty. Thus, although a few Marcellus well pads were located along our study streams, they tended to primarily impact the lower portions of the study streams. Between the 2010 and 2011 breeding seasons, shale gas development activities accelerated across the study area and began to increase especially on ridgetops. As a result of ridgetop activity, the whole downstream network of some streams became disturbed by sedimentation and surface runoff for the remainder of the study. LWWA experienced a $1.5 \%$ increase in area affected by timber harvests in 2010-2011 (Farwell et al. 2016), but these and pre-existing harvests did not result in complete forest canopy loss (Sheehan et al. 2014) and typically were not intersecting or influencing streams where we monitored waterthrushes. Shale gas development peaked in 2011, but starting in 2013, shale gas development abated site-wide and in general became concentrated on specific streams and ridgetops. Clearing for additional new well pads occurred late (June-July) in the 2013 breeding season with well pad completion in 2014, in addition to re-drilling of an existing well pad. There was no new shale gas development or activity in the 2015 breeding season. There were no "control" streams given that the majority of forest loss and fragmentation in the surrounding landscape resulted from recent shale gas activities (Farwell et al. 2016), but shale gas disturbance was concentrated on some streams more than others as indicated by the large annual range in percent of stream disturbed (range 0-66.9\%; Table 1).

\section{Mapping and Quantifying Disturbances}

Within a Geographic Information System (GIS), we used a sequence of leaf-on and leafoff aerial photographs from the National Agriculture Imagery Program (NAIP) for 2011 and 2014, satellite Quickbird imagery for 2009, and extensive annual ground-truthing to manually digitize areas of forest canopy disturbance within the study area for each year of the study. All 
forest canopy disturbances were classified as shale gas development related (i.e., well pads and associated road and pipeline infrastructure) or unrelated or pre-existing (i.e., forest roads, recent even-aged timber harvests, and various types of existing clearings) using FRAGSTATS 4 (McGarigal et al. 2012). We determined the percentage of forest canopy disturbance from shale gas development (GasFCD) and non-shale gas development (OtherFCD) sources within a $100 \mathrm{~m}$ radius of each nest for use as habitat covariates in nest survival models (Table 2). We used 100 $m$ radius because forest edges may negatively affect the reproductive success of ground-nesting species at this scale (Flaspohler et al. 2001). We classified a few conventional impacts (i.e., stream-side vertical pump jacks) as related to shale gas development because their pads were managed in conjunction with nearby shale gas infrastructure and because their targeted formation, even though they remained shallow after development, was listed as Marcellus (WVGES 2015). Gas well records (WVDEP 2015) were used to verify target shale formations, drilling status, and start dates for all well disturbances.

Surface (i.e., 3D) lengths of each study stream (average length $4.1 \pm 0.54 \mathrm{~km}$, range 0.95-7.4 km) were calculated in GIS using a 3 m resolution digital elevation model and defined to have a drainage basin of 9.0 hectares ( $24 \mathrm{k}$ scale or higher resolution) to delineate the uppermost headwater reaches. To describe and model waterthrush demography and riparian habitat quality as a function of shale gas disturbance, we created four continuous and one binary variable based on disturbance categories at the stream, territory, and nest scale. The first (StreamGas) described mostly localized streamside disturbance indicative of the presence of any shale gas infrastructure or activity (Figure 2A, Table 2). A section of stream was considered disturbed when well pads, infrastructure, or frequent vehicular activity (Figure 2E) were within $60 \mathrm{~m}$ of the stream centerline, the typical extent of waterthrush streamside use (Mattsson and Cooper 2009). When a stream had visually observable sedimentation from shale gas development (Figure 2F), we classified the entire stream network downstream of the sedimentation beginning point as disturbed. Streams were frequently and extensively groundtruthed each season, so there were no stream reaches where sedimentation events were likely to be missed.

We created a second shale gas disturbance category (StreamRunoff) that focused solely on potential run-off into streams from shale gas contaminants (Figure 2B, Table 2). A stream was considered disturbed at and below a well pad or retaining pond (similar to Latta et al. 2015), 
resulting in the whole downstream network classified as at risk for surface pollution based on elevational maps and ground truthing. The StreamRunoff category did not include pipeline or road disturbance and was a broader, distance-independent, disturbance category describing potential water pollution. For each year of the study, we then calculated the proportion of each stream disturbed for both the StreamGas and the StreamRunoff disturbance categories.

We calculated the proportion of each territory (a 60-m buffer around each territory vector; Mattsson and Cooper 2009) that was disturbed by StreamGas and called this metric TerrGas (Figure 2C, Table 2). The proportion of each territory disturbed by StreamRunoff was termed TerrRunoff (Figure 2D, Table 2). We classified each waterthrush nest location as undisturbed or disturbed by StreamGas within $60-\mathrm{m}$ around the nest and called this variable NestGas.

\section{Territory Density and Length}

We mapped waterthrush territories in 2009-2011 and 2013-2015 along 14 streams with varying amounts of StreamGas and StreamRunoff (Table 1) to determine annual territory density and length. Territories were mapped for 11 streams in all years, Hiles Run and Huss Pen Run were mapped in 2014-2015, and Carpenters Run was mapped in 2009 and 2014-2015 due to restricted access. Territorial waterthrushes were target-netted and banded with an aluminum U.S. Geological Survey leg band and a unique combination of plastic color bands to allow identification of individuals. Waterthrush territories are typically described as a length (m) instead of area given that they form linear territories along a stream reach (Mulvihill et al. 2008), therefore all analyses were based on territory length. Waterthrush territory density is the number of individual territories per stream km monitored (Hallworth et al. 2011). Waterthrush territories were delineated typically from April 1-June 29 each year. Standardized territory mapping (Robbins 1970, Bibby et al. 1992) was conducted in 2009 (8 visits per stream) and 2010 (5 visits per stream). In 2011, we switched to a more opportunistic approach that allowed for mapping waterthrush locations and behaviors during nest searching of each stream ( $\geq 5$ visits per stream). During 2013-2015, standardized territory mapping included $\geq 6$ (average $11.5 \pm 0.6$ ) visits along each stream reach, with visits preceding peak incubation initiation, and visits within 4 hours after sunrise to ensure high rates of detection (Mattsson and Cooper 2006). Observations were recorded using in-field spot-mapping on topographic maps during 2009-2011 and with a WAAS-enabled Garmin 60CSX GPS unit with accuracy $\leq 5 \mathrm{~m}$ in 2013-2015. Given frequent and 
similar site visits each year and some of the same observers monitoring waterthrush in multiple years of the study, we can reasonably assume any changes in annual territory length would not be due to using in-field spot-mapping vs. GPS territory mapping methods.

\section{Nest Abandonment, Survival, and Productivity}

Nest searching and monitoring occurred concurrently with territory mapping to determine nest abandonment rate, survival and productivity. Waterthrush have the occasional behavior of creating "nonbreeding nests" (Mattsson et al. 2009) that are abandoned before nest construction is completed (Frantz personal observation). Shale gas disturbed areas may have higher nest abandonment rates (Davis 2014) where waterthrush possibly could increase the number of nonbreeding nests in these areas. In 2013-2015, any partially built or fully built nest of unknown, post-hoc fate was tallied on each stream as a potentially abandoned nest, which we called a failed attempt. Rarely a nest can survive more than one season partially intact and its older age evident (Frantz personal observation), but any questionable nest was not counted.

We monitored nests typically every 3-4 days initially and more frequently as fledging approached (Martin and Geupel 1993). We used nestling morphology to determine hatch date (Mattsson and Cooper 2009). We assumed an undamaged empty nest had fledged if the nest was active the day before and had approached the predicted fledge date. We attempted to verify fledging by looking for fledglings or adults carrying food if a nest was believed to have fledged. We counted number of eggs to determine clutch size of nests with complete clutches. The number of fledglings for each successful nest was the count of nestlings in the visit prior to fledging. Nests were considered successful if they produced at least one waterthrush fledgling, including nests parasitized by Brown-headed Cowbirds (Molothrus ater).

\section{Riparian Habitat Quality Assessment}

Riparian habitat quality was assessed using the Habitat Suitability Index specifically designed for waterthrushes (HSI; Prosser and Brooks 1998) and the US Environmental Protection Agency (EPA) Rapid Bioassessment for high gradient streams (Barbour et al. 1999). The HSI is a broad-scale evaluation of waterthrush instream foraging and upland habitat suitability that ranges from 0-1 (Prosser and Brooks 1998). The EPA index (range of 0-200) assesses stream quality based primarily on instream characteristics that relate to the abundance and composition of waterthrush aquatic macroinvertebrate prey, and therefore may indicate relative quality of instream foraging habitat (Wood et al. 2016). The HSI and EPA index were 
quantified in a $100 \mathrm{~m}$ stream segment centered on each nest in 2009. In later years we used a 50 $\mathrm{m}$ segment centered on each nest to make the indices more sensitive to habitat immediately surrounding waterthrush nests. Mattsson and Cooper (2006) conducted EPA assessments on stream reaches that were $20 \mathrm{X}$ channel width in length. Our average channel width of $3.7 \mathrm{~m} \mathrm{X} 20$ approximates our $50 \mathrm{~m}$ segment. We did not collect EPA or HSI data in 2015 due to time constraints.

\section{Analysis}

Territory density and length. To model the effect of gas well development on waterthrush territory density, we used a generalized linear mixed model (GLMM) with study stream as a random effect and year and StreamGas as fixed effects. For these mixed models and all hereafter, we did not test more than one gas disturbance variable per analysis to avoid multicollinearity. The response variable was the number of territories for each stream in each year sampled with the length of each stream included as an offset. We specified a Poisson distribution based on the absence of overdispersion in the fixed-effects version of this model (Zuur et al. 2009). Modeling was performed using the glmer function within the lme4 package (Bates et al. 2015) in R (R Development Core Team 2014). For this model as well as the other mixed models mentioned below, model residuals were evaluated graphically and we used various data exploration diagnostic tools detailed in Zuur et al. (2010) to ensure model assumptions were met. Statistical significance $(\alpha=0.05)$ was assessed via a likelihood ratio test (Zuur et al. 2009). If year was significant, a post-hoc contrast Kruskal-Wallis sum rank test was completed with Bonferroni correction using the dunn.test R package (Dinno 2016) to determine between which years territory density differed.

We used a gamma family GLMM to test whether territory length with stream as a random effect differed among years (glmmADMB R package; Bolker et al. 2012). Overall statistical significance and post-hoc testing for year was done in the same manner as territory density. To test the hypothesis that territory length would increase with a decrease in territory density (Lack 1954), we related territory length to territory density with an Asymptotic Spearman Rho Correlation Test with R packages coin (Hothorn et al. 2015a) and psych (Revelle 2017).

Nest abandonment, survival, productivity, and source-sink threshold. To examine nest abandonment on streams from 2013-2015, we calculated percent failed attempts, hereafter 
nest abandonment, which was divided by the total of all nests on a stream, including fledged nests that could not be found $(n=18)$. We also calculated annual nest abandonment \pm standard error (SE) to evaluate trends over time. We correlated nest abandonment per stream to StreamGas using an Asymptotic Spearman Rho Correlation Test with R packages "coin" (Hothorn et al. 2015a) and "psych" (Revelle 2017).

We used Program MARK 7.1 (White and Burnham 1999) to estimate daily survival rate (DSR) of waterthrush nests in each year of the study. Of 364 total nests across all years, we removed 84 nests that did not reach the egg-laying stage, that were discovered post-fate, or had unknown fates and thus did not meet the assumptions of MARK. We assumed a 29-day nesting period (egg-laying 5, incubation 14, nestling 10 days) based on the chronology of nests monitored on our study area to calculate annual nest survival using DSR. We plotted annual nest survival \pm SE to graphically evaluate trends over time.

We developed a set of 11 a priori candidate models (Buckland et al. 1997) containing temporal, shale gas disturbance, and habitat covariates that we hypothesized might influence DSR of waterthrush nests. We did not include random effects (i.e., stream) in any model due to the difficulty of modeling such effects in nest survival analyses, but recognize that the random effect of stream could have accounted for variability among study streams if present. All a priori models included temporal covariates to account for their influence on nest survival based on previous literature: nest age, quadratic effect of time within-season (TT), and average daily rainfall. We included nest age because nests may be more vulnerable as they age (Dinsmore et al. 2002, Grant et al. 2005, Burhans et al. 2010), and because a similar covariate called nest stage was the most supported nest survival model in a 2011 waterthrush benthic aquatic prey study (Wood et al. 2016). We included TT because it was most parsimonious in a post-hoc waterthrush nest survival model (Mattsson and Cooper 2009). We included mean daily rainfall (Rain, mm) because headwater riparian systems are subject to seasonality and annual changes in rainfall (Richardson and Danehy 2006) that can affect waterthrush nest survival rates (Mattsson and Cooper 2009). For each nest, we averaged daily rainfall estimates across the period in which an active nest was under observation (Mattsson and Cooper 2009). Precipitation estimates were pooled from four Weather Underground, Inc. network stations closest (avg. $36 \mathrm{~km})$ to the study area (three weather stations in 2009). We included an additional fixed year effect as a variable of interest in some models because shale gas development increased over the study period (Farwell 
et al. 2016) and to account for annual variation in DSR associated with biotic and abiotic factors not included in our models. We did not include a model with year only because we a priori evaluated nest survival graphically to review trends and found some overlap in annual estimates.

The primary variables of interest included three shale gas disturbance covariates (TerrGas, TerrRunoff, NestGas) and two habitat covariates (GasFCD, OtherFCD; Table 2). Gas disturbance covariates were not combined in an additive fashion in a single model because they are related metrics, and the habitat covariates were not combined in a single model as we wanted to distinguish if the source of forest canopy disturbance was important. We chose GasFCD and OtherFCD as habitat covariates as we hypothesized that shale gas development through the removal and fragmentation of riparian forest cover could negatively influence waterthrush reproduction through modified predator assemblages and activity as well as altered stream hydrology and water quality (Petit and Petit 1996, Mulvihill et al. 2008, Mattsson and Cooper 2009) and because waterthrushes are known to be sensitive to removal of forest canopy cover (O’Connell et al. 2003).

We used Akaike's Information Criterion for small sample sizes (AICc) to evaluate support for candidate models (Burnham and Anderson 2002) in program MARK. We modeled the binomially distributed data with the user-defined, logit-link function while simultaneously considering associations with temporal, shale gas disturbance, and habitat covariates. We assessed the relative plausibility of each model in each model set by comparing Akaike weights $\left(\mathrm{W}_{\mathrm{i}}\right)$. We considered the model with the lowest AICc value to be the best-supported model given the data, and any models with $\triangle \mathrm{AICc}<2$ were considered plausible (Burnham and Anderson 2002). We used model-averaged regression coefficients (Burnham and Anderson 2002) and 85\% confidence intervals (hereafter CIs) to infer biological importance of covariates in plausible AICc models as $95 \%$ CIs with the information-theoretic approach can lead to variable selection uncertainty (Arnold 2010).

We quantified average overall individual and average annual population level nest productivity using an approach similar to Boves et al. (2015). Mean number of fledglings per successful nest per male (the capita value) was multiplied by nest survival (DSR ${ }^{29}$ ) separately for areas undisturbed and disturbed by shale gas development. Areas undisturbed by shale gas development $(n=78)$ were categorized as territories with TerrGas $=0 \%$, and areas disturbed by shale gas development $(n=55)$ as territories with any amount of TerrGas (range 2.7-100\%). For 
population productivity, the individual productivity capita value was calculated per year, multiplied by annual nest survival, and then multiplied by average annual territory density to determine if average annual population productivity changed over time. Significance of individual productivity between areas undisturbed and disturbed by shale gas development and for population productivity across years was evaluated graphically by examining overlap of $95 \%$ CI error bars for simple biological inference (Payton et al. 2003, MacGregor-Fors and Payton 2013). Productivity SEs used to construct the CIs were unadjusted mean number of fledglings SE values to reflect the full range of variability for each metric (T. Boves, personal communication).

Additionally, we assessed whether productivity can compensate for adult mortality (e.g., Robinson and Morse 2007) by calculating a source-sink threshold (Pulliam 1988). Since the threshold is the minimum number of fledglings needed to compensate for adult mortality, productivity above or below the threshold allowed us to evaluate if habitat quality is sufficient for local populations to be maintained. In the manner of Robinson and Morse (2000), the sourcesink threshold was the annual productivity per pair necessary to compensate for adult mortality modeled as 2(1- $\phi)$ divided by $\phi_{0}$ where $\phi$ is adult survival and $\phi_{0}$ is juvenile survival. We calculated overall adult mortality $(2(1-\phi))$ using the average of our separate estimates of male and female apparent survival $(\phi)$. Male survival $(\phi)$ was $0.56 \pm 0.04$ and female $\phi$ was $0.44 \pm$ 0.08 (Frantz et al. 2019). We assumed juvenile survival to be half the adult value (Nolan 1978) since low estimates $(\leq 0.30)$ are likely more accurate than previously thought $($ McKim-Louder et al. 2013). The source-sink threshold value was multiplied by nest survival ( $\mathrm{DSR}^{29}$ ) to convert to the same scale as individual productivity values. We then graphically evaluated if average individual productivity in areas undisturbed and disturbed by shale gas development fell above or below the threshold value and based significance on overlapping 95\% CI error bars for simple biological inference where CI proportion overlap of $\leq 0.5$ is considered significant (Cumming and Finch 2005).

Riparian habitat quality assessment. We used a beta family GLMM to compare HSI scores for nest-centered segments located in shale gas disturbed and undisturbed territories using the glmmADMB R package (Bolker et al. 2012). Models included TerrGas and year as a fixed effect and stream as a random effect. Because the 2009 HSI index was collected at a $100 \mathrm{~m}$ stream length segment and following years were at $50 \mathrm{~m}$ segments, we used t-tests to compare HSI scores from 2009 to 2010, two years when percent of stream disturbed was the same. We 
found no differences $\left(\mathrm{Z}_{78}=1.45, P=0.15\right)$, so we did not account for stream segment length differences in our models. Our model had marginal overdispersion $\left(\chi_{240}{ }^{2}=1.15, P=0.051\right)$, so we added an observer-level random effect (OLRE) where each observation receives a unique random effect level that can absorb extra-parametric variability (Harrison 2015). Statistical significance ( $\alpha=0.05$ ) was assessed via a likelihood ratio test (Zuur et al. 2009). If year was significant, we completed a post-hoc contrast Kruskal-Wallis rank sum test to indicate between which years HSI scores differed.

We used linear mixed effect modeling (LMM) in R package lme4 (Bates et al. 2015) to assess nest-centered EPA index scores in disturbed and undisturbed territories. Models included percent shale gas territory disturbance and year as a fixed effect and stream as a random effect. We did not test other gas disturbance variables within the same model to avoid multicollinearity. T-tests indicated a significant difference between EPA index scores from years 2009 (100 m assessment) and 2010 (50 $\mathrm{m}$ assessment; $t_{78}=6.12, P<0.001$. Therefore we dropped 2009 data from our model to avoid variability from stream segment length, and assumed 2010 was representative of initial gas disturbances to streams because \% disturbance on streams was the same in 2009 and 2010. We used R package afex (Singmann et al. 2015) to retrieve p-values for the $\mathrm{F}$ test assessment of fixed effects. We used a post-hoc Tukey HSD test using R package multcomp (Hothorn et al. 2015b) to determine between which years EPA scores differed. We set significance as $\alpha=0.05$ for all tests.

\section{RESULTS}

\section{Territory Density and Length}

In six years we monitored 400 waterthrush territories. Waterthrush territory density was not related to StreamGas $\left(\chi_{1}^{2}=0.002, P=0.97\right)$, but was significantly different by year and generally declined over time $\left(\chi_{5}{ }^{2}=13.424, P=0.02\right.$, Table 3$)$. A post-hoc contrast KruskalWallis sum rank test for year indicated territory density was significantly higher in 2010 than $2015\left(\chi_{5}^{2}=3.05, P=0.02\right)$. Across years, study streams had a mean of $23.4 \% \pm 0.03$ of their length disturbed by gas development (range 0.0-66.9\%, Table 1).

Territory length was significantly different by year and generally increased over time $\left(\chi_{5}^{2}\right.$ $=59.44, P=<0.001$, Table 3). A post-hoc test for year indicated territory length was greater in 2009 than in $2010\left(\chi_{5}^{2}=3.10, P=0.01\right)$, but was less in 2009 than $2014\left(\chi_{5}{ }^{2}=-3.82, P=0.001\right)$ and $2015\left(\chi_{5}^{2}=-3.84, P=<0.001\right)$. Territory length was less in 2010 than $2011\left(\chi_{5}^{2}=-2.79, P=\right.$ 
0.02), $2013\left(\chi_{5}^{2}=-4.90, P=<0.001\right), 2014\left(\chi_{5}^{2}=-6.95, P=<0.001\right)$, and $2015\left(\chi_{5}^{2}=-6.83, P=\right.$ $<0.001)$. Territory length also was less in 2011 than $2014\left(\chi 5^{2}=-4.00, P=<0.001\right)$ and 2015 $\left(\chi_{5}^{2}=-4.01, P=<0.001\right)$. Territory length significantly increased as territory density decreased $\left(\right.$ Rho $\left.=-0.49, Z_{394}=-9.66, P<0.001\right)$.

\section{Nest Abandonment, Survival, Productivity, and Source-sink Threshold}

During 2013-2015, 59 nests of unknown fate were potentially abandoned or a failed nesting attempt (average $1.5 \pm 0.3$ failed attempts per stream). There was not a statistically significant relationship between nest abandonment on streams and StreamGas $\left(\mathrm{Rho}=0.22, \mathrm{Z}_{38}=\right.$ $1.40, P=0.16)$. Nest abandonment rates on streams were $16.9 \pm 0.1 \%, 37.3 \pm 0.1 \%$, and $9.4 \pm$ $0.04 \%$ annually. Annual daily and seasonal nest survival peaked in 2010-2011 and generally declined over time (Table 3). Overall mean DSR was $96.4 \pm 0.3 \%$ and yielded average nest survival of $34.3 \pm 3.1 \%$. Across all years, eight nests were parasitized by Brown-headed Cowbirds, primarily in later years of the study (Table 3).

Of 11 a priori models (Table 4), four models that had habitat (GasFCD) and gas (TerrRunoff, TerrGas, NestGas) covariates were supported ( $\triangle \mathrm{AICc}<2$ ). The two models that included TerrRunoff and TerrGas accounted for most of the variation in DSR $\left(w_{\mathrm{i}}=0.28\right.$ and 0.27). Model-averaged regression coefficient $85 \%$ CIs did not overlap zero for Rain and GasFCD with positive influence on DSR, while TerrGas, TerrRunoff, and NestGas did not overlap zero and had a negative influence on DSR (Table 5, Figure 3). About a third (29.6\%) of nests monitored had NestGas, and nest survival dropped from $37.3 \pm 4.3 \%$ in undisturbed areas to $30.7 \pm 4.5 \%$ in areas disturbed by shale gas. Territories containing nests had on average $24.7 \pm$ $2.1 \%$ of TerrGas and $21.8 \pm 2.2 \%$ of TerrRun. Nests across years were predominately forested $(94.0 \pm 0.5 \%)$ with $2.3 \pm 0.3 \%$ GasFCD. NestAge and TT had regression coefficients that overlapped zero, indicating little or highly variable influence on DSR.

Overall population productivity was $2.3 \pm 0.5$ fledglings $/ \mathrm{km}$ and generally declined from early years of the study (2009-2011) to later years (2013-2015, Table 3) based on 95\% CIs. Overall individual productivity was $1.5 \pm 0.1$ (SE) fledglings per adult male. Individual productivity was higher in areas undisturbed (1.6 \pm 0.2 fledglings) than disturbed (1.4 \pm 0.2$)$ by shale gas based on 95\% CIs (Figure 4). The completed source-sink equation was 2(1-0.50) / 0.25 , with 0.50 the average of male and female adult survival and juvenile survival assumed to be half that value at 0.25 , resulting in 1.4 fledglings per pair. The source-sink threshold of 1.4 
fledglings per pair was below the individual annual productivity in areas undisturbed by shale gas (Figure 4) suggesting these are source habitats. However, the threshold overlapped the productivity for areas disturbed by shale gas (average $56.7 \pm 4.5 \%$ TerrGas in disturbed areas) suggesting these are borderline sink habitats.

\section{Riparian Habitat Quality}

HSI scores were negatively related to TerrGas $\left(\chi_{1}^{2}=65.34, P<0.001\right.$, Figure 5), and differed by year $\left(\chi_{4}^{2}=34.84, P<0.001\right.$, Table 3$)$. A post-hoc contrast Kruskal-Wallis sum rank test for year indicated HSI scores were significantly higher in 2009 than in $2013\left(\chi_{4}{ }^{2}=4.03, P<\right.$ $0.001)$ and in 2009 than in $2014\left(\chi_{4}{ }^{2}=3.14, P=0.01\right)$.

EPA index scores were negatively related to TerrGas $\left(F_{1,158}=14.54, P<0.001\right.$, Figure $5)$, and differed by year $\left(F_{3,196}=14.07, P<0.001\right.$, Table 3$)$. A post-hoc Tukey HSD test for year indicated EPA index scores were significantly higher in 2010 than in $2014\left(Z_{394}=3.29, P=\right.$ 0.005), higher in 2011 than in $2013\left(Z_{394}=-4.26, P<0.001\right)$, and lower in 2013 than in 2014 $\left(\mathrm{Z}_{394}=6.18, P<0.001\right)$.

\section{DISCUSSION}

Over our six year study at LWWMA, we saw general declines in waterthrush territory density, nest survival, nest productivity, and riparian habitat quality concurrent with a site-wide increase in shale gas-related disturbance (Farwell et al. 2016). Our source-sink threshold suggests that individuals breeding in areas disturbed by shale gas development are potentially in sink habitat and are more at risk of population decline than individuals in areas undisturbed by shale gas development. Declines in waterthrush demography occurred despite $<5 \%$ forest cover loss at our predominately forested study site (Farwell et al. 2016) which suggests that factors other than loss of forest cover also influenced demography (Wood et al. 2016). In general, all demographic parameters for waterthrushes appeared to be affected negatively by shale gas disturbances occurring in headwater stream ecosystems (Table 3). To our knowledge, our study is the first to establish the potential for Marcellus-Utica shale gas development to affect reproductive success and productivity of forest birds.

Waterthrush territory density declined across years, but was not explained by StreamGas. Streams on average had less than a quarter $(22.5 \% \pm 2.6)$ of their length disturbed by StreamGas (Table 1), and no stream was ever completely disturbed (maximum 66.9\%). Consequently, undisturbed areas occurred on every stream, so waterthrush could shift their territories to forage 
and place nests in undisturbed sections of streams. Waterthrush on acidified streams in Pennsylvania used a similar strategy (Mulvihill et al. 2008). Despite waterthrush exhibiting high site fidelity (O’Connell et al., 2003), we noted that by the end of our study our initial high territory densities of $1.5 \mathrm{~km}^{-1}$ had dropped to 1 territory $\mathrm{km}^{-1}$, lower than typical densities across the breeding range (Mattsson et al. 2009). A Headwater Stream Assessment based on waterthrushes in PA found that $0-1$ territories $\mathrm{km}^{-1}$ indicated degradation and 1-2 territories $\mathrm{km}^{-1}$ indicated possible degradation (O’Connell et al., 2003). This suggests increased degradation of our study streams across our study period, as was also suggested by our declining HSI scores. The decline in riparian stream quality over time likely influenced the decrease in territory density and increase in territory lengths in our study. Increasing length of territories in disturbed areas may be a mechanism that allows waterthrushes to compensate for poor habitat quality (Mulvihill et al. 2008). Waterthrushes increasing their territory lengths may need additional foraging resources to meet minimal breeding requirements, as suggested by greater territory densities in 2011 in areas where macroinvertebrate density, biomass, and stream quality were higher (Wood et al. 2016).

Nest survival was positively influenced by average daily rainfall, similar to Mattsson and Cooper's (2009) finding of maximum daily survival rate at intermediate $(3-10 \mathrm{~mm})$ rainfall levels. This intermediate rainfall range is similar to what waterthrushes encountered during the active nesting period at our study site (range $0-11.2 \mathrm{~mm}$, average $3.6 \pm 0.1 \mathrm{~mm}$ ). Rainfall in this range likely leads to increased prey availability, foraging efficiency, and therefore nest vigilance (Mattsson and Cooper 2009). Lack of sufficient water flow was likely more of a factor than flooding in our headwater system as only four nests were confirmed to have failed from high water events. At the beginning of the breeding period our streams were typically flowing, but by late summer when young were fledging, streams had intermittent or little flow. While not a documented threat to waterthrushes on our headwater study streams, shale gas operations withdraw large amounts of surface and groundwater from small streams (Entreken et al. 2011). As such, waterthrushes breeding downstream of water withdrawal operations have the potential to be negatively affected by altered hydrology in the same manner that water withdrawals affect other species, such as brook trout (Salvelinus fontinalis) (Weltman-Fahs and Taylor 2013).

After accounting for the positive influence of rainfall, waterthrush DSR also had a significant negative relationship with three shale gas development covariates. TerrRunoff was a 
measure of potential surface water contamination, while TerrGas and NestGas assessed the physical presence of shale gas infrastructure and included human activity and sedimentation (Table 2, Table 5). All previous bird community studies of Marcellus shale drilling in the Appalachians have focused primarily on presence of gas infrastructure, with less attention to noise and light levels (Davis 2014, Barton et al. 2016, Farwell et al. 2016). Waterthrushes in our study could have been directly affected by the presence of infrastructure given the similar findings of negative effects from oil and gas development on bird species from other regions (Van Wilgenburg et al. 2013, Thompson et al. 2015, Hethcoat and Chalfoun 2015), although we must also consider indirect effects on stream and terrestrial food webs from possible contamination (Entrekin et al. 2011). For example, waterthrushes in areas disturbed by shale gas development had higher levels of barium and strontium in their feathers than waterthrush in areas undisturbed by shale gas (Latta et al. 2015). Because barium and strontium are two heavy metals associated with the drilling process (Chapman et al. 2012), and LWWMA was a sampled region in Latta et al. (2015), this finding could be related to our modeling result that TerrRunoff negatively influenced DSR. Heavy metals can interfere with DNA methyl transfer (Hala et al. 2014), so one potential mechanism by which DSR can be affected is by differential methylation via epigenetics (see Chapter 6).

Previous studies have shown potential waterthrush vulnerability to forest habitat fragmentation (Robbins 1979, McIntyre 1995, Adams 2007) and declines in abundance after loss of $\sim 16 \%$ forest from the landscape (Becker et al. 2015). In contrast, waterthrush in our study showed a slight positive relationship between GasFCD and DSR. Clearing of land for shale gas development in some instances may increase net primary production in streams (Johnson et al. 2015) and increase certain types of aquatic prey, such as shredders (Barton 2016), thus GasFCD potentially increased some aquatic prey taxa for waterthrushes. In addition, Davis (2014) found that while nest survival was lower for Field Sparrows (Spizella pusilla) in the presence of gas wells, gas pipelines and access roads had a lower index of predation risk, possibly from increased noise (Francis et al. 2012) or light (de Molenaar et al. 2006) levels, even though predation typically increases near forest edges (Paton 1994). However, these potential benefits from GasFCD could be offset by higher abandonment rates (Davis 2014) or cowbird nest parasitism in areas disturbed by shale gas development. Although few nests were parasitized (2.9\% of nests) on our study area compared to other waterthrush studies (range 0-81\%; Mattson 
et al. 2009), we observed an apparent increase in parasitism rates of waterthrush nests across years as forest cover declined and the majority of parasitized nests (75\%) failed. Concurrently, cowbird detections increased from $2.1 \%$ of sample points in 2008 to $27.5 \%$ in 2015 (Farwell et al. 2016). Parasitized nests had double the amount of GasFCD $(5.7 \% \pm 2.2)$ than non-parasitized nests $(2.7 \% \pm 0.3)$. Given that average forest cover of nests was $94.0 \% \pm 0.5$ and waterthrush will not occupy areas of $<40 \%$ forest cover (O'Connell et al. 2003), GasFCD may play only a minor role, at least initially, among several factors (i.e., rainfall and shale gas disturbance) in nest survival.

Waterthrush are persistent renesters with only 5-6 days between attempts (Mulvihill et al. 2002), in addition to the behavior of creating "nonbreeding nests" (Mattsson et al. 2009, Frantz personal observation). Average nesting attempts for our study site (including successful and unsuccessful individuals, and nest building attempts) was $1.04 \pm 0.04$ but up to five attempts were documented. We did not detect a statistically significant association between nest abandonment and amount of stream disturbance. A weak, negative relationship can be suggested, but there is no way to determine whether a nest of unknown fate (i.e., nests that cannot be used in typical nest survival analyses) were truly abandoned, failed, or left unfinished for other reasons. Negative discrimination of Brown-headed Cowbird eggs by waterthrush has been documented (Robinson 1990), so parasitism could be under-represented by nests that failed before clutch completion or before active observation, as we can only document apparent acceptance of parasitized nests. Further behavioral monitoring will be needed to discriminate nonbreeding nests from actual failed nests found post-hoc, and whether waterthrush will increase the number of nonbreeding nests or relocate a nest due to shale gas disturbance.

Population productivity generally declined over time, and areas disturbed by shale gas development had lower individual productivity, broadly overlapping with the source-sink threshold (Figure 3). Corresponding with lower individual productivity, lower nest survival, and decreased riparian habitat quality with increasing disturbance, areas disturbed by shale gas development may be at greater risk for being sink habitat. Our source-sink values match other studies showing productivity in optimal (or presumably undisturbed) source habitat to be barely above estimated source-sink thresholds (Morse 1996, Holmes et al. 1996). Headwater streams may need to be buffered from potential disturbances if they are only marginally source habitats even under ideal conditions (Morse and Robinson 2000). 


\section{Conclusion}

Our study is one of the first to demonstrate that shale gas development can affect reproductive success and productivity in a wildlife population, likely by the presence of shale gas infrastructure and by indirect negative effects to stream health and aquatic prey (Wood et al. 2016). Increasing overall aquatic ecosystem health necessitates measures to protect water quality from upstream sediment load and pollutant sources (Cook et al. 2015) which would require watershed scale (Merovich et al. 2013) habitat conservation efforts. Spills and erosion are the most commonly reported environmental violations (Rahm et al. 2015), which could be avoided with setbacks from streams and avoidance of building in steep grades (Evans and Kiesecker 2014). Development is outpacing implementation of best management practices (Brittingham et al. 2014), so placing well pads further away from water than currently permissible may be the most effective way to avoid multiple disturbances from shale gas (Milt et al. 2016).

For effective mitigation strategies at a regional level, additional species and area-specific studies are needed (Northrup and Wittemyer 2013) as well as clarification of the specific mechanisms involved in species' responses (Hethcoat and Chalfoun 2015) to shale gas disturbance. Our study results combined with post-fledgling survival data (Streby and Anderson 2011), and a cross-ecosystem evaluation of food web interactions (Soininen et al. 2015) with potential contaminants would fill important knowledge gaps. Lack of information regarding the full range and interdependence of waterthrush demographic responses to shale gas development should not negate immediate risk management activities (Loss 2016), especially if multiple lines of evidence suggest decline and negative demographic response of a known important bioindicator of headwater stream ecosystems.

\section{ACKNOWLEDGMENTS}

West Virginia Division of Natural Resources (WVDNR) provided access to the study area and Wheeling Jesuit University provided access to field housing. We thank many field assistants and graduate students who collected data during our six year study. In particular we thank J. Mizel, D. Becker, and K. Aldinger for assistance with data collection and analysis approaches. We thank L. Farwell, S. Latta, A. Welsh, M. Strager, and S. Welsh for helpful comments that 
improved the manuscript. Any use of trade, firm, or product names is for descriptive purposes only and does not imply endorsement by the U.S. Government.

Funding statement: Our research was funded by West Virginia Division of Natural Resources, U.S. Department of Energy National Energy Technology Laboratory, West Virginia University, and National Aviary. None of our funders had any influence on the content of the submitted or published manuscript and only the U.S. Geological Survey required approval of the final manuscript prior to publication as required in their Fundamental Sciences Practices protocols.

Ethics statement: Banding was conducted under USGS banding permit \#23412 and \#23059. This study was completed under the auspices of West Virginia University IACUC protocol \#040302, 07-0303.

Author contributions: P.B.W. and G.G. conceived the original idea for the project with P.B.W. supervising the research and securing most of the research funding. M.W.F., J.S., and G.G. conducted the research. M.W.F. and P.B.W. wrote the paper with input from J.S. Methods were developed by M.W.F., P.B.W., J.S. and G.G. M.W.F. analyzed the data. P.B.W. and M.W.F. contributed substantial resources.

\section{LITERATURE CITED}

Adams, K. (2007). Using Avifauna for ecological assessment in streamside management zones implemented by forestry best management practices. MS Thesis, Clemson University, Clemson, $\mathrm{SC}$.

Arnold, T. W. (2010). Uninformative parameters and model selection using Akaike's Information Criterion. Journal of Wildlife Management 74:1175-1178.

Barbour, M. T., J. Gerritsen, B. D. Snyder, and J. B. Stribling. (1999). Rapid bioassessment protocols for use in streams and wadeable rivers: periphyton, benthic macroinvertebrates and fish, second edition. EPA 841-B-99-002. U.S. Environmental Protection Agency, Office of Water, Washington, D.C.

Barton, E. P., S. E. Pabian, and M. C. Brittingham. (2016). Bird community response to Marcellus shale gas development. Journal of Wildlife Management 80:1301-1313.

Barton, J. A. (2016). In-stream leaf decomposition as an indicator of Marcellus shale impairment across a land use gradient. MS thesis, Bucknell University, Lewisburg, PA, USA.

Bates, D., M. Maechler, B. Bolker, and S. Walker. (2015). Fitting linear mixed-effects models using lme4. Journal of Statistical Software 67:1-48. Package 'Ime4'. Version 1.1-10. https://CRAN.R-project.org/package=lme4. 
Becker, D. A., P. B. Wood, M. P. Strager, and C. Mazzarella. (2015). Impacts of mountaintop mining on terrestrial ecosystem integrity: identifying landscape thresholds for avian species in the central Appalachians, United States. Landscape Ecology 30:339-356.

Bibby, C. J., N. D. Burgess, and D. A. Hill. (1992). Bird Census Techniques. Academic Press, London.

Bolker, B., H. Skaug, A. Magnusson, and A. Nielsen. (2012). Getting started with the glmmADMB package. Package 'glmmADMB'. Version 0.6.5. http://glmmadmb.r-forge.rproject.org.

Boves, T. J., A. D. Rodewald, P. B. Wood, D. A. Buehler, J. L. Larkin, T. B. Wigley, and P. D. Keyser. (2015). Habitat quality from individual- and population-level perspectives and implications for management. Wildlife Society Bulletin 39(2):443-447.

Brittingham, M. C., K. O. Maloney, A. M. Farag, D. D. Harper, and Z. H. Bowen. (2014). Ecological risks of shale oil and gas development to wildlife, aquatic resources and their habitats. Environmental Science and Technology 48:11034-11047.

Buckland, S. T., K. P. Burnham, and N. H. Augustin. (1997). Model selection: An integral part of inference. Biometrics 53:603-618.

Burnham, K. P., and D. R. Anderson. (2002). Model Selection and Multimodel Inference: An Information-Theoretic Approach. Springer-Verlag, New York, New York, USA.

Burhans, D. E., B. G. Root, T. L. Shaffer, and D. C. Dey. (2010). Songbird nest survival is invariant to early-successional restoration treatments in a large river floodplain. Wilson Journal of Ornithology 122:307-317.

Chapman, E. C., R. C. Capo, B. W. Stewart, C. S. Kirby, R. W. Hammack, K. T. Schroeder, and H. M. Edenborn. (2012). Geochemical and strontium isotope characterization of produced waters from Marcellus Shale natural gas extraction. Environmental Science \& Technology 46:3545-3553.

Cook, N. A., E. A. Sarver, L. H. Krometis, and J. Huang. (2015). Habitat and water quality as drivers of ecological system health in Central Appalachia. Ecological Engineering 84:180-189.

Cumming, G., and S. Finch. (2005). Inference by eye: Confidence intervals, and how to read pictures of data. American Psychologist 60:170-180.

Davis, R. (2014). Impacts of non-renewable resource extraction on shrubland songbird nest success and abundance. MS Thesis, West Virginia University, Morgantown, WV.

de Molenaar, J. G., M. E. Sanders, and D. A. Jonkers. (2006). Road lighting and grassland birds: local influence of road lighting on a Black-tailed Godwit population. In Ecological 
Consequences of Artificial Night Lighting (C. Rich and T. Longcore, Editors). Island Press, Washington D.C., USA.

Dinno, A. (2016). Package 'dunn.test'. Version 1.3.2. https://CRAN.R-

project.org/package $=$ dunn.test

Dinsmore, S. J., G. C. White, and F. L. Knopf. (2002). Advanced techniques for modeling avian nest survival. Ecology 83:3476-3488.

DOE (Department of Energy) (2009). Modern shale gas development in the United States: A primer. Office of Fossil Energy and National Energy Technology Laboratory, U.S. Department of Energy, Washington, D.C. http://energy.gov/sites/prod/files/2013/03/f0/ShaleGasPrimer_Online_4-2009.pdf.

DOE (Department of Energy) (2010) Projecting the economic impact of Marcellus shale gas development in West Virginia: A preliminary analysis using publicly available data. Office of Fossil Energy and National Energy Technology Laboratory, U.S. Department of Energy, Washington, D.C. http://www.netl.doe.gov/energyanalyses/pubs/WVMarcellusEconomics3.pdf.

Drohan, P. J., M. Brittingham, J. Bishop, and K. Yoder. 2012. Early trends in landcover change and forest fragmentation due to shale gas development in Pennsylvania: A potential outcome for the Northcentral Appalachians. Environmental Management 49:1061-1075.

Dunscomb, J. K., J. S. Evans, J. M. Strager, M. P. Strager, and J. M. Kiesecker. (2014). Assessing future energy development across the Appalachian Landscape Conservation Cooperative. The Nature Conservancy, Charlottesville, VA. 48 pp with appendices. Appalachian Landscape Conservation Cooperative Grant \#2012-02.

EIA (Energy Information Administration). (2011). Review of emerging resources: U.S. shale gas and shale oil plays. U.S. Department of Energy, Washington, D.C.

https://www.eia.gov/analysis/studies/usshalegas/pdf/usshaleplays.pdf.

Entrekin, S., M. Evans-White, B. Johnson, and Hagenbuch, E. (2011). Rapid expansion of natural gas development poses a threat to surface waters. Frontiers in Ecology and the Environment 9:503-511.

Evans, J. S., and J. M. Kiesecker. (2014). Shale gas, wind and water: Assessing the potential cumulative impacts of energy development on ecosystem services within the Marcellus play. PLoS ONE 9:e89210.

Farwell, L. S., P. B. Wood, J. Sheehan, and G. A. George. (2016). Shale gas development effects on the songbird community in a central Appalachian forest. Biological Conservation 201:78-91.

Flaspohler, D. J., S. A. Temple, and R. N. Rosenfeld. (2001). Species specific edge effects on nest success and breeding bird density in a forested landscape. Ecological Applications 11:3246. 
Francis, C. D., C. P. Ortega, R. I. Kennedy, and P. J. Nylander. (2012). Are nest predators absent from noisy areas or unable to locate nests? Ornithological Monographs 74:101-110.

Frantz, M. W., P. B. Wood, J. Sheehan, and G. George. (2019). Louisiana Waterthrush (Parkesia motacilla) survival and site fidelity in an area undergoing shale gas development. The Wilson Journal of Ornithology 131:84-95.

Grant, T. A., T. L. Shaffer, E. M. Madden, and P. J. Pietze. (2005). Time-specific variation in passerine nest survival: new insights into old questions. The Auk 122:661-672.

Hala, D., D. B. Huggett, and W. W. Burggren. (2014). Environmental stressors and the epigenome. Drug Discovery Today: Technologies 12:e3-e8.

Hallworth, M. T., L. R. Reitsma, and K. Parent. (2011). Habitat use of the Louisiana Waterthrush during the non-breeding season in Puerto Rico. The Wilson Journal of Ornithology 123:567-574.

Harrison, X. A. (2015). A comparison of observation-level random effect and beta-binomial models for modelling overdispersion in binomial data in ecology \& evolution. PeerJ 3:e1114.

Hethcoat, M. G., and A. D. Chalfoun. (2015). Energy development and avian survival in Wyoming, USA: a test of a common disturbance index. Biological Conservation 184:327-334.

Holmes, R. T., P. P. Marra, and T. W. Sherry. (1996). Habitat-specific demography of breeding Black-throated Blue Warblers (Dendroica caerulescens):

Implications for population dynamics. Journal of Animal Ecology 71:183-195.

Hothorn, T., K. Hornik, M. A. van de Wiel, H. Winell, and A. Zeileis. (2015A).

Package 'coin'. Version 1.1-2. https://CRAN.R-project.org/package=coin.

Hothorn, T., F. Bretz, P. Westfall, R. M. Heiberger, A. Schuetzenmeister, and S. Scheibe. (2015B). Package 'multcomp'. Version 1.4-1. https://CRAN.R-project.org/package=multcomp.

Lack, D. (1954). The natural regulation of animal numbers. Oxford: The Clarendon Press.

Johnson, E., B. J. Austin, E. Inlander, C. Gallipeau, M. A. Evans-White, and S. Entrekin. (2015). Stream macroinvertebrate communities across a gradient of natural gas development in the Fayetteville Shale. Science of the Total Environment 530-531:323-332.

Kirol, C. P., J. L. Beck, S. V. Huzurbazar, M. J. Holloran, and S. N. Miller. (2015). Identifying Greater Sage-Grouse source and sink habitats for conservation planning in an energy development landscape. Ecological Applications 25:968-990.

Latta, S. C., L. C. Marshall, M. W. Frantz, and J. Toms. (2015). Evidence from two shale regions that a riparian songbird accumulates metals associated with hydraulic fracturing. Ecosphere 6:144. 
Loss, S. R. (2016). Avian interactions with energy infrastructure in the context of other anthropogenic threats. The Condor: Ornithological Applications 118:424-432.

MacGregor-Fors, I., and M. E. Payton. (2013). Contrasting diversity values: statistical inferences based on overlapping confidence intervals. PLoS ONE 8:e56794.

Martin, T. E., and G. R. Geupel. (1993). Nest-monitoring plots: Methods for locating nests and monitoring success. Journal of Field Ornithology 64:507-519.

Mattsson, B. J., and R. J. Cooper. (2006). Louisiana Waterthrushes (Seiurus motacilla) and habitat assessment as cost-effective indicators of instream biotic integrity. Freshwater Biology 51:1941-1958.

Mattsson, B. J., and R. J. Cooper. (2009). Multi-scale analysis of the effects of subseasonal rainfall extremes on reproduction by an obligate riparian bird in urban and rural landscapes. The Auk 126:64-76.

Mattsson, B. J., T. L. Master, R. S. Mulvihill, W. D. Robsinson. (2009). Louisiana Waterthrush (Parkesia motacilla). The birds of North America (P. G. Rodewald, Editor). Ithaca: Cornell Lab of Ornithology. https://birdsna-org.bnaproxy.birds.cornell.edu/Species Account/bna/species/louwat.

McGarigal, K., S. A. Cushman, and E. Ene. (2012). FRAGSTATS v4: Spatial pattern analysis program for categorical and continuous maps. University of Massachusetts, Amherst, MA. http://www.umass.edu/landeco/research/fragstats/fragstats.html.

McIntyre, N., (1995). Effects of forest patch size on avian diversity. Landscape Ecology 10:8599.

McKim-Louder, M. I., J. P. Hoover, T. J. Benson, W. M. Schelsky. (2013). Juvenile survival in a neotropical migratory songbird is lower than expected. PLOS ONE 8:e56059.

MCOR (Marcellus Center for Outreach and Research). (2016). Tri-state unconventional shale wells (PA, WV, OH). http://www.marcellus.psu.edu/resources/maps.php (Last updated December 31, 2015. Accessed Mar.15, 2016).

Merovich, G. T., J. T. Petty, M. P. Strager, and J. B. Fulton. (2013). Hierarchical classification of stream condition: a house-neighborhood framework for establishing conservation priorities in complex riverscapes. Freshwater Science 32:874-891.

Milt, A.W., T. Gagnolet, and P. W. Armsworth. (2016). Synergies and tradeoffs among environmental impacts under conservation planning of shale gas surface infrastructure. Environmental Management 57:21-30.

Morse, S. F. (1996). Source-sink population dynamics of Kentucky Warblers in a complex forested landscape in southern Illinois. MS Thesis. University of Illinois, Urbana-Champaign, IL. 
Mulvihill, R. S., A. Cunkelman, L. Quattrini, T. J. O’Connell, and T. L. Master. (2002). Opportunistic polygyny in the Louisiana Waterthrush. The Wilson Bulletin 114:106-113.

Mulvihill, R. S., F. L. Newell, and S. C. Latta. (2008). Effects of acidification on the breeding ecology of a stream-dependent songbird, the Louisiana Waterthrush (Seiurus motacilla). Freshwater Biology 53:2158-2169.

Nolan, V., Jr. (1978). The ecology and behavior of the Prairie Warbler, Dendroica discolor. Ornithological Monograph, no. 26.

Northrup, J. M., and G. Wittemyer. (2013). Characterising the impacts of emerging energy development on wildlife, with an eye towards mitigation. Ecology Letters 16:112-125.

O'Connell, T. J., L. E. Jackson, and R. P. Brooks. (2000). Bird guilds as indicators of ecological condition in the central Appalachians. Ecological Applications 10:1706-1721.

O’Connell, T. J., R. P. Brooks, S. E. Laubscher, R. S. Mulvihill, and T. E. Master. (2003). Using bioindicators to develop a calibrated index of regional ecological integrity for forested headwater ecosystems. Final report to U. S. Environmental Protection Agency, STARS Grants Program. Report No. 2003-1. Penn State Cooperative Wetlands Center, Penn State University, University Park, PA.

Paton, P. W. (1994). The effect of edge on avian nest success: How strong is the evidence? Conservation Biology 8:17-26.

Payton, M. E., M. H. Greenstone, and N. Schenker. (2003). Overlapping confidence intervals or standard error intervals: What do they mean in terms of statistical significance? Journal of Insect Science 3:1-6.

Petit, L. J., and D. R. Petit. (1996). Factors governing habitat selection by Prothonotary Warblers: Field tests of the Fretwell-Lucas models. Ecological Monographs 66:367-387.

Prosser, D. J., and R. P. Brooks. (1998). A verified habitat suitability index for the Louisiana Waterthrush. Journal of Field Ornithology 69:288-298.

Pulliam, H. R. (1988). Sources, sinks, and population regulation. The American Naturalist 132:652-661.

Rahm, B. G., S. Vedachalam, L. R. Bertoia, D. Mehta, V. Sandeep Vanka, and S. J. Riha. (2015). Shale gas operator violations in the Marcellus and what they tell us about water resource risks. Energy Policy 82:1-11.

R Core Team. (2014). R: A language and environment for statistical computing. R Foundation for Statistical Computing, Vienna, Austria. http://www.Rproject.org/. Revelle, W. (2017). Package 'psych'. Version 1.7.5. https://CRAN.Rproject.org/package=psych. 
Richardson, J. S., and R. J. Danehy. (2006). A synthesis of the ecology of headwater streams and their riparian zones in temperate forests. Forest Science 53:131-147.

Robbins, C. S. (1970). Recommendations for an international standard for a mapping method in bird census work. Audubon Field Notes 24:723-726.

Robbins, C. S. (1979). Effect of forest fragmentation on bird populations. Pages 198-213 in USDA, Forest Service. Management of North Central and Northeastern Forests for Nongame Birds. Workshop Proceedings, U.S. Department of Agriculture Forest Service, General Technical Reports NC-51. USDA Forest Service, North Central Forest Experimental Station, St. Paul, MN.

Robinson, W. D. (1990). Louisiana waterthrush foraging behavior and microhabitat selection in southern Illinois. MS Thesis, Southern Illinois University, Carbondale, IL.

Robinson, S. K., and S. F. Morse. (2007). Conservation insights from demographic studies of migratory songbirds in the American Midwest. Pages 225-232 in Strategies for bird conservation: the Partners in Flight planning process. (Bonney, R., D. N. Pashley, R. J. Cooper, and L. Niles, Editors). Proceedings of the third Partners in Flight workshop. U.S. Department of Agriculture Forest Service, Rocky Mountain Research Station, Ogden, UT.

Sauer, J. R., D. K. Niven, J. E. Hines, D. J. Ziolkowski, Jr., K. L. Pardieck, J. E. Fallon, and W. A. Link. (2017). The North American Breeding Bird Survey, Results and Analysis 1966-2015 version 12.23.2015. USGS Patuxent Wildlife Research Center, Laurel, Maryland http://www. mbr-pwrc.usgs.gov/bbs/.

Sheehan, J., P. B. Wood, D. A. Buehler, P. D. Keyser, J. L. Larkin, A. D. Rodewald, T. B. Wigley, T. J. Boves, G. A. George, M. H. Bakermans, T. A. Beachy, A. Evans, M. E. McDermott, F. L. Newell, K. A. Perkins, and M. White. (2014). Avian response to timber harvesting applied experimentally to manage Cerulean Warbler breeding populations. Forest Ecology and Management 321:5-18.

Singmann, H., B. Bolker, J. Westfall, F. Aust, S. Højsgaard, J. Fox, M. A. Lawrence, and U. Mertens. (2015). Package 'afex: analysis of factorial experiments'. Version 0.16-1. https://CRAN.R-project.org/package=afex.

Soininen, J., P. Bartels, J. Heino, M. Luoto, and H. Hillebrand. (2015). Toward more integrated research in aquatic and terrestrial environments. BioScience 65:174-182.

Souther, S., M. W. Tingley, V. D. Popescu, D. T. S. Hayman, M. E. Ryan, T. A. Graves, B. Harth, and K. Terrell. (2014). Biotic impacts of energy development from shale: research priorities and knowledge gaps. Frontiers in Ecology and the Environment 12:330-338. 
Stracey, C. M., and S. K. Robinson. (2012). Are urban habitats ecological traps for a native songbird? Season-long productivity, apparent survival, and site fidelity in urban and rural habitats. Journal of Avian Biology 43:50-60.

Streby, H. M., and D. E. Andersen. (2011). Seasonal productivity in a population of migratory songbirds: Why nest data are not enough. Ecosphere 2:7.

Thompson, S. J., D. H. Johnson, N. D. Niemuth, and C. A. Ribic. (2015). Avoidance of unconventional oil wells and roads exacerbates habitat loss for grassland birds in the North American Great Plains. Biological Conservation 192:82-90.

USFWS (United States Fish and Wildlife Service). (2008). Birds of conservation concern 2008. United States Department of Interior, Fish and Wildlife Service, Division of Migratory Bird Management, Arlington, Virginia. http://www.fws.gov/migratorybirds.

Van Wilgenburg, S. L., K. A. Hobson, E. M. Bayne, and N. Koper. (2013). Estimated avian nest loss associated with oil and gas exploration and extraction in the western Canadian sedimentary basin. Avian Conservation and Ecology 8:9. http://www.ace-eco.org/vol8/iss2/art9/.

Weltman-Fahs, M., and J. M. Taylor. (2013). Hydraulic fracturing and brook trout habitat in the Marcellus Shale region: Potential impacts and research needs. Fisheries 38:4-15.

White, G. C., and K. P. Burnham. (1999). Program MARK: Survival estimation from populations of marked animals. Bird Study 46:S120-130.

Wood, P., M. Frantz, and D. Becker. (2016). Louisiana Waterthrush and benthic macroinvertebrate response to shale gas development. Journal of Fish \& Wildlife Management 7: 423-433.

Woods, A. J., J. M. Omernik, and D. D. Brown. (1999). Level III and IV ecoregions of Delaware, Maryland, Pennsylvania, Virginia, and West Virginia, U.S. U.S. Environmental Protection Agency, National Health and Environmental Effects Research Laboratory, Corvallis, OR. ftp://ftp.epa.gov/wed/ecoregions/reg3/reg3_eco_desc.doc.

WVDEP (West Virginia Department of Environmental Protection). (2015). Oil and gas production data. 2015. State of West Virginia. http://www.dep.wv.gov/oil-and-gas/databaseinfo/Pages/default.aspx.

WVGES (West Virginia Geological and Economic Survey). (2015). WV Marcellus shale wells: completed, permitted, and cancelled episodes. http://www.wvgs.wvnet.edu/www/datastat/devshales.htm.

Zuur, A. F., E. N. Ieno, N. J. Walker, A. A. Saveliev, and G. M. Smith. (2009). Mixed Effects Models and Extensions in Ecology with R. Springer, New York. 
Zuur, A. F., E. N. Ieno, and C. S. Elphick. (2010). A protocol for data exploration to avoid common statistical problems. Methods in Ecology and Evolution 1:3-14. 


\section{TABLES}

Table 1. Annual percent of each study stream's length that was disturbed by shale gas development or activity (StreamGas, SG; see Table 2) or potentially affected by runoff (StreamRunoff, SR) from shale gas well pads (not including pipeline or road disturbance). The last new well pad construction occurred near study streams in 2014.

\begin{tabular}{|c|c|c|c|c|c|c|c|c|c|c|c|c|}
\hline \multirow[b]{2}{*}{ Study Streams } & \multicolumn{2}{|c|}{2009} & \multicolumn{2}{|c|}{2010} & \multicolumn{2}{|c|}{2011} & \multicolumn{2}{|c|}{2013} & \multicolumn{2}{|c|}{2014} & \multicolumn{2}{|c|}{2015} \\
\hline & SG & SR & SG & SR & SG & SR & SG & SR & SG & SR & SG & SR \\
\hline Buffalo East Run & 14.9 & 7.6 & 14.9 & 7.6 & 14.9 & 7.6 & 7.6 & 7.6 & 7.6 & 7.6 & 7.6 & 7.6 \\
\hline Buffalo West Run & 53.5 & 2.6 & 47.4 & 2.3 & 58.7 & 2.9 & 2.9 & 2.9 & 2.8 & 2.8 & 2.7 & 2.7 \\
\hline Carpenter Run & 0.0 & 3.3 & $*$ & $*$ & $*$ & $*$ & 0.0 & 3.3 & 0.0 & 3.3 & 0.0 & 3.3 \\
\hline Hiles Run & $*$ & $*$ & $*$ & * & * & $*$ & 0.0 & 19.7 & 0.0 & 19.7 & 0.0 & 19.7 \\
\hline Huss Pen Run & $*$ & $*$ & $*$ & $*$ & $*$ & $*$ & 0.0 & 18.4 & 0.0 & 18.4 & 0.0 & 18.4 \\
\hline Megans Run & 0.0 & 4.3 & 0.0 & 4.0 & 13.7 & 4.2 & 0.0 & 40.5 & 0.0 & 40.5 & 0.0 & 40.5 \\
\hline Nettles Run & 12.8 & 22.2 & 12.8 & 22.2 & 12.8 & 22.2 & 13.5 & 20.7 & 13.5 & 20.7 & 13.5 & 20.7 \\
\hline Olive Run & 1.9 & 23.5 & 2.0 & 24.6 & 2.0 & 24.6 & 16.7 & 50.7 & 16.7 & 50.7 & 16.7 & 50.7 \\
\hline Owl Run & 27.1 & 10.0 & 27.1 & 10.0 & 27.1 & 10.0 & 10.0 & 9.7 & 10.0 & 9.7 & 10.0 & 9.7 \\
\hline Sees Run & 7.2 & 7.4 & 7.2 & 7.4 & 21.1 & 8.0 & 28.8 & 27.4 & 32.9 & 27.4 & 32.9 & 27.4 \\
\hline Slabcamp Run & 54.6 & 49.0 & 57.4 & 51.5 & 56.8 & 51.0 & 25.8 & 53.1 & 45.2 & 53.1 & 41.4 & 53.1 \\
\hline Snake North Run & 53.9 & 13.5 & 53.7 & 13.5 & 51.5 & 12.9 & 66.9 & 9.2 & 66.9 & 9.2 & 66.9 & 9.2 \\
\hline Snake South Run & 51.9 & 9.7 & 50.5 & 9.5 & 50.5 & 9.5 & 58.7 & 8.6 & 58.7 & 8.6 & 58.7 & 8.6 \\
\hline Wyatt Run & 0.0 & 3.8 & 0.0 & 3.8 & 46.7 & 59.2 & 10.9 & 66.7 & 47.0 & 66.7 & 10.9 & 66.7 \\
\hline
\end{tabular}

Avg. Shale Gas Disturbance (\%): StreamGas (SG)

\begin{tabular}{|c|c|c|c|c|c|c|}
\hline $\begin{array}{l}\text { All study streams } \\
(\mathrm{n}=14)\end{array}$ & $23.1 \pm 6.8$ & $24.8 \pm 7.0$ & $32.3 \pm 6.3$ & $17.3 \pm 5.7$ & $21.5 \pm 6.4$ & $18.7 \pm 6.0$ \\
\hline $\begin{array}{l}\text { Consistently } \\
\text { monitored }(n=9)\end{array}$ & $25.2 \pm 7.1$ & $24.8 \pm 7.0$ & $32.3 \pm 6.3$ & $22.0 \pm 6.6$ & $27.4 \pm 7.2$ & $23.7 \pm 7.0$ \\
\hline
\end{tabular}

Avg. Potential Runoff (\%): StreamRunoff (SR)

\begin{tabular}{|c|c|c|c|c|c|c|}
\hline $\begin{array}{l}\text { All study streams } \\
(\mathrm{n}=14)\end{array}$ & $13.1 \pm 3.8$ & $14.2 \pm 4.3$ & $19.3 \pm 5.7$ & $24.2 \pm 5.5$ & $24.2 \pm 5.5$ & $24.2 \pm 5.5$ \\
\hline $\begin{array}{l}\text { Consistently } \\
\text { monitored }(n=9)\end{array}$ & $14.6 \pm 4.5$ & $14.9 \pm 4.7$ & $20.5 \pm 6.2$ & $28.9 \pm 7.1$ & $28.9 \pm 7.1$ & $28.9 \pm 7.1$ \\
\hline
\end{tabular}

*Not monitored 
Table 2. Variables used in analyses evaluating the demographic response of Louisiana Waterthrush to shale gas development. Nest survival is daily survival rate (DSR) over a 29-day nesting period $\left(\mathrm{DSR}^{29}\right)$.

\begin{tabular}{|c|c|c|}
\hline Variable of interest & Notation & Analysis \\
\hline Intercept only & CONSTANT (C) & Nest Survival \\
\hline Year of Study & Year & $\begin{array}{l}\text { Nest Survival, Productivity, } \\
\text { Territory Density, Territory } \\
\text { Length, Riparian Habitat Quality }\end{array}$ \\
\hline Nest Age & NestAge & Nest Survival \\
\hline Time within-season (quadratic time trend) & $\mathrm{TT}$ & Nest Survival \\
\hline Average Daily Rainfall & Rain & Nest Survival \\
\hline $\begin{array}{l}\text { Shale Gas Nest Disturbance } \\
\quad \text { (undisturbed }=0, \text { disturbed }=1)\end{array}$ & NestGas & Nest Survival \\
\hline Percent of Stream Disturbed by Shale Gas & StreamGas & $\begin{array}{l}\text { Territory Density, Nest } \\
\text { Abandonment }\end{array}$ \\
\hline $\begin{array}{l}\text { Percent of Stream with Potential } \\
\text { Contaminant Runoff }\end{array}$ & StreamRunoff & Description only \\
\hline Percent of Territory Disturbed by Shale Gas & TerrGas & $\begin{array}{l}\text { Nest Survival, Productivity, } \\
\text { Source-sink Threshold, Riparian } \\
\text { Habitat Quality }\end{array}$ \\
\hline $\begin{array}{l}\text { Percent of Territory with Potential } \\
\text { Contaminant Runoff }\end{array}$ & TerrRunoff & Nest Survival \\
\hline Shale Gas Forest Canopy Disturbance (\%) & GasFCD & Nest Survival \\
\hline Non-gas Forest Canopy Disturbance (\%) & OtherFCD & Nest Survival \\
\hline Habitat Suitability Index (HSI) score & HSI & Riparian Habitat Quality \\
\hline $\begin{array}{l}\text { Environmental Protection Agency (EPA) } \\
\text { Rapid Bioassessment index }\end{array}$ & EPA & Riparian Habitat Quality \\
\hline
\end{tabular}


Table 3. Louisiana Waterthrush demography across six years in response to shale gas development at Lewis Wetzel Wildlife Management Area, WV. Population productivity is mean number of fledglings/successful nest/year multiplied by annual nest survival and average annual territory density $/ \mathrm{km}$ of stream. Also shown are average annual EPA and habitat suitability index (HSI) scores \pm SE. A larger EPA or HSI score indicates better riparian habitat quality.

\begin{tabular}{|c|c|c|c|c|c|c|c|c|c|}
\hline Year & $\begin{array}{l}\text { Territory } \\
\text { Density } \\
\text { (territories } \\
\text { /km) }\end{array}$ & $\begin{array}{l}\text { Territory } \\
\text { Length }(\mathbf{m})\end{array}$ & $\begin{array}{l}\text { Daily } \\
\text { Survival } \\
\text { Rate } \\
\text { (DSR) }\end{array}$ & $\begin{array}{l}\text { Nest } \\
\text { Survival } \\
\left(\text { DSR }^{29} \text { ) }\right.\end{array}$ & $\begin{array}{l}\text { \# of } \\
\text { Nests }\end{array}$ & $\begin{array}{l}\% \text { Nests } \\
\text { Parasitized }\end{array}$ & $\begin{array}{l}\text { Population } \\
\text { Productivity } \\
\text { (per km) } \pm \\
95 \% \text { CIs }\end{array}$ & $\begin{array}{l}\text { EPA Index } \\
\text { (range 0- } \\
\text { 200) }\end{array}$ & $\begin{array}{l}\text { HSI } \\
\text { (range 0-1) }\end{array}$ \\
\hline 2009 & $1.5 \pm 0.1$ & $573.7 \pm 23.9$ & $96.4 \pm 0.9$ & $34.3 \pm 8.9$ & 41 & 0.0 & $2.32 \pm 0.59$ & $171.8 \pm 2.0$ & $0.82 \pm 0.02$ \\
\hline 2010 & $1.8 \pm 0.1$ & $443.3 \pm 23.1$ & $98.2 \pm 0.5$ & & 39 & 2.6 & $4.63 \pm$ & & $0.79 \pm 0.02$ \\
\hline 2011 & $1.5 \pm 0.1$ & $556.4 \pm 31.2$ & $96.7 \pm 0.7$ & $38.0 \pm 8.0$ & 47 & 0.0 & $2.56 \pm 0.25$ & $158.6 \pm 1.8$ & $0.78 \pm 0.02$ \\
\hline 2013 & $1.2 \pm$ & $659.0 \pm 3$ & $95.8 \pm 0.7$ & & 65 & 4.6 & & & $0.76 \pm 0.02$ \\
\hline 2014 & $1.1 \pm 0.1$ & $772.1 \pm 41.9$ & $95.4 \pm 0.7$ & $25.7 \pm 5.8$ & 54 & 5.6 & $1.16 \pm 0.35$ & $165.6 \pm 2.2$ & $0.77 \pm 0.02$ \\
\hline 2015 & $1.0 \pm 0.1$ & $815.9 \pm 49.3$ & $96.1 \pm 0.9$ & $31.9 \pm 8.4$ & 34 & 3.0 & $1.31 \pm 0.42$ & $*$ & $*$ \\
\hline
\end{tabular}

*not sampled in 2015 
Table 4. AICc model results of 11 a priori nest survival models using Program MARK. See Table 2 for model notation. $\triangle \mathrm{AICc}=$ difference from the top model, $w_{\mathrm{i}}=$ Akaike weight, and $\mathrm{K}$ $=$ the number of parameters in each model.

\begin{tabular}{lccc}
\hline Model & $\boldsymbol{\Delta A I C c}$ & $\boldsymbol{w}_{\boldsymbol{i}}$ & $\boldsymbol{K}$ \\
\hline C + Rain + NestAge + TT + TerrRunoff & $0.00^{\mathrm{a}}$ & 0.28 & 6 \\
C + Rain + NestAge + TT + TerrGas & 0.04 & 0.27 & 6 \\
C + Rain + NestAge + TT + GasFCD & 1.87 & 0.10 & 6 \\
C + Rain + NestAge + TT + NestGas & 1.97 & 0.10 & 6 \\
C + Rain + NestAge + TT + OtherFCD & 2.23 & 0.09 & 6 \\
C + Rain + NestAge + TT + Year + TerrGas & 2.97 & 0.06 & 11 \\
C + Rain + NestAge + TT + Year + TerrRunoff & 4.79 & 0.02 & 11 \\
C + Rain + NestAge + TT + Year + GasFCD & 5.59 & 0.01 & 11 \\
C + Rain + NestAge + TT + Year + NestGas & 5.59 & 0.01 & 11 \\
C + Rain + NestAge + TT + Year + OtherFCD & 5.92 & 0.01 & 11 \\
CONSTANT (C) & 9.72 & $<0.00$ & 1 \\
\hline
\end{tabular}

${ }^{\mathrm{a}}$ The AICc value of the top model was 765.17

Table 5. Summary results for nest survival covariates $(n=7)$ from the top supported AICc models $(n=4)$ based on model-averaged regression coefficients, with unconditional standard error (SE) and 85\% confidence intervals. Significant covariates with non-overlapping confidence intervals are bolded.

\begin{tabular}{llll}
\hline Parameter & Estimate & Unconditional SE & Confidence Interval \\
\hline Rain & $\mathbf{0 . 2 0 7}$ & $\mathbf{0 . 0 6 4}$ & $\mathbf{0 . 1 1 4 , 0 . 2 9 9}$ \\
TerrGas & $\mathbf{- 0 . 0 0 4}$ & $\mathbf{0 . 0 0 1}$ & $\mathbf{- 0 . 0 0 5}, \mathbf{- 0 . 0 0 3}$ \\
TerrRunoff & $\mathbf{- 0 . 0 0 3}$ & $\mathbf{0 . 0 0 1}$ & $\mathbf{- 0 . 0 0 5 , - 0 . 0 0 2}$ \\
NestGas & $\mathbf{- 0 . 1 0 9}$ & $\mathbf{0 . 0 2 3}$ & $\mathbf{- 0 . 1 4 2 , - 0 . 0 7 5}$ \\
GasFCD & $\mathbf{0 . 0 1 2}$ & $\mathbf{0 . 0 0 2}$ & $\mathbf{0 . 0 0 8 , \boldsymbol { 0 . 0 1 5 }}$ \\
NestAge & -0.024 & 0.017 & $-0.049,0.002$ \\
TT & 0.010 & 0.042 & $-0.051,0.070$ \\
\hline
\end{tabular}




\section{FIGURES}

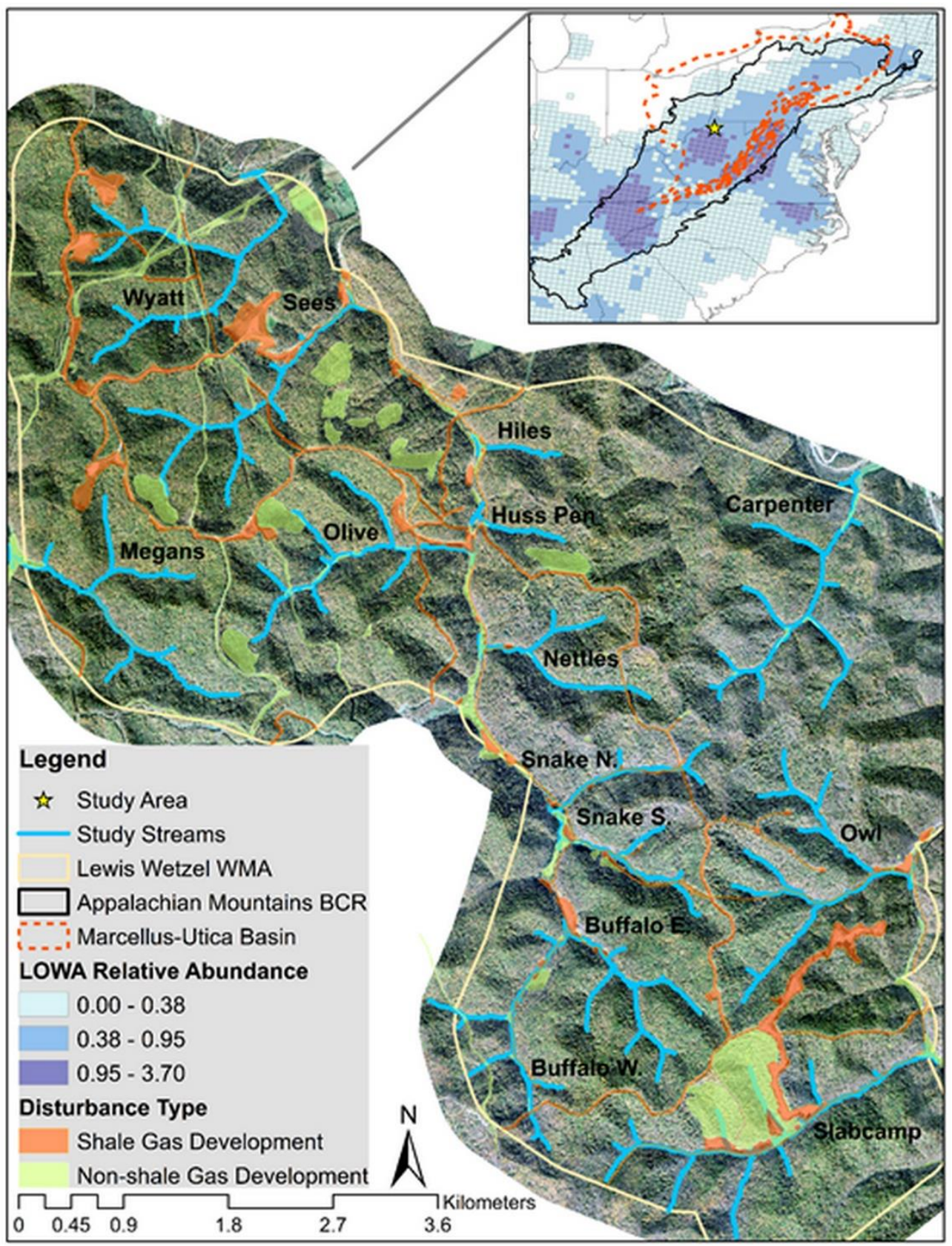

Figure 1. Our study area includes fourteen forested 1st and 2nd order headwater streams in the Lewis Wetzel Wildlife Management Area (WMA). It lies within the Marcellus-Utica shale basin, is within the core Louisiana Waterthrush (LOWA) range based on Breeding Bird Survey (BBS) data, and falls in the Appalachian Mountains Bird Conservation Region (BCR) in the eastern United States. LOWA Relative Abundance represents average waterthrush counts from nearby survey routes. 


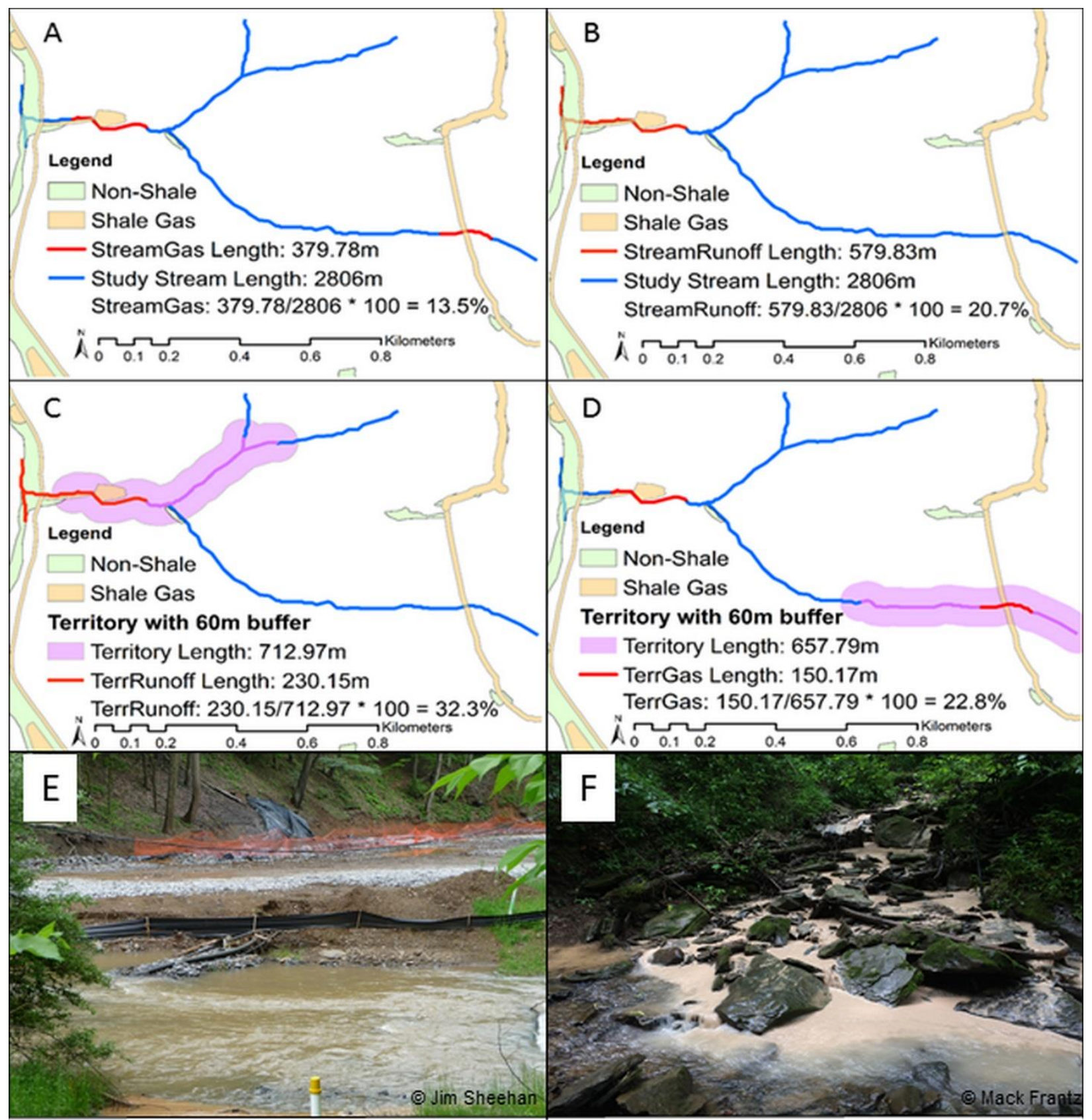

Figure 2. Examples of quantifying shale gas disturbances at the stream (A, B) and territory (C, D) scale and types of disturbance $(\mathrm{E}, \mathrm{F})$. A section of stream considered disturbed from frequent vehicular activity along a modified road $(\mathrm{E})$. Sedimentation we traced upstream to its point of origin at an active shale gas well pad $(\mathrm{F})$. 

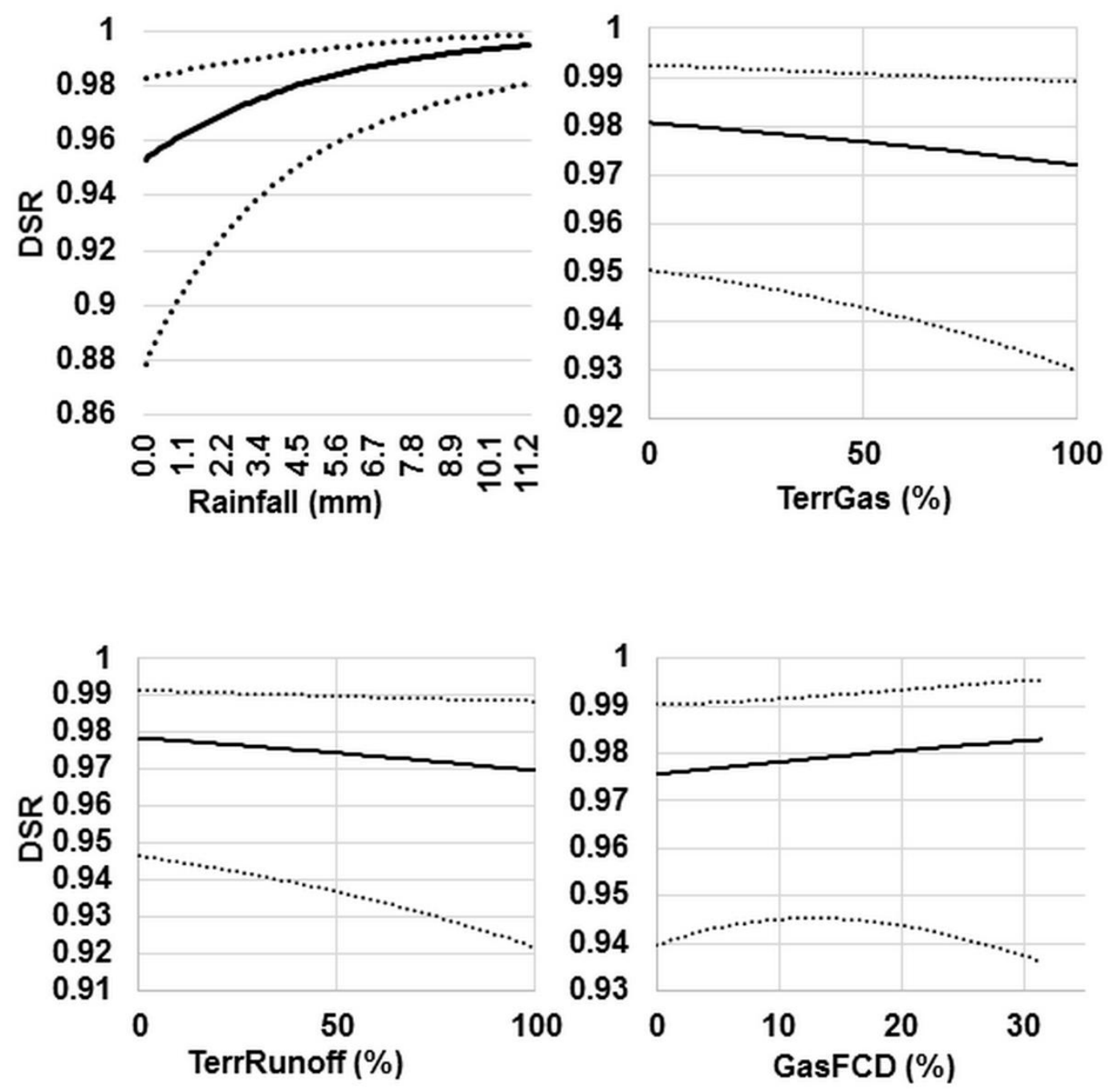

Figure 3. Four nest survival covariates that significantly influenced waterthrush daily survival rate (DSR). The binary response covariate NestGas also significantly influenced DSR (not depicted). See table 5 for model results and table 2 for covariate notation 


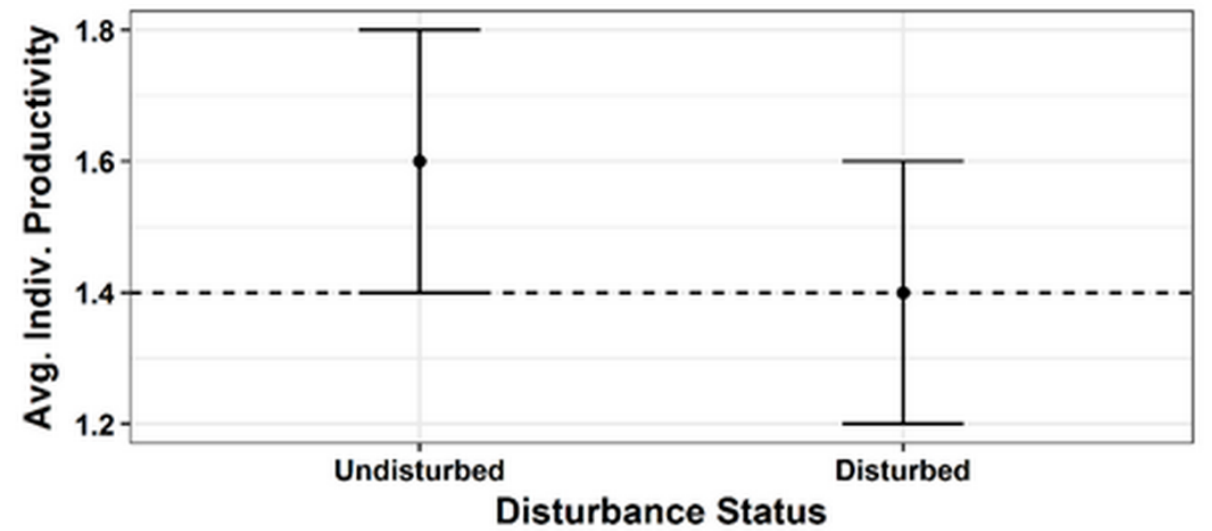

Figure 4. Average individual productivity (avg. \# fledglings/successful nest/male * nest survival) $\pm 95 \%$ CIs in areas undisturbed and disturbed by shale gas to a source-sink threshold (gray bracketed line) of 1.4 fledglings. 

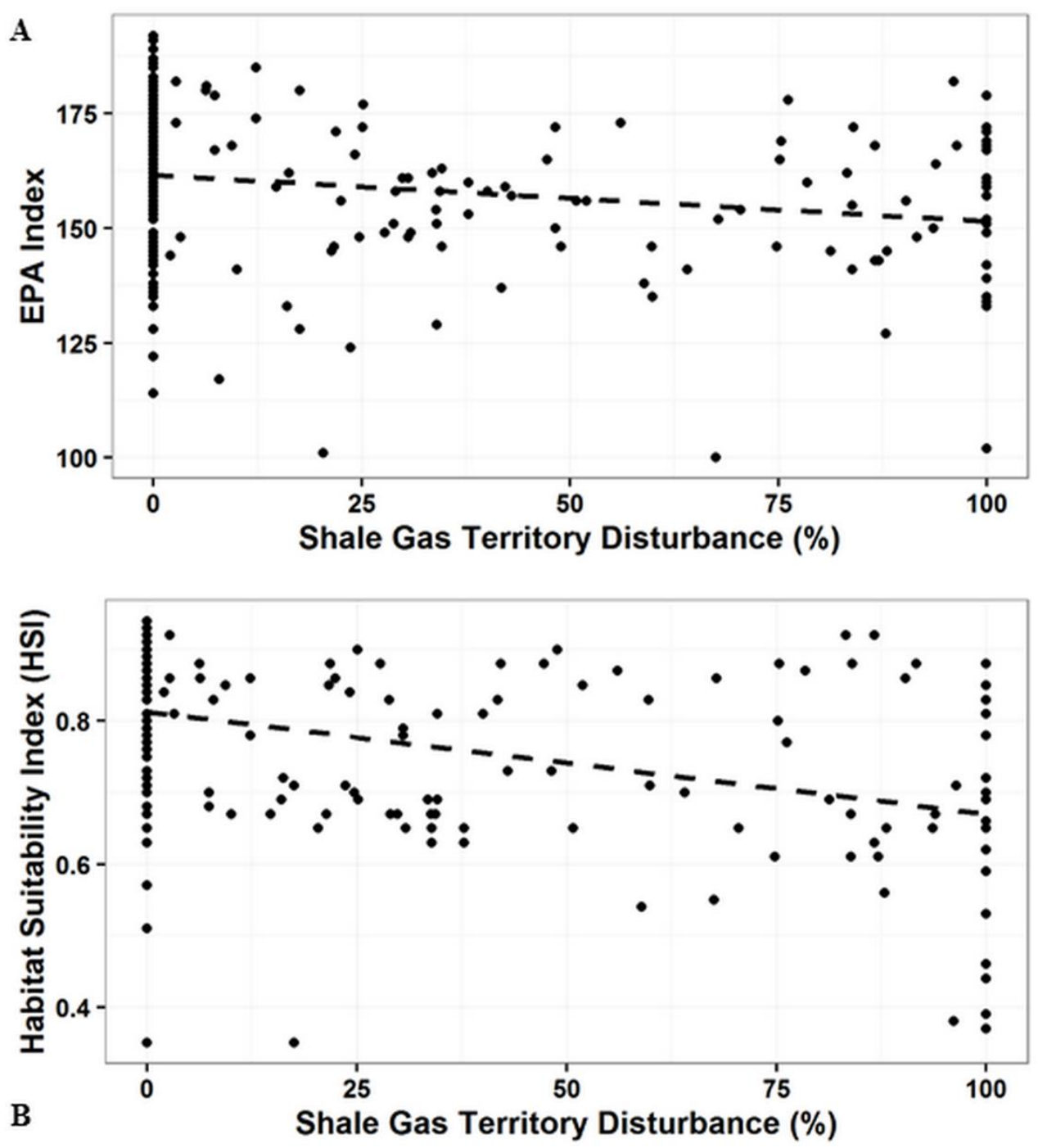

Figure 5. EPA Index and Habitat Suitability Index (HSI) scores in relation to TerrGas (A, B, respectively). 


\title{
CHAPTER. 3. LOUISIANA WATERTHRUSH (PARKESIA MOTACILLA) SURVIVAL AND SITE FIDELITY IN AN AREA UNDERGOING SHALE GAS DEVELOPMENT.
}

Chapter 3 was published in the peer-reviewed journal The Wilson Journal of Ornithology.

\section{Citation:}

Frantz, M. W., P. B. Wood, J. Sheehan, and G. George. 2019. Louisiana Waterthrush (Parkesia motacilla) survival and site fidelity in an area undergoing shale gas development. The Wilson Journal of Ornithology. https://doi.org/10.1676/18-6.1.

\begin{abstract}
We quantified Louisiana Waterthrush (Parkesia motacilla) site fidelity and apparent survival across a 6 year period in an area undergoing shale gas development. Waterthrush initially exhibited high site fidelity that declined over time. At the same time, the number of unpaired males defending territories increased as did natal fidelity. We identified site fidelity factors that influenced if adult males and females returned. More males returned either due to or regardless of amount of shale gas disturbance and lower riparian habitat quality. Females were less likely to return with increased number of breeding attempts. Females in shale gas disturbed areas had a higher number of breeding attempts and lower individual productivity. We saw a general nonsignificant trend in declining apparent survival over time. Overall apparent survival estimates for adult males (0.56) and females (0.44) were similar to those reported for other populations. Apparent survival candidate models suggested weak, positive relationships of increased survival with shale gas territory disturbance, disturbance with year, and year for adult males, and a positive relationship of increased survival with hydraulic fracturing runoff for adult females although regression coefficients overlapped zero for all model-supported covariates implying no statistical significance. Since waterthrush can maintain pair bonds from the previous year and females must pick a nest site within the defended male's territory, there are potential conflicts between factors that influence adult survival and site fidelity that may affect long-term population persistence. Our study adds to previous evidence that shale gas disturbed areas may serve as sink habitats.
\end{abstract}

Key words: bioindicator, ecological trap, headwater stream, Marcellus-Utica, site fidelity, source-sink, survival 


\section{INTRODUCTION}

The Louisiana Waterthrush (Parkesia motacilla; hereafter waterthrush) is a headwater stream specialist known for its ability to respond to changes in ecological conditions (Mattsson and Cooper 2006). Many of the forested stream ecosystems in which the waterthrush primarily breed have rapidly undergone unconventional shale gas development, particularly in the Marcellus-Utica shale region (Evans and Kiesecker 2014). The majority (71\%) of the Appalachian region at greatest potential risk of energy development is forested, with shale gas overlapping 66\% of this region (Dunscomb et al. 2014). The waterthrush is a species of conservation concern on the US Fish and Wildlife Service National List (USFWS 2008) due to its specialized habitat, and almost all of its core breeding range also overlaps the Marcellus-Utica shale region (Sauer et al. 2014).

Shale gas development can negatively affect waterthrush reproductive success and productivity (Frantz et al. 2018a) and their benthic macroinvertebrate prey (Wood et al. 2016, Frantz et al 2018b). However, it is not known if shale gas development can be a source of mortality, something that focal species-based modeling of potentially vulnerable taxa can answer (Brittingham et al. 2014). Stream disturbances such as acidification can affect waterthrush site fidelity (Mulvihill et al. 2008), so similar risks presented from shale gas are of particular interest (Souther et al. 2014), especially because waterthrush typically exhibit high site fidelity (Mulvihill et al. 2002, O’Connell et al. 2003) and forage on pollution-sensitive aquatic prey like Ephemeroptera (Trevelline et al. 2016). Across a 6 year study (2009-2011, 2013-2015), we quantified waterthrush annual first-year return rates (i.e., site fidelity), factors that might affect annual site fidelity, and apparent annual survival across 14 headwater streams with varying amounts of shale gas disturbance. Given that we observed annual declines in waterthrush habitat quality, nest survival, and productivity at our study site (Frantz et al. 2018a), we hypothesized that shale gas development would negatively affect site fidelity and apparent survival because site fidelity can directly influence fecundity and survival of individuals (Hoover 2003).

\section{METHODS}

\section{Study area}

We studied waterthrush along 14 st- and 2nd-order headwater stream tributaries that totaled $58.1 \mathrm{~km}$ at Lewis Wetzel Wildlife Management Area (LWWMA) located in Wetzel County, West Virginia, USA (Frantz et al. 2018a, 2018b). The study area overlays the 
Marcellus-Utica shale region, covers 6,521 ha (Farwell et al. 2016), and occurs where waterthrush reach their highest densities within the central Appalachians (Sauer et al. 2014). In 2009-2010, the majority of Marcellus wells and their water-holding ponds were located along the main stem of Buffalo Run where the majority of our 14 headwater study streams empty. Thus, although a few Marcellus well pads were located along our study streams, they tended to primarily impact the lower portions. Between the 2010 and 2011 breeding seasons, shale gas development activities began to increase on the ridgetops. Clearing for additional new well pads occurred late in the 2013 breeding season with well pad completion in 2014, in addition to redrilling of an existing well pad. There was no new shale gas development or activity in the 2015 breeding season. Shale gas disturbance on streams was highly variable within each year (Fig. 1), but on average across all years streams had $22.5 \pm 2.6 \%$ of their length disturbed by shale gas development (range 0-67\%). There were no "control" streams given that the majority of forest loss and fragmentation in the surrounding landscape resulted from recent shale gas activities (Farwell et al. 2016), but shale gas disturbance was concentrated on some streams more than others (Fig. 1; Frantz et al. 2018a).

\section{Stream and territory disturbance mapping}

Within a Geographic Information System (GIS), we used a sequence of leaf-on and leafoff aerial imagery and extensive ground-truthing to manually digitize areas of disturbance within the study area. All disturbances were classified as shale gas related (i.e., well pads and associated road and pipeline infrastructure) or as being unrelated or pre-existing (e.g., powerline right-ofway). Gas well records (WVDEP 2015) were used to verify target shale formations, drilling status, and start dates for all well disturbances. Surface (i.e., 3D) lengths for each study stream vector were calculated in the GIS using a $3 \mathrm{~m}$ resolution digital elevation model and defined to have a drainage basin of 22.25 acres to delineate the uppermost headwater reaches.

To model site fidelity and apparent survival as a function of shale gas disturbance, we created 2 continuous variables based on our disturbance classifications. For each year of the study, we calculated the proportion of each study stream that was disturbed by shale gas (stream length disturbed divided by total stream length monitored). Any portion of a stream was considered disturbed where well pads or infrastructure were within $60 \mathrm{~m}$ of the stream centerline, which is the typical extent of waterthrush streamside use (Mattsson and Cooper 2009). Frequent vehicular activity on roads resulting from shale gas within $60 \mathrm{~m}$ of the streams additionally 
counted as disturbance, which was commonplace in 2009-2011. Stream reaches also were considered disturbed when sedimentation within a reach resulted from shale gas development (e.g., well pad construction) at any distance from the stream, resulting in the entire downstream network classified as disturbed. All of these stream disturbances collectively describe mostly localized streamside disturbance indicative of the presence of any shale gas infrastructure or activity, and we calculated a variable called TerrGas that was the proportion of each territory affected by these shale gas related disturbances. We created a second disturbance variable, TerrRunoff, focused solely on potential shale gas contaminant erosional runoff. For this variable, a stream reach was considered disturbed if it was directly at or below a well pad or retaining pond (similar to Latta et al. 2015), resulting in the whole downstream network classified as being at risk for surface pollution based on elevational maps and ground truthing. Thus, TerrRunoff was a broader, distance-independent, disturbance category related strictly to water quality.

We annually mapped waterthrush territories along each stream (see Frantz et al. 2018a for detailed methods). We then placed the $60 \mathrm{~m}$ buffer over individual waterthrush territory vectors, mapped on the same stream reach centerlines, to calculate the proportion $(0-100 \%)$ of each territory disturbed by shale gas (territory length disturbed divided by total territory length); this created a TerrGas and TerrRunoff variable for each territory.

\section{Louisiana Waterthrush banding and resighting}

Territorial adult waterthrush were target-netted and banded during 2009-2011 and 20132015 with an aluminum US Geological Survey leg band and a unique combination of colored plastic bands to allow identification of individuals. Starting in 2010, nestlings were banded $\sim 7-8$ days after hatching. All study streams $(n=14)$ were searched intensively ( $\geq 5$ stream visits) throughout each breeding season for banded individuals during territory mapping and nest monitoring (see Frantz et al. 2018 for full description). We used resightings of banded individuals to calculate first-year return rates as a measure of site fidelity, to calculate adult apparent survival, to aid in territory delineation, and to calculate male pairing rate (\% males paired/year). We calculated pairing rate only for 2013-2015 since only records of banded females were kept prior to 2013.

First-year return rates were the proportion of newly color-banded individuals that were resighted the following year (e.g., Iverson 1988), in contrast to return rates including individuals banded in any given year (e.g., Hoover 2003), so that annual return rates reflected the amount of 
shale gas disturbance that occurred the year an individual was banded. Apparent survival was the probability an adult waterthrush remained alive and available for resighting, and therefore is not true survival probability of marked waterthrush in our population since mortality and permanent emigration cannot be distinguished (White and Burnham 1999, Lindberg and Rexstad 2002).

\section{Nest and riparian habitat monitoring}

Nest searching and monitoring occurred concurrently with territory mapping in the same manner as Wood et al. (2016) and Frantz et al. (2018a). We monitored most nests every 3-4 days initially and more frequently as fledging approached (Martin and Geupel 1993). We assumed an undamaged empty nest had fledged if the nest was active the day before and had approached the predicted fledge date. Waterthrush will have multiple breeding attempts if their nest fails (average $1.4 \pm 0.05$ attempts; MWF, unpubl. data). A pair was considered successful (i.e., nest success) if they produced at least one fledgling from their attempts.

Riparian habitat quality at each nest monitored was assessed as a factor influencing site fidelity using the Habitat Suitability Index specifically designed for waterthrush (hereafter HSI; Prosser and Brooks 1998) and the US EPA Rapid Bioassessment Protocol for high gradient streams (hereafter EPA; Barbour et al. 1999) in the same manner as Wood et al. (2016) and Frantz et al. (2018). The HSI is a broad-scale evaluation of waterthrush instream foraging and upland habitat suitability (Prosser and Brooks 1998) while EPA assesses stream quality based primarily on instream characteristics that relate to the abundance and composition of waterthrush aquatic macroinvertebrate prey (Wood et al. 2016, Frantz et al. 2018b).

\section{Analysis}

Return rates and site fidelity - We calculated apparent first-year return rates, hereafter site fidelity, as the number of newly banded individuals divided by the number that were resighted the following year for all adults, adult males, adult females, and nestlings to evaluate general trends in annual site fidelity for all years of study except 2013. Since the study did not occur in 2012, the 2013 return rate was based on individuals banded in 2011. Although we recognize this return rate is likely a low estimate, we felt it provided valuable information for examining the overall trend across years.

Site fidelity is high and persistent in waterthrush, thus annual return has been used as a proxy for survivorship (Latta et al. 2016) and also can be used to determine factors that may influence site fidelity (e.g., "decision rules" in Stracey and Robinson 2012). A conditional 
inference tree (ctree) analysis was performed separately for adult male and female waterthrush to determine what variables might affect the decision to return to a site. Return was modeled as a binomial response (returned or did not return the following year) in relation to TerrGas, TerrRunoff, nest success (yes/no), number of breeding attempts, HSI score, and EPA index in individually fitted models. The ctree analysis involved binary recursive partitioning and permutational testing on the site fidelity dataset structures with all returns for individuals included ( $n=149$ male and 35 female returns) using partykit (Hothorn and Zeileis 2016), with test statistics and $P$ values obtained from a structural change test using strucchange (Zeileis et al. 2015) in program $\mathrm{R}$ ( $\mathrm{R}$ Core Team 2014). Ctree is a nonparametric method that avoids overfitting, is less susceptible than traditional regression techniques to multicollinearity, and stops splitting the data once the null hypothesis of independence cannot be rejected $(\alpha=0.05$; Hothorn and Zeileis 2016).

If any site fidelity factors were significant for males or females, we compared the average site fidelity factor value \pm standard error $(\mathrm{SE})$ between return and no return groups of the sex in question. If nest success or number of breeding attempts was significant for males or females, we also compared individual nest productivity between return and no return groups of the sex in question since productivity was lower in shale gas disturbed areas in our long-term study (Frantz et al. 2018a). We quantified individual productivity using an approach similar to Boves et al. (2015) where mean number of fledglings per successful nest per male was multiplied by nest survival (e.g., Frantz et al. 2018a). Additionally if TerrGas or TerrRunoff was a significant site fidelity factor for either sex, we compared these variables between areas with and without shale gas disturbance for each sex.

Apparent survival - We modeled apparent adult survival $(\phi)$ using the Cormack-JollySeber (Cormack 1964, Jolly 1965, Seber 1965) model using RMark (Laake 2013) in R. We removed any individuals from analysis that were not confirmed as part of a breeding territory to avoid modeling possible transients ( $n=12$ males, $n=2$ females). We modeled banded male adults $(n=94)$ separately from females since fewer females $(n=26)$ were banded and thus had a dissimilar encounter history. Encounter probability $(p)$ was kept constant in all models because we assumed color bands were not lost and equal resight efforts occurred across years. Overall apparent survival from the constant model (covariate-independent null model) was estimated for males and females separately for relative comparison with survival values reported in other 
studies (e.g., Boulton et al. 2009). We also report survival estimates from the top supported male and female models to be inclusive of any differences.

We evaluated 3 covariates in models for males to determine if there was a disturbance level or annual influence to apparent survival: avgTerrGas, avgTerrRunoff, and year. The covariate avgTerrGas was the average of shale gas territory disturbance (i.e., TerrGas) across all years that an individual returned. The covariate avgTerrRunoff was the average potential hydraulic fracturing runoff (i.e., TerrRunoff) across all years an individual returned. Given high site fidelity in waterthrush (O'Connell et al. 2003), we felt avgTerrGas or avgTerrRunoff would indicate if there was an overall disturbance or runoff (e.g., sedimentation or surface water pollution) level that affected survival rather than modeling only initial disturbance levels. For males, we included all additive and interactive models for avgTerrGas and avgTerrRunoff with year. The 2 gas disturbance covariates were not combined in a single model since they are related metrics $\left(R^{2}=0.53\right.$ males, 0.63 females $)$.

We modeled year as we hypothesized that apparent survival would decrease in concert with decreasing return rates. Time intervals between occasions (year) were specified in the model, which corrects for inconsistent lengths of time (i.e., no data collected in 2012). For females, however, we could only model avgTerrGas and avgTerrRunoff because the sample size was too small to include a time-dependence parameter.

We used Akaike's Information Criterion for small sample sizes (AICc, as opposed to QAICc), to evaluate support for apparent survival candidate models (Burnham and Anderson 2002) based on lack of overdispersion using a bootstrapped goodness-of-fit test (Cooch and White 2016). We considered the model with the lowest AICc value to be the best-supported model given the data, and any models with $\triangle \mathrm{AICc}<2$ were considered plausible (Burnham and Anderson 2002). We assessed the relative plausibility of each model in each model set by comparing Akaike weights $\left(w_{i}\right)$. We used model-averaged regression coefficients across all models that contained the covariate (Burnham and Anderson 2002) and 85\% confidence intervals (hereafter CIs) to infer biological importance of covariates in plausible AICc models because 95\% CIs with the information-theoretic approach can lead to variable selection uncertainty (Arnold 2010). 


\section{RESULTS}

In our 6 year study, we banded 187 adult and 222 nestling waterthrush. Adult waterthrush initially exhibited high site fidelity (>63\% during 2009-2010) that declined annually to $32 \%$ by 2015 (Table 1). Males and females also had declining trends. Resighting effort was $\geq 5$ visits per stream in 2009-2011 and $\geq 6$ visits per stream in 2013-2015, which suggests that the decline in site fidelity was not a result of decreased effort. Natal site fidelity was consistently low across years (Table 1) with a high of 5\% of banded nestlings resighted in 2015.

Of the 6 factors we tested, 3 influenced site fidelity of adult males and one influenced that of adult females (Table 2, Fig. 2). Males that returned had higher TerrGas $(37.0 \pm 4.6 \%)$ values than those that did not return $\left(25.1 \pm 4.1 \% ; S_{147}=3.75, P=0.053\right)$. Males that returned had lower EPA scores $(154.8 \pm 2.2)$ than those that did not return $\left(160.8 \pm 1.9\right.$ score; $S_{104}=4.17$, $P=0.041)$. Males that returned also had lower HSI scores $(0.73 \pm 0.02)$ than those that did not return $\left(0.78 \pm 0.01\right.$ score; $\left.S_{104}=5.30, P=0.021\right)$. For females, individuals that did not return had more breeding attempts $(2.1 \pm 0.3)$ than females that did return $(1.3 \pm 0.1$ attempts; Fig. 3 , Table 2) $\left(S_{30}=3.79, P=0.051\right)$.

Male apparent survival $(\phi)$ using the constant model was $0.56 \pm 0.04$ and $0.55 \pm 0.04$ from the top supported model (avgTerrGas). For males, 3 models were supported ( $\triangle \mathrm{AICc}<2$ ), which included avgTerrGas, avgTerrGas plus year, and year (Table 3) with model weights of $0.33,0.26$, and 0.21 , respectively. Model-averaged regression coefficient estimates for avgTerrGas and year were positive but $85 \%$ CIs overlapped zero for avgTerrGas and year indicating little or highly variable effect on male survival (Table 4). Yearly survival peaked in 2011 but in general decreased from the beginning to the end of the study (Table 1).

Female survival using the constant model was $0.44 \pm 0.08$ and $0.43 \pm 0.08$ from the top supported model (avgTerrRunoff). The constant model had the most support with weight of 0.54 but the avgTerrRunoff model competed with weight of 0.24 (Table 3). The regression coefficient estimate for avgTerrRunoff was positive, and while having model support, CIs overlapped zero indicating little or high variable effect on females (Table 4).

\section{DISCUSSION}

Over our 6 year study at LWWMA, we saw general declines in waterthrush first-year return rates concurrent with a site-wide increase in shale gas-related disturbance (Farwell et al. 2016). However, our study could not distinguish whether more males returned either due to or 
regardless of amount of shale gas territory disturbance. Waterthrush are known to exhibit high site fidelity ( $\sim 40 \%$; O’Connell et al. 2003 ), with males returning to the same territory annually and up to $50 \%$ of returning females occupying the same territories, frequently reuniting with the same male (Mulvihill et al. 2002). Observed return rates are the product of resighting probability, annual survival, and site fidelity (Schlossberg 2009). Given that we had thorough resight effort on our streams, return rates reflected some combination of annual survival and site fidelity. Apparent survival of adults in our study (males 0.56, females 0.44) was similar to the waterthrush survival rate of 0.47 reported for the northeastern United States (Mattsson et al. 2009). While year was not a significant covariate in apparent survival analysis, in general yearly survival peaked early in the study then declined toward the end of the study parallel to declining return rates (Table 1).

Natal fidelity is typically low in migratory passerines (Weatherhead and Forbes 1994, Schlossberg 2009) including waterthrush (O'Connell et al. 2003) as we also found in our study area $(1.7 \pm 1.2 \%$ resighted). Territory densities were high $(>1.5$ territories $/ \mathrm{km})$ in 2009-2011 compared to when the study ended ( $1.0 \pm 0.1$ territories $/ \mathrm{km}$; Frantz et al. 2018a); while there was a general increase in the number of nestlings banded over the study period, we did not document natal resights until 2014 and 2015 (Table 1) when territory densities were lowest. Increased natal fidelity was not enough to counter adult loss where the percent of unpaired males went from $0 \%$ in 2013, when the decline in adult site fidelity was first noticeable, to $>10 \%$ in 2014 and 2015. Natal dispersal of waterthrush at our study area could be density-dependent (Greenwood and Harvey 1982) because when areas are saturated, dispersing may enhance individual survival or reproductive prospects of finding unoccupied, suitable breeding habitat (Förschler et al. 2010). Information on natal dispersal is currently lacking (Mattsson et al. 2009), and vital when shale gas development has the potential to heavily develop forest core ecosystems where headwater streams (Drohan et al. 2012) and waterthrush co-occur.

Covariates we tested to explain survival were inconclusive, but avgTerrGas and avgTerrRunoff may have positive relationships with male and female survival (Tables 3 and 4). This is in line with site fidelity factors for males where more males returned either due to or regardless of higher shale gas territory disturbance and lower riparian habitat quality (Table 2). Waterthrush frequently retain pair bonds (Mattsson et al. 2009), which may put factors that influence male and female site fidelity or nesting decisions at odds; in almost all cases where the 
banded male and female both returned from the previous year (71\%, 5 of 7 pairs), they retained that bond in our study (MWF, unpubl. data). The number of breeding attempts can affect female return, and females with no shale gas territory disturbance had a lower number of breeding attempts than did females in disturbed areas (Table 2). Shale gas development had negative effects on nest survival and productivity in our long-term study (Frantz et al. 2018a). If we evaluate individual productivity adjusted for nest survival (i.e., Boves et al. 2015, Frantz et al. 2018a), females in shale gas disturbed areas also had lower productivity than did those in shale gas undisturbed areas (Table 2).

In the same manner that choice of nest site can create opposing selection pressures on nest success and fledgling survival (Streby et al. 2014), waterthrush may face perceived costs and benefits from TerrGas or TerrRunoff in a territory with its own survival and nest survival in conflict. If factors that influence site fidelity via annual return can also be a measure of survivorship (Latta et al. 2016), factors that affect reproductive success may also influence female return. This is particularly a concern if males who arrive first to set up a territory (Mattsson et al. 2009), and consequently females who must select a nest site within the defended male's territory, are initially "drawn" to shale gas disturbed areas. Shale gas disturbed areas may provide lower predation risk but lead to higher nest abandonment and parasitism (Davis 2014). Shale gas disturbed areas also can alter aquatic food webs (Grant et al. 2016) and benthic communities (Wood et al. 2016, Frantz et al. 2018b), the primary food of waterthrush. For instance, it may alter leaf pack breakdown creating patch-specific communities with more macroinvertebrates and shredders than sites without shale gas (Barton 2016). Waterthrush will leaf-pull at dead leaves submerged in water (Mattsson et al. 2009), but a benthic study in 2011 (Wood et al. 2016) and 2013-2014 (G.T. Merovich, Jr., West Virginia University, unpubl. data) at our study site suggest shale gas development negatively altered benthic macroinvertebrate communities. Waterthrush at our study site were likely able to meet all their foraging needs (Frantz et al. 2018b), so it is unclear otherwise why waterthrush would be "attracted" to these areas. For example, waterthrush can forage off-stream on terrestrial invertebrates or in undisturbed areas to compensate for loss of preferred aquatic prey (Mulvihill et al. 2008) and as observed on our study area (MWF and PBW, unpubl. data). Since other types of forest anthropogenic disturbances can serve as ecological traps (Weldon and Haddad 2005, Boves et al. 
2013), concern is warranted when shale gas disturbed areas may be borderline "sink" (Pulliam 1988) habitats (Frantz et al. 2018a).

We cannot firmly establish if shale gas development was the causal mechanism for declining return rates. In the same manner that habitat specialists can exhibit delay to extinction until a new equilibrium is reached following habitat loss (i.e., extinction debt; Kuussaari et al. 2009), there may be a time lag in potential negative influences of shale gas development on waterthrush site fidelity and survival. Initial collective evidence from this and our long-term demographic study suggests shale gas development may have conflicting effects on waterthrush site fidelity and apparent survival that in the long term may negatively affect population persistence by impairing reproductive effort and productivity. However, if population growth rates are governed more through adult survival probabilities than reproductive rates (Sæther and Bakke 2000), there is the possibility population growth rates could be higher in shale gas disturbed areas. Low sample size $(<100)$ can affect accuracy of typical survivorship analysis (Naef-Daenzer and Grüebler 2014), and there are carryover effects for this species as a result of body condition (Latta et al. 2016). As such, continued and full annual cycle monitoring will be required for more support and to understand all contributions to adult survival. Strong evidence is required that a habitat serves as an ecological trap (Robertson and Hutto 2006). Waterthrush need to be studied on a regional scale (Brawn and Robinson 1996) to know the extent to which shale gas disturbed areas could serve as potential sinks or ecological traps (Gates and Gysel 1978), and whether these are temporal, dynamic relationships (Fauth 2000).

\section{ACKNOWLEDGMENTS}

West Virginia Division of Natural Resources (WVDNR) provided access to the study area and Wheeling Jesuit University provided access to field housing. We thank many field assistants and graduate students who collected data during our 6 year study. In particular we thank J. Mizel, D. Becker, K. Aldinger, and A. Duerr for assistance with data collection, analysis, or guidance. We

thank S. Latta, A. Welsh, M. Strager, S. Welsh, and C. Rota for helpful comments that improved the manuscript. Our research was funded by West Virginia Division of Natural Resources, US Department of Energy National Energy Technology Laboratory, West Virginia University, and National Aviary. Banding was conducted under USGS banding permits \#23412 and \#23059 and West Virginia University IACUC protocol \#04-0302, 07-0303. Any use of trade, firm, or product names is for descriptive purposes only and does not imply endorsement by the US Government. 


\section{LITERATURE CITED}

Arnold TW. 2010. Uninformative parameters and model selection using Akaike's Information Criterion. Journal of Wildlife Management 74:1175-1178.

Barbour MT, Gerritsen J, Snyder BD, Stribling JB. 1999. Rapid bioassessment protocols for use in streams and wadeable rivers: Periphyton, benthic macroinvertebrates and fish, second edition. Washington (DC): US Environmental Protection Agency, Office of Water. EPA 841-B-99-002.

Barton JA. 2016. In-stream leaf decomposition as an indicator of Marcellus shale impairment across a land use gradient [master's thesis]. Lewisburg (PA): Bucknell University.

Boulton RL, Lockwood JL, Davis MJ, Pedziwilk A, Boadway KA, et al. 2009. Endangered Cape Sable Seaside Sparrow survival. Journal of Wildlife Management 73:530-537.

Boves TJ, Buehler DA, Sheehan J, Wood PB, Rodewald AD, et al. 2013. Emulating natural disturbances for declining late-successional species: A case study of the consequences for Cerulean Warblers (Setophaga cerulea). PLOS ONE 8:e52107.

Boves TJ, Rodewald AD, Wood PB, Buehler DA, Larkin JL, et al. 2015. Habitat quality from individual- and population-level perspectives and implications for management. Wildlife Society Bulletin 39:443-447.

Brawn JD, Robinson SK. 1996. Source-sink population dynamics may complicate the interpretation of long-term census data. Ecology 77:3-12.

Brittingham MC, Maloney KO, Farag AM, Harper DD, Bowen ZH. 2014. Ecological risks of shale oil and gas development to wildlife, aquatic resources and their habitats. Environmental Science and Technology 48:11034-11047.

Burnham KP, Anderson DR. 2002. Model selection and multimodel inference: An informationtheoretic approach. New York (NY): Springer-Verlag.

Cooch E, White G. 2016. Program MARK: “A gentle introduction.” 16th ed [cited 14 Sep 2016]. http://www.phidot.org/software/mark/docs/book/

Cormack RM. 1964. Estimates of survival from the sighting of marked animals. Biometrika 51:429-438.

Davis R. 2014. Impacts of non-renewable resource extraction on shrubland songbird nest success and abundance [master's thesis]. Morgantown (WV): West Virginia University.

Drohan PJ, Brittingham M, Bishop J, Yoder K. 2012. Early trends in landcover change and forest fragmentation due to shale gas development in Pennsylvania: A potential outcome for the Northcentral Appalachians. Environmental Management 49:1061-1075. 
Dunscomb JK, Evans JS, Strager JM, Strager MP, Kiesecker JM. 2014. Assessing future energy development across the Appalachian Landscape Conservation Cooperative. Charlottesville (VA): The Nature Conservancy.

Evans JS, Kiesecker JM. 2014. Shale gas, wind and water: Assessing the potential cumulative impacts of energy development on ecosystem services within the Marcellus play. PLOS ONE 9:e89210.

Farwell LS, Wood PB, Sheehan J, George GA. 2016. Shale gas development effects on the songbird community in a central Appalachian forest. Biological Conservation 201:78-91.

Fauth PT. 2000. Reproductive success of Wood Thrushes in forest fragments in northern Indiana. Auk 117:194-204.

Förschler M, del Val E, Bairlein F. 2010. Extraordinary high natal philopatry in a migratory passerine. Journal of Ornithology 151:745-748.

Frantz MW, Wood PB, Sheehan J, George G. 2018a. Demographic response of a migratory songbird of conservation concern to shale gas development. Condor: Ornithological Applications 120:265-282.

Frantz, MW, Wood PB, Merovich, GT Jr. 2018b. Demographic characteristics of an avian predator, Louisiana Waterthrush (Parkesia motacilla), in response to its aquatic prey in a Central Appalachian USA watershed impacted by shale gas development. PLOS ONE 13:e206077. https://doi.org/10.1371/journal.pone.0206077.

Gates JE, Gysel LW. 1978. Avian nest dispersion and fledging success in field-forest ecotones. Ecology 59:871-883.

Grant CJ, Lutz AK, Kulig AD, Stanton MR. 2016. Fracked ecology: Response of aquatic trophic structure and mercury biomagnification dynamics in the Marcellus shale formation. Ecotoxicology 25:1739-1750.

Greenwood PJ, Harvey PH. 1982. The natal and breeding dispersal of birds. Annual Review of Ecology, Evolution, and Systematics 13:1-21.

Hendricks P. 1991. Site fidelity and renesting of female American Pipits. Journal of Field Ornithology 62:338-342.

Hoover JP. 2003. Decision rules for site fidelity in a migratory bird, the Prothonotary Warbler. Ecology 84:416-430.

Hothorn TK, Zeileis A. 2016. Package 'partykit.' Version 1.1-1 [cited 2 May 2017]. https://CRAN.R-project.org/package=partykit 
Iverson SS. 1988. Site tenacity in culvert-nesting Barn Swallows in Oklahoma. Journal of Field Ornithology 59:337-344.

Jolly GM. 1965. Explicit estimates from capture-recapture data with both death and immigration stochastic model. Biometrika 52:225-247.

Kuussarri M, Bommarco R, Heikkinen RK, Helm A, Krauss J, et al. 2009. Extinction debt: A challenge for biodiversity conservation. Trends in Ecology \& Evolution 24:564-571.

Laake JL. 2013. RMark: An R interface for analysis of capture-recapture data with MARK. AFSC Processed Rep 2013-01. Seattle (WA): NOAA, National Marine Fisheries Service, Alaska Fisheries Science Center.

Latta SC, Cabezas S, Mejia DA, Paulino MM, Almonte H, et al. 2016. Carry-over effects provide linkages across the annual cycle of a Neotropical migratory bird, the Louisiana Waterthrush Parkesia motacilla. Ibis 158:395-406.

Latta SC, Marshall LC, Frantz MW, Toms J. 2015. Evidence from two shale regions that a riparian songbird accumulates metals associated with hydraulic fracturing. Ecosphere 6:144. Lindberg MS, Rexstad E. 2002. Capture-recapture sampling designs. In: El-Shaaraw ES, Piegorsch WW, editors. Encyclopedia of environmetrics. Volume 1. Chichester (UK): John Wiley and Sons; p. 251-262.

Martin TE, Geupel GR. 1993. Nest-monitoring plots: Methods for locating nests and monitoring success. Journal of Field Ornithology 64:507-519.

Mattsson BJ, Cooper RJ. 2006. Louisiana Waterthrushes (Seiurus motacilla) and habitat assessment as cost-effective indicators of instream biotic integrity. Freshwater Biology 51:19411958.

Mattsson BJ, Cooper RJ. 2009. Multi-scale analysis of the effects of subseasonal rainfall extremes on reproduction by an obligate riparian bird in urban and rural landscapes. Auk 126:64-76.

Mattsson BJ, Master TL, Mulvihill RS, Robinson WD. 2009. Louisiana Waterthrush (Parkesia motacilla). In: Poole AF, editor. Birds of North America. Ithaca (NY): Cornell Lab of Ornithology. https://doi.org/10.2173/bna.151

Mulvihill RS, Cunkelman A, Quattrini L, O’Connell TJ, Master TL. 2002. Opportunistic polygyny in the Louisiana Waterthrush. Wilson Bulletin 114:106-113.

Mulvihill RS, Newell FL, Latta SC. 2008. Effects of acidification on the breeding ecology of a stream-dependent songbird, the Louisiana Waterthrush (Seiurus motacilla). Freshwater Biology 53:2158-2169.

Naef-Daenzer B, Grüebler MU. 2014. Effects of radio-tag characteristics and sample size on estimates of apparent survival. Animal Biotelemetry 2:2. 
O’Connell TJ, Brooks RP, Laubscher SE, Mulvihill RS, Master TE. 2003. Using bioindicators to develop a calibrated index of regional ecological integrity for forested headwater ecosystems. University Park (PA): Penn State University, Penn State Cooperative Wetlands Center. Final report to US Environmental Protection Agency, STAR Grants Program. Report No. 2003-01.

Prosser DJ, Brooks RP. 1998. A verified habitat suitability index for the Louisiana Waterthrush. Journal of Field Ornithology 69:288-298.

Pulliam HR. 1988. Sources, sinks, and population regulation. American Naturalist 132:652-661.

R Core Team. 2014. R: A language and environment for statistical computing. Vienna (Austria): R Foundation for Statistical Computing.

Robertson BA, Hutto RL. 2006. A framework for understanding ecological traps and an evaluation of existing evidence. Ecology 87:1075-1085.

Sæther B-E, Bakke Ø. 2000. Avian life history variation and contribution of demographic traits to the population growth rate. Ecology 81:642-653.

Sauer JR, Hines JE, Fallon JE, Pardieck KL, Ziolkowski DJ, Link WA. 2014. The North American Breeding Bird Survey, results and analysis 1966-2013. Version 01.30.2015. Laurel (MD): USGS Patuxent Wildlife Research Center [cited 14 Sep 2016]. http://www.mbrpwrc.usgs.gov/bbs/

Schlossberg S. 2009. Site fidelity of shrubland and forest birds. Condor 111:238-246.

Seber GAF. 1965. A note on the multiple recapture census. Biometrika 52:249-259.

Souther S, Tingley MW, Popescu VD, Hayman DTS, Ryan ME, et al. 2014. Biotic impacts of energy development from shale: Research priorities and knowledge gaps. Frontiers in Ecology and the Environment 12:330-338.

Stracey CM, Robinson SK. 2012. Are urban habitats ecological traps for a native songbird? Season-long productivity, apparent survival, and site fidelity in urban and rural habitats. Journal of Avian Biology 43:50-60.

Streby HM, Refsnider JM, Peterson SM, Andersen DE. 2014. Retirement investment theory explains patterns in songbird nest site choice. Proceedings of the Royal Society B 281:20131834.

Trevelline B, Latta SC, Marshall LC, Nuttle T, Porter BA. 2016. Molecular analysis of nestling diet in a long-distance Neotropical migrant, the Louisiana Waterthrush (Parkesia motacilla). Auk: Ornithological Advances 133:415-428. 
[USFWS] United States Fish and Wildlife Service. 2008. Birds of conservation concern 2008. Arlington (VA): US Department of Interior, Fish and Wildlife Service, Division of Migratory Bird Management [cited 14 Sep 2016]. http://www.fws.gov/migratorybirds Weatherhead PJ, Forbes MRL. 1994. Natal philopatry in passerine birds: Genetic or ecological influences? Behavioral Ecology 5:426-433.

Weldon AJ, Haddad NM. 2005. The effects of patch shape on Indigo Buntings: Evidence for an ecological trap. Ecology 86:1422-1431.

[WVDEP] West Virginia Department of Environmental Protection. 2015. Oil and gas production data. 2015. State of West Virginia [cited 14 Sep 2016]. http://www.dep.wv.gov/oil-andgas/databaseinfo/Pages/default.aspx

White GC, Burnham KP. 1999. Program MARK: Survival estimation from populations of marked animals. Bird Study 46:S120-S139.

Wood P, Frantz M, Becker D. 2016. Louisiana Waterthrush and benthic macroinvertebrate response to shale gas development. Journal of Fish \& Wildlife Management 7:423-433.

Zeileis A, Leisch F, Hornik K, Kleiber C, Hansen B, Merkle EC. 2015. Package 'strucchange.' Version 1.5-1 [cited 24 Nov 2016]. https://CRAN.R-project.org/package=strucchange 


\section{TABLES}

Table 1. Annual percent apparent site fidelity (\# banded in previous year divided by \# resighted) for adult and nestling waterthrush. Annual adult male apparent survival $(\phi)$ and standard error (SE) from the year-only covariate model. Annual adult apparent survival was modeled for males only since female sample size was too small for a time-dependence parameter. Year interval represents a year +1 time interval for reporting apparent site fidelity and survival from the previous year. The study did not occur in 2012, so the 2011-2013 return rates are for individuals banded in 2011. Note only one female was banded in 2011 for the $0 \%$ female return rate from 2011-2013. Years where fidelity or survival could not be calculated are indicated with "-" either due to no newly banded waterthrush the previous year or because the study ended in 2015 .

\begin{tabular}{|c|c|c|c|c|c|c|c|c|c|}
\hline \multirow[b]{2}{*}{ Year } & \multicolumn{3}{|c|}{ Number Banded } & \multirow{2}{*}{$\begin{array}{l}\text { Year } \\
\text { interval }\end{array}$} & \multicolumn{4}{|c|}{ Percent apparent site fidelity } & \multirow[b]{2}{*}{$\begin{array}{l}\text { Male } \phi \\
\text { (SE) }\end{array}$} \\
\hline & Male & Female & Nestling & & Male & Female & All adult & Nestling & \\
\hline 2009 & 11 & 0 & 0 & $2009-2010$ & 63.6 & - & 63.6 & - & $0.56(0.17)$ \\
\hline 2010 & 17 & 3 & 10 & 2010-2011 & 64.7 & 67.0 & 65.0 & 0.0 & $0.63(0.11)$ \\
\hline 2011 & 10 & 1 & 22 & 2011-2013 & 60.0 & 0.0 & 54.5 & 0.0 & $0.74(0.07)$ \\
\hline 2013 & 47 & 14 & 112 & 2013-2014 & 42.5 & 57.1 & 45.9 & 1.8 & $0.53(0.07)$ \\
\hline 2014 & 21 & 10 & 78 & 2014-2015 & 33.3 & 30.0 & 32.3 & 5.1 & $0.39(0.07)$ \\
\hline 2015 & 33 & 20 & 0 & - & - & - & - & - & - \\
\hline
\end{tabular}


Table 2. A descriptive summary of site fidelity factors ( \pm standard error, SE) for adult male and female waterthrush that differed between returned vs. did not return birds (noted with *) and compared between shale gas disturbed and undisturbed territories. Productivity is the number of fledglings produced adjusted for nest survival in shale gas disturbed/undisturbed territories in the manner of Boves et al. (2015) and Frantz et al. (2018a). Higher EPA (range: 0-200) and HSI (range: $0-1$ ) scores are indicative of better riparian habitat quality for waterthrush and their aquatic prey.

\begin{tabular}{lllll}
\hline Return/Disturbance status & Sample total & \% TerrGas* & EPA* & HSI* \\
\hline Males $(\boldsymbol{n}=\mathbf{1 4 9})$ & & & & \\
No return, TerrGas disturbance & $52 \%(39$ of 75$)$ & $48.3(5.7)$ & $159.9(2.4)$ & $0.78(0.02)$ \\
No return, No TerrGas disturbance & $48 \%(36$ of 75$)$ & 0 & $161.7(2.98)$ & $0.79(0.02)$ \\
\hline $\begin{array}{l}\text { Return, TerrGas disturbance } \\
\text { Return, No TerrGas disturbance }\end{array}$ & $62 \%(46$ of 74$)$ & $59.5(4.9)$ & $152.5(3.1)$ & $0.68(0.02)$ \\
& $38 \%(28$ of 74$)$ & 0 & $158.2(2.9)$ & $0.82(0.01)$ \\
\hline & & & & \\
Return/Disturbance status & Sample total & \% TerrGas & attempts* & Productivity \\
\hline $\begin{array}{l}\text { Females }(\boldsymbol{n}=\mathbf{3 5}) \\
\text { No return, TerrGas disturbance }\end{array}$ & $48 \%(10$ of 21$)$ & $40.9(11.5)$ & $2.2(0.3)$ & $1.44(0.01)$ \\
No return, No TerrGas disturbance & $52 \%(11$ of 21$)$ & 0 & $1.9(0.4)$ & $1.49(0.02)$ \\
\hline Return, TerrGas disturbance & $57 \%(8$ of 14$)$ & $54.1(9.6)$ & $1.4(0.2)$ & $1.50(0.01)$ \\
Return, No TerrGas disturbance & $43 \%(6$ of 14$)$ & 0 & $1.3(0.3)$ & $1.61(0.01)$ \\
\hline
\end{tabular}


Table 3. Cormack-Jolly-Seber candidate models used to estimate male and female apparent survival $(\phi)$. AvgTerrGas was the average of shale gas territory disturbance across all years that an individual returned. AvgTerrRunoff was the average of potential hydraulic fracturing runoff in a territory across all years that an individual returned. The covariate year modeled time dependency (4 parameters). $\triangle \mathrm{AICc}=$ distance from the top model, $w_{i}=$ Akaike weight, $\mathrm{K}=$ the number of parameters in each model. The model term $\phi(\sim 1)$ indicates apparent survival was held constant. Model term $p(\sim 1)$ for encounter probability was held constant in every model. The constant model is $\phi(\sim 1) p(\sim 1)$.

\begin{tabular}{lllll}
\hline Model & AICc & $\Delta$ AICc & $\boldsymbol{w}_{\boldsymbol{i}}$ & $\boldsymbol{K}$ \\
\hline Males $(\boldsymbol{n}=\mathbf{9 4})$ & & & & \\
$\phi(\sim$ avgTerrGas $) p(\sim 1)$ & 225.41 & 0.00 & 0.33 & 3 \\
$\phi(\sim$ avgTerrGas + year $) p(\sim 1)$ & 225.89 & 0.48 & 0.26 & 7 \\
$\phi(\sim$ year $) p(\sim 1)$ & 226.29 & 0.88 & 0.21 & 6 \\
$\phi(\sim$ avgTerrRunoff + year $) p(\sim 1)$ & 228.18 & 2.76 & 0.08 & 7 \\
$\phi(\sim 1) p(\sim 1)$ & 228.25 & 2.84 & 0.08 & 2 \\
$\phi(\sim$ avgTerrRunoff $) p(\sim 1)$ & 229.92 & 4.51 & 0.03 & 3 \\
$\phi(\sim$ avgTerrGas $*$ year $) p(\sim 1)$ & 232.66 & 7.25 & 0.01 & 10 \\
$\phi(\sim$ avgTerrRunoff $*$ year $) p(\sim 1)$ & 247.40 & 22.00 & $<0.001$ & 10 \\
& & & & \\
Females $(\boldsymbol{n}=26)$ & & & & \\
$\phi(\sim 1) p(\sim 1)$ & 50.74 & 0.00 & 0.58 & 2 \\
$\phi(\sim$ avgTerrRunoff $) p(\sim 1)$ & 52.56 & 1.82 & 0.24 & 3 \\
$\phi(\sim$ avgTerrGas $) p(\sim 1)$ & 53.08 & 2.34 & 0.18 & 3 \\
\hline
\end{tabular}


Table 4. Summary results for male and female apparent survival $(\phi)$ in the top supported models (i.e., models where $\triangle \mathrm{AICc}<2$ ). Male results are model-averaged regression coefficients while female results are unstandardized regression coefficients \pm standard error (SE). AvgTerrGas was the average of shale gas territory disturbance across all years that an individual returned.

AvgTerrRunoff was the average potential hydraulic fracturing runoff in a territory across all years an individual returned. The covariate year modeled time dependency. Model supported covariates $(n=3)$ were not significant and had overlapping confidence intervals.

\begin{tabular}{llll}
\hline Parameter & Estimate & SE & 85\% confidence interval \\
\hline Males & & & \\
avgTerrGas & 0.011 & 0.072 & $-0.092,0.115$ \\
year & 0.327 & 2.282 & $-2.958,3.613$ \\
Females & & & \\
avgTerrRunoff & 0.006 & 0.008 & $-0.005,0.018$ \\
\hline
\end{tabular}




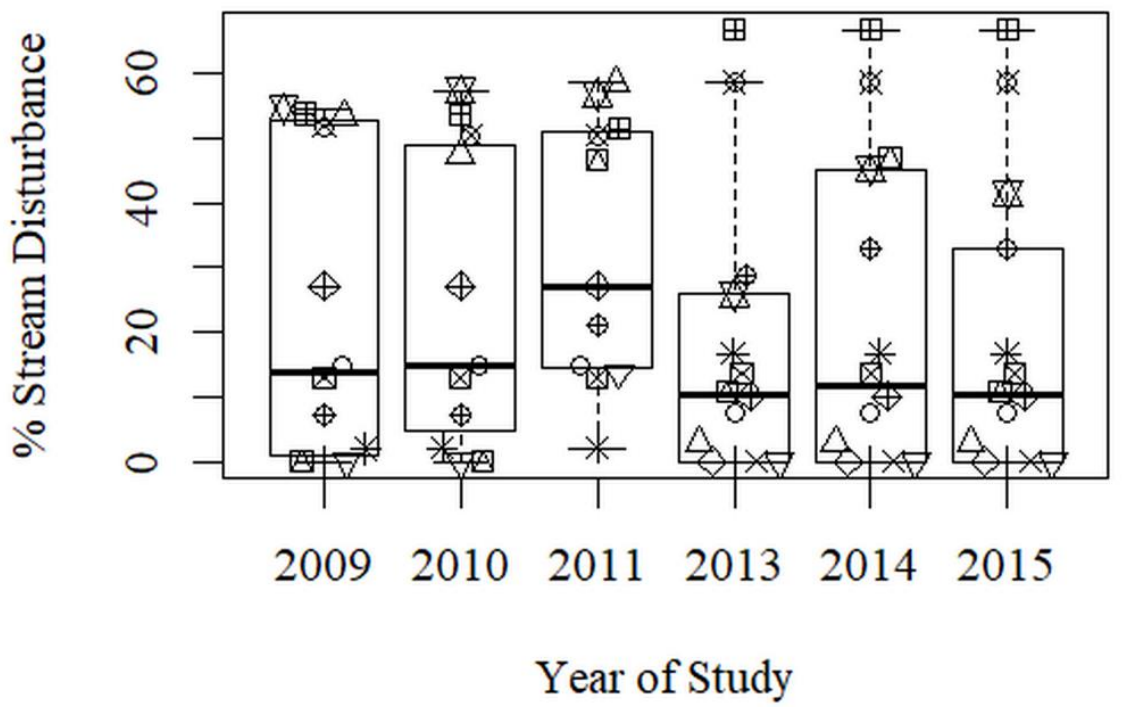

\section{Study Streams}

- Buffalo East Run

$\triangle$ Buffalo West Run

+ Carpenter Run

$\times$ Hiles Run

$\diamond$ Huss Pen Run

$\nabla$ Megans Run

$\otimes$ Nettles Run

* Olive Run

$\oplus$ Owl Run

* Sees Run

Slabcamp Run

田 Snake North Run

Snake South Run

四 Wyatt Run

Figure 1. A box and whisker plot of disturbance on headwater streams $(n=14)$ resulting from shale gas development over a 6 year period (2009-2011, 2013-2015) at Lewis Wetzel Wildlife Management Area (LWWMA) located in northwestern West Virginia. 


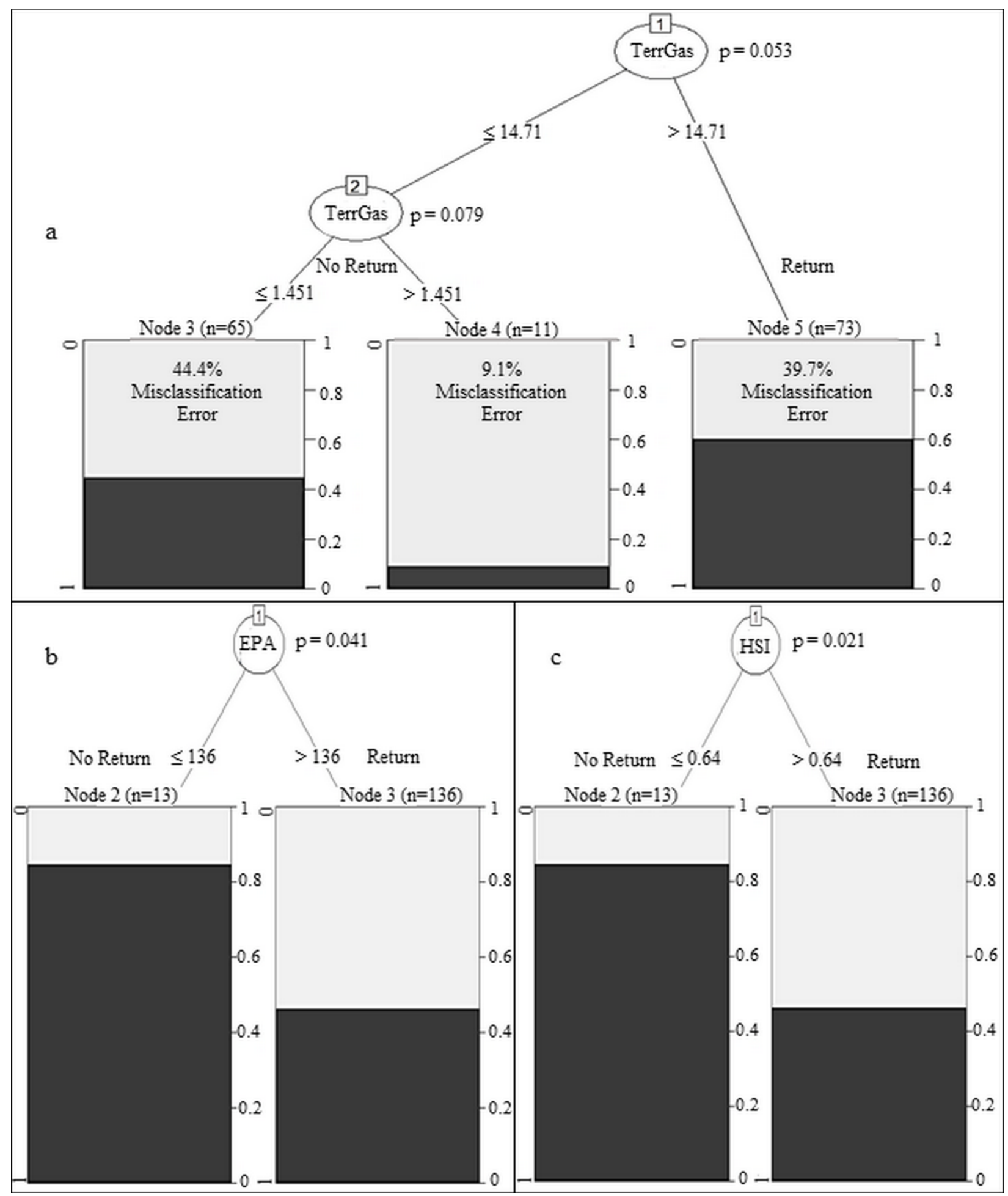

Figure 2. Conditional inference trees showing significant splits in data structure for TerrGas (a), EPA (b), and HSI (c) in explaining adult male waterthrush site fidelity, and percent misclassification error rate represented in assigning individuals to that group. 


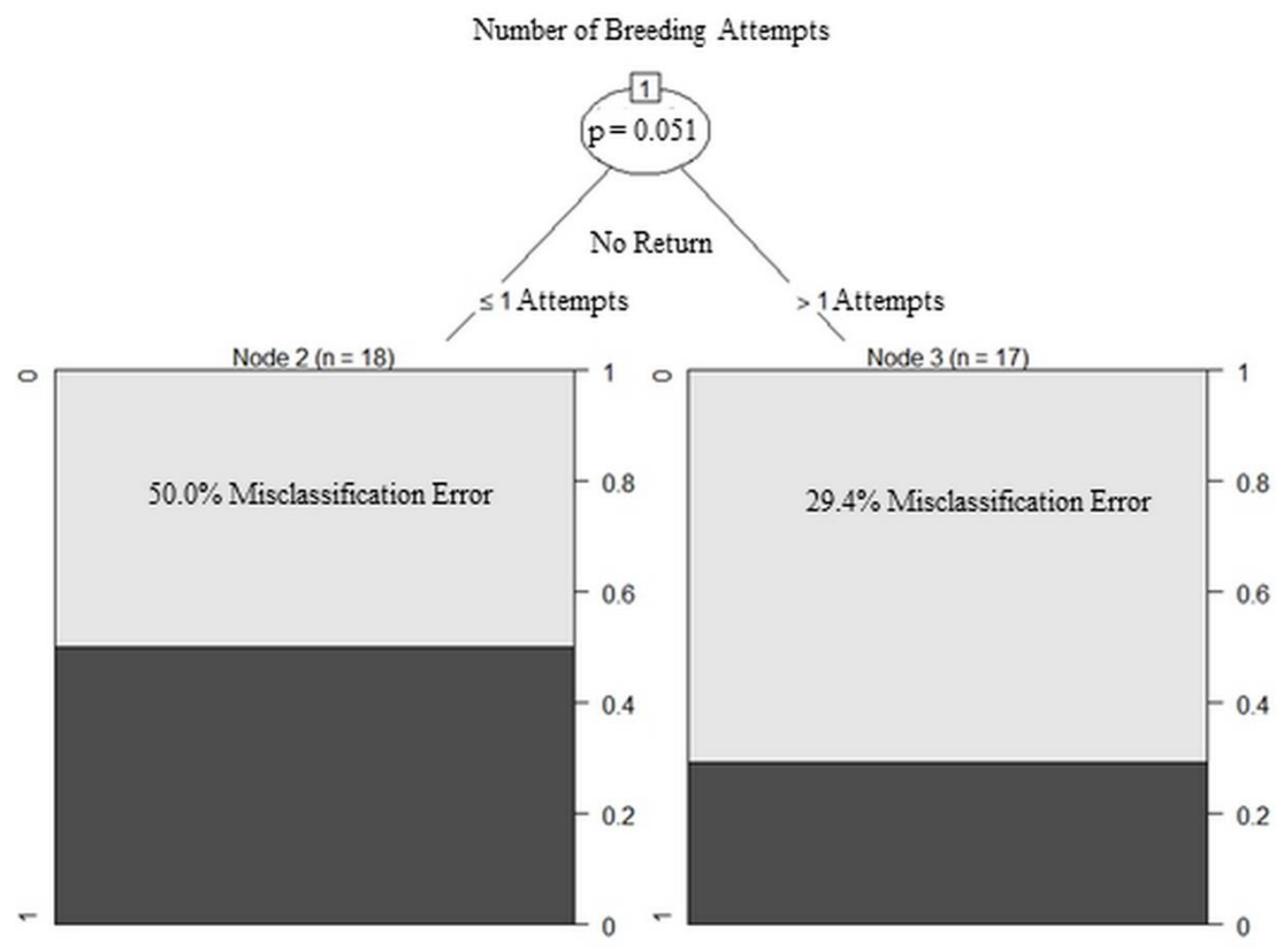

Figure 3. A conditional inference tree showing a significant split in data structure for the number of breeding attempts in explaining adult female waterthrush site fidelity, and percent misclassification error rate represented in assigning individuals to that group. 


\section{PART 3. SPATIAL ASSESSMENT OF LOUISIANA WATERTHRUSH FORAGING}

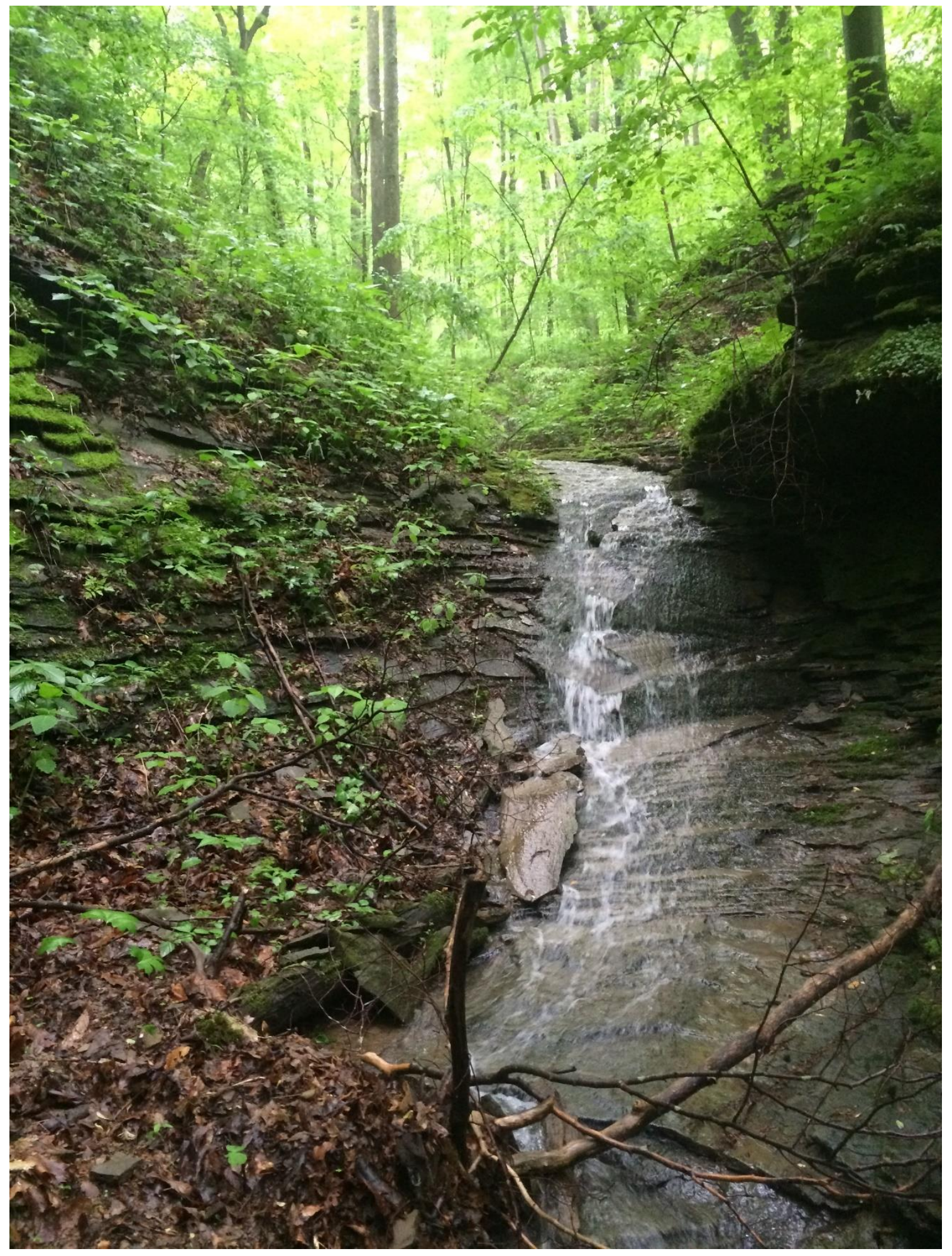




\title{
CHAPTER 4. DEMOGRAPHIC CHARACTERISTICS OF AN AVIAN PREDATOR, LOUISIANA WATERTHRUSH (PARKESIA MOTACILLA), IN RESPONSE TO ITS AQUATIC PREY IN A CENTRAL APPALACHIAN USA WATERSHED IMPACTED BY SHALE GAS DEVELOPMENT.
}

Chapter 4 was published in the peer-reviewed journal PLOS ONE. The PLOS ONE online version includes supplemental files of all data used in analysis.

\section{Citation:}

Frantz, M. W., P. B. Wood, and G. T. Merovich, Jr. 2018. Demographic characteristics of an avian predator, Louisiana Waterthrush (Parkesia motacilla), in response to its aquatic prey in a Central Appalachian USA watershed impacted by shale gas development. PLOS ONE 13(11): e0206077. https://doi.org/10.1371/journal.pone.0206077.

\begin{abstract}
We related Louisiana Waterthrush (Parkesia motacilla) demographic response and nest survival to benthic macroinvertebrate aquatic prey and to shale gas development parameters using models that accounted for both spatial and non-spatial sources of variability in a Central Appalachian USA watershed. In 2013, aquatic prey density and pollution intolerant genera (i.e., pollution tolerance value <4) decreased statistically with increased waterthrush territory length but not in 2014 when territory densities were lower. In general, most demographic responses to aquatic prey were variable and negatively related to aquatic prey in 2013 but positively related in 2014 . Competing aquatic prey covariate models to explain nest survival were not statistically significant but differed annually and in general reversed from negative to positive influence on daily survival rate. Potential hydraulic fracturing runoff decreased nest survival both years and was statistically significant in 2014. The EPA Rapid Bioassessment protocol (EPA) and Habitat Suitability Index (HSI) designed for assessing suitability requirements for waterthrush were positively linked to aquatic prey where higher scores increased aquatic prey metrics, but EPA was more strongly linked than HSI and varied annually. While potential hydraulic fracturing runoff in 2013 may have increased Ephemeroptera, Plecoptera, and Trichoptera (EPT) richness, in 2014 shale gas territory disturbance decreased EPT richness. In 2014, intolerant genera decreased at the territory and nest level with increased shale gas disturbance suggesting the potential for localized negative effects on waterthrush. Loss of food resources does not seem directly or solely responsible for demographic declines where waterthrush likely were able to meet their foraging needs. However collective evidence suggests there may be a shale gas disturbance threshold at which waterthrush respond negatively to aquatic prey community
\end{abstract}


changes. Density-dependent regulation of their ability to adapt to environmental change through acquisition of additional resources may also alter demographic response.

\section{INTRODUCTION}

The rapid development of hydraulic fracturing techniques in the last decade has allowed the expansion of development for unconventional drilling activity, hereafter shale gas development [1]. The Marcellus-Utica shale basin is one of the largest natural gas plays underlying part of the northeastern United States with substantial growth in gas production [2-3]. As of 2015, over 140,000 ha of land have been developed, with deciduous forest one of the major habitat types affected with high ecosystem service costs [4]. Shale gas development has outpaced the ability to create adequate management practices that protect against harm to aquatic and terrestrial wildlife communities and their habitat [5]. The trend for core forest disturbance from shale gas development where headwater streams occur [6] stresses the need for regional monitoring and research in these ecosystems.

Although there is local and regional variability in risks to water resources from shale gas development [7], shale gas development commonly occurs $<300 \mathrm{~m}$ from streams, increasing the threat of surface water degradation from sedimentation, altered stream flow, and the introduction of contaminants [8]. Johnson et al. [9] found that differences in benthic macroinvertebrate communities were dependent on the level of gas activity, and Grant et al. [10] found that stream $\mathrm{pH}$, fish biodiversity, and taxa richness were negatively correlated with the number of gas wells. Additionally, Lutz and Grant [11] found that shale gas disturbed streams were more acidic and had lower index of biotic integrity (IBI) scores. However, other studies found shale gas development did not have any noticeable impact on water quality [12], or in least intrusive scenarios no evidence of impacts on fish, salamander, and crayfish assemblages [13]. Shale gas development has the potential to alter the base of aquatic food webs [14] and may be associated with bioaccumulated contaminants in an apex predator [15], but no study has yet followed potential effects from shale gas development across trophic levels of the aquatic-terrestrial interface.

Terrestrial and aquatic ecosystems are closely linked through cross-habitat physical mechanisms and energy fluxes, leaving research focusing only on land or water ecologically incomplete [16]. In particular, dynamics of forested headwater stream ecosystems occur at the aquatic-terrestrial interface [17]. Headwater streams are the critical sources of water, sediment, 
organic matter, and nutrients for the rest of the system [18], and are therefore vital for ecological integrity [19]. Furthermore, headwater streams, despite their predominance of drainage area and total stream length, are largely overlooked for protection or regulation despite their strong influence on downstream reaches [20].

Species with specialized terrestrial or aquatic habitat needs that overlap forested freshwater ecosystems [21-22] undergoing shale gas development may be the most vulnerable to disturbance [5]. The Louisiana Waterthrush (Parkesia motacilla), hereafter waterthrush, is a habitat specialist and species of conservation concern [23] that breeds in contiguous riparian forests [24] and forages on benthic macroinvertebrates, hereafter aquatic prey, in well-developed riffle and pool areas [25]. Waterthrushes are considered bioindicators of riparian ecosystem integrity [25] due to their stream dependency [26-27].

Over a six-year waterthrush demography study (2009-2011, 2013-2015) at Lewis Wetzel Wildlife Management Area (LWWMA) located in northwestern West Virginia, we observed general annual declines in territory density, reproductive success, and riparian habitat quality with increases in shale gas development [28], as well as declines in site fidelity and apparent survival (M. Frantz, pers. comm.). In 2011 and 2013-2014, two benthic studies on the same study area linked shale gas development to both strong (2011) and weak (2013-2014) negative influences on benthic community structure ([29]; G. Merovich, pers. comm.). The 2011 study also evaluated waterthrush demographic response to aquatic prey and found territory density and clutch size were greater in higher quality stream corridors during a year when shale gas activity was high [29]. However, Wood et al. [29] spanned only one breeding season with a limited sample size ( $\mathrm{n}=12$ watershed samples) at the watershed-scale, meriting further evaluation with increased sampling efforts at other spatial scales (territory and nest).

As a follow-up to these previous studies, in 2013-2014 we: 1) evaluated the congruence between aquatic prey and riparian quality indices used to gauge waterthrush habitat (i.e., US EPA Rapid Bioassessment Protocol, EPA; Habitat Suitability Index, HSI), 2) evaluated if the amount of shale gas disturbance or potential hydraulic fracturing runoff in a territory or at a nest influence aquatic prey, and 3) quantified waterthrush demographic response to aquatic prey changes. We hypothesized that aquatic prey should be positively linked with riparian quality habitat scores. EPA and HSI scores were negatively affected by shale gas development [28]. As a consequence of habitat degradation, we expected a negative relationship between aquatic prey 
metrics and the amount of shale gas disturbance or potential hydraulic fracturing runoff in a territory or at a nest. We also hypothesized that clutch size, number of fledglings, and territory density would have a positive association with aquatic prey metrics. Annual territory length increased as territory densities decreased [28], so we expected smaller territories to be indicative of higher quality aquatic prey and stream quality (e.g., [30]). Nest survival was minimally affected by aquatic prey in 2011 [29] but we hypothesized that any stream impairment effects on the aquatic prey would affect nest survival.

\section{METHODS}

\section{Study area}

We studied waterthrush along $58.1 \mathrm{~km}$ of $1 \mathrm{st}-$ and 2 nd-order headwater stream tributaries $(\mathrm{n}=14)$ at Lewis Wetzel Wildlife Management Area (LWWMA) located in northwestern West Virginia (Fig 1). Our waterthrush aquatic prey study in 2013-2014 was part of a waterthrush demography study over a six year period (2009-2011, 2013-2015; [28]). The study area overlays the Marcellus-Utica shale region and occurs where waterthrush reach their highest densities within the central Appalachians [31]. The LWWMA is part of a regional core designated as a priority conservation planning area for both aquatic and terrestrial targets [32].

During our study, shale gas development activities included building of conventional (shallower formations) and Marcellus well pads, timbering for yet unbuilt well pads, the expansion of existing road and pipeline infrastructure, and the construction of new infrastructure. In 2008, the LWWMA was $95.3 \%$ forested and had $0.4 \%$ shale gas land cover; the first shale gas well development began in 2007 [33]. Between the 2010 and 2011 breeding seasons, shale gas development activities that occurred since 2007 accelerated across the study area and began to increase especially on ridgetops. In 2011, study area-wide shale gas land cover was $1.3 \%$ and increased to 2.7\% in 2013-2014 ([33]; Table 1). Starting in 2013, shale gas development abated study area-wide and instead became concentrated to specific streams and ridgetops. Clearing for additional new well pads occurred late (June-July) in the 2013 breeding season with well pad completion in 2014, in addition to re-drilling of an existing well pad. There was no new shale gas development or activity in the 2015 breeding season. In 2015, the LWWMA was $90.8 \%$ forested and $3.9 \%$ in shale gas development land cover, with $83.1 \%$ of shale gas development resulting in direct forest loss [33]. In summary, 2013 disturbances slowed and affected streams more 
noticeably late in the breeding season, while in 2014 shale gas activity peaked again, particularly at Slabcamp Run, but did not achieve 2011 levels of activity (Appendix Table 1).

\section{Mapping of streams and shale gas disturbance}

Within a Geographic Information System (GIS), we used a sequence of leaf-on and leafoff aerial photographs from the National Agriculture Imagery Program (NAIP) for 2011 and 2014, satellite Quickbird imagery for 2009, and extensive annual ground-truthing to manually digitize areas of disturbance within the study area for each year of the long-term study, including years 2013-2014 of the aquatic prey study (see Frantz et al. [28] for full description). All forest canopy disturbances were classified as shale gas related (i.e., well pads and associated road and pipeline infrastructure, frequent truck traffic, and visual stream sedimentation) or as being unrelated or pre-existing (i.e., forest roads, recent even-aged timber harvests, and various types of existing clearings). We classified a few conventional impacts (i.e., stream-side vertical pump jacks) as related to shale gas development because their pads were managed in conjunction with nearby shale gas infrastructure and because their targeted formation, even though they remained shallow after development, was listed as Marcellus [34]. Gas well records [35] were used to verify target shale formations, drilling status, and start dates for all well disturbances.

Lengths of each study stream (average length $4.1 \pm 0.54 \mathrm{~km}$, range $0.95-7.4 \mathrm{~km}$ ) were calculated in GIS using a 3D functional surface length tool and a $3 \mathrm{~m}$ resolution digital elevation model to account for topography, and study streams were defined to have a drainage basin of 9.0 hectares (i.e., <100 ha; [36]) to delineate the uppermost headwater reaches (24 k scale or higher resolution; e.g., [37]). To describe and model waterthrush demography and riparian habitat quality as a function of shale gas disturbance, we created four continuous and one binary variable based on disturbance categories at the stream, territory, and nest scale. The first (termed StreamGas) described mostly localized streamside disturbance indicative of the presence of any shale gas infrastructure or activity. A section of stream was considered disturbed when well pads, infrastructure, or frequent vehicular activity were within $60 \mathrm{~m}$ of the stream centerline, which is the typical extent of waterthrush streamside use (i.e., $60 \mathrm{~m}$; [38]). When a stream had visually observable sedimentation that resulted from shale gas development at any distance from the stream, we classified the entire stream network downstream of the sedimentation beginning point as disturbed. Streams were frequently and extensively ground-truthed each season, so there were no stream reaches where sedimentation events were likely to be missed. 
We created a second shale gas disturbance category (termed StreamRunoff) that focused solely on potential run-off into streams from shale gas contaminants. A stream was considered disturbed from at and below a well pad or retaining pond (similar to Latta et al. [15]), resulting in the whole downstream network classified as at risk for surface pollution based on elevational maps and ground truthing. This category did not include pipeline or road disturbance and was a broader, distance-independent, disturbance category describing potential water pollution. For each year of the study, we then calculated the proportion of each stream disturbed for each of these two disturbance categories.

We calculated the proportion of each waterthrush territory (a 60-m buffer around each territory vector) that was disturbed by StreamGas and called this metric TerrGas. The proportion of each territory disturbed by StreamRunoff was termed TerrRunoff. We classified each waterthrush nest location as undisturbed or disturbed by StreamGas within 60-m around the nest and called this variable NestGas. Hereafter we use StreamGas, StreamRunoff, TerrGas, TerrRunoff, and NestGas to describe shale gas disturbance metrics (Table 1, Appendix Table 2).

\section{Waterthrush riparian habitat quality}

Riparian habitat quality was assessed using the Habitat Suitability Index specifically designed for waterthrush (hereafter HSI; [25]) and the US EPA Rapid Bioassessment Protocol for high gradient streams (hereafter EPA [39]) in the same manner as Wood et al. [29] and Frantz et al. [28]. The HSI is a broad-scale evaluation of waterthrush instream foraging habitat, nesting habitat, and upland habitat suitability [25]. The EPA assesses stream quality based primarily on instream characteristics that relate to the abundance and composition of aquatic organisms, and therefore may indicate relative quality of instream foraging habitat for waterthrush [29]. The HSI and EPA indices were quantified in a 50-m stream reach centered on each nest location monitored to make the indices sensitive to habitat immediately surrounding waterthrush nests.

\section{Waterthrush demographic monitoring}

We quantified annual waterthrush territory length (m), territory density (\# territories $/ \mathrm{km}$ ), and nest survival for our 14 study streams as described in Frantz et al. [28]. Waterthrush territories were delineated as linear vectors along each stream during April 1-June 29 using standardized territory mapping ( $\geq 6$ stream visits [40-41]). Nest searching and monitoring occurred concurrently with territory mapping. Locations of waterthrush observations and nests 
were recorded with a WAAS-enabled Garmin 60CSX GPS unit with accuracy $\leq 5 \mathrm{~m}$ in $2013-$ 2015.

To calculate daily survival rate (DSR) for nest survival, we monitored nests typically every three-four days initially and more frequently as fledging approached [42]. We assumed an undamaged empty nest had fledged if the nest was active the day before and had approached the predicted fledge date. Nest sites were revisited at least one more time to verify either no activity or renesting if the nest was not active prior to the expected fledge date. We counted number of eggs to determine clutch size of nests with complete clutches, and the number of fledglings for each successful nest was the count of nestlings in the visit prior to fledging. Nests were considered successful if they produced at least one waterthrush fledgling, including nests parasitized by Brown-headed Cowbirds (Molothrus ater).

\section{Aquatic prey sampling}

Aquatic prey occurring in riffle habitat adjacent to nest site locations were sampled once per nest using a Surber sampler. Nest site samples $(\mathrm{n}=178)$ were collected shortly after the nest fledged, failed, or had been abandoned (May 22 - July 28, 2013; June 16 - July 6, 2014) to assess relative prey availability near the time a nest contained fledglings. During sample collection, we scrubbed rocks ( $>8 \mathrm{~cm}$ in diameter) and disturbed sediment $3-\mathrm{cm}$ below the stream bed within the Surber frame for a total of 3 minutes [27]. We separated aquatic prey from detritus for each sample in the field and stored all organic matter in $70 \%$ or $95 \%$ ethanol.

Post-field season, aquatic prey in benthic samples were sorted, counted, and identified to genus level. Body lengths were also measured to estimate biomass (crayfish excluded). To summarize the aquatic prey composition for each sample, we calculated a family level multimetric IBI called the West Virginia Stream Condition Index (WVSCI [43]), and a genus level multimetric IBI called the Genus Level Index of Most Probable Stream Status (GLIMPSS), version $\mathrm{CF}$, which does not require the genus-level identification of Chironomidae or Oligochaeta [44]. The values we calculated for both indices are based on sampling methods that are slightly modified [45] from the standard methods (i.e., Surber samples and all individuals used in calculations). Thus, they are not strictly interpretable as indicators of stream ecosystem health as originally intended. Nevertheless, they still quantify the composition and integrity of the aquatic prey resource available to waterthrush. We additionally calculated overall aquatic prey density and biomass using length-mass regressions [46]. In total, we selected six aquatic 
prey metrics to relate to waterthrush demography: WVSCI, GLIMPSS, biomass, density, EPT richness (component of WVSCI), and number of intolerant genera (component of GLIMPSS where pollution tolerance value is $<4$ ); Appendix Table 2).

\section{Analysis}

We used spatial generalized linear mixed models (hereafter SGLMMs) to assess relationships between waterthrush demography and aquatic prey as well as between riparian habitat quality and aquatic prey for each year (i.e., 2013, 2014) separately. SGLMMs accounted for possible effects of spatial autocorrelation and were modeled using corrHLfit within the spaMM package [47-48] in R [49]. Model residuals were evaluated graphically, extreme or influential data outliers identified graphically and with packages car [50] and stats [49] for potential removal, and other data exploration diagnostic tools were used [51] to ensure model assumptions were met. We used $\mathrm{x}-\mathrm{y}$ coordinates as a spatial random effect in a Matern correlation model and included a stream random effect. For all SGLMMs, we determined statistical significance of fixed effects using a likelihood ratio test and set significance at $\alpha=0.10$ to be cautiously moderate in our assessment of biological significance [52].

We evaluated the degree to which the six aquatic prey metrics were related to riparian habitat quality (i.e., EPA and HSI scores) in individual SGLMM models. We also tested the relationship between the six aquatic prey metrics and the shale gas disturbance metrics for the nest and territory scales (TerrGas, TerrRunoff, and NestGas) as G. Merovich (pers. comm.) found differences in benthic communities up and downstream of shale gas development. We modeled WVSCI, GLIMPSS, biomass, and density using a Gaussian distribution with biomass and density receiving a $\log 10$ transformation to approximate normality. We removed an outlier from our benthic density dataset because it was identified as a strong influential outlier not representative of other samples $\left(6422.2 \mathrm{~m}^{2}\right.$ vs. $354.7 \pm 31.3$ per $\mathrm{m}^{2}$ average density) by using the outlierTest and influence.measures functions with packages car and stat. EPT richness and number of intolerant genera were modeled using the Conway-Maxwell-Poisson (COM-Poisson [53-54]) distribution that generalizes the Poisson distribution to handle a wide range of under and over-dispersion typically found in ecological count data [55]. If a COM-Poisson model could not converge, we substituted with a Poisson distributed model ( $\mathrm{n}=12$ models). Because Wood et al. [29] did not assess EPA and HSI in relation to aquatic prey metrics for their 2011 data, we completed a retrospective analysis of their 2011 data. We used Pearson (i.e., EPA) and 
Spearman (i.e., HSI) correlation coefficients to relate 2011 EPA and HSI to aquatic prey metrics with package psych [56] for comparison to our 2013-2014 results.

We additionally assessed the relationship between waterthrush demography (number of fledglings, clutch size, territory length, and territory density) and the six aquatic prey variables in individual SGLMM models as above. Number of fledglings, clutch size, and territory density were modeled using the COM-Poisson distribution. Territory length was modeled using a gamma distribution. We removed an outlier sample from the fledging dataset where only one fledgling was represented due to Brown-headed Cowbird (Molothrus ater) parasitism. Because the Wood et al. [29] aquatic prey study did not assess territory length, we used a Pearson correlation on data collected in 2011 in the same manner as riparian habitat quality above to relate the six aquatic prey variables to territory length for comparison to our 2013-2014 results.

We used program MARK 7.1 (Colorado State University, Ft. Collins, Colorado, USA, [57]) to estimate daily survival rate (DSR) of monitored waterthrush nests in 2013 and 2014. We removed 63 nests that did not meet the assumption requirements of program MARK and 11 nests that had no benthic information, leaving 107 nests for analysis. We assumed a 29-day nesting period (egg-laying 5, incubation 14, nestling 10 days) based on the chronology of nests monitored on our study area [28].

We developed a set of 7 a priori candidate models [58] that we hypothesized might influence DSR of waterthrush nests based on the results of Wood et al. [29] and Frantz et al. [28]. All covariates are defined in Appendix Table 2. All a priori models included 3 temporal covariates and a shale gas covariate that influenced nest survival in our study area [28]; they included nest age (NestAge), quadratic effect of time of nesting within the breeding season (TT), average daily rainfall (Rain), and percent potential hydraulic fracturing runoff within a territory (TerrRunoff). Instead of an intercept model with no covariates, these 4 covariates formed our base null model given their known importance [28], allowing us to assess whether aquatic prey also influenced nest survival by accounting for them. Nest age indicates vulnerability as the nest ages [59] and within-season trends in DSR reflect dynamic activity patterns of nest predators (e.g., [60]). Mean daily rainfall (in $\mathrm{mm}$ ) by influencing prey availability affects waterthrush nest survival $[28,38]$ as headwater riparian systems are subject to seasonality and annual changes in rainfall [61]. For each nest, we averaged daily rainfall estimates across the period in which an active nest was under observation [38]. Precipitation estimates were pooled from four Weather 
Underground, Inc. network stations closest (avg. $36 \mathrm{~km}$ ) to the study area. Six additive models included the null model plus each of our aquatic prey covariates of interest.

We used Akaike's Information Criterion for small sample sizes (AICc) to evaluate support for candidate models [62] in program MARK. We modeled the binomially distributed data with the user-defined, logit-link function while simultaneously considering associations with the covariates of interest. We considered the model with the lowest AICc value to be the best-supported model given the data, and any models with $\triangle \mathrm{AICc}<2$ were considered plausible. We used regression coefficients and $85 \%$ confidence intervals (hereafter CIs) to infer biological importance of covariates in plausible AICc models [63]. We model-averaged NestAge, TT, Rain, and TerrRunoff across all models [62].

\section{RESULTS}

Stream disturbance due to shale gas (i.e., StreamGas) was $32.3 \%$ in 2011, dropped to $17.3 \%$ in 2013 , and elevated to $21.5 \%$ in 2014 , reflecting different levels of shale gas activity despite study area-wide shale gas land cover not changing between 2013 and 2014 (Table 1; Appendix Table 1; Fig 2). The potential for hydraulic fracturing runoff within streams (i.e., StreamRunoff) increased from 19.3\% in 2011 to $24.2 \%$ in 2013 and 2014 (Table 1). The percent of each waterthrush territory disturbed by shale gas (i.e., TerrGas) had the same patterns as StreamGas while TerrRunoff increased each year (Table 1). Only 20.3\% of territories (39 of 192 total from 2011, 2013-2014) had their full territory length (100\%) disturbed by TerrGas or TerrRunoff.

In 2013, aquatic prey biomass and density increased with increasing EPA score, while in 2014 intolerant genera increased with increasing EPA score (Table 2; Fig 2). No relationships were statistically significant in 2013 between HSI and aquatic prey, but in 2014 intolerant genera and WVSCI (approaching significance) increased with increasing HSI score (Table 2; Fig 2). For 2011 data, aquatic prey biomass had a statistically significant, positive correlation with EPA ( $\mathrm{R}^{2}$ $=0.67, P=0.02)$ and HSI $($ Rho $=0.51, P=0.09)$. In 2013, EPT richness increased with increasing TerrRunoff, but in 2014 EPT richness decreased with increasing TerrGas (Table 3; Fig 2). In 2014, intolerant genera decreased with increasing TerrRunoff, TerrGas, and NestGas (Table 3; Fig 2).

All tests for the relationships between clutch size, number of fledglings, and territory density with aquatic prey metrics were statistically non-significant (Table 4). Territory length 
decreased with increasing aquatic prey density and number of intolerant genera in 2013 (Table 4; Fig 2). For 2011 data, territory length had a statistically significant, negative correlation with GLIMPSS, EPT richness, and number of intolerant genera $\left(\mathrm{R}^{2}=-0.65,-0.68,-0.67, P=0.02\right.$; Fig 2), respectively.

Of 7 a priori nest survival models (Table 5), 6 different models were supported ( $\triangle \mathrm{AICc}$ $<2)$ in 2013 and 2014. The null base model had the most weight in both years $(w i=0.25,0.28)$. The model with EPT richness had the most weight of the 5 supported aquatic prey models in $2013(w \mathrm{i}=0.17)$ and GLIMPSS the most in 2014 ( $w \mathrm{i}=0.18)$. Regression coefficient $85 \%$ CIs overlapped zero for all aquatic prey covariates indicating little, no, or highly variable influence on DSR, but the direction of the relationship between nest survival and aquatic prey switched from negative to positive for 5 of the 6 aquatic prey covariates from 2013 to 2014 (Table 6). In the null base model Rain had positive influence on DSR in 2013 and 2014, while TerrRunoff had negative influence on nest survival in 2014 (Table 6). MARK-formatted files (.inp file extension) used to analyze the relationship between waterthrush nest survival and aquatic prey are S1 Datasets 5 and 6.

\section{DISCUSSION}

Shale gas disturbances on our headwater stream ecosystem varied with the intensity of shale gas development that year ([28]; Table 1; Appendix Table 1). Our follow-up study was able to establish how shale gas alterations to riparian habitat quality and the food web can lead to potential effects at a higher trophic level in an apex predator. By also documenting waterthrush demography decline (Table 1, [28]) and shifts in aquatic prey community structure ([29]; G. Merovich pers. comm.) due to shale gas development, our study establishes the extent of dependency of waterthrush demographic response and adaptation due to the integrity of ecosystem conditions at the aquatic-terrestrial interface.

\section{Waterthrush foraging resources}

Our study builds a connection for decreasing riparian habitat quality due to shale gas altering, at least in part, waterthrush foraging resources. The EPA riparian habitat assessment has been successfully used in other studies in conjunction with waterthrush occupancy to explain biotic integrity [27]. Higher EPA index and HSI scores were indicative of a larger and healthier aquatic prey community in our system although not with all metrics and statistical significance was dependent on year (Table 2). Additionally, EPT richness and intolerant genera were 
negatively related to shale gas disturbance, mainly in 2014 (Table 3); this was important to establish since waterthrush riparian habitat quality was negatively affected by shale gas [28]. Overall, HSI was less reliable than EPA for describing aquatic prey, which may be due to HSI consisting of not just food (i.e., stream habitat and quality) scores, but also scores tabulated for waterthrush habitat cover, nesting, and a surrounding landscape classifier [25].

\section{Waterthrush demographic responses}

Most demographic responses to aquatic prey were variable or statistically non-significant. Even so, general demographic responses were negatively related to aquatic prey in 2013 then shifted to a positive response in 2014 when shale gas disturbance had a stronger negative influence on aquatic prey and nest survival (Table 4, Table 5). On streams acidified by mine drainage, waterthrush establish larger territories and forage on peripheral and novel prey items (e.g., terrestrial salamanders) to acquire sufficient prey resources [31]. We saw a similar effect where territory length increased with measures indicating poorer aquatic prey base (e.g., low EPT genus richness). However, territory length in 2014 tended to increase with increasing aquatic prey metrics, opposite of previous years (Table 4). Waterthrush likely had the ability to compensate for loss of food resources by foraging in undisturbed parts of their territory, in addition to increasing territory length, as only $20.3 \%$ of territories had their full territory length disturbed by TerrGas or TerrRunoff. The waterthrush's compensation ability in combination with the decline in annual territory density likely contributed to the disassociation between territory length and aquatic prey in 2014. In contrast, given the stronger response and higher territory densities in 2011 , under normal territory density conditions ( $\geq 1.5$ territories $/ \mathrm{km})$ the hypothesis of smaller territories indicate higher quality habitat and foraging resources [30] likely still holds true.

\section{Shale gas disturbance influences on nest survival and aquatic prey}

Models used to explain nest survival were also dependent on year (Table 5) with TerrRunoff significantly decreasing daily survival rate in 2014 (Table 6). Our study aligns with Wood et al. [29] in that aquatic prey likely is less influential on nest survival than temporal effects like rain or shale gas disturbance [28]. While our waterthrush-related shale gas disturbance metrics (i.e., TerrGas, TerrRunoff, and NestGas) suggest conflicting yet overall weak negative effects on aquatic prey (Table 3), aquatic prey community structure at our study area quantified upstream and downstream of shale gas at a subwatershed scale also mirrored 
shale gas activity: community changes differed the most in 2011 [29], were weaker in 2013, and then slightly stronger in 2014 but not as much as 2011 when shale gas activity was highest (G. Merovich, pers. comm.; Appendix Table 1).

\section{Implications}

The year-to-year waterthrush demographic responses to aquatic prey in our study were not strongly proportional but instead followed relatively weaker patterning. Timing of benthic sampling in 2013 in relation to shale gas activity levels likely in part explain the lack of a clear signal between waterthrush demography and its aquatic prey. New shale gas activity in 2013 was not as evident until near or after sampling late in the breeding season (S1 Table 1), and shale gas well pad construction and drilling typical of our study site and elsewhere occur in "pulses" [5]. With our sampling design, we were able to detect benthic community responses as stronger in 2014 than 2013 (similar to G. Merovich, pers. comm.), but increased sampling efforts during appropriate sampling periods may be even more critical for higher food web organisms in overcoming variability of demographic response to shale gas.

Our study, through collective evidence, suggests the potential for localized negative effects to aquatic prey from shale gas development, in particular EPT and intolerant taxa that are believed to be the waterthrush's preferred prey [24]. Additionally, the shift in demographic response in 2014 when shale gas disturbance had stronger negative effects on aquatic prey and nest survival may suggest a shale gas disturbance threshold ([64]; Fig 2) at which waterthrush respond and adapt to aquatic prey in the same manner aquatic prey community structure concurrently reflected levels of annual disturbance ([29]; G. Merovich, pers. comm.). Waterthrush are most likely to forage in locations that have higher EPT and intolerant genera [29], making it important to maintain or improve riparian habitat quality linked directly with their aquatic prey. In consideration of population regulatory mechanisms (e.g., [65]) that may influence annual demographic response and adaptability, continued long-term monitoring will be required to discern if a threshold of shale gas disturbance exists that alters aquatic prey communities and, in turn, affects demography of higher-level trophic linkages [66-67]. To some degree, waterthrush in our system appear to have the ability to adapt and meet their foraging needs. However, based on the response in 2011 and 2014 when aquatic prey was the most affected by shale gas, mechanisms used to compensate when stream disturbance is conservatively $\geq 25 \%$ (Fig 2) may be less dependable, altering demography. The fact that benthic 
communities even within pristine streams may be at risk when isolated within heavily impacted regions [68], and the tendency for upper reaches of Appalachian headwater streams to have resource extraction activities [69], warrants more attention to multi-dimensional wildlife community responses within aquatic-terrestrial linkages associated to shale gas development.

\section{ACKNOWLEDGMENTS}

West Virginia Division of Natural Resources (WVDNR) provided access to the study area and Wheeling Jesuit University provided access to field housing. We thank Jack Toriello, Robert (Blake) Hepner, Darin Blood, Jerry Kreiser, Steve Daniels, Jess Cosentino, and Ashley Akers who collected data in 2013-2014 for the project. We additionally thank Jim Sheehan for project assistance, and Stuart Welsh for manuscript review. This study was completed under the auspices of West Virginia University IACUC protocol \#04-0302, 07-0303. Any use of trade, firm, or product names is for descriptive purposes only and does not imply endorsement by the U.S. Government.

\section{LITERATURE CITED}

1. Arthur DJ, Langhus B, Alleman D. An overview of modern shale gas development in the United States. ALL Consulting; 2008. 18 pp.

2. Energy Information Administration (EIA). 2017. Marcellus shale play: geology review. 14 pp.

3. Energy Information Administration (EIA). 2017. Utica shale play: geology review. 18 pp.

4. Moran MD, Taylor NT, Mullins TF, Sardar SS, McClung MR. Land-use and ecosystem service costs of unconventional US oil and gas development. Front Ecol Environ. 2017; 15:237-242.

5. Brittingham MC, Maloney KO, Farag AM, Harper DD, Bowen ZH. Ecological risks of shale oil and gas development to wildlife, aquatic resources and their habitats. Environ Sci Technol. 2014; 48:11034-11047.

6. Drohan PJ, Brittingham M, Bishop J, Yoder K. Early trends in landcover change and forest fragmentation due to shale-gas development in Pennsylvania: a potential outcome for the Northcentral Appalachians. Environmental Management 2012; 49:1061-1075.

7. Mauter MS, Alvarez PJJ, Burton A, Cafaro DC, Chen W, Gregory KB, et al. Regional variation in water-related impacts of shale gas development and implications for emerging international plays. Environ Sci Technol. 2014; 48:8298-8306. 
8. Entrekin S, Evans-White M, Johnson B, Hagenbuch E. Rapid expansion of natural gas development poses a threat to surface waters. Front Ecol Environ. 2011; 9:503-511.

9. Johnson E, Austin BJ, Inlander E, Gallipeau C, Evans-White MA, Entrekin S. Stream macroinvertebrate communities across a gradient of natural gas development in the Fayetteville Shale. Sci Total Environ. 2015; 530-531:323-332.

10. Grant CJ, Weimer AB, Marks NK, Perow ES, Oster JM, Brubaker KM, et al. Marcellus and mercury: Assessing potential impacts of unconventional natural gas extraction on aquatic ecosystems in northwestern Pennsylvania. J Environ Sci Health A Tox Hazard Subst Environ Eng. 2015; 50:482-500.

11. Lutz AK, Grant CJ. Impacts of hydraulic fracturing development on macroinvertebrate biodiversity and gill morphology of net-spinning caddisfly (Hydropsychidae, Diplectrona) in northwestern Pennsylvania, USA. J Freshw Ecol. 2016; 31:211-217.

12. Austin BJ, Scott E, Massey L, Evans-White MA, Entrekin S, Haggard BE. Unconventional natural gas development did not result in detectable changes in water chemistry (within the South Fork Little Red River). Environ Monit Assess. 2017; 189:209.

13. Keller DH, Horwitz RJ, Mead JV, Belton TJ. Natural gas drilling in the Marcellus shale region: well pad densities and aquatic communities. Hydrobiologia 2017; 795:49-64.

14. Grant CJ, Lutz AK, Kulig AD, Stanton MR. Fracked ecology: response of aquatic trophic structure and mercury biomagnification dynamics in the Marcellus shale formation.

Ecotoxicology 2016; 25:1739-1750.

15. Latta SC, Marshall LC, Frantz MW, Toms J. Evidence from two shale regions that a riparian songbird accumulates metals associated with hydraulic fracturing. Ecosphere 2015; 6:144.

16. Gregory SV, Swanson FJ, McKee WA, Cummins KW. An ecosystem perspective of riparian zones. BioScience 1991; 41:540-551.

17. Nakano S, Miyasaka H, Kuhara N. Terrestrial-aquatic linkages: Riparian arthropod inputs alter trophic cascades in a stream food web. Ecology 1999; 80:2435-2441.

18. Gomi T, Sidle RC, Richardson JS. Understanding processes and downstream linkages of headwater systems. BioScience 2002; 5:905-916.

19. Freeman MC, Pringle CM, Jackson CR. Hydrologic connectivity and the contribution of stream headwaters to ecological integrity at regional scales. J Am Water Resour Assoc. 2007; 43:5-14.

20. MacDonald LH, Coe D. Influence of headwater streams on downstream reaches in forested areas. Forest Science 2007; 53:148-168. 
21. Dunscomb JK, Evans JS, Strager JM, Strager MP, Kiesecker JM. Assessing future energy development across the Appalachian Landscape Conservation Cooperative. 48 pp with appendices. Appalachian Landscape Conservation Cooperative Grant. 2014; \#2012-02. The Nature Conservancy, Charlottesville, VA.

22. Evans JS, Kiesecker JM. Shale gas, wind and water: Assessing the potential cumulative impacts of energy development on ecosystem services within the Marcellus play. PLoS ONE 2014; 9:e89210.

23. United States Fish and Wildlife Service (USFWS). Birds of conservation concern 2008. Arlington (VA): United States Department of Interior, Fish and Wildlife Service, Division of Migratory Bird Management. 2008 [cited 2015 December 24]. Available from: http://www.fws.gov/migratorybirds.

24. Mattsson BJ, Master TL, Mulvihill RS, Robsinson WD. Louisiana Waterthrush (Parkesia motacilla). In: Rodewald PG, editor. The birds of North America. Ithaca: Cornell Lab of Ornithology; 2009. Available from: https://birdsna-org.bnaproxy.birds.cornell.edu/Species Account/bna/species/louwat.

25. Prosser DJ, Brooks RP. A verified habitat suitability index for the Louisiana Waterthrush. J Field Ornithol. 1998; 69:288-298.

26. O'Connell TR, Brooks RP, Laubscher SE, Mulvihill RS, Master TE. Using bioindicators to develop a calibrated index of regional ecological integrity for forested headwater ecosystems. Final report. University Park (PA): Penn State Cooperative Wetlands Center, Penn State University. U.S. Environmental Protection Agency, STAR Grants Program; 2003. Report No. 2003-01.

27. Mattsson BJ, Cooper RJ. Louisiana waterthrushes (Seiurus motacilla) and habitat assessment as cost-effective indicators of instream biotic integrity. Freshw Biol. 2006; 51:1941-1958.

28. Frantz MW, Wood PB, Sheehan J, George G. Demographic Response of a stream obligate Songbird of conservation concern to shale gas development. The Condor: Ornithological Applications 2018; 120:265-282.

29. Wood P, Frantz M, Becker D. Louisiana Waterthrush and benthic macroinvertebrate response to shale gas development. J Fish Wildl Manag. 2016; 7:423-433.

30. Mulvihill RS, Newell FL, Latta SC. Effects of acidification on the breeding ecology of a stream-dependent songbird, the Louisiana Waterthrush (Seiurus motacilla). Freshw Biol. 2008; 53:2158-2169.

31. Sauer JR, Hines JE, Fallon JE, Pardieck KL, Ziolkowski DJ, Link WA. The North American breeding bird survey, results and analysis 1966-2013 [dataset]. Version 01.30.2015. 2014 [cited 2015 December 24]. Laurel (MD): USGS Patuxent Wildlife Research Center. Available from: http://www.mbr-pwrc.usgs.gov/bbs/. 
32. Leonard, PB, Baldwin RF, Hanks RD. Landscape-scale conservation design across biotic realms: sequential integration of aquatic and terrestrial landscapes. Sci. Rep. 2017; 7:14556.

33. Farwell LS, Wood PB, Sheehan J, and George GA. Shale gas development effects on the songbird community in a central Appalachian forest. Biol Conserv. 2016; 201:78-91.

34. West Virginia Geological and Economic Survey (WVGES). WV Marcellus shale wells: completed, permitted, and cancelled episodes. 2015 [cited 2015 December 24]. State of West Virginia. Available from: http://www.wvgs.wvnet.edu/www/datastat/devshales.htm.

35. West Virginia Department of Environmental Protection (WVDEP). Oil and gas production data. 2015 [cited 2015 December 24]. State of West Virginia. Available from: http://www.dep.wv.gov/oil-and-gas/databaseinfo/Pages/default.aspx.

36. Swanson FJ, Johnson SL, Gregory SV, Acker SA. Flood disturbance in a forested mountain landscape. BioScience 1998; 48:681-689

37. Strager MP, Petty JT, Strager JM, Barker-Fulton J. A spatially explicit framework for quantifying downstream hydrologic conditions. J Environ Manage. 2009; 90:1854-1861.

38. Mattsson BJ, Cooper RJ. Multi-scale analysis of the effects of subseasonal rainfall extremes on reproduction by an obligate riparian bird in urban and rural landscapes. Auk 2009; 126:64-76.

39. Barbour MT, Gerritsen J, Snyder BD, Stribling JB. Rapid Bioassessment protocols for use in streams and wadeable rivers: periphyton, benthic macroinvertebrates and fish, second edition. 1999; EPA 841-B-99-002. U.S. Environmental Protection Agency, Office of Water, Washington, D.C.

40. Robbins CS. Recommendations for an international standard for a mapping method in bird census work. Audubon Field Notes 1970; 24:723-726.

41. Bibby CJ, Burgess ND, Hill DA. Bird Census Techniques. London: Academic Press; 1992.

42. Martin TE, Geupel GR. Nest-monitoring plots: Methods for locating nests and monitoring success. J Field Ornithol. 1993; 64:507-519.

43. Gerritsen J, Burton J, Barbour MT. A stream condition index for West Virginia wadeable streams. Owing Mills: Tetra Tech, Inc.; 2000.

44. Pond GJ, Bailey JE, Lowman BM, Whitman MJ. Calibration and validation of a regionally and seasonally stratified macroinvertebrate index for West Virginia wadeable streams. Environ Monit Assess. 2013; 185:1515-1540. 
45. Merriam ER, Petty JT, Merovich GT, Fulton JB, Strager MP. Additive effects of mining and residential development on stream conditions in a central Appalachian watershed. J North Am Benthol Soc. 2011; 30:399-418.

46. Benke AC, Huryn AD, Smock LA, Wallace JB. Length-mass relationships for freshwater macroinvertebrates in North America with particular reference to the southeastern United States. $\mathrm{J}$ of the North American Benthological Society 1999; 18:308-343.

47. Roussett F, Ferdy J-B. Testing environmental and genetic effects in the presence of spatial autocorrelation. Ecography. 2014; 37:781-790.

48. Roussett F. Package 'spaMM'. Version 2.0.0 [software]. 2017 [cited 2017 July 19]. Available from: https://CRAN.Rproject.org/package=spaMM.

49. R Core Team. R: A language and environment for statistical computing. R Foundation for Statistical Computing, Vienna, Austria. [software]. 2014 [cited 2017 July 19]. Available from: http://www.Rproject.org/.

50. Fox J, Weisberg S, Adler D, Bates D, Baud-Bovy G, Ellison S, Firth D, Friendly M, Gorjanc G, Graves S, Heiberger R, Laboissiere R, Monette G, Murdoch D, Nilsson H, Ogle D, Ripley B, Venables W, Winsemius D, Zeileis A, R-Core. Package 'car'. Version 2.1-5 [software]. 2017 [cited 2017 July 19]. Available from: https://CRAN.R-project.org/package=car.

51. Zuur AF, Ieno EN, Elphick CS. A protocol for data exploration to avoid common statistical problems. Methods Ecol and Evol. 2010; 1:3-14.

52. Askins RA, Lynch JF, Greenberg R. Population declines in migratory birds in eastern North America. Current Ornithol. 1990; 7:1-57.

53. Conway RW, Maxwell WL. A queuing model with state dependent service rates. J Indstrl Engng. 1962; 12:132-136.

54. Shmueli G, Minka TP, Kadane JB, Borle S, Boatwright P. A useful distribution for fitting discrete data: revival of the Conway-Maxwell-Poisson distribution. J R Stat Soc Ser C Appl Stat. 2005; 54:127-142.

55. Ridout MS, Besbeas P. An empirical model for underdispersed count data. Statistical Modeling. 2004; 4:77-89.

56. Revelle W. Package 'psych'. Version 1.7.5 [software]. 2017 [cited 2017 July 19]. Available from: https://CRAN.R-project.org/package=psych.

57. White GC, Burnham KP. Program MARK: survival estimation from populations of marked animals. Bird Study 1999; 46:S120-130. 
58. Buckland ST, K. P. Burnham KP, Augustin NH. Model selection: an integral part of inference. Biometrics 1997; 53:603-618.

59. Dinsmore SJ, White GC, Knopf FL. Advanced techniques for modeling avian nest survival. Ecology 2002; 83:3476-3488.

60. Sperry JH, Peak RG, Cimprich DA, Weatherhead PJ. 2008. Snake activity affects seasonal variation in nest predation risk for birds. J. Avian Biol. 2008; 39:379-383.

61. Richardson JS, Danehy RJ. A synthesis of the ecology of headwater streams and their riparian zones in temperate forests. Forest Science 2006; 53:131-147.

62. Burnham KP, Anderson DR. Model selection and multimodel inference: an informationtheoretic approach. New York: Springer-Verlag; 2002.

63. Arnold TW. Uninformative parameters and model selection using Akaike's Information Criterion. J Wildl Manage. 2010; 74:1175-1178.

64. Becker DA, Wood PB, Strager MP, Mazzarella C. Impacts of mountaintop mining on terrestrial ecosystem integrity: identifying landscape thresholds for avian species in the central Appalachians, United States. Landscape Ecology 2015; 30:339-356.

65. Lack D. The natural regulation of animal numbers. Oxford: The Clarendon Press; 1954.

66. Lowe WH, Likens GE. Moving headwater streams to the head of the class. BioScience 2005; 55:196-197.

67. Meyer JL, Strayer DL, Wallace JB, Eggert SL, Helfman GS, Leonard NE. The contribution of headwater streams to biodiversity in river networks. J Am Water Resour Assoc. 2007; 43:86-103.

68. Merriam ER, Petty JT. Under siege: isolated tributaries are threatened by regionally impaired metacommunities. Sci Total Environ. 2016; 560-561:170-178.

69. Cook NA, Sarver EA, Krometis LH, Huang J. Habitat and water quality as drivers of ecological system health in Central Appalachia. Ecol Eng. 2015; 84:180-189. 


\section{TABLES}

Table 1. Louisiana Waterthrush annual demographic, riparian habitat quality, and shale gas disturbance metrics (mean \pm SE) at Lewis Wetzel Wildlife Management Area, WV at peak (2011) and later stages (2013-2014) of shale gas development. Our study associated waterthrush response to aquatic prey community changes in relation to shale gas disturbance. All metrics are a subset of those originally reported in Frantz et al. [28] excepting \% shale gas land cover which is cited from Farwell et al. [33]. Variable names are defined in Appendix Table 2.

\begin{tabular}{llll}
\hline Variable & $\mathbf{2 0 1 1}$ & $\mathbf{2 0 1 3}$ & $\mathbf{2 0 1 4}$ \\
\hline Riparian Habitat Quality & & & \\
EPA Index (range 0-200) & $158.6 \pm 1.8$ & $148.9 \pm 2.1$ & $165.6 \pm 2.2$ \\
HSI (range 0-1) & $0.78 \pm 0.02$ & $0.76 \pm 0.02$ & $0.77 \pm 0.02$ \\
& & & \\
Demography & & & \\
Territory Density & $1.5 \pm 0.1$ & $1.2 \pm 0.1$ & $1.1 \pm 0.1$ \\
Territory Length (m) & $556.4 \pm 31.2$ & $659.0 \pm 34.3$ & $772.1 \pm 41.9$ \\
Nest Survival & $38.0 \pm 8.0$ & $28.5 \pm 6.1$ & $25.7 \pm 5.8$ \\
Clutch Size & $4.8 \pm 0.1$ & $4.6 \pm 0.1$ & $4.4 \pm 0.1$ \\
Fledglings & $4.5 \pm 0.1$ & $4.7 \pm 0.1$ & $4.1 \pm 0.2$ \\
& & & \\
Disturbance & & & \\
\% TerrGas & $38.0 \pm 5.2$ & $18.0 \pm 3.4$ & $27.2 \pm 4.5$ \\
\% TerrRunoff & $20.0 \pm 4.5$ & $32.9 \pm 5.2$ & $36.0 \pm 5.0$ \\
\% StreamGas & $32.3 \pm 6.3$ & $17.3 \pm 5.7$ & $21.5 \pm 6.4$ \\
\% StreamRunoff & $19.3 \pm 5.7$ & $24.2 \pm 5.5$ & $24.2 \pm 5.5$ \\
\% Shale Gas Land Cover & 1.3 & 2.7 & 2.7 \\
\hline
\end{tabular}


Table 2. Association between waterthrush riparian habitat quality indices (i.e., EPA and HSI) and aquatic prey metrics in spatial generalized linear mixed models. In 2013, aquatic prey biomass and density increased with increasing EPA score, while in 2014 intolerant genera increased with increasing EPA score. No relationships were statistically significant in 2013 between HSI and aquatic prey, but in 2014 intolerant genera and WVSCI (approaching significance) increased with increasing HSI score. Results with ${ }^{\mathrm{P}}$ are from a Poisson model. $\mathrm{P}$ values of variables that are statistically significant are bolded. Variable names are defined in S1 Table $2 . \mathrm{LRT}=$ likelihood ratio test $\chi 2$ statistic. $\beta=$ beta estimate of fixed effect.

\begin{tabular}{|c|c|c|c|c|c|c|}
\hline Independent Variable & $\boldsymbol{\beta} \pm \mathbf{S E}$ & LRT $\chi^{2}$ & p value & $\bar{\beta} \pm \mathbf{S E}$ & LRT $\chi^{2}$ & p value \\
\hline & GLIMPSS & & & WVSCI & & \\
\hline \multicolumn{7}{|l|}{ Year 2013} \\
\hline EPA & $0.120 \pm 0.092$ & 1.670 & 0.196 & $0.006 \pm 0.081$ & 0.010 & 0.922 \\
\hline HSI & $13.700 \pm 14.480$ & 0.938 & 0.333 & $1.991 \pm 12.515$ & 0.030 & 0.864 \\
\hline \multicolumn{7}{|l|}{ Year 2014} \\
\hline EPA & $0.069 \pm 0.066$ & 1.128 & 0.288 & $0.014 \pm 0.045$ & 0.464 & 0.496 \\
\hline HSI & $10.890 \pm 11.221$ & 0.961 & 0.327 & $11.540 \pm 7.582$ & 2.594 & 0.107 \\
\hline & $\underline{\text { Density }}$ & & & $\underline{\text { Biomass }}$ & & \\
\hline \multicolumn{7}{|l|}{ Year 2013} \\
\hline EPA & $0.005 \pm 0.002$ & 5.000 & 0.025 & $0.010 \pm 0.004$ & 2.862 & 0.091 \\
\hline HSI & $-0.307 \pm 0.399$ & 0.601 & 0.438 & $0.219 \pm 0.752$ & 0.106 & 0.744 \\
\hline \multicolumn{7}{|l|}{ Year 2014} \\
\hline EPA & $0.0003 \pm 0.002$ & 0.017 & 0.896 & $0.002 \pm 0.003$ & 0.771 & 0.380 \\
\hline HSI & $0.337 \pm 0.351$ & 0.645 & 0.422 & $0.148 \pm 0.494$ & 0.171 & 0.679 \\
\hline & EPT Richness & & & Intolerant Genera & & \\
\hline \multicolumn{7}{|l|}{ Year 2013} \\
\hline EPA & $0.010 \pm 0.015$ & 0.599 & 0.439 & $0.006 \pm 0.005^{\mathrm{P}}$ & $1.665^{\mathrm{P}}$ & $0.197^{\mathrm{P}}$ \\
\hline HSI & $-1.026 \pm 2.517$ & 0.036 & 0.850 & $-0.679 \pm 0.718^{P}$ & $0.869^{\mathrm{P}}$ & $0.351^{\mathrm{P}}$ \\
\hline \multicolumn{7}{|l|}{ Year 2014} \\
\hline EPA & $-0.005 \pm 0.007$ & 0.327 & 0.567 & $0.005 \pm 0.002$ & 3.160 & 0.075 \\
\hline HSI & $1.581 \pm 1.266$ & 2.109 & 0.146 & $0.828 \pm 0.399$ & 4.573 & 0.032 \\
\hline
\end{tabular}


Table 3. Association between waterthrush aquatic prey and shale gas disturbance metrics in spatial generalized linear mixed models. Results with ${ }^{\mathrm{P}}$ are from a Poisson model. In 2013, EPT richness increased with increasing TerrRunoff, but in 2014 EPT richness decreased with increasing TerrGas. In 2014, intolerant genera decreased with increasing TerrRunoff, TerrGas, and NestGas. $\mathrm{P}$ values of variables that are statistically significant are bolded. Variable names are defined in S1 Table 2. LRT = likelihood ratio test $\chi^{2}$ statistic. $\beta=$ beta estimate of fixed effect.

\begin{tabular}{|c|c|c|c|c|c|c|}
\hline Independent Variable & $\boldsymbol{\beta} \pm \mathbf{S E}$ & LRT $\chi^{2}$ & $p$ value & $\boldsymbol{\beta} \pm \mathbf{S E}$ & LRT $\chi^{2}$ & p value \\
\hline & GLIMPSS & & & WVSCI & & \\
\hline \multicolumn{7}{|l|}{ Year 2013} \\
\hline TerrGas & $-0.008 \pm 0.062$ & 0.020 & 0.888 & $0.012 \pm 0.055$ & 0.053 & 0.818 \\
\hline TerrRunoff & $0.024 \pm 0.044$ & 0.253 & 0.615 & $0.046 \pm 0.039$ & 1.372 & 0.241 \\
\hline NestGas & $0.303 \pm 3.745$ & 0.003 & 0.958 & $-1.028 \pm 3.048$ & 0.112 & 0.738 \\
\hline \multicolumn{7}{|l|}{ Year 2014} \\
\hline TerrGas & $-0.054 \pm 0.046$ & 1.398 & 0.237 & $-0.022 \pm 0.033$ & 0.391 & 0.532 \\
\hline TerrRunoff & $-0.029 \pm 0.035$ & 0.622 & 0.430 & $-0.026 \pm 0.025$ & 1.640 & 0.200 \\
\hline NestGas & $\begin{array}{l}-1.989 \pm 3.270 \\
\text { Density }\end{array}$ & 0.367 & 0.545 & $\begin{array}{l}-0.748 \pm 2.277 \\
\text { Biomass }\end{array}$ & 0.100 & 0.752 \\
\hline \multicolumn{7}{|l|}{ Year 2013} \\
\hline TerrGas & $0.002 \pm 0.002$ & 2.388 & 0.122 & $0.005 \pm 0.003$ & 2.338 & 0.126 \\
\hline TerrRunoff & $0.002 \pm 0.001$ & 2.162 & 0.141 & $0.003 \pm 0.002$ & 0.469 & 0.493 \\
\hline NestGas & $0.044 \pm 0.095$ & 0.219 & 0.640 & $0.215 \pm 0.179$ & 1.495 & 0.221 \\
\hline \multicolumn{7}{|l|}{ Year 2014} \\
\hline TerrGas & $-0.0004 \pm 0.001$ & 0.040 & 0.842 & $-0.00004 \pm 0.002$ & 0.003 & 0.960 \\
\hline TerrRunoff & $-0.0002 \pm 0.001$ & 0.006 & 0.939 & $0.0004 \pm 0.002$ & 0.085 & 0.771 \\
\hline NestGas & $-0.061 \pm 0.098$ & 0.280 & 0.597 & $0.003 \pm 0.144$ & 0.006 & 0.940 \\
\hline & $\underline{\text { EPT Richness }}$ & & & Intolerant Genera & & \\
\hline \multicolumn{7}{|l|}{ Year 2013} \\
\hline TerrGas & $0.003 \pm 0.003^{\mathrm{P}}$ & $0.576^{\mathrm{P}}$ & $0.448^{\mathrm{P}}$ & $0.012 \pm 0.012$ & 1.071 & 0.301 \\
\hline TerrRunoff & $0.017 \pm 0.008$ & 4.381 & 0.036 & $0.007 \pm 0.008$ & 0.789 & 0.375 \\
\hline NestGas & $-0.034 \pm 0.175$ & 0.068 & 0.794 & $0.215 \pm 0.672$ & 0.114 & 0.736 \\
\hline \multicolumn{7}{|l|}{ Year 2014} \\
\hline TerrGas & $-0.010 \pm 0.006$ & 2.572 & 0.109 & $-0.004 \pm 0.002$ & 4.934 & 0.026 \\
\hline TerrRunoff & $-0.003 \pm 0.004$ & 0.681 & 0.409 & $-0.003 \pm 0.001$ & 4.136 & 0.042 \\
\hline NestGas & $-0.424 \pm 0.399$ & 1.056 & 0.304 & $-0.180 \pm 0.112$ & 2.756 & 0.097 \\
\hline
\end{tabular}


Table 4. Association between waterthrush demographic response (i.e., clutch size, number of fledglings, territory length and territory density) and its aquatic prey in spatial generalized linear mixed models. All tests for the relationships between clutch size, number of fledglings, and territory density with aquatic prey metrics were statistically non-significant. Territory length decreased with increasing aquatic prey density and number of intolerant genera in 2013. Results with ${ }^{\mathrm{P}}$ are from a Poisson model. $\mathrm{P}$ values of variables that are statistically significant are bolded. Variable names are defined in S1 Table 2. LRT $=$ likelihood ratio test $\chi^{2}$ statistic. $\beta=$ beta estimate of fixed effect.

\begin{tabular}{|c|c|c|c|c|c|c|}
\hline Dependent Variable & $\boldsymbol{\beta} \pm \mathbf{S E}$ & LRT $\chi^{2}$ & p value & $\boldsymbol{\beta} \pm \mathbf{S E}$ & LRT $\chi^{2}$ & p value \\
\hline & GLIMPSS & & & WVSCI & & \\
\hline \multicolumn{7}{|l|}{ Year 2013} \\
\hline Clutch size & $-0.009 \pm 0.012$ & 0.535 & 0.464 & $-0.004 \pm 0.013$ & 0.100 & 0.751 \\
\hline Fledglings & $-0.004 \pm 0.017$ & 0.056 & 0.812 & $0.003 \pm 0.019$ & 0.831 & 0.362 \\
\hline Territory length & $0.001 \pm 0.001$ & 0.143 & 0.705 & $-0.001 \pm 0.003$ & -0.790 & 1.000 \\
\hline Territory density & $-0.0003 \pm 0.009$ & 0.001 & 0.970 & $-0.002 \pm 0.004^{\mathrm{P}}$ & $0.445^{\mathrm{P}}$ & $0.505^{\mathrm{P}}$ \\
\hline \multicolumn{7}{|l|}{ Year 2014} \\
\hline Clutch size & $0.002 \pm 0.014$ & 0.016 & 0.900 & $0.017 \pm 0.020$ & 0.734 & 0.392 \\
\hline Fledglings & $-0.019 \pm 0.026$ & 0.523 & 0.469 & $-0.007 \pm 0.041$ & 0.033 & 0.859 \\
\hline Territory length & $0.001 \pm 0.001$ & 0.341 & 0.559 & $0.002 \pm 0.003$ & 0.745 & 0.388 \\
\hline \multirow[t]{2}{*}{ Territory density } & $0.001 \pm 0.004^{\mathrm{P}}$ & $0.037^{\mathrm{P}}$ & $0.847^{\mathrm{P}}$ & $0.001 \pm 0.012$ & 0.007 & 0.934 \\
\hline & $\underline{\text { Density }}$ & & & $\underline{\text { Biomass }}$ & & \\
\hline \multicolumn{7}{|l|}{ Year 2013} \\
\hline Clutch size & $-0.00002 \pm 0.001^{\mathrm{P}}$ & $0.001^{\mathrm{P}}$ & $0.975^{\mathrm{P}}$ & $0.00004 \pm 0.0002^{\mathrm{P}}$ & $0.047^{\mathrm{P}}$ & $0.828^{\mathrm{P}}$ \\
\hline Fledglings & $0.0001 \pm 0.001^{\mathrm{P}}$ & $0.009^{\mathrm{P}}$ & $0.924^{\mathrm{P}}$ & $0.0001 \pm 0.001$ & 0.009 & 0.924 \\
\hline Territory length & $-0.001 \pm 0.0003$ & 8.535 & 0.003 & $-0.0003 \pm 0.0002$ & 2.338 & 0.126 \\
\hline Territory density & $-0.0001 \pm 0.001$ & 0.009 & 0.925 & $-0.0001 \pm 0.001$ & 0.086 & 0.769 \\
\hline \multicolumn{7}{|l|}{ Year 2014} \\
\hline Clutch size & $0.0003 \pm 0.0005$ & 0.465 & 0.495 & $0.00001 \pm 0.0001^{\mathrm{P}}$ & $0.012^{\mathrm{P}}$ & $0.912^{\mathrm{P}}$ \\
\hline Fledglings & $0.0005 \pm 0.001$ & 0.811 & 0.368 & $0.0004 \pm 0.0003$ & 2.125 & 0.145 \\
\hline Territory length & $0.00002 \pm 0.0001$ & 0.098 & 0.754 & $0.000002 \pm 0.00004$ & 0.001 & 0.979 \\
\hline \multirow[t]{2}{*}{ Territory density } & $-0.00002 \pm 0.0003$ & 0.014 & 0.907 & $-0.00004 \pm 0.0002$ & 0.048 & 0.826 \\
\hline & EPT Richness & & & Intolerant Genera & & \\
\hline \multicolumn{7}{|l|}{ Year 2013} \\
\hline Clutch size & $-0.005 \pm 0.031^{\mathrm{P}}$ & $0.027^{\mathrm{P}}$ & $0.868^{\mathrm{P}}$ & $-0.079 \pm 0.067$ & 1.380 & 0.240 \\
\hline Fledglings & $0.008 \pm 0.047$ & 0.027 & 0.870 & $-0.007 \pm 0.041^{\mathrm{P}}$ & $0.031^{\mathrm{P}}$ & $0.860^{\mathrm{P}}$ \\
\hline Territory length & $-0.014 \pm 0.017$ & -0.460 & 1.000 & $-0.040 \pm 0.018$ & 4.62 & 0.032 \\
\hline Territory density & $-0.008 \pm 0.023^{\mathrm{P}}$ & $0.162^{\mathrm{P}}$ & $0.687^{\mathrm{P}}$ & $-0.001 \pm 0.049$ & 0.001 & 0.981 \\
\hline \multicolumn{7}{|l|}{ Year 2014} \\
\hline Clutch size & $0.019 \pm 0.041^{\mathrm{P}}$ & $0.213^{\mathrm{P}}$ & $0.645^{\mathrm{P}}$ & $0.020 \pm 0.074$ & 0.072 & 0.788 \\
\hline Fledglings & $0.076 \pm 0.158$ & 0.233 & 0.629 & $-0.054 \pm 0.115$ & 0.218 & 0.641 \\
\hline Territory length & $0.023 \pm 0.014$ & 2.486 & 0.115 & $0.010 \pm 0.007$ & 1.864 & 0.172 \\
\hline Territory density & $0.003 \pm 0.051$ & 0.004 & 0.947 & $-0.001 \pm 0.038$ & 0.0003 & 0.985 \\
\hline
\end{tabular}


Table 5. Year 2013 and 2014 AICc model results of 7 a priori nest survival models with aquatic prey covariates using Program MARK. Of 7 a priori nest survival models, 6 different models were supported $(\triangle \mathrm{AICc}<2)$ in 2013 and 2014 with the null base model having the most weight in both years $(\mathrm{wi}=0.25,0.28) . \Delta \mathrm{AICc}=$ distance from the top model, and $w_{\mathrm{i}}=$ Akaike weight. Variable names are defined in Appendix Table 2.

\begin{tabular}{lccc}
\hline Model & AICc & $\boldsymbol{\Delta A I C c}$ & $\boldsymbol{w i}$ \\
\hline Year 2013 & & & \\
Rain + NestAge + TT + TerrRunoff & 152.33 & 0 & 0.25 \\
Rain + NestAge + TT + TerrRunoff + EPT Richness & 153.12 & 0.79 & 0.17 \\
Rain + NestAge + TT + TerrRunoff + WVSCI & 153.36 & 1.04 & 0.15 \\
Rain + NestAge + TT + TerrRunoff + Density & 153.51 & 1.18 & 0.14 \\
Rain + NestAge + TT + TerrRunoff + GLIMPSS & 154.00 & 1.67 & 0.11 \\
Rain + NestAge + TT + TerrRunoff + Biomass & 154.30 & 1.97 & 0.09 \\
Rain + NestAge + TT + TerrRunoff + Intolerant Genera & 154.35 & 2.02 & 0.09 \\
& & & \\
Year 2014 & & & \\
\hline Rain + NestAge + TT + TerrRunoff & 164.56 & 0 & 0.28 \\
Rain + NestAge + TT + TerrRunoff + GLIMPSS & 165.39 & 0.83 & 0.18 \\
Rain + NestAge + TT + TerrRunoff + EPT Richness & 166.35 & 1.79 & 0.11 \\
Rain + NestAge + TT + TerrRunoff + WVSCI & 166.36 & 1.80 & 0.11 \\
Rain + NestAge + TT + TerrRunoff + Intolerant Genera & 166.47 & 1.92 & 0.11 \\
Rain + NestAge + TT + TerrRunoff + Density & 166.48 & 1.92 & 0.11 \\
Rain + NestAge + TT + TerrRunoff + Biomass & 166.59 & 2.03 & 0.10 \\
\hline
\end{tabular}


Table 6. Annual waterthrush nest survival covariates found in the top supported ( $\triangle \mathrm{AICc}<2, \mathrm{n}=$ 6) and unsupported $(n=1)$ AICc models based on regression coefficients, standard error (SE), and $85 \%$ confidence intervals. In the null base model Rain had positive influence on daily survival rate (DSR) in 2013 and 2014, while TerrRunoff had negative influence on nest survival in 2014. Significant covariates with non-overlapping confidence intervals are bolded. Covariates included in every model to account for their influence (i.e., Rain, NestAge, TT, and TerrRunoff; [28]) have model-averaged regression coefficients and unconditional SEs. Variable names are defined in S1 Table 2.

\begin{tabular}{llll}
\hline Parameter & Estimate & SE & Confidence Interval \\
\hline Year 2013 & & & \\
Rain & $\mathbf{0 . 4 1 5}$ & $\mathbf{0 . 1 9 1}$ & $\mathbf{0 . 1 4 0 , 0 . 6 9 0}$ \\
TerrRunoff & -0.001 & 0.002 & $-0.005,0.002$ \\
NestAge & -0.052 & 0.043 & $-0.113,0.009$ \\
TT & 0.077 & 0.155 & $-0.147,0.300$ \\
EPT Richness & -0.116 & 0.103 & $-0.317,0.085$ \\
Density & -0.002 & 0.002 & $-0.005,0.002$ \\
Biomass & -0.0002 & 0.001 & $-0.002,0.001$ \\
WVSCI & -0.018 & 0.018 & $-0.054,0.018$ \\
GLIMPSS & -0.009 & 0.015 & $-0.037,0.020$ \\
Not in top supported: & & & \\
Intolerant Genera & -0.014 & 0.099 & $-0.208,0.180$ \\
& & & \\
Year 2014 & & & \\
Rain & $\mathbf{0 . 3 8 0}$ & $\mathbf{0 . 1 8 3}$ & $\mathbf{0 . 1 1 8 , 0 . 6 4 3}$ \\
TerrRunoff & $\mathbf{- 0 . 0 0 5}$ & $\mathbf{0 . 0 0 2}$ & $\mathbf{- 0 . 0 0 8 , - 0 . 0 0 2}$ \\
NestAge & 0.016 & 0.047 & $-0.052,0.084$ \\
TT & -0.022 & 0.080 & $-0.137,0.094$ \\
EPT Richness & -0.052 & 0.104 & $-0.255,0.151$ \\
Density & 0.0001 & 0.0004 & $-0.001,0.001$ \\
WVSCI & 0.012 & 0.023 & $-0.034,0.057$ \\
GLIMPSS & 0.016 & 0.015 & $-0.013,0.045$ \\
Intolerant Genera & 0.027 & 0.076 & $-0.121,0.175$ \\
Not in top supported: & & & \\
Biomass & 0.00004 & 0.0003 & $-0.001,0.001$ \\
\hline
\end{tabular}




\section{FIGURES}

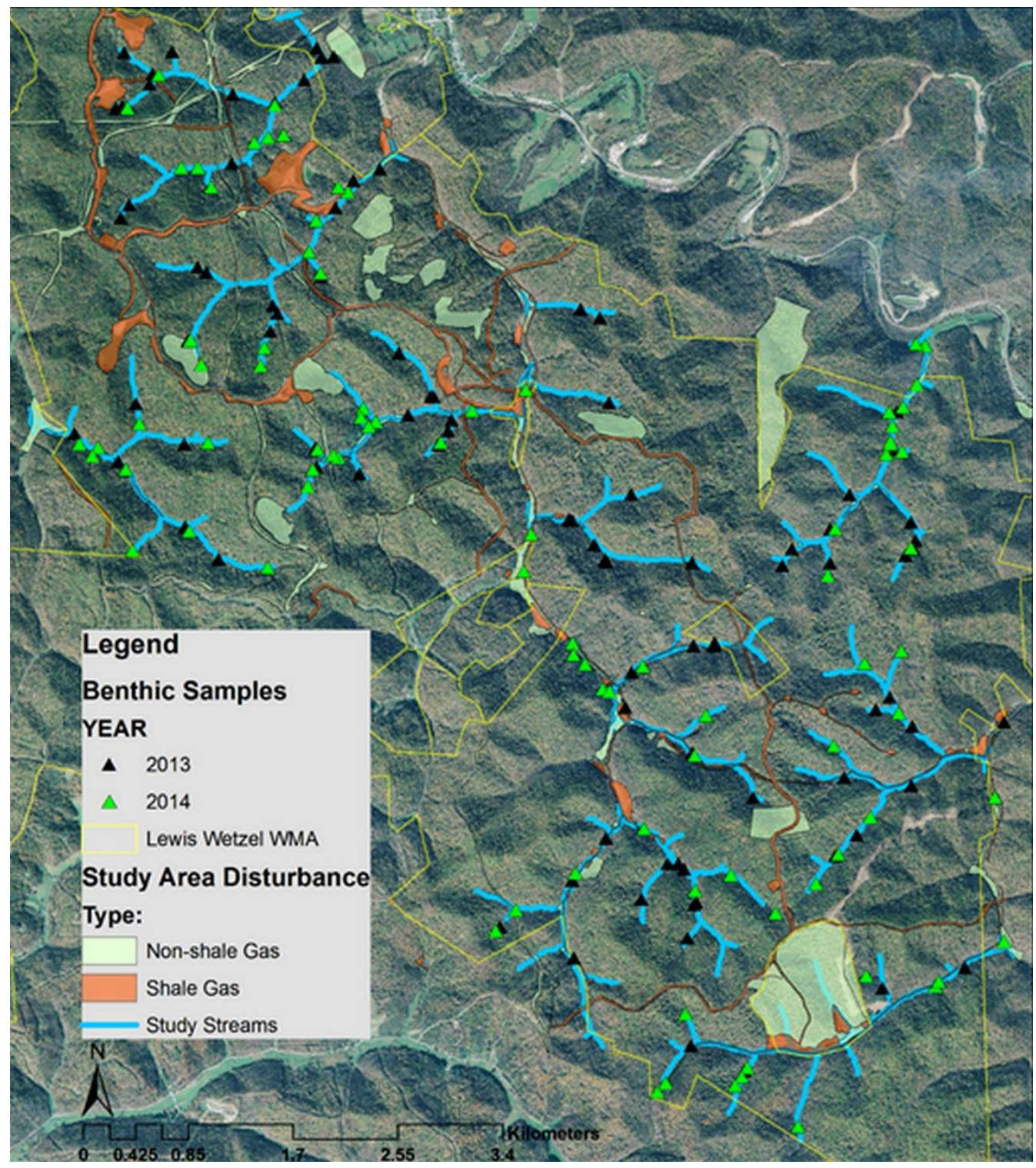

Fig 1. Location of study streams, benthic sampling locations, and stream reaches disturbed by shale gas development during 2013-2014 on the Lewis Wetzel Wildlife Management Area in northwestern West Virginia. The larger light green patches of non-shale gas disturbance are primarily timber harvests with partial canopy removal. 


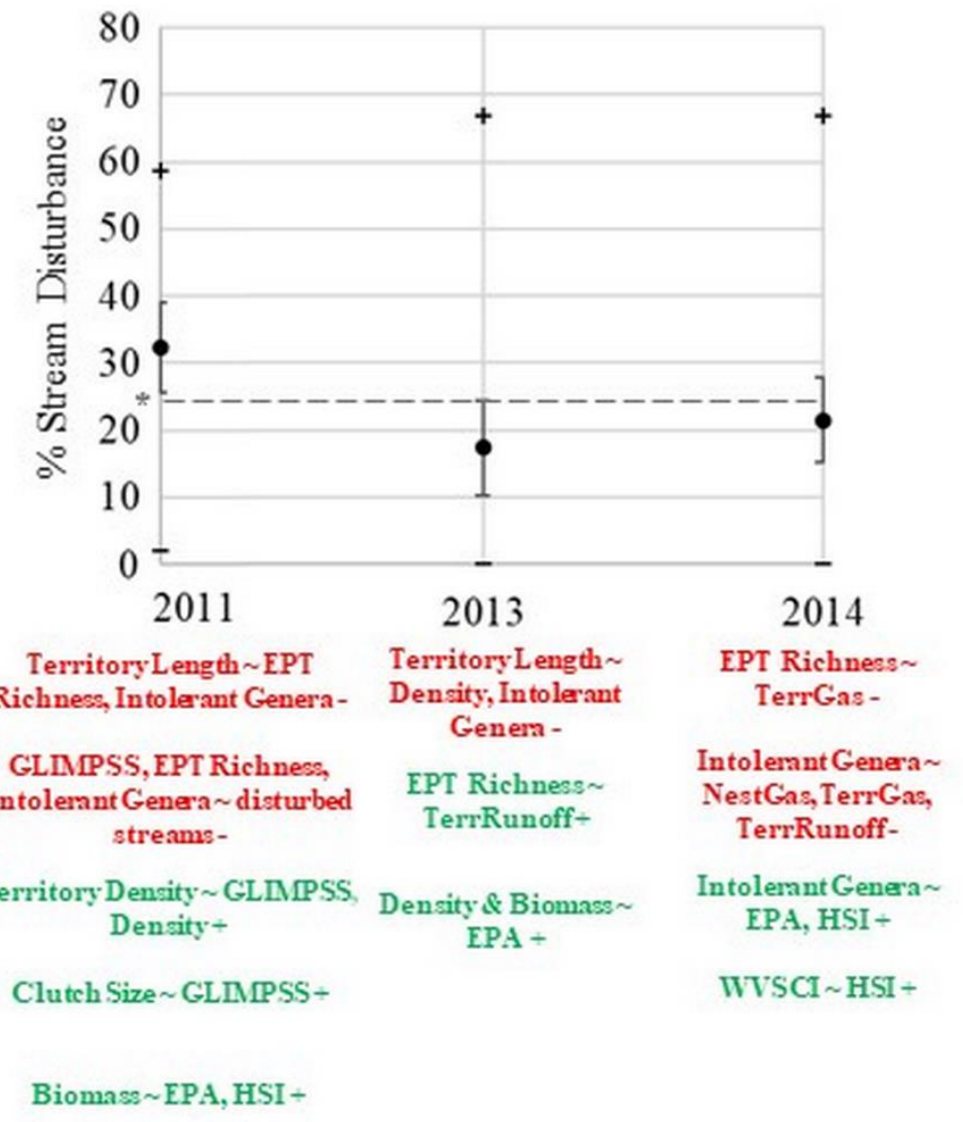

Fig 2. The average amount of shale gas related disturbance \pm standard error (SE) and range (black + and -) on headwater streams $(\mathrm{n}=14)$, in addition to statistically significant positive (green) and negative (red) demographic vs. aquatic prey responses over a six year period (20092011, 2013-2015) at Lewis Wetzel Wildlife Management Area (LWWMA) located in northwestern West Virginia. Nest survival results are not displayed. The bracketed line represents a hypothetical, conservative disturbance threshold $(\geq 25 \%)$ at which waterthrush demography may be more negatively affected based on the strongest and second strongest demographic responses to aquatic prey in 2011 and 2014. Variable names are defined in S1 Table 2. 


\section{APPENDIX}

Appendix Table 1. Annual shale gas disturbance activity at Lewis Wetzel Wildlife Management Area study streams in 2011, 2013, and 2014. Our research season for several ridgetop and stream research projects occurred relatively from April-July of each year, with time periods referring to this research season range. $\mathrm{R}=$ new ridgetop activity, $\mathrm{S}=$ new stream activity (streamside road activity or stream sedimentation), $\mathrm{W}=$ new well pad activity, $\mathrm{P}=$ parts considered disturbed from activity in previous years, $\mathrm{N}=$ no new activity. Superscripts $\mathrm{B}=$ Brief or intermittent activity period(s), $\mathrm{E}=$ Early in waterthrush breeding season, $\mathrm{L}=$ Late in waterthrush breeding season, and $\mathrm{C}=$ continuous activity.

As a result of previous and newly started ridgetop activity in 2010-2011 the whole downstream network of some streams became at risk for sedimentation and surface runoff for the remainder of the study. In 2013, construction started on a new compressor station located before reaching Snake North, meaning all headwater stream bases emptying into Buffalo Run north of this site was near heavy truck traffic from 2013-2014. In late 2013 (June-July), construction started on a new well pad at the base of Owl Run which was previously a homestead with all drilling completed by July-August 2014. Well pad construction started on the ridgetops above Olive Run in 2013 with wells not becoming active until 2014; otherwise the stream remained mostly undisturbed except for maintenance of a forested track for pump jack accessibility. Activity at Buffalo East and West Run was mainly concentrated at their confluence where an active shale gas pad was located, especially in 2013-2014 where disturbance was otherwise minimal. In 2013-2014, Wyatt and especially Sees Run were subject to sedimentation slips into the stream from compromised erosional control below well pads or access roads, especially during any rainfall event; Wyatt Run had a new unsodded pipeline connector that caused brief sedimentation early in the research season.

In 2014, activity at Slabcamp Run increased from the previous year from a well pad being redrilled but was commonly subject to streamside disturbance. Sees Run had increased sedimentation in 2014 from an active access road hillside partially collapsing and filling a stream valley. In summary, 2013 disturbances were just starting to occur but did not necessarily directly affect the streams during the time waterthrush were sampled in 2013, and in 2014 shale gas activity peaked again, particularly at Slabcamp Run, but did not achieve 2011 levels of activity. 


\begin{tabular}{|c|c|c|c|}
\hline Study Streams & 2011 & 2013 & 2014 \\
\hline Buffalo East Run & $\mathrm{P}, \mathrm{S}^{\mathrm{B}}$ & $\mathrm{P}, \mathrm{W}^{\mathrm{EB}}$ & $\mathrm{P}, \mathrm{W}^{\mathrm{B}}$ \\
\hline Buffalo West Run & $\mathrm{P}, \mathrm{S}^{\mathrm{B}}$ & $\mathrm{P}, \mathrm{W}^{\mathrm{EB}}$ & $\mathrm{P}, \mathrm{W}^{\mathrm{B}}$ \\
\hline Carpenter Run & $\mathrm{N}$ & $\mathrm{N}$ & $\mathrm{N}$ \\
\hline Hiles Run & $\mathrm{N}$ & $\mathrm{N}$ & $\mathrm{N}$ \\
\hline Huss Pen Run & $\mathrm{N}$ & $\mathrm{N}$ & $\mathrm{N}$ \\
\hline Megans Run & $\mathrm{S}^{\mathrm{B}}, \mathrm{R}^{\mathrm{C}}$ & $\mathrm{P}, \mathrm{R}^{\mathrm{C}}$ & $\mathrm{P}, \mathrm{R}^{\mathrm{C}}, \mathrm{W}$ \\
\hline Nettles Run & $\mathrm{P}, \mathrm{R}^{\mathrm{L}}$ & $\mathrm{P}, \mathrm{S}^{\mathrm{B}}$ & $\mathrm{P}$ \\
\hline Olive Run & $\mathrm{P}, \mathrm{W}, \mathrm{S}$ & $\mathrm{P}, \mathrm{S}^{\mathrm{B}}, \mathrm{R}$ & $\mathrm{P}, \mathrm{S}^{\mathrm{B}}, \mathrm{R}, \mathrm{W}$ \\
\hline Owl Run & $\mathrm{P}, \mathrm{S}$ & $\mathrm{P}, \mathrm{W}^{\mathrm{L}}$ & $\mathrm{P}, \mathrm{W}^{\mathrm{C}}$ \\
\hline Sees Run & $\mathrm{P}, \mathrm{R}^{\mathrm{C}}, \mathrm{W}, \mathrm{S}$ & $\mathrm{P}, \mathrm{R}^{\mathrm{C}}, \mathrm{S}^{\mathrm{C}}, \mathrm{W}$ & $\mathrm{P}, \mathrm{R}^{\mathrm{C}}, \mathrm{S}^{\mathrm{C}}$ \\
\hline Slabcamp Run & $\mathrm{P}, \mathrm{W}, \mathrm{S}$ & $\mathrm{P}, \mathrm{W}, \mathrm{S}$ & $\mathrm{P}, \mathrm{R}^{\mathrm{L}}, \mathrm{W}^{\mathrm{C}}, \mathrm{S}^{\mathrm{C}}$ \\
\hline Snake North Run & $\mathrm{P}, \mathrm{S}$ & $\mathrm{P}$ & $\mathrm{P}$ \\
\hline Snake South Run & $\mathrm{P}, \mathrm{S}$ & $\mathrm{P}$ & $\mathrm{P}$ \\
\hline Wyatt Run & $\mathrm{R}^{\mathrm{C}}, \mathrm{W}$ & $\mathrm{P}, \mathrm{R}^{\mathrm{C}}, \mathrm{S}^{\mathrm{EB}}, \mathrm{W}$ & $\mathrm{P}, \mathrm{R}^{\mathrm{C}}, \mathrm{S}^{\mathrm{B}}, \mathrm{W}$ \\
\hline $\begin{array}{l}\text { Nest/Stream } \\
\text { Sampling Dates }\end{array}$ & May 6-9 & May 22 - July 28 & June 16 - July 6 \\
\hline
\end{tabular}


Appendix Table 2. Variables used to evaluate the demographic response and nest survival of Louisiana Waterthrush to aquatic prey and shale gas development. Nest survival is daily survival rate (DSR) over a 29-day nesting period. We evaluated Louisiana Waterthrush demographic response to aquatic prey and shale gas development using spatial generalized linear mixed models (SGLMMs).

\begin{tabular}{lll}
\hline Variable of interest & Notation & Analysis \\
\hline Nest Age & NestAge & Nest Survival \\
Time within-season (quadratic time trend) & TT & Nest Survival \\
Average Daily Rainfall & Rain & Nest Survival \\
Percent of Stream Disturbed by Shale Gas & StreamGas & Description only \\
Percent of Stream with Potential Contaminant & StreamRunoff & Description only \\
Runoff & NestGas & SGLMM \\
$\begin{array}{l}\text { Shale Gas Nest Disturbance } \\
\quad \text { undisturbed=0, disturbed=1) }\end{array}$ & TerrGas & SGLMM \\
Percent of Territory Disturbed by Shale Gas & TerrRunoff & Nest Survival, SGLMM \\
Percent of Territory with Potential Contaminant & & \\
Runoff & Clutch Size & SGLMM \\
Clutch Size & Fledglings & SGLMM \\
Number of Fledglings & Territory Length & SGLMM \\
Territory Length & Territory Density & SGLMM \\
Territory Density & WVSCI & Nest Survival, SGLMM \\
West Virginia Stream Condition Index & GLIMPSS & Nest Survival, SGLMM \\
Genus Level Index of Most Probable Stream & & \\
Status & Biomass & Nest Survival, SGLMM \\
Aquatic Prey Biomass & Density & Nest Survival, SGLMM \\
Aquatic Prey Density & Intolerant Genera & Nest Survival, SGLMM \\
Number of Intolerant Genera & EPT Richness & Nest Survival, SGLMM \\
Ephemeroptera, Plecoptera, Trichoptera (EPT) & & \\
Richness & HSI & SGLMM \\
Habitat Suitability Index (HSI) score & EPA & SGLMM \\
Environmental Protection Agency (EPA) Rapid \\
Bioassessment index & & \\
\hline
\end{tabular}




\title{
CHAPTER 5. SPATIAL STREAM MODELING OF LOUISIANA WATERTHRUSH (PARKESIA MOTACILLA) FORAGING SUBSTRATE AND AQUATIC PREY IN A WATERSHED UNDERGOING SHALE GAS DEVELOPMENT.
}

Chapter 5 is written in style of the peer-reviewed journal Food Webs.

\begin{abstract}
We demonstrate use of spatial stream network models (SSNMs) for the first time on an aquaticterrestrial organism, the Louisiana Waterthrush (Parkesia motacilla), to explore relationships between this bioindicator songbird and stream monitoring data in an area undergoing shale gas development. SSNMs allowed us to account for spatial autocorrelation inherent to stream monitoring data and properties that traditional modeling approaches cannot capture to elucidate factors that affect waterthrush foraging locations. We monitored waterthrush along $58.1 \mathrm{~km}$ of 1st- and 2nd-order headwater stream tributaries $(n=14)$ in northwestern West Virginia over a two year period (2013-2014), sampled benthic macroinvertebrates in waterthrush territories, and collected wetted perimeter stream channel and water chemistry data. Spatial models outperformed traditional regression models and made a statistical difference in whether stream covariates of interest were considered relatable to waterthrush foraging. Waterthrush foraging probability index (FPI) was greater in areas where family (West Virginia Stream Condition Index, WVSCI) and genus-level (Genus Level Index of Most Probable Stream Status, GLIMPSS) multi-metric indices of biotic stream integrity were higher. Waterthrush were found foraging both where stream locations were hydrologically connected and unconnected by stream flow. These stream foraging locations were relatively closer to undisturbed headwaters where WVSCI and GLIMPSS were predicted to be highest. While there was no significant relationship between FPI and shale gas land use on a catchment area scale, further information on bioaccumulation of contaminants in benthic macroinvertebrates of shale gas disturbed areas is needed before establishing the extent to which waterthrush foraging may be affected by shale gas development.
\end{abstract}

\section{INTRODUCTION}

A natural property of ecological data is autocorrelation where nearby objects are more likely to exhibit the same patterns for reasons not due to chance (Legendre, 1993). Since the advent of classical statistics (e.g. Fisher, 1935), many spatial models were developed that can account for the non-independence of ecological observations. However, spatial models are not 
created equally in handling violations of statistical assumptions (Dormann, 2007) and are designed mainly for terrestrial ecology (e.g. Fortin and Dale, 2005). Large, long-term datasets are being collected globally on streams as part of biomonitoring efforts to determine environmental conditions and change (Buss et al., 2015), making it increasingly important to choose appropriate statistical methods for valid assessment of stream network data (Rushworth et al., 2015). Spatial models that incorporate the unique properties of streams as dendritic networks with restricted, directed movement of resources through the landscape would be more ideal than the current trend of adopting terrestrial modeling techniques to streams (Issak et al., 2014). Recently, a series of spatial stream network models (SSNMs) were created for benthic organisms that account for stream properties (e.g. branching, flow direction and connectivity, confluences) and allow analysis of typical environmental monitoring data via stream-based spatial-weighting and autocovariance structures (Cressie et al., 2006; Ver Hoef et al., 2006; Peterson and Ver Hoef, 2010). Spatial autocorrelation is a confounding source of variability for covariates of interest on a stream network, where dismissing or ignoring it can lead to important information being discarded or lack of statistical inference (Legendre, 1993).

Wildlife communities in the Appalachian region, particularly in forested freshwater ecosystems (Dunscomb et al., 2014; Evans and Kiesecker, 2014), are threatened by unconventional shale gas development (Farwell et al. 2016; Frantz et al. 2018a). Shale gas wells in the Marcellus shale region are commonly within 100-300 m of stream channels, and often even closer to headwater drainage areas (Entrekin et al., 2011). Headwater streams are the critical sources of water, sediment, organic matter, and nutrients for the rest of the system (Gomi et al., 2002), and are therefore vital for ecological integrity (Freeman et al., 2007). Furthermore, headwater streams, despite their predominance of drainage area and total stream length, are largely overlooked for protection or regulation contrary to their potential effect on downstream reaches and aquatic life (MacDonald and Coe, 2007).

The Louisiana Waterthrush (Parkesia motacilla), hereafter waterthrush, is an established biological indicator of aquatic stream integrity (O'Connell et al., 2000; Mulvihill et al., 2008) and species of conservation concern (USFWS, 2008). Waterthrush feed primarily on benthic macroinvertebrates (Mattsson et al., 2009) and breed along forested headwater streams, reaching some of their highest abundances in the Marcellus shale region (Sauer et al., 2014). Over a sixyear period, shale gas disturbance negatively affected waterthrush riparian habitat quality, nest 
productivity, and nest survival suggesting potential long-term population consequences (Frantz et al., 2018a). Given the propensity for shale gas in the Appalachian region to be developed on ridgetops near headwater streams (Cook et al., 2015), there is a need to evaluate how downstream communities, both aquatic and terrestrial, can be affected by potential surface water pollution (Entrekin et al., 2011). In particular, the food webs along the aquatic-terrestrial interface may be indirectly influenced by surface water contamination depending on where the organisms reside or forage along the stream network. Waterthrush are known to compensate for the loss of food resources by increasing their territory sizes and foraging in nearby undisturbed areas (Mulvihill et al., 2008; Frantz et al., 2018a). As such, a more detailed study of headwater streams and foraging of a stream-dependent organism would shed light on whether shale gas development is influencing food resources, especially if we can account for the spatial influence of stream properties.

In this study, we tested SSNMs on an aquatic-terrestrial organism to evaluate their utility in quantifying characteristics of waterthrush foraging areas based on 1) water chemistry, 2) a waterthrush foraging score based on stream channel data, 3) shale gas land use based on reach contributing area (i.e. catchment area), and 4) multi-metric indices of biotic stream integrity at the family and genus level. We hypothesized that waterthrush foraging would more likely occur in areas with higher biotic stream integrity and with higher abundance of pollution sensitive aquatic prey such as Ephemeroptera, Plecoptera, and Trichoptera (EPT) believed to be the waterthrush's preferred prey items (Mattsson et al., 2009). We also hypothesized that waterthrush foraging activity would be negatively related to areas of higher shale gas land use and water chemistry (i.e. higher conductivity, total dissolved solids, $\mathrm{pH}$, and water temperature) as surface water pollution (e.g. Latta et al., 2015) and decreased riparian habitat quality (e.g. Wood et al., 2016; Frantz et al. 2018b) from shale gas development may negatively alter aquatic prey communities (Johnson et al., 2015).

\section{METHODS}

\section{Study Area}

We studied waterthrush along $58.1 \mathrm{~km}$ of 1st- and 2nd-order headwater stream tributaries $(\mathrm{n}=14)$ at Lewis Wetzel Wildlife Management Area (LWWMA) located in northwestern West Virginia (Fig. 1). Our waterthrush foraging study occurred in 2013 and 2014 as part of a larger waterthrush demography study over a six year period (Frantz et al. 2018a, 2018b). The study 
area lies within the Permian Hills subdivision of the Western Allegheny Plateau Ecoregion, an area of deeply dissected topography and relatively continuous Appalachian Oak and MixedMesophytic Forest (Woods et al., 1999) with elevations of 221-480 m. It overlays the MarcellusUtica shale region and occurs where waterthrush reach their highest densities within the central Appalachians (Sauer et al., 2014).

Prior to our study, LWWMA was $95 \%$ forested with the first unconventional gas well development and activity, hereafter shale gas, starting in 2007 (Farwell et al., 2016). Shale gas at our study area and within the surrounding region since then has rapidly increased (WVGES, 2015). By 2015, LWWMA was $91 \%$ forested with forest loss primarily due to shale gas development (Farwell et al., 2016). Over the six year study period, gas well development activities included building of conventional and Marcellus well pads, timbering for yet unbuilt well pads, the expansion of existing road and pipeline infrastructure, and the construction of new infrastructure. Between the 2010 and 2011 breeding seasons, shale gas development activities began to increase on the ridgetops (Frantz et al., 2018a, 2018b). Therefore during the waterthrush foraging study in 2013-2014 the whole downstream network of some streams became disturbed by sedimentation and surface runoff from ridgetop activity (Frantz et al., 2018a, 2018b).

\section{Mapping of Streams and Disturbance}

Within a Geographic Information System (GIS), we used a sequence of leaf-on and leafoff aerial (e.g. NAIP) imagery and extensive ground-truthing to manually digitize areas of disturbance within the study area (see Frantz et al., 2018a for full description). All disturbances were classified as shale gas related (e.g. well pads and associated road and pipeline infrastructure) or as being unrelated or pre-existing (e.g. forest roads, recent even-aged timber harvests, and various types of existing clearings). We classified a few conventional impacts (i.e., stream-side vertical pump jacks) as related to shale gas development because their pads were managed in conjunction with nearby shale gas infrastructure and because their targeted formation, even though they remained shallow after development, was listed as Marcellus (WVGES, 2015). Gas well records (WVDEP, 2015) were used to verify target shale formations, drilling status, and start dates for all well disturbances. Lengths of each study stream (average length $4.1 \pm 0.54 \mathrm{~km}$, range $0.95-7.4 \mathrm{~km}$ ) were calculated in GIS using a 3D functional surface length tool and a $3 \mathrm{~m}$ resolution digital elevation model to account for topography, and study streams were defined to have a drainage basin of 9 hectares (i.e. <100 ha, Swanson et al., 1998) 
to delineate the uppermost headwater reaches (24 k scale or higher resolution; e.g. Strager et al., 2009).

\section{Waterthrush Foraging Observations}

We mapped waterthrush territories along 14 streams with varying degrees of shale gas disturbance in 2013-2014 from early April to late June each year. Standardized territory mapping (Robbins, 1970; Bibby et al., 1992) included $\geq 6$ (average $11.5 \pm 0.6$ ) visits along each stream reach, with visits preceding peak incubation initiation, and visits within 4 hours after sunrise to ensure high rates of detection (Mattsson and Cooper, 2006). While delineating territories, observations were made whether waterthrush were foraging or not (e.g. singing, territorial dispute, flying) and mapped with a WAAS-enabled Garmin 60CSX GPS unit with accuracy $\leq 5 \mathrm{~m}$. We recorded observations of both male and female waterthrush since neither foraging rate nor microhabitat use differs between the sexes (Robinson, 1990). When a waterthrush was detected, we only approached close enough for observation without perceptibly influencing behavior (Ritz and Rodewald, 2010). Waterthrush are just as likely to be "loafing" as they are foraging in a given location (Robinson, 1990). Therefore any observation where a waterthrush was observed to flush when first encountered was categorized as non-foraging, although we recognize the possibility that waterthrush may have flushed mid-forage. We varied the order and time of day we monitored study streams to prevent any time of day effects (Shield, 1977), so waterthrush observations overall should not be influenced by our presence nor time of day. We concurrently searched for and monitored waterthrush nests during these visits.

\section{Wetted Perimeter Data}

To evaluate in-stream riparian habitat quality for foraging waterthrush, we collected several stream channel metrics every $50 \mathrm{~m}$ along each stream using a wetted perimeter protocol designed to determine optimal waterthrush foraging substrate locations (Master et al., 2005). Sampling locations were assigned in GIS prior to entering the field using Linear Referencing, which created routes along the stream that accounted for stream bend. Points were not sampled that fell on private property ( $n=58$ points $)$, on completely dry sections of streams $(n=30$ points), or stream sections with water flow too high for waterthrush ( $n=5$ points). This resulted in sampling of 1121 points among the fourteen headwater streams. Wetted perimeter data were collected in 2013 for Olive Run and Wyatt Run, and for the remainder of the streams in 2015. The data were collected in late June-July to be representative of year-round flow conditions. 
At each 50m sampling point, a small-link metal chain was draped across the stream at points where water during a high flow event at each edge of the stream meets the bank. This resulted with the ends of the chain curving up each side of the stream bank and stopping at the uppermost portion at which water could flow, creating a "U-shape" with the chain. The chain conformed to all irregularities in the stream channel (e.g. rocks, logs) comprising the bottom substrate, including those sticking up above water. Using a meter tape, the lengths of chain that were above water and stretched over rocks or logs were measured (in meters) as an exposed point measurement with the number of exposed points tallied. The chain was then removed from the water and stretched to full length, with the distance between the two points that marked the edges of the stream measured. The full chain length was a wetted perimeter measurement, where a wet distance could be calculated from subtracting the exposed distance. We measured stream depth (in $\mathrm{cm}$ ) at five regularly spaced intervals across the same start and end points of the chain: water's edge on both sides, a quarter of the way in from middle on both sides, and middle of stream. A waterthrush foraging substrate score was calculated by taking the wetted perimeter value and dividing it by the average stream depth at that point (Mulvihill and Latta, Unpublished results). A higher wetted perimeter to mean depth ratio presumably indicated relatively better foraging substrate, and smaller values poorer foraging substrate (Mulvihill and Latta, Personal communication). At every $50 \mathrm{~m}$ sampling point, we also collected water chemistry data in the form of $\mathrm{pH}$, total dissolved solids (TDS, g/L), conductivity $(\mu \mathrm{S} / \mathrm{cm})$, and water temperature $\left({ }^{\circ} \mathrm{C}\right)$ with Hannah Instruments and an Oakton PC 10 Series multi-parameter probes.

\section{Benthic Macroinvertebrate Sampling}

We sampled macroinvertebrates in riffle habitat adjacent to nest site locations using a Surber sampler in 2013 and 2014. Nest site samples $(n=178)$ were collected shortly after the nest fledged, failed, or had been abandoned (from mid-June to late July) to assess relative prey availability at the time the site was used by waterthrush. Additional macroinvertebrate samples were collected from waterthrush foraging locations $(n=65$; average $165 \pm 12.6 \mathrm{~m}$ from nest site locations) during two timed bouts, one each in May and June. The two bouts were later pooled into one sample after we found no taxa differences between the time periods. During sample collection, we scrubbed rock substrates and disturbed sediment $3-\mathrm{cm}$ below the stream bed within the Surber frame for a total of 3 minutes (Mattsson and Cooper, 2006). We separated 
macroinvertebrates from detritus for each sample in the field and stored them in $95 \%$ or $70 \%$ ethanol.

Macroinvertebrates in benthic samples were sorted, counted, identified to genus level, and body lengths measured by an environmental scientist certified by the Society of Freshwater Scientists in macroinvertebrate identification. For each sample, we calculated several commonly used community metrics both at the family (e.g. family taxa richness) and genus (e.g. genus taxa richness) levels of resolution. These metrics were used to calculate multimetric indices of biotic integrity, one at the family level (West Virginia Stream Condition Index, WVSCI; Gerritsen et al., 2000) and one at the genus level (Genus Level Index of Most Probable Stream Status; GLIMPSS, version CF), which does not require the genus-level identification of Chironomidae (Pond et al., 2013).

\section{GIS Data Preparation and Stream Formatting}

In ArcMap GIS 10.2.2 (ESRI, Redlands, CA), foraging observations and macroinvertebrate sampling points were mapped along with the wetted perimeter point grid plotted along the headwater streams. Waterthrush typically travel no further than $60 \mathrm{~m}$ away from their linear territories (Mattsson and Cooper, 2009) and will forage off stream more often as the breeding season progresses (Robinson, 1990). Therefore we placed a $60 \mathrm{~m}$ buffer around each wetted perimeter sampling point. Using a spatial join, all foraging and non-foraging observations within those buffers were assigned to the wetted perimeter grid. Metrics from macroinvertebrate sampling points were merged into a single new output if they fell within a $60 \mathrm{~m}$ buffer, and then averaged if more than one point fell within a buffer. Any wetted perimeter points that did not have any foraging or non-foraging observations nor macroinvertebrate data were removed from our response variable. A foraging probability index (FPI, 0-100\%), our response variable, was derived from the number of foraging observations divided by the total observations (foraging and non-foraging) for the $60 \mathrm{~m}$ area. Calculating FPI in this manner gave a mostly continuous index since a $60 \mathrm{~m}$ buffer overlapped the $50 \mathrm{~m}$ wetted perimeter points, meaning observations and benthic samples could be assigned to more than one nearby wetted perimeter sample point. We defined FPI as a relative index that gauged where waterthrush were most likely to be found foraging. Rather than assume any areas with no waterthrush observations (i.e. points that we did not use for FPI) were non-optimal foraging areas, we reserved these wetted perimeter points for testing model prediction. 
Gas variables (\% Marcellus Pad, \% Gas Pad (unconventional and conventional), \% Gas Infrastructure) were created first as reach contributing area (RCA; i.e. catchment area scale) attributes using the STARS (Spatial Tools for the Analysis of River Systems) toolbox (Peterson and Ver Hoef 2014) in ArcMap GIS as a means of calculating land use. The Accumulate Values Downstream and Watershed Attributes tools were used to create and assign the gas RCA values to sampled points on the stream. To get a percentage contribution of each gas variable, we divided the value assigned to each stream sample by the total watershed area representative of all segment watersheds encompassing the study streams $\left(33.4 \mathrm{~km}^{2}\right.$ total). Percent (\%) Marcellus Pad included three retention ponds that may pose the same concerns to surface water contamination. While we included a metric that had conventional gas well pads (\% Gas Pad), all major landscape alterations, development, and activity seen during the duration of our study would not have occurred without shale gas at our study site (Farwell et al., 2016). Percent (\%) Gas Infrastructure included all well pads, pipelines, retention ponds, and access roads leading to well sites.

Stream segment vectors were simplified to avoid converging streams and have minimum pseudonodes (Peterson and Ver Hoef, 2014). In the original study design, parts of Buffalo Run that the headwater streams emptied into were included as part of the boundaries of each study stream since many times a waterthrush territory would border or include part of Buffalo Run (Frantz et al., 2018a). These sections of Buffalo Run were removed from each study stream since each stream can only have one outlet in SSNMs. Stream segments were also extensively preprocessed to ensure they were digitized in a downward flow direction and any network topology errors removed that may interfere with spatial weighting calculations.

\section{Model Spatial Distance and Weight Preprocessing}

All model analyses were done using the Spatial Stream Network (SSN) package (Ver Hoef et al., 2014) in R (R Core Team, 2014) and SSN object preprocessing for import in ArcGIS using the STARS toolbox (Peterson and Ver Hoef, 2014). In order to fit spatial models using spatial weights, we first determined stream segment proportional influence and additive function values using STARS. Stream segment proportional influence was based on RCA for each line segment watershed area (Peterson and Ver Hoef, 2010). Spatial weight was based on RCA since it serves as a surrogate for flow volume (Friedan et al., 2014). These values were contributed in $\mathrm{R}$ to create the spatial weights (Ver Hoef et al., 2014). Upstream distance between a stream 
outlet and each stream segment and sample point were calculated with STARS (Peterson and Ver Hoef, 2014) to be used in R for calculating hydrologic flow-connected and -unconnected distances (see Ver Hoef and Peterson, 2010) in R. The processed dataset was stored and displayed as a Landscape Network (LSN) that included all spatial and geographic relationships for the streams and stream dataset (Theobald et al., 2006; Peterson and Ver Hoef, 2014).

\section{Model Variables, Covariance, Selection, and Evaluation}

We initially reviewed all data graphically and through diagnostic tools to test assumptions of normality and applied data transformations if it improved approximation to normality (Zuur et al., 2010). Torgegrams (i.e. semivariograms for streams; see Zimmerman and Ver Hoef, 2016) were used to assess spatial autocorrelation which breaks up the semivariance into flow-connected and -unconnected structures (Ver Hoef et al., 2014). Based on diagnostic evaluation we added a $\log 10$ data transformation for temperature, total dissolved solids (TDS, $\mathrm{g} / \mathrm{L})$, conductivity $(\mu \mathrm{S} / \mathrm{cm})$, and foraging score.

Our SSNMs used a mixed-model autocovariance structure consisting of exponential tailup (TU), tail-down (TD), and exponential Euclidean. TU and TD autocovariance models represent water flow-connected (i.e. TU and TD) and-unconnected relationships (i.e. TD) along the stream and is based on hydrologic (rather than "traditional" straight-line Euclidean) distance (extensive explanation can be found in Ver Hoef and Peterson, 2010). Euclidean distance was included for comparison since it is a traditionally used distance. Autocovariance models were not determined a priori (Friedan et al., 2014) as a partial sill, range parameter, and overall nugget effect estimated for each model helps determine relative influence of the components in individual models for either model improvement or removal (Ver Hoef and Peterson, 2010).

We used an exploratory multi-stage model selection process for model evaluation that allowed us to determine autocovariance structure and what covariates to keep for further evaluation (Friedan et al., 2014). We modeled covariates individually since we were interested in which ones had the most predictive power and were statistically significant before comparing the individual covariates in a final model set. As such, there was no need to examine correlations of covariates to avoid multicollinearity. We set $\alpha=0.10$ to avoid missing any variables that may be of ecological relevance. We first ran a non-spatial linear regression model equivalent for each variable for comparison and evaluation of spatially-influenced properties in spatial models, and because non-spatial linear regression models are traditionally how the variables would have been 
modeled. Only significant variables $(P<0.10)$ from the non-spatial models were placed into spatial models. Initial covariance structures of spatial models were mixed and fixed to exponential TU, exponential TD, and exponential Euclidean since we expected variability in how spatial weights may affect each covariate.

Maximum likelihood (ML) estimation was used to estimate parameters of Gaussian models (response variable FPI). Akaike's Information Criterion (AIC; Akaike, 1974; Burnham and Anderson, 2002) was used to compare models which penalized for additional spatial autocovariance structures (Ver Hoef and Peterson, 2010). $\mathrm{R}^{2}$ and root mean square prediction error (RMSPE) based on the observed response variable and leave one out cross validation (LOOCV) predictions were also calculated. Variance decomposition was used to determine the total amount of variation associated with a response variable (Ver Hoef et al., 2014). Predictions from wetted perimeter locations with no waterthrush observations were generated using universal kriging (Cressie, 1993).

The next stage of model selection involved selecting the best autocovariance structure (Friedan et al., 2014). If exponential TU/TD models had a higher partial sill than Euclidean autocovariance, we added Mariah, Spherical, and Linear-with-sill to test before final selection of autocovariance. Final models were evaluated by AIC, RMSPE, and by examining the influence of each variance component. We mapped and visually examined prediction values \pm standard error (SE) as one means of determining overall model performance (Bennett et al., 2013) along with plotting of LOOCV predictions and SEs against the observed data. Post-hoc Spearman's Rho correlation index tests in R were used to determine what components of WVSCI, GLIMPSS, or foraging score were associated to FPI if those covariates were found important during model selection.

\section{RESULTS}

During 2013-2014, we collected 948 foraging and non-foraging observations of waterthrush. Each stream had an overall average of $30.6 \pm 7.2$ foraging and $37.1 \pm 6.2$ nonforaging observations (average $67.7 \pm 11.1$ total observations per stream, range 4-214) collected. We had 318 60-m buffered wetted perimeter sampling points for analysis that included both waterthrush observations and benthic samples, and an additional 103 saved for prediction modeling that had benthic samples but no waterthrush observations. Each stream had an average of $22.7 \pm 3.4$ sampling points (range $3-42$ ). Each sampling point contained on average $4.1 \pm 0.2$ 
waterthrush observations (range 1-30). Average foraging observations at each sampling point were $2.0 \pm 0.2$ (range 0-30) and average non-foraging observations were $2.0 \pm 0.1$ (range 0-14). Overall average foraging probability index (FPI) on each stream based on the sampling points was $47.9 \pm 4.5 \%$ (range $20.3-80.4 \%$, Fig. 2).

Stream temperature, benthic biomass, benthic density, GLIMPSS, and WVSCI were significant in explaining foraging probability index (FPI) according to the non-spatial linear regression models $(P<0.10$, Table 1$)$. A torgegram for FPI suggested there may be higher spatial autocorrelation between flow-connected sample points at short distances, but both flowconnected and unconnected samples have high autocorrelation (Fig. 3). The torgegram also suggested using both tail up (TU) and tail down (TD) autocovariance structures in initial spatial models to obtain the full range of autocorrelation.

The five significant variables were placed into individual spatial models where only GLIMPSS and WVSCI remained significant $(P<0.05$, Table 2). Given support that tail down (TD) models performed better than tail up (TU) models (Table 3), we added two more tail down variance components for AIC model comparison (Table 4). In final AIC model comparison between WVSCI and GLIMPSS, there was more support for WVSCI explaining FPI than GLIMPSS (Table 5) with competing indication of TD and Euclidean variance structure (Table 6). Final models for WVSCI and GLIMPSS had low predictive power with almost all model variance explained by the autocovariance component rather than the covariate (Table 6, Fig. 4 and 5). Post-hoc spearman rank correlation tests between FPI and WVSCI/GLIMPSS metrics (no. Ephemeroptera genera, no. Plecoptera genera, no. intolerant taxa tolerance value <4, and EPT richness) were all significant (Rho=0.24, 0.20, 0.23, and 0.22 respectively, $P<0.001$, Fig. $6)$.

\section{DISCUSSION}

Our study is the first to apply SSNMs to relate trophic levels across the aquatic-terrestrial interface using a semi-aquatic organism that is not necessarily as restricted in movement as benthic organisms. Overall, spatial models outperformed traditional regression models, and made a statistical difference in whether stream covariates of interest were considered relatable to waterthrush foraging areas. While the spatial models had poor predictive power, SSNMs allowed us to assign variability due to spatial autocorrelation and evaluate potential trends involved in foraging on headwater streams. Stream temperature, biomass, and density were significant using 
standard linear regression, but were no longer significant once we considered spatial autocorrelation. Therefore using standard statistical approaches could have led to making a type I error for these covariates (Dormann et al., 2007).

We did not find a relationship between foraging substrate score based on wetted perimeter data and FPI (Table 1). The protocol was designed on 1st and 2nd order waterthrush study streams in Pennsylvania (PA) that are relatively wider, less bank, deeper water depth, and more perennial (Latta, 2009) than our narrow streams with steeper topography. Consequently, the wetted perimeter protocol may be region and stream-type specific, and water depth in relation to exposed or wetted areas that create available foraging microhabitat less important for perennial streams with many ephemeral and intermittent tributaries. For example, less availability of bank nest substrate in PA meant nests were commonly found off-stream in root balls of fallen trees (S. Latta, Unpublished results), whereas nests in root balls were rare at our study site (1 of 184 nests in 2013-2014; M. Frantz, Unpublished results). Master et al. (2005) found waterthrush densities on wintering grounds were higher on streams with higher wetted perimeter values, suggesting the need to test these protocols elsewhere in the waterthrush breeding range.

Waterthrush benthic studies were completed in 2011 and 2013-2014 during peak (2011), abated (2013), and elevated (2014) shale gas development at our study site. We found that waterthrush territory densities were greater on streams with higher GLIMPSS scores (Wood et al., 2016), which supports our significant spatial models with GLIMPSS and WVSCI. Higher GLIMPSS and WVSCI values indicate better riparian habitat quality and therefore more foraging resources for waterthrush (Frantz et al. 2018b). Our spatial model suggested at minimum a weak relationship between FPI and these multi-metric indices, at least relative to nesting locations where the majority of our benthic samples were collected. Friedan et al. (2014) used SSNMs to determine drivers of family and genus-level macroinvertebrate indices and wondered whether using coarser (mainly family-level) macroinvertebrate identification could have masked spatial patterns or reduced predictive power. In our case, using family vs. genus-level indices did not make a difference in residual variance of autocovariance, with WVSCI only having minor model selection support over GLIMPSS in explaining FPI (Tables 5 and 6). Our results suggest familylevel taxonomic resolution may be good enough to indicate most likely waterthrush foraging areas. 
Territory densities in 2011 were greater where Ephemeroptera, Plecoptera, and Trichoptera densities were higher, along with higher biomass (Wood et al., 2016). Territory density declines in 2013-2014 in part lead to the disassociation between aquatic prey biomass, density, and waterthrush demographic response at a nest and territory level (Frantz et al., 2018b). While biomass and density were no longer significant in our spatial models, there is still a positive association between richness of these sensitive taxa orders and FPI (Figure 6). We did not assess biomass or density by size class, by which waterthrush may have shown a stronger, significant response (Wood et al., 2016) in the spatial models. Overall riparian habitat site quality may be more important to waterthrush site assessment (Frantz et al., 2018a) than benthic metrics or in-stream characteristics alone for FPI. Indeed, waterthrush appear to be able to adapt to shale gas disturbance and meet all their foraging needs until potentially a certain disturbance threshold is reached (Frantz et al. 2018b). Nest survival in 2011 was best explained by Habitat Suitability Index (HSI), which describes both nesting and foraging components important to waterthrush (Wood et al., 2016).

The three $\%$ gas land use covariates were not significant in the initial non-spatial models (Table 1). These three variables were non-normal and could not approximate normality with traditional transformations, so technically were not appropriate for the linear models. Waterthrush have a negative demographic response to the physical presence of shale gas at localized levels of the nest or territory (Frantz et al., 2018a, 2018b), as well as their aquatic prey (Frantz et al. 2018b), so it is unclear the extent to which waterthrush foraging may change due to catchment-level shale gas disturbance. There are undisturbed stream segments and ephemeral tributaries on every stream giving opportunities to forage elsewhere (Wood et al., 2016), and waterthrush can compensate for food loss (Mulvihill et al., 2008). While this suggests to some extent adaptability in selecting foraging locations, shale gas disturbed areas have the potential to serve as sink habitats (Frantz et al., 2018a), so waterthrush may be breeding or foraging in an ecological trap (Gates and Gysel, 1978; Robertson and Hutto, 2006; Frantz et al. 2019). Additionally, waterthrush in shale gas disturbed areas bioaccumulate more heavy metals associated with the drilling process than those in undisturbed shale gas areas at our study site and elsewhere (Latta et al., 2015; Chapter 6). Foraging on macroinvertebrates is likely one way the heavy metals bioaccumulate, and we do not know how that factors into FPI. Shale gas well pad construction and drilling typical of our study site and others occur in "pulses" (Brittingham et al., 
2014), making ephemeral disturbances such as sedimentation or potential runoff entering a stream system where waterthrush hold breeding territories difficult to quantify. SSNMs that can treat both spatial and temporal effects and allow non-linear data structures may be better suited to model these relationships (O'Donnell et al., 2014; Rushworth, 2014; Rushworth et al., 2015).

While our spatial models performed better than non-spatial models, they still had poor predictive power (Table 6, Fig. 4). Aquatic prey community responses were weaker in 20132014 at a nest and territory level than in 2011 in relation to shale gas activity levels (Frantz et al. 2018b) which may also translate to weaker predictive power at the catchment-level for these years of the study. Additionally, Friedan et al. (2014) found that spatial-weighting schemes made a substantial difference in model performance and affected variables differently. Our only spatial weighting scheme consisted of reach contributing area (RCA) (i.e. catchment area, Horizon Systems Corporation, 2007) and represented the aerial extent that contributes overland flow to a stream line segment. Some other spatial-weighting options to consider are Shreve's stream order (1967) or consideration of slope at stream segments. While catchment area may have been an appropriate scale for gas land use variables, a spatial weighting scheme such as slope that reflects local scale variability may have been more appropriate for headwater streams (Friedan et al., 2014). Our headwater streams have steep topography and many ephemeral tributaries, and headwaters are known to have high between stream variability of habitat and high macroinvertebrate beta diversity within and among catchments (Clarke et al., 2008).

Waterthrush have linear territories on the stream (Mulvihill et al., 2008) and typically fly up and down the stream corridor rather than around it (M. Frantz, Personal observation). As such it makes sense that tail-down (TD) autocovariance structure explained the most model variability as it allows correlation of samples between flow-connected and -unconnected stream segments. Euclidean distance having almost equal explanation of model variability likely reflects some combination of terrestrial components to waterthrush ecology and territory-scale or higher attributes. However predictive power depends not only on autocovariance structure but the covariates themselves (Friedan et al., 2014). For instance, FPI was likely not representative on Carpenter Run which could have introduced some unnecessary variability in the data (Fig. 2). Priority during our six year (2009-2011, 2013-2015) waterthrush demography project was to accurately delineate waterthrush territories, with emphasis on collecting new location points that reflected all boundaries of a waterthrush territory. While we monitored Carpenter Run for nests 
in 2013, we did not start collecting territory and foraging observations until 2014. Introducing stream $(\mathrm{n}=14)$ as a random effect post-hoc in the WVSCI and GLIMPSS models may have explained between 4.6-6.5\% of model variance (e.g. AIC $=41.81, \mathrm{RMSPE}=0.232$ for WVSCI with Exponential TD autovariance + Stream). This emphasizes the importance of not only thorough observation collection but accounting for headwater stream heterogeneity.

Collecting large data sets due to stream monitoring programs is becoming commonplace (Rushworth et al., 2015), stressing the need to use the proper statistical tools that will provide optimal performance and prediction power. While our spatial models had poor performance power, we can still produce predictive maps that can direct us to potentially important waterthrush foraging areas to evaluate further such as upper reaches of headwater tributaries (Fig. 5). The utility of SSNMs have been used previously to predict fish densities (Issak et al., 2016), and now for an apex avian predator that habits the aquatic-terrestrial interface, and thus has the potential for land managers with waterthrush occurrence data to prioritize management or conservation areas given the waterthrush's role as a bioindicator of aquatic stream integrity (O’Connell et al., 2000; Mulvihill et al., 2008). Our exploratory SSNM analyses are a starting point to inquire further into food-web interactions between waterthrush, macroinvertebrates, and potential surface water contamination, and serves as an example of how spatial autocorrelation coming from multiple sources and scales may influence study implications.

\section{ACKNOWLEDGMENTS}

West Virginia Division of Natural Resources (WVDNR) provided access to the study area and Wheeling Jesuit University provided access to field housing. Our research was funded by WVDNR, West Virginia University, National Aviary, and Appalachian Stewardship Foundation. We thank Jack Toriello, Blake Hepner, Darin Blood, Jerry Kreiser, Steve Daniels, Tasso Cocoves, Nick Glover, and Ashley Akers for collecting data for this project. We additionally thank Jim Sheehan for project assistance and Ross Andrew for manuscript review. This study was completed under the auspices of West Virginia University IACUC protocol \#04-0302, 070303. Any use of trade, firm, or product names is for descriptive purposes only and does not imply endorsement by the U.S. Government. 


\section{LITERATURE CITED}

Akaike, H. 1974. A new look at the statistical model identification. IEEE Trans.

Automat. Contr. 19, 716-722.

Bennett, N.D., Croke, B.F.W., Guariso, G., Guillaume, J.H.A., Hamilton, S.H., Jakeman, A.J., Marsili-Libelli, S., Newham, L.T.H., Norton, J.P., Perrin, C., Pierce, S.A., Robson, B., Seppelt, R., Voinov, A.A., Fath, B.D., Andreassian, V. 2013. Characterising performance of environmental models. Environ. Model. Softw. 40, 1-20.

Bibby, C.J., Burgess, N.D., Hill, D.A. 1992. Bird Census Techniques. Academic Press, London. $257 \mathrm{pp}$.

Brittingham, M.C., Maloney, K.O., Farag, A.M., Harper, D.D., Bowen, Z.H. 2014. Ecological risks of shale oil and gas development to wildlife, aquatic resources and their habitats. Environ. Sci. and Technol. 48, 11034-11047.

Burnham, K.P., Anderson, D.R. 2002. Model selection and multimodel inference: An information-theoretic approach. Springer-Verlag, New York, New York, USA.

Buss, D.F., Carlisle, D.M., Chon, T-S, Culp, J., Harding, J.S., Keizer-Vlek, H.E., Robinson, W.A., Strachan, S., Thirion, C., Hughes, R.M. 2015. Stream biomonitoring using macroinvertebrates around the globe: a comparison of large-scale programs. Environ. Monit. Assess. 187, 4132.

Clarke, A., Mac Nally, R., Bond N., Lake, P.S. 2008. Macroinvertebrate diversity in headwater streams: a review. Freshw. Biol. 53, 1707-1721.

Cook, N.A., Sarver, E.A., Krometis, L.H., Huang, J. 2015. Habitat and water quality as drivers of ecological system health in Central Appalachia. Ecol. Eng. 84, 180-189.

Cressie, N. 1993. Statistics for spatial data, revised edition. New York: John Wiley and Sons.

Cressie, N., Frey, J., Harch, B., Smith, M. 2006. Spatial prediction on a river network.

J. Agric. Biol. Environ. Stat. 11, 127-150.

Dormann, C.F., McPherson, J.M., Araújo, M.B., Bivand, R., Bolliger J., Carl, G., Davies, R.G., Hirzel, A., Jetz, W., Kissling, W.D., Kühn, I., Ohlemüller, R., Peres-Neto, P.R., Reineking, B., Schröder, B., Schurr, F.M., Wilson, R. 2007. Methods to account for spatial autocorrelation in the analysis of species distributional data: a review. Ecography 30, 609-628.

Dunscomb, J.K., Evans, J.S., Strager, J.M., Strager, M.P., Kiesecker, J.M. 2014. Assessing future energy development across the Appalachian Landscape Conservation Cooperative. The Nature Conservancy, Charlottesville, VA. 48 pp with appendices. Appalachian Landscape Conservation Cooperative Grant \#2012-02.

Entrekin, S., Evans-White, M., Johnson, B., \& Hagenbuch, E. 2011. Rapid expansion of natural gas development poses a threat to surface waters. Front. Ecol. Environ. 9, 503-511. 
ESRI. 2011. ArcMap GIS Desktop. Release 10.2.2. Environmental Systems Research Institute, Redlands, CA.

Evans, J.S., Kiesecker, J.M. 2014. Shale gas, wind and water: Assessing the potential cumulative impacts of energy development on ecosystem services within the Marcellus play. PLoS ONE 9, e89210.

Farwell, L.S., Wood, P.B., Sheehan, J., George, G.A. 2016. Shale gas development effects on the songbird community in a central Appalachian forest. Biol. Conserv. 201, 78-91.

Fisher, R.A. 1935. The design of experiments. Oliver and Boyd, Edinburgh.

Fortin, M.J., Dale, M.R. 2005. Spatial analysis: A guide for ecologists. Cambridge: Cambridge University Press.

Frantz, M.W., Wood, P.B., Sheehan, J., George, G. 2018a. Demographic Response of a Migratory Songbird of Conservation Concern to Shale Gas Development. The Condor: Ornithological Applications 120, 265-282.

Frantz, M.W., Wood, P.B., Merovich Jr., G.T. 2018b. Demographic characteristics of an avian predator, Louisiana Waterthrush (Parkesia motacilla), in response to its aquatic prey in a Central Appalachian USA watershed impacted by shale gas development. PLoS ONE 13, e0206077.

Frantz, M.W., Wood, P.B., Sheehan, J., George, G. 2019. Louisiana Waterthrush (Parkesia motacilla) Survival and Site Fidelity in an Area Undergoing Shale Gas Development. The Wilson Journal of Ornithology 131, 84-95.

Freeman, M.C., Pringle, C.M., Jackson, C.R. 2007. Hydrologic connectivity and the contribution of stream headwaters to ecological integrity at regional scales. J. Am. Water Resour. Assoc. 43, 5-14.

Gates, J.E., Gysel, L.W. 1978. Avian nest dispersion and fledging success in field-forest ecotones. Ecology 59, 871-883.

Gerritsen, J., Burton, J., Barbour, M.T. 2000. A stream condition index for West Virginia wadeable streams. Tetra Tech Inc., Owing Mills.

Gomi, T., Sidle, R.C., Richardson, J.S. 2002. Understanding processes and downstream linkages of headwater systems. Bioscience 52, 905-916.

Isaak, D.J., Peterson, E.E., Ver Hoef, J.M., Wenger, S.J., Falke, J.A., Torgersen, C.E., Sowder, C., Steel, E.A., Marie-Josee Fortin, M-J, Jordan, C.E., Ruesch, A.S., Som, N., Monestiez, P. 2014. Applications of spatial statistical network models to stream data. WIREs Water 1, 277294. 
Isaak, D.J., Ver Hoef, J.M., Peterson, E.E., Horan, D.L., Nagel, D.E. 2016. Scalable population estimates using spatial-stream-network SSN models, fish density surveys, and national geospatial database frameworks for streams. Can. J. Fish. Aquat. Sci. 74, 147-156.

Johnson E., Austin, B.J., Inlander E., Gallipeau, C., Evans-White, M.A., Entrekin, S. 2015. Stream macroinvertebrate communities across a gradient of natural gas development in the Fayetteville Shale. Sci. Total Environ. 530-531:323-332.

Latta, K. 2009. What determines success? Breeding habitat characteristics of the Louisiana Waterthrush (Seirus motacilla). Senior Thesis. University of Michigan. 16 pp.

Latta, S.C., Marshall, L.C., Frantz M.W., Toms, J. 2015. Evidence from two shale regions that a riparian songbird accumulates metals associated with hydraulic fracturing. Ecosphere 6, 144.

Legendre, P. 1993. Spatial autocorrelation: trouble or new paradigm? Ecology 74, 1659-1673.

MacDonald, L.H., Coe, D. 2007. Influence of headwater streams on downstream reaches in forested areas. Forest Science 53, 148-168.

Master, T.L., Mulvihill, R.S., Leberman, R.C., Sanchez, J., Carman, E. 2005. A Preliminary Study of Riparian Songbirds in Costa Rica, with Emphasis on Wintering Louisiana Waterthrushes. USDA Forest Service Gen. Tech. Rep. PSW-GTR-191, 528-532.

Mattsson, B.J., Cooper, R.J. 2006. Louisiana waterthrushes (Seiurus motacilla) and habitat assessment as cost-effective indicators of instream biotic integrity. Freshw. Biol. 51, 1941-1958.

Mattsson, B.J., Master, T.L., Mulvihill, R.S., Robinson, W.D.2009. Louisiana Waterthrush (Parkesia motacilla). In: Poole A.F. (Ed). Birds of North America. Cornell Lab of Ornithology, Ithaca, NY. https://doi.org/10.2173/bna.151.

Mulvihill, R.S., Newell, F.L., Latta S.C. 2008. Effects of acidification on the breeding ecology of a stream-dependent songbird, the Louisiana Waterthrush (Seiurus motacilla). Freshw. Biol. 53, 2158-2169.

O'Connell T.J., Jackson, L.E., Brooks, R.P. 2000. Bird guilds as indicators of ecological condition in the central Appalachians. Ecol. Appl. 10, 1706-1721.

O’Donnell, D., Rushworth, A., Bowman, A.W., Scott, E.M. 2014. Flexible regression models over river networks. J. R. Stat. Soc. Ser. C. Appl. Stat., 63, Part I, 47-63.

Peterson, E.E., Ver Hoef, J.M. 2010. A mixed-model moving-average approach to geostatistical modeling in stream networks. Ecology 91, 644-651.

Peterson, E.E., Ver Hoef, J.M. 2014. STARS: An ArcGIS toolset used to calculate the spatial information needed to fit spatial statistical models to stream network data. J. Stat. Softw. 56,117. 
Pond, G.J., Bailey, J.E., Lowman, B.M., Whitman, M.J. 2013. Calibration and validation of a regionally and seasonally stratified macroinvertebrate index for West Virginia wadeable streams. Environ. Monit. Assess. 185, 1515-1540.

R Core Team. 2014. R: A Language and Environment for Statistical Computing. R Foundation for Statistical Computing, Vienna, Austria. http://www.Rproject.org/.

Robbins, C.S. 1970. Recommendations for an international standard for a mapping method in bird census work. Audubon Field Notes 24, 723-726.

Robertson, B.A., Hutto, R.L. 2006. A framework for understanding ecological traps and an evaluation of existing evidence. Ecology 87, 1075-1085.

Robinson, W.D. 1990. Louisiana waterthrush foraging behavior and microhabitat selection in southern Illinois. Masters Thesis, Southern Illinois University, Carbondale, IL.

Rushworth, A.M. 2014. smnet: Smoothing for stream network data. R package version 1.0.

Rushworth, A.M., Peterson, E.E., Ver Hoef, J.M., Bowman A.W. 2015. Validation and comparison of geostatistical and spline models for spatial stream networks. Environmetrics 26, $327-338$.

Sauer, J.R., Hines, J.E., Fallon, J.E., Pardieck, K.L., Ziolkowski, D.J., Link, W.A. 2014. The North American Breeding Bird Survey, Results and Analysis 1966-2013 version 01.30.2015. USGS Patuxent Wildlife Research Center, Laurel, Maryland. http://www.mbrpwrc.usgs.gov/bbs/.

Shields, W.M. 1977. The effect of time of day on avian census results. Auk 2, 380-383.

Shreve, R.L. 1967. Infinite topologically random channel networks. J. Geol. 75, 178-186.

Strager, M.P., Petty, J.T., Strager, J.M., Barker-Fulton, J. 2009. A spatially explicit framework for quantifying downstream hydrologic conditions. J. Environ. Manage. 90, 1854-1861.

Swanson, F.J., Johnson, S.L., Gregory, S.V., Acker, S.A. 1998. Flood disturbance in a forested mountain landscape. BioScience 48, 681-689

Theobald, D.M., Norman, J.B., Peterson, E., Ferraz, S., Wade, A., Sherburne, M.R. 2006. Functional linkage of water basins and streams FLoWS v1 Users Guide: ArcGIS tools for network-based analysis of freshwater ecosystems. Natural Resource Ecology Lab, Colorado State University, Fort Collins, CO. 43 pg.

USFWS (United States Fish and Wildlife Service). 2008. Birds of Conservation Concern 2008. United States Department of Interior, Fish and Wildlife Service, Division of Migratory Bird Management, Arlington, Virginia. 85 pp. [Online] http://www.fws.gov/migratorybirds. 
Ver Hoef, J.M., Peterson, E.E. 2010. A moving average approach for spatial statistical models of stream networks. Journal of the American Statistical Association 105, 6-18.

Ver Hoef, J.M., Peterson, E.E., Clifford, D., Shah, R. 2014. The SSN package: An R package used to fit spatial statistical models to stream network data. Journal of Statistical Software 56, 1-45.

Vitz, A.C., Rodewald, A.D. 2010. Movements of fledgling Ovenbirds (Seirus aurocapilla) and Worm-Eating Warblers (Helmitheros vermivorum) within and beyond the natal home range. Auk $127,364-371$.

Wood, P., Frantz, M., Becker, D. 2016. Louisiana Waterthrush and benthic macroinvertebrate response to shale gas development. J. Fish Wildl. Manag. 7, 423-433.

Woods, A.J., Omernik, J.M., Brown, D.D. 1999. Level III and IV Ecoregions of Delaware, Maryland, Pennsylvania, Virginia, and West Virginia, U.S. U.S. Environmental Protection Agency, National Health and Environmental Effects Research Laboratory, Corvallis, OR. [Online] ftp://ftp.epa.gov/wed/ecoregions/reg3/reg3_eco_desc.doc.

WVDEP (West Virginia Department of Environmental Protection). 2015. Oil and gas production data. 2015. State of West Virginia. [Online]

http://www.dep.wV.gov/oil-and-gas/databaseinfo/Pages/default.aspx.

WVGES (West Virginia Geological and Economic Survey). 2015. WV Marcellus Shale Wells: Completed, Permitted, and Cancelled Episodes. [Online] http://www.wvgs. wvnet.edu/www/datastat/devshales.htm.

Zimmerman, D.L., Ver Hoef, J.M. 2017. The torgegram for fluvial variography: Characterizing spatial dependence on stream networks. J. Comput. Graph. Stat. 26:2, 253-264.

Zuur, A.F., Ieno, E.N., Elphick, C.S. 2010. A protocol for data exploration to avoid common statistical problems. Methods Ecol. Evol. 1, 3-14. 


\section{TABLES}

Table 1. Initial non-spatial linear models (with nugget) to test the relationship between foraging score, water chemistry, macroinvertebrate metrics, shale gas land use and foraging probability index (FPI). Covariates with bolded $P$ values were significant at $\alpha=0.10 . \mathrm{R}^{2}$ is a generalized value of model fit and the partial sill (sill minus nugget) was included to assess variance of a covariate without the nugget effect.

\begin{tabular}{lcccccc}
\hline Variable & Estimate & SE & $\boldsymbol{t}$ value & P value & $\mathbf{R}^{\mathbf{2}}$ & Partial sill \\
\hline Foraging Score & 0.046 & 0.054 & 0.855 & 0.393 & 0.0023 & 0.122 \\
Temperature $\left({ }^{\circ} \mathrm{C}\right)$ & -1.073 & 0.619 & -1.732 & $\mathbf{0 . 0 8 4}$ & 0.01 & 0.121 \\
$\mathrm{pH}$ & 0.048 & 0.077 & 0.627 & 0.531 & 0.0012 & 0.122 \\
$\mathrm{TDS}, \mathrm{g} / \mathrm{L}$ & -0.052 & 0.106 & -0.494 & 0.622 & 0.0001 & 0.122 \\
$\mu \mathrm{S} / \mathrm{cm}$ & -0.055 & 0.098 & -0.554 & 0.580 & 0.001 & 0.122 \\
GLIMPSS & 0.004 & 0.001 & 3.008 & $\mathbf{0 . 0 0 3}$ & 0.03 & 0.119 \\
WVSCI & 0.005 & 0.002 & 2.948 & $\mathbf{0 . 0 0 3}$ & 0.03 & 0.119 \\
Biomass & 0.101 & 0.037 & 2.724 & $\mathbf{0 . 0 0 7}$ & 0.02 & 0.120 \\
Density & 0.115 & 0.056 & 2.053 & $\mathbf{0 . 0 4 1}$ & 0.01 & 0.121 \\
\% Marcellus Pad & -0.054 & 0.183 & -0.294 & 0.769 & 0.0003 & 0.122 \\
\% All Pad & -0.062 & 0.175 & -0.353 & 0.725 & 0.0004 & 0.122 \\
\% Gas Infrastructure & -0.018 & 0.086 & -0.213 & 0.832 & 0.0001 & 0.122 \\
\hline
\end{tabular}

Table 2. Initial spatial generalized linear models to test the relationship between foraging score, water chemistry, macroinvertebrate metrics, shale gas land use and foraging probability index (FPI). Covariates with bolded $P$ values were significant at $\alpha=0.10 . \mathrm{R}^{2}$ is a generalized value of model fit and the partial sill (sill minus nugget) was included to assess variance of a covariate without the nugget effect.

\begin{tabular}{lcccccc}
\hline Variable & Estimate & SE & $\boldsymbol{t}$ value & P value & $\mathbf{R}^{\mathbf{2}}$ & Partial sill \\
\hline Temperature & -0.747 & 0.842 & -0.887 & 0.376 & 0.002 & 0.0003 \\
GLIMPSS & 0.003 & 0.001 & 2.114 & $\mathbf{0 . 0 3 5}$ & 0.01 & 0.0003 \\
WVSCI & 0.004 & 0.002 & 2.493 & $\mathbf{0 . 0 1 3}$ & 0.02 & 0.0003 \\
Biomass & 0.051 & 0.039 & 1.281 & 0.201 & 0.01 & 0.0003 \\
Density & 0.074 & 0.054 & 1.360 & 0.174 & 0.01 & 0.0003 \\
\hline
\end{tabular}


Table 3. Initial mixed autocovariance components (VAC) of the WVSCI and GLIMPSS spatial models. The nugget captures variability due to measurement error and/or spatial variability at less than the sampling distance. The range represents the distance at which the covariate is no longer spatially autocorrelated. The partial sill (sill minus nugget) assesses variance of a covariate without the nugget effect. Percent VAC is the percentage of residual variance accounted for by each autocovariance component. Based on higher partial sill values for Exponential TD, we added Mariah, Spherical, and Linear-with-sill TD to test before final selection of autocovariance components.

\begin{tabular}{llcc}
\hline Variance component & WVSCI & GLIMPSS \\
\hline Tail down (TD) & Autocovariance function & Exponential & Exponential \\
& Range & 561.606 & 588.130 \\
& Partial sill & 0.073 & 0.067 \\
& VAC $_{\mathrm{TD}}(\%)$ & 0.56 & 0.52 \\
\hline Tail up (TU) & Autocovariance function & Exponential & Exponential \\
& Range & 433.213 & 734.33 \\
& Partial sill & 0.00000145 & 0.0000003 \\
& VAC $_{\text {TU }}(\%)$ & 0.00001 & 0.000002 \\
\hline Euclidean (Euc) & Autocovariance function & Exponential & Exponential \\
& Range & 409.006 & 400.174 \\
& Partial sill & 0.055 & 0.061 \\
& VAC $_{\text {Euc }}(\%)$ & 0.42 & 0.47 \\
\hline Nugget & Nugget & 0.0003 & 0.0003 \\
& VAC $_{\text {Nugget }}(\%)$ & 0.002 & 0.002 \\
\hline
\end{tabular}


Table 4. AIC model comparison for WVSCI and GLIMPSS spatial models with Exponential Euclidean, Exponential tail down (TD), Spherical TD, and Linear plus sill TD autocovariance components in comparison to the non-spatial model with less parameters. Lowest leave-one-out cross-validation root-mean-square-prediction error (RMSPE) and AIC value was used to assess which models to select for final model comparison.

\begin{tabular}{lcc}
\hline Variance component & AIC & RMSPE \\
\hline WVSCI & & \\
Nugget (non-spatial) & 243.057 & 0.346 \\
Exponential Euclidean + Nugget & 41.250 & 0.233 \\
Exponential TD + Nugget & 40.469 & 0.233 \\
Spherical TD + Nugget & 41.971 & 0.236 \\
Linear plus sill TD + Nugget & 42.898 & 0.236 \\
GLIMPSS & & \\
\hline Nugget (non-spatial) & 243.403 & 0.346 \\
Exponential Euclidean + Nugget & 43.691 & 0.235 \\
Exponential TD + Nugget & 42.981 & 0.234 \\
Spherical TD + Nugget & 45.036 & 0.238 \\
Linear plus sill TD + Nugget & 45.969 & 0.238 \\
\hline
\end{tabular}

Table 5. Final AIC model comparison for WVSCI \& GLIMPSS. Lowest leave-one-out crossvalidation root-mean-square-prediction error (RMSPE) and AIC value was used to select what model best explains foraging probability index (FPI).

\begin{tabular}{llcc}
\hline Model & Variance component & AIC & RMSPE \\
\hline FPI $\sim$ GLIMPSS & Exponential Euclidean + Nugget & 43.691 & 0.235 \\
FPI $\sim$ GLIMPSS & Exponential TD + Nugget & 42.981 & 0.234 \\
FPI $\sim$ WVSCI & Exponential Euclidean + Nugget & 41.250 & 0.233 \\
FPI $\sim$ WVSCI & Exponential TD + Nugget & 40.469 & 0.233 \\
FPI $\sim$ WVSCI & Spherical TD + Nugget & 41.971 & 0.236 \\
\hline
\end{tabular}


Table 6. Final autocovariance components (VAC) of the WVSCI and GLIMPSS spatial models that best explain foraging probability index (FPI). The nugget captures variability due to measurement error and/or spatial variability at less than the sampling distance. The range represents the distance at which the covariate is no longer spatially autocorrelated. The partial sill (sill minus nugget) assesses variance of a covariate without the nugget effect. Percent VAC is the percentage of residual variance accounted for by each autocovariance component.

\begin{tabular}{llcc}
\hline Variance component & WVSCI & GLIMPSS \\
\hline Tail down & Autocovariance function & Exponential & Exponential \\
& Range & 494.821 & 494.117 \\
& Partial sill & 0.128 & 0.128 \\
& VAC $_{\text {TD }}(\%)$ & 0.98 & 0.98 \\
\hline Tail down & Autocovariance function & Spherical & Spherical \\
& Range & 282.836 & NA \\
& Partial sill & 0.129 & NA \\
& VAC $_{\text {TD }}(\%)$ & 0.97 & NA \\
\hline Euclidean (EUC) $)$ & Autocovariance function & Exponential & Exponential \\
& Range & 462.148 & 459.309 \\
& Partial sill & 0.128 & 0.128 \\
& VAC $_{\text {EUC }}(\%)$ & 0.98 & 0.98 \\
\hline Nugget & Nugget & 0.0003 & 0.0003 \\
& VAC $_{\text {Nugget }}(\%)$ & 0.002 & 0.002 \\
\hline
\end{tabular}




\section{FIGURES}

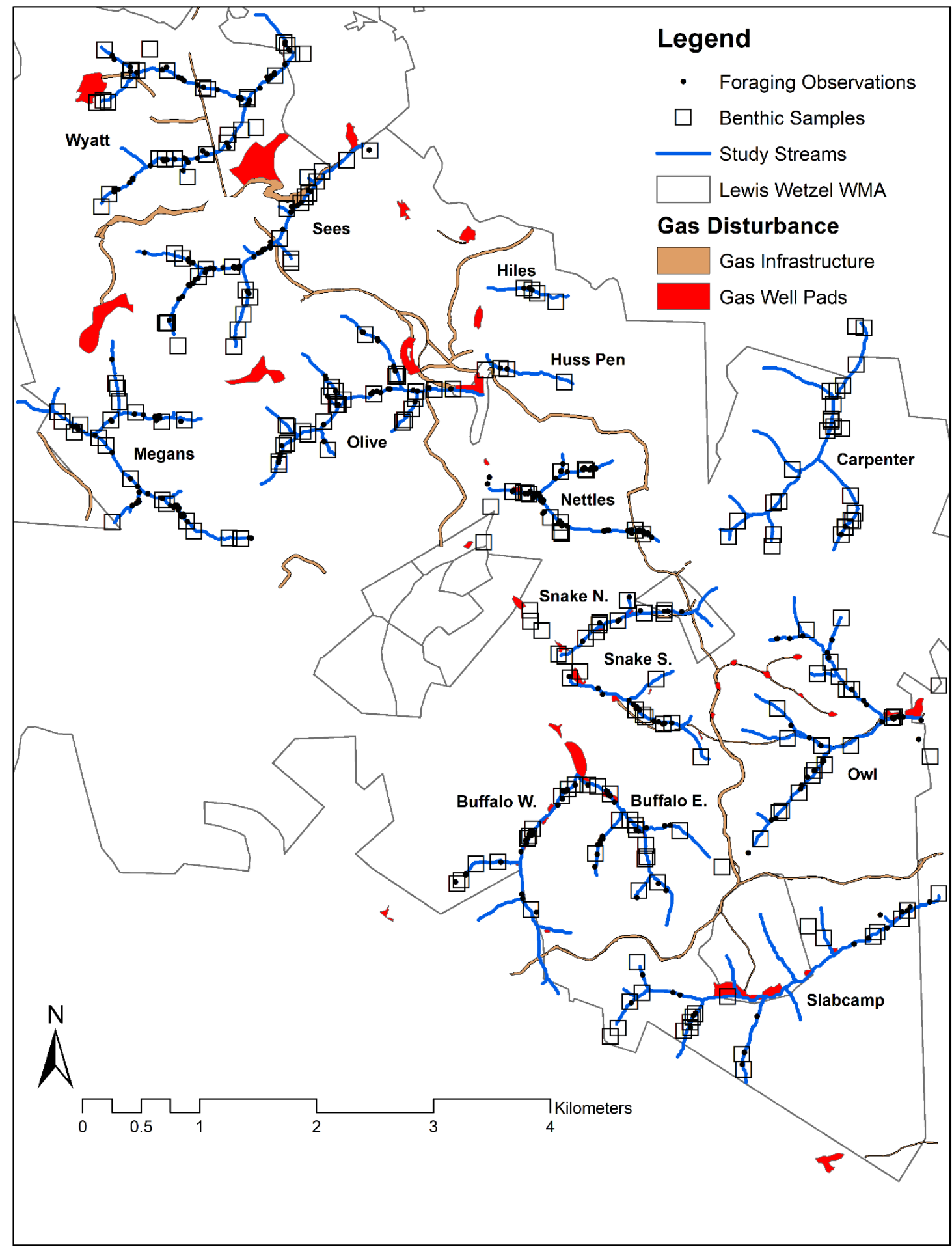

Fig. 1. Study Area Map. Our study area, Lewis Wetzel Wildlife Management Area (LWWMA), lies within the Marcellus-Utica shale basin. We observed Louisiana Waterthrush foraging on fourteen 1 st and 2 nd order headwater streams and collected benthic macroinvertebrate samples during 2013-2014. 


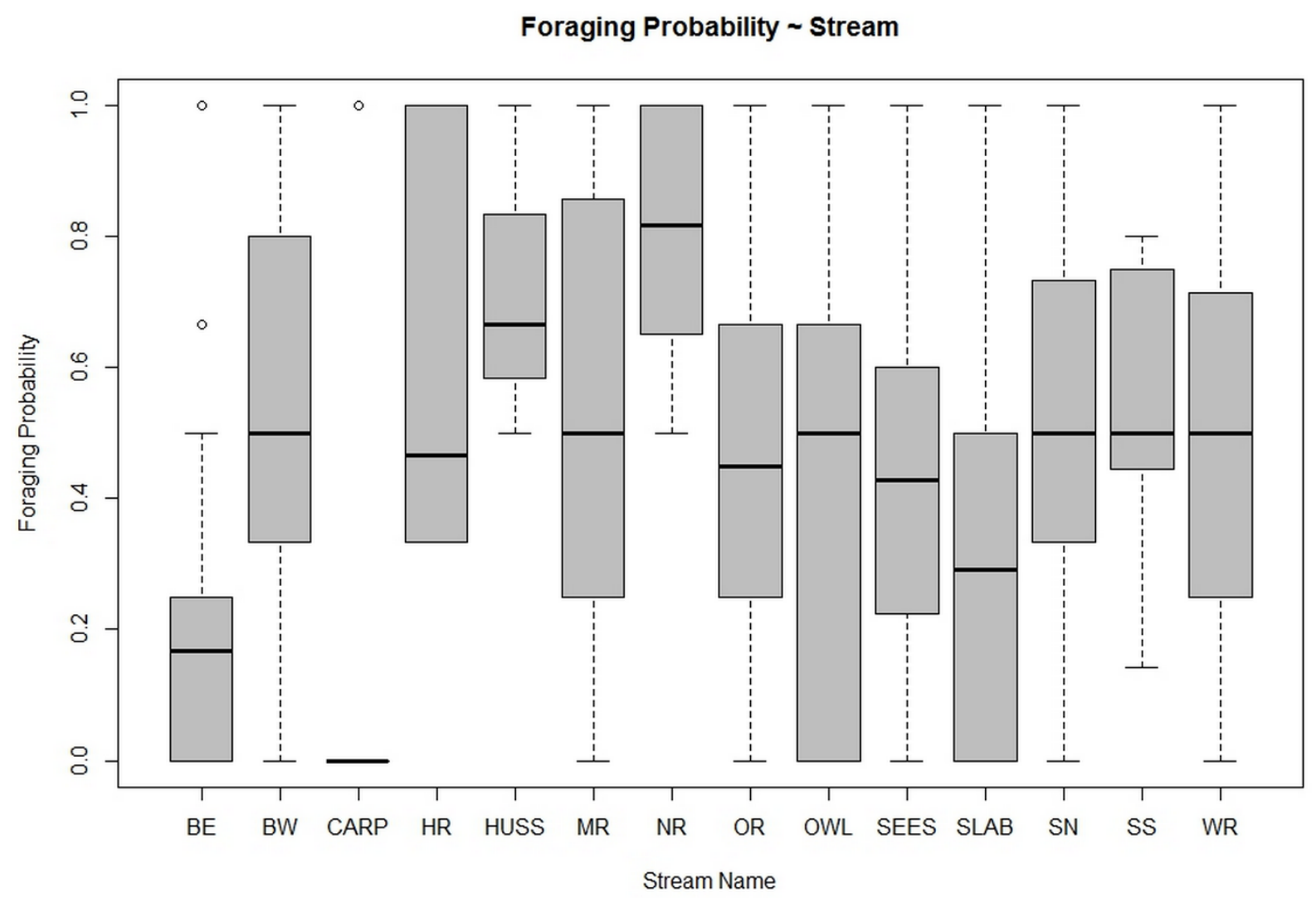

Fig. 2. Foraging Probability Index by Stream. Overall foraging probability index (FPI, 0$100 \%$ ) on each stream during 2013-2014. FPI was derived from the number of foraging observations/total observations for a $60 \mathrm{~m}$ area surrounding each wetted perimeter grid point on the stream. FPI was a relative index that gauged where waterthrush were most likely to be found foraging. Note Carpenter Run (CARP) only had two foraging observations, limiting the ability to make inferences about FPI on that stream. 


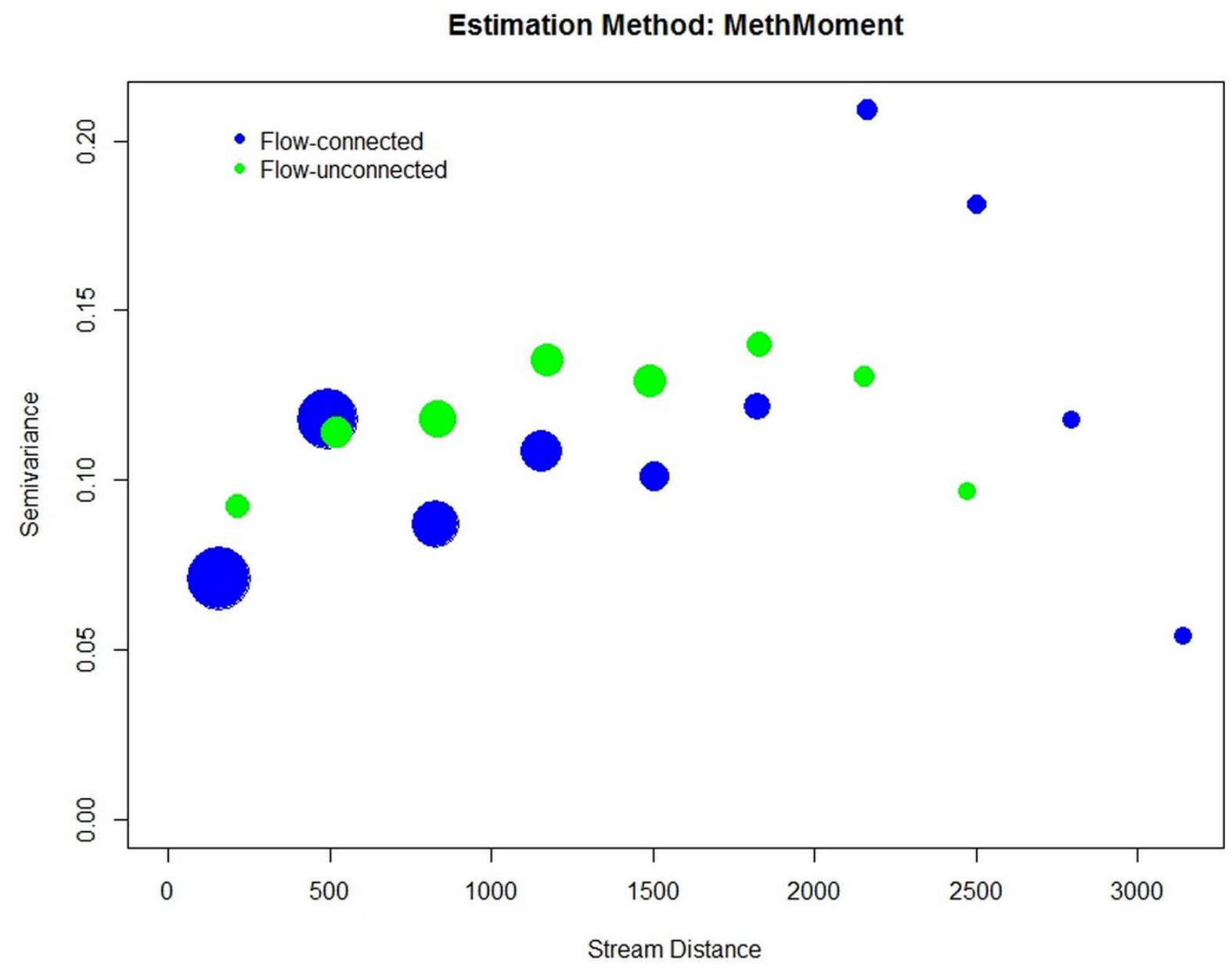

Fig. 3. Foraging Probability Index Torgegram. An example of a torgegram for foraging probability index (FPI) which is a modified type of semivariogram. A torgegram displays semivariance (spatial autocorrelation) for samples on streams into flow-connected and unconnected structures to assist with model fitting. Diameters of circles are proportional to the number of pairs of points in each bin. 

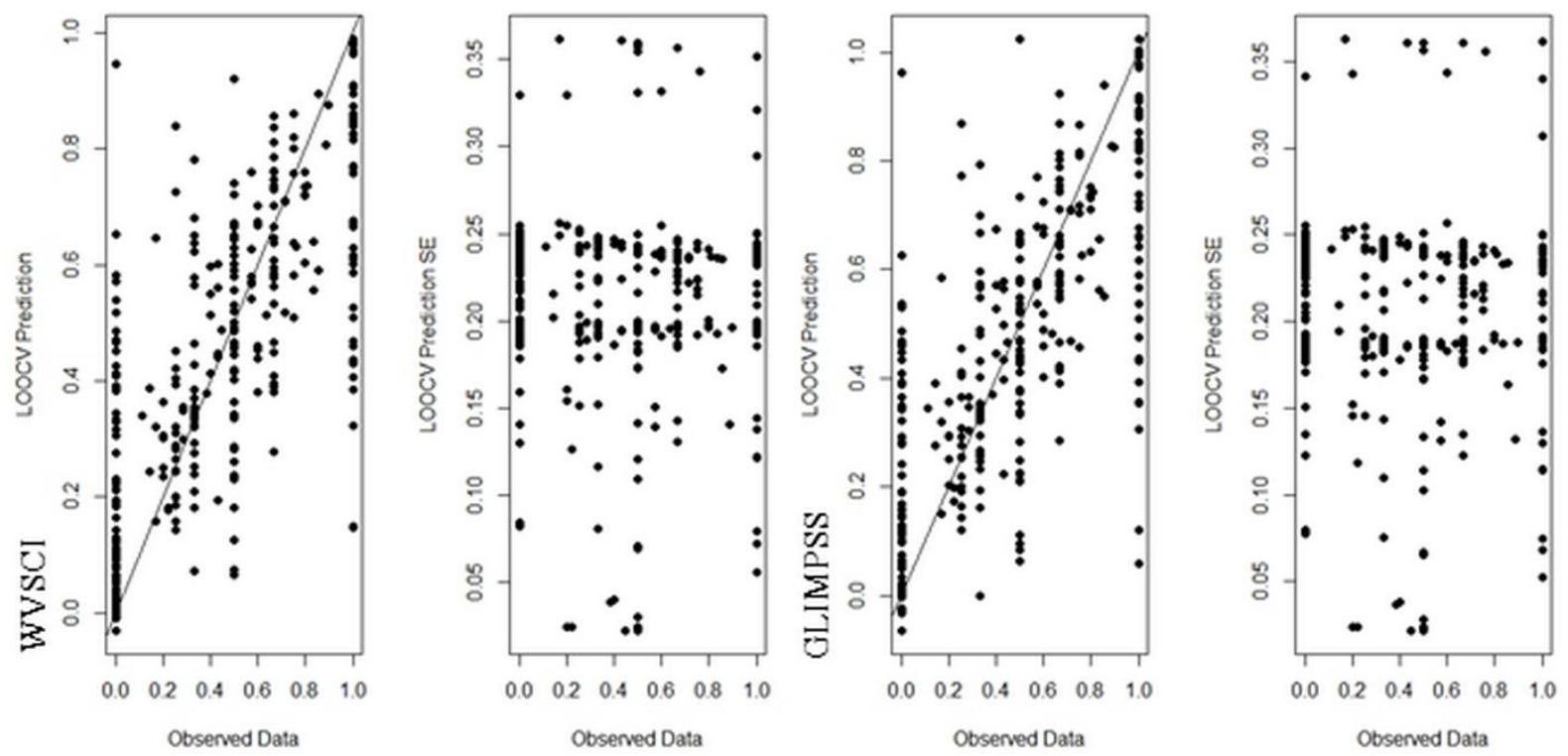

Fig. 4. Model Performance. Leave one out cross validation predictions (LOOCV) and standard error (SE) against the observed data for the top WVSCI and GLIMPSS spatial models as one means of assessing model performance. 


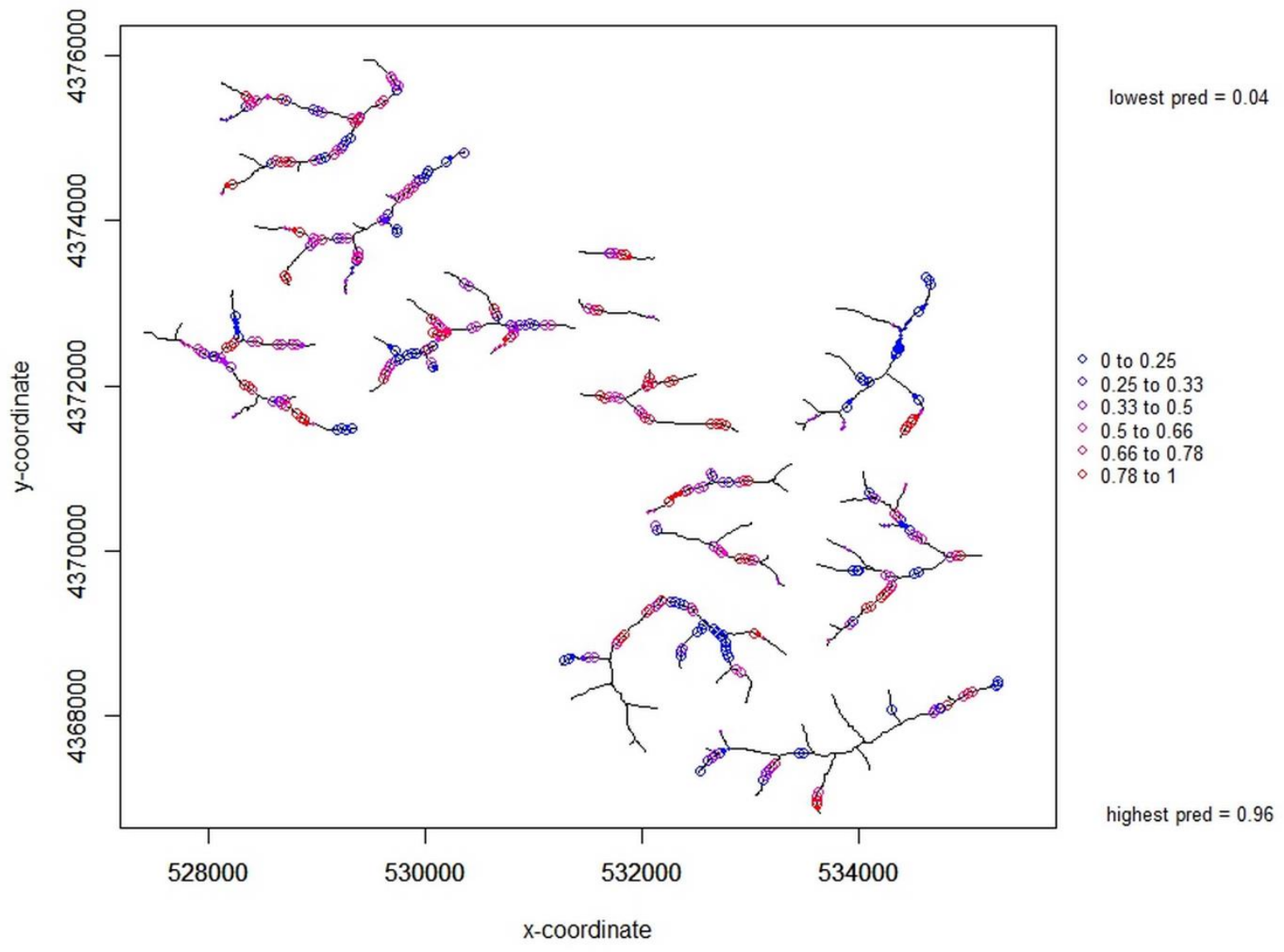

Fig. 5. Prediction Map. An example of prediction values mapped for WVSCI (solid circles) in relation to collected WVSCI data (open circles). The larger the solid circle, the more confidence in the prediction value (note most circles are small). Red values have a higher foraging probability index (FPI) than blue values. 

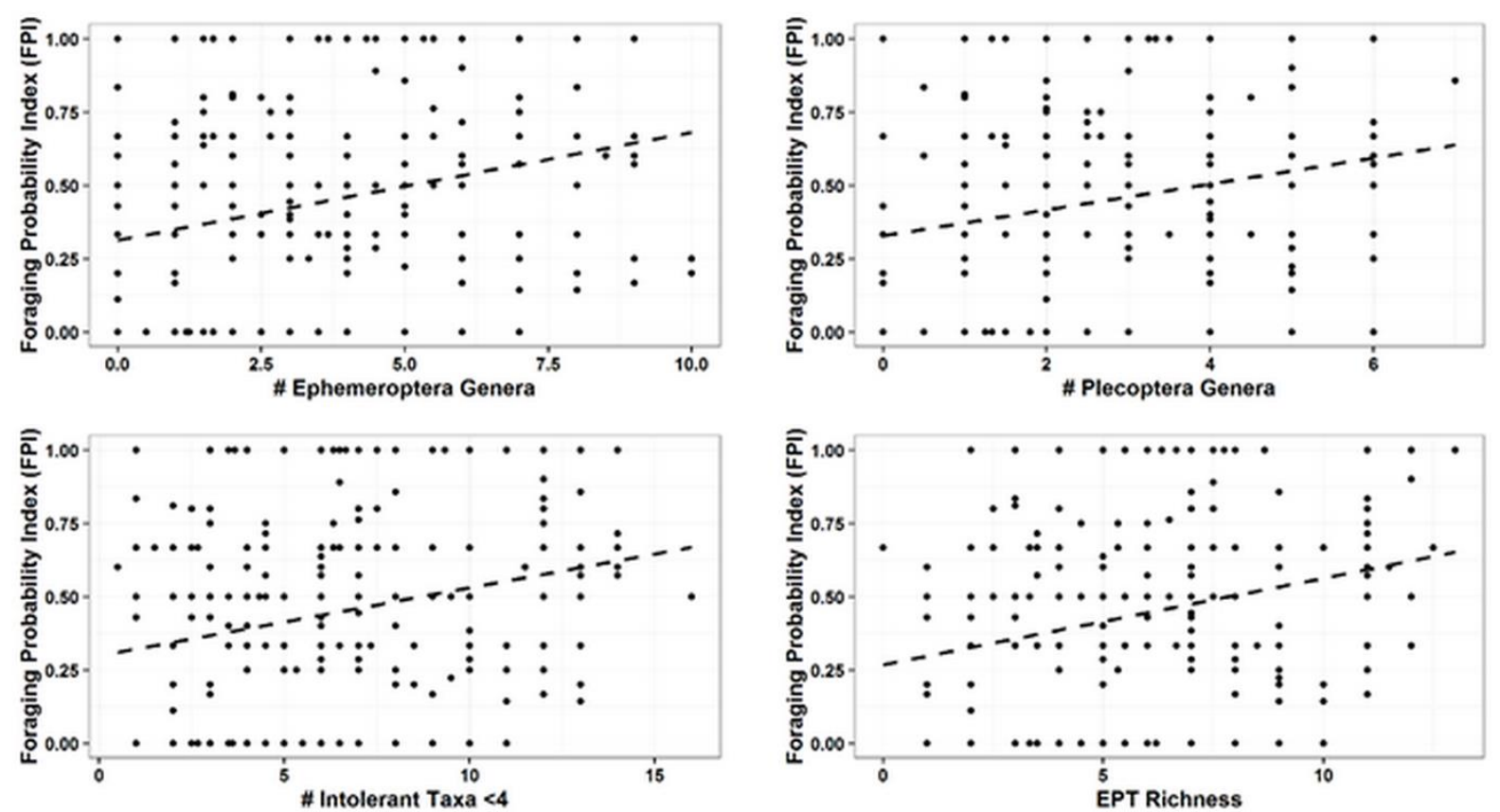

Fig. 6. Foraging Probability Index Correlations. Post-hoc spearman rank correlation tests between foraging probability index (FPI) and WVSCI/GLIMPSS metrics (no. Ephemeroptera genera, no. Plecoptera genera, no. intolerant taxa tolerance value <4, and EPT richness). All tests were significant $(\mathrm{Rho}=0.24,0.20,0.23, \& 0.22$ respectively, $P<0.001)$. 
PART 4. LOUISIANA WATERTHRUSH MOLECULAR ECOLOGY

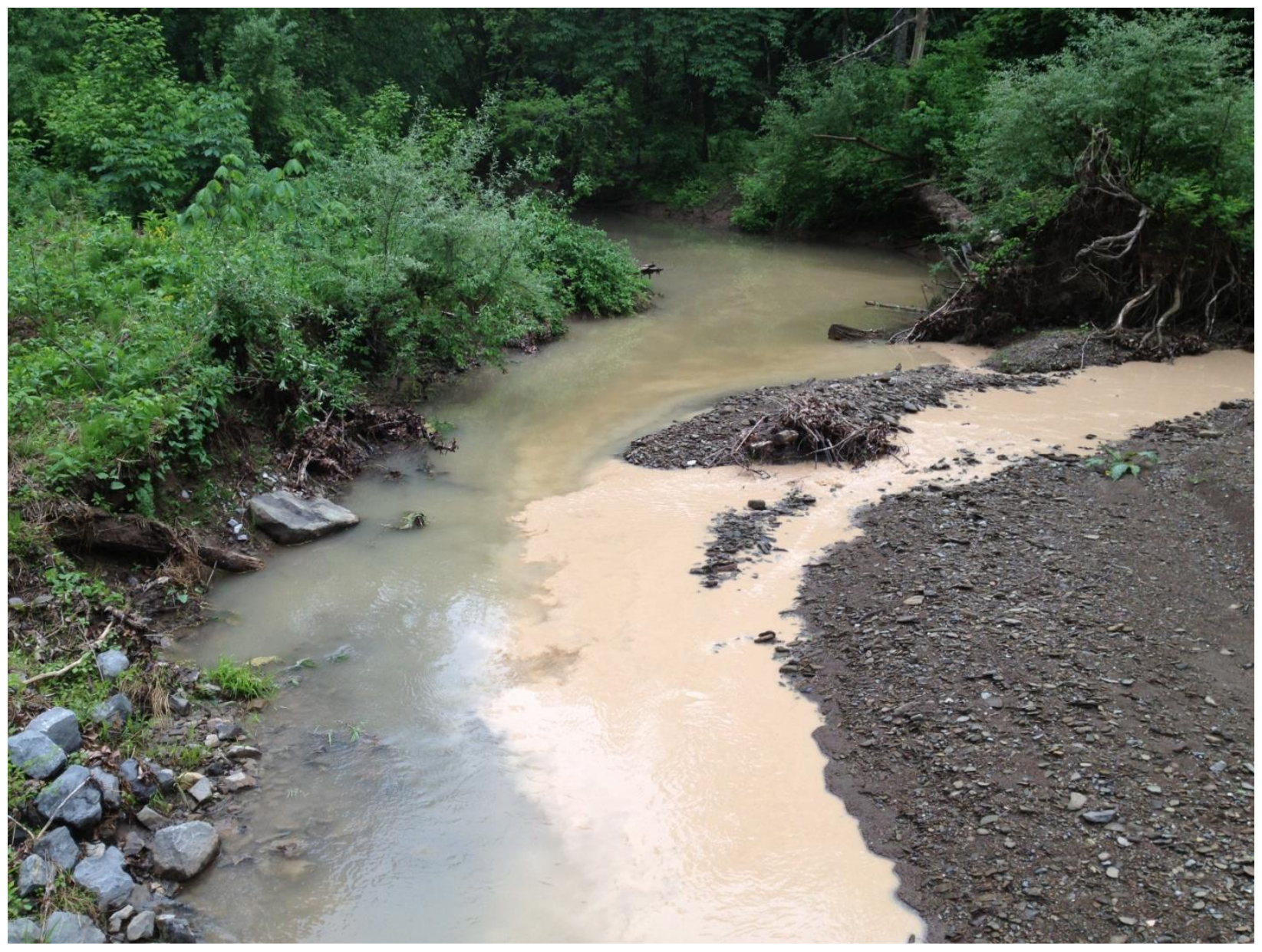




\title{
CHAPTER 6. EPIGENETIC RESPONSE OF LOUISIANA WATERTHRUSH (PARKESIA MOTACILLA) RELATED TO SHALE GAS DEVELOPMENT.
}

\author{
Chapter 6 is written in style of the peer-reviewed journal Ibis.
}

\begin{abstract}
Epigenetic mechanisms such as DNA methylation may vary in response to environmental stressors and introduce adaptive or maladaptive gene expression within and among wild bird populations. We examined the association between DNA methylation and demographic characteristics of the Louisiana Waterthrush (Parkesia motacilla) in addition to potential differential methylation from shale gas development in a Central Appalachian watershed during 2013-2015. We also evaluated the degree to which an individual's methylated state was subject to change across years in individuals that returned over the course of more than one breeding season (i.e., recaptures). Overall population methylation differed between adult male and female waterthrush where adult males generally had fewer methylated restriction sites. Differential methylation also occurred between adult females and nestlings. Age influenced differential methylation in both adult males and females where there was generally decreased methylation with age. While adult male recaptures had decreased methylation with age, adult female recaptures had increased methylation with age. Adult males were differentially methylated between shale gas undisturbed and disturbed areas at a population and restriction site (i.e., loci) level, where restriction sites were predominately less methylated in shale gas disturbed areas, a trend consistently seen year to year in adult male recaptures. Barium (Ba) and strontium (Sr) data were collected in 2013 feather samples where adult males had fewer methylated sites at higher concentrations of $\mathrm{Ba}$ and $\mathrm{Sr}$, while nestlings displayed no correlation of methylation to $\mathrm{Ba}$ and $\mathrm{Sr}$ concentrations. Adult females displayed increased methylation with increased $\mathrm{Sr}$, a trend also seen year to year in adult female recaptures. Overall, results of our study suggest sex-specific influences of shale gas development on gene expression that may affect long-term population survival and fitness.
\end{abstract}

Keywords: bioindicator, contaminants, DNA methylation, Marcellus-Utica, shale gas. INTRODUCTION

Natural gas production in the United States is expected to increase under all economic and demographic projections through 2050 primarily from continued unconventional drilling activity (hereafter shale gas development) of the Marcellus-Utica shale basin (EIA 2018). The 
central Appalachian region experienced some of the quickest growth over the last decade in shale gas development (MCOR 2016) since the underlying Marcellus-Utica shale is the most expansive basin and has the most potentially recoverable gas (DOE 2009). Between 2008 and 2018, 15,939 shale gas wells were developed at 5,674 sites across the Marcellus-Utica shale basin (Jacquet et al. 2018), with 2,528 wells developed in West Virginia (WVDEP 2018). The hydraulic fracturing process used to extract natural gas (Mongelli 2018) presents environmental challenges to wildlife (Brittingham et al. 2014) and watersheds (Latta et al. 2015), especially as it outpaces the ability to implement best management practices that avoid risks to aquatic and terrestrial wildlife communities and their habitat (Brittingham et al. 2014).

The Louisiana Waterthrush (Parkesia motacilla), hereafter waterthrush, is a forested headwater stream specialist known for its ability to respond to changes in ecological conditions (Mattsson and Cooper 2006) and is a species of conservation concern (USFWS 2008) due to its specialized habitat. As a biological indicator of biotic stream integrity (O'Connell et al. 2000, Mulvihill et al. 2008), waterthrush feed primarily on benthic macroinvertebrate aquatic prey (Mattsson et al., 2009) in well-developed riffle and pool areas (Prosser and Brooks 1998). In a long-term study, shale gas development negatively affected waterthrush demography (Frantz et al. 2018a, Frantz et al. 2019) and its aquatic prey (Wood et al. 2016, Frantz et al. 2018b), but we do not know if shale gas development may also influence waterthrush at a physiological (e.g., Kleist et al. 2018) or molecular level.

Little is known about epigenetic mechanisms in birds (Fresard et al. 2013), with only a small number of epigenetic studies conducted on wild bird populations (Schrey et al. 2012; Sheldon et al. 2018). Epigenetic modifications, such as DNA methylation, are an evolutionary "soft" inheritance of gene expression that can be either adaptive or maladaptive for the individual (Burdge and Lillycrop 2010). Epigenetic variation is dictated mostly by genetic control (Bossdorf et al. 2008), but it is the times when epigenetic variation is partly or completely independent of genetic control (Richards 2006) that is of the most interest to ecologists (Bossdorf et al. 2008). DNA methylation may vary in response to environmental stressors (Richards et al. 2010) and induce epigenetic changes that are inherited by future generations (Richards 2006; Herrera and Bazaga 2011). Chemical pollutants are one form of environmental stressor that may affect DNA methylation (Reyna-López et al. 1997; Pilsner et al. 2010). For instance, heavy metals may induce changes by affecting synthesis of substrate S-adenosylmethione (SAM) and 
its ability to donate methyl groups to methyltransferase enzymes (Hala et al. 2014). Epigenetic modifications therefore may facilitate a quick response to a changing environment (Rando and Verstrepen 2007; Bossdorf et al. 2008) by potentially introducing ecologically-relevant phenotypic variation within and among populations (Schrey et al. 2013).

As an apex predator, the waterthrush may be exposed to contaminants occurring in their aquatic prey or present in surface water of their riparian habitat. Previous work at our study sites found barium $(\mathrm{Ba})$ and strontium $(\mathrm{Sr})$, two heavy metals associated with the hydraulic fracturing process (Entrekin et al. 2011, Chapman et al. 2012), were bioaccumulated in waterthrush feathers at higher levels in shale gas disturbed areas than in undisturbed areas (Latta et al. 2015). Since waterthrush reach some of their highest abundances in the Marcellus shale region (Sauer et al. 2017), it is important to investigate the role of environmental stressors (especially anthropogenic ones) at the molecular level if stressors can increase DNA methylation variance (Dowen et al. 2012) or result in differential methylation by habitat type (Foust et al. 2016; McNew et al. 2017). Adult females can have a higher body condition index (BCI) than adult males in similar quality territories and can tolerate a wider range of territory quality (Latta et al. 2016). Thus, we expected differential methylation between adult males and females and for adult males to have a stronger response to shale gas development. We expected older adults to have fewer methylated restriction sites than younger adults and for nestlings to be differentially methylated from adults because decreased methylation is correlated with age in birds (De PaoliIseppi et al. 2018). Presuming nestlings are less exposed to stress during the hatching to fledging stage than adults during the breeding season, we hypothesized a weak response to shale gas development between shale gas disturbed and undisturbed areas if differential methylation can correlate to a gradient of stress (Sun et al. 2018). Finally, we hypothesized that heavy metal concentrations are inversely correlated to the number of methylated restriction sites since contaminants interfere with methyl transfer (Hala et al. 2014).

From 2013-2015, we 1) examined how shale gas development may influence variation in DNA methylation (hereafter differential methylation) of waterthrush occurring on territories identified as shale gas undisturbed and disturbed; 2) determined if differential methylation of DNA fragments or loci, hereafter restriction sites, varied by sex and age; 3) identified if differentially methylated restriction sites were potentially under selection; 4) correlated methylated restriction sites to $\mathrm{Ba}$ and $\mathrm{Sr}$ heavy metal concentrations bioaccumulated in 
waterthrush feathers; and 5) evaluated the degree to which an individual's methylated state was subject to change across years.

\section{METHODS}

\section{Study Area}

We studied waterthrush epigenetic response (2013-2015) as part of a six-year study along 14 1st- and 2nd-order forested headwater stream tributaries that totaled $58.1 \mathrm{~km}$ at the Lewis Wetzel Wildlife Management Area (LWWMA; 39 29.654' N, 80 38.491' E) located in Wetzel County, West Virginia, USA (Frantz et al. 2018a, 2018b, 2019). In 2008, LWWMA was 95.3\% forested with the first shale gas development starting in 2007 (Farwell et al. 2016). By 2015, LWWMA was $90.8 \%$ forested with forest loss (4.5\%) primarily due to shale gas (Farwell et al. 2016), but with no new shale gas development or activity during the 2015 breeding season. Shale gas disturbance on streams was highly variable within each year, but on average across 2013-2015 streams had 19.2 $\pm 3.4 \%$ of their length disturbed by shale gas development (range 0-67\%; Frantz et al. 2018a).

\section{Louisiana Waterthrush banding and monitoring}

Annually, territorial adult waterthrush were target-netted and banded with an aluminum US Geological Survey leg band and a unique combination of colored plastic bands to allow identification of individuals while nestlings were banded $~ 7-8$ days after hatching (Frantz et al. 2019). Age (nestlings = hatching year [HY]; adults = second year [SY], after second year [ASY], or after hatching year [AHY]) was determined from plumage characteristics (Pyle 1997)). Blood $(5-10 \mu \mathrm{L})$ was collected from 146 individual adults and 159 nestlings by venipuncture from the ulnar vein of the wing for epigenetic analysis. Ten additional blood samples were collected from nine adult recaptures in following years with one individual recaptured in two subsequent years. Blood samples were preserved in RNAlater Stabilizing Solution (Invitrogen Corporation, Grand Island NY) and were refrigerated until DNA extraction. Feather samples were collected from adults and nestlings in 2013 to measure Barium $(\mathrm{Ba})$ and Strontium $(\mathrm{Sr})$ bioaccumulation as part of a contaminant study (Latta et al. 2015).

Waterthrush territories were delineated along each stream during April 1-June 29 using standardized territory mapping ( $>6$ stream visits) with nest searching, nest monitoring, and resightings of banded individuals occurring concurrently with territory mapping (Frantz et al. 2019). We digitized annual shale gas disturbance on the study area and classed each territory as 
undisturbed or disturbed by shale gas (see Frantz et al. 2018a for details), creating a binary (undisturbed or disturbed) TerrGas and TerrRunoff variable for each territory. TerrGas described presence or absence of localized streamside disturbance from any shale gas infrastructure or activity. TerrRunoff focused solely on potential shale gas contaminant erosional run-off from direct and mostly upstream sources (similar to Latta et al. 2015).

\section{Differential Methylation}

DNA was extracted with a DNeasy Kit (Qiagen, Valencia CA) and quantified using a Nanodrop (ThermoScientific) for analysis of differential methylation. Methylation-sensitive amplified fragment length polymorphism (MS-AFLP), a DNA fingerprinting method for nonmodel organisms (Schrey et al. 2013), was performed as outlined in Schrey et al. (2012) with the modification that digestion and ligation were performed in one step and digestion-ligation incubation for three hours. Selective PCR products were evaluated using a Beckman Coulter CEQ 8000 Genetic Analysis System. The protocol was performed with >10\% random duplication of samples $(n=40)$ to choose consistent restriction sites for scoring and validate individual results; any restriction sites that could not be validated were removed. Each restriction site was scored as either methylated or unmethylated for individuals, creating an epigenotype per individual (Schrey et al. 2012).

\section{Statistical Analysis}

We completed Analysis of Molecular Variance (AMOVA) tests to calculate $\Phi_{\text {st }}(\mathrm{PhiPT}$, a genetic distance estimate) and characterize overall population differential methylation by sex, age, and shale gas disturbance using GenAlEx (Peakall and Smouse 2006, 2012). We tested if there was overall population differential methylation between adult males, adult females, and nestlings. For adult males and females, we further examined influence of age by comparing SY to ASY; AHYs ( $n=7)$ were removed from analysis due to age uncertainty. We also tested overall population differential methylation between shale gas undisturbed and disturbed areas for TerrGas and TerrRunoff in adult males, adult females, and nestlings. When any overall population comparison was statistically significant, restriction sites were also analyzed individually to determine which restriction sites were driving the overall differential methylation. Statistical significance was determined by 9999 permutations with $a=0.10$ to not miss variation that may be of biological significance (Askins et al. 1990). BAYESCAN (Foll and Gaggiotti 2008) was used to identify any outlier restriction sites as potentially under selection from those 
previously determined to be statistically significant. Log10 values of posterior odds (PO) were interpreted as a type of Bayes factor for evidence of selection using Jeffreys' scale for Bayes factors (Jeffreys 1961; Foll and Gaggiotti 2008).

If TerrGas or TerrRunoff was statistically significant for adult males, adult females, or nestlings, the restriction sites driving the overall differential methylation were used to correlate the total amount of methylation across restriction sites to $\mathrm{Ba}$ and $\mathrm{Sr}$ heavy concentrations bioaccumulated in waterthrush feathers. Otherwise, all restriction sites were used. The test was limited to waterthrush sampled in 2013 that had both blood samples and Ba and Sr feather data from Latta et al. (2015). A Box-Cox transformation was performed on Ba and $\mathrm{Sr}$ data (in ppm) to approach normality using R package car (Fox et al. 2015) in R (R Core Team 2014). We used the transformed $\mathrm{Ba}$ and $\mathrm{Sr}$ data to conduct a Pearson correlation of the total amount of methylation across restriction sites to $\mathrm{Ba}$ and $\mathrm{Sr}$ concentrations using $\mathrm{R}$ package psych (Revelle 2017).

\section{RESULTS}

We confirmed 100 restriction sites ranging from 135-591 DNA base pairs in length that we could score for differential methylation. There was differential methylation in all individuals scored $(n=315)$, where all individuals except for two had a unique epigenotype across all restriction sites. Across all statistically significant population level comparisons, withinpopulation variation ranged $97-99 \%$ and among population variation ranged $1-3 \%$ in the differentially methylated populations (Table 1).

Adult males $(n=107)$ were differentially methylated from adult females $(n=49$; Table 1), with over 39 restriction sites differentially methylated by sex (Appendix Table 1). Across all restriction sites and only those that were statistically significant for adult males, adult males had fewer methylated restriction sites than adult females (Appendix Table 2). Adult females were differentially methylated from nestlings (Table 1) at 35 restriction sites (Appendix Table 1), but adult males were not (Table 2). Adult females had more methylated restriction sites than nestlings across all restriction sites and those that were statistically significant (Appendix Table 3).

Adult males and adult females were both differentially methylated by age (Table 1). Adult males had 21 restriction sites differentially methylated between SY and ASY individuals (Appendix Table 1), while adult females had 18 restriction sites (Appendix Table 1). All 21 restriction sites in adult males were less methylated as an ASY (Appendix Table 4), whereas in 
adult females 16 of 18 restriction sites were less methylated (Appendix Table 5). Out of the 21 and 18 restriction sites differentially methylated by age in adult males and females, only about 10\% (four restriction sites: 340, 419, 532, 541) were the same between the sexes.

Adult males were not differentially methylated by TerrRunoff (Table 2). However, adult males from territories with presence of TerrGas were differentially methylated from those with absence of TerrGas (Table 1). Adult males had 10 restriction sites that were differentially methylated between shale gas undisturbed and disturbed territories (Appendix Table 1). Nine of the 10 restriction sites were less methylated in shale gas disturbed territories (Appendix Table 6); only one of these restriction sites (i.e., 541) was also a significant restriction site for adult male age. Adult females and nestlings were not differentially methylated by TerrGas or TerrRunoff, although adult females had $1 \%$ among population variance for TerrRunoff (Table 2). No evidence for restriction sites potentially under selection was found for any of the statistically significant differentially methylated restriction sites by sex, adult females vs. nestlings, adult male and female age, nor TerrGas (Appendix Table 7).

For adult males $(n=46)$, the number of methylated restriction sites decreased with increasing $\mathrm{Sr}\left(\mathrm{R}^{2}=-32, P=0.03\right.$; Figure 1$)$. The number of methylated restriction sites also tended to decrease with increasing $\mathrm{Ba}$, but it was not statistically significant $\left(\mathrm{R}^{2}=-19, P=0.20\right)$. Adult female $(\mathrm{n}=11)$ methylated restriction sites increased with increasing $\operatorname{Sr}\left(\mathrm{R}^{2}=0.55, P=\right.$ 0.08; Figure 1). The number of methylated restriction sites for adult females tended to increase with increasing $\mathrm{Ba}$, but it was not statistically significant $\left(\mathrm{R}^{2}=0.46, P=0.16\right)$. Nestlings $(\mathrm{n}=$ 29) did not have any statistically significant correlations for the number of methylated restriction sites with $\mathrm{Sr}\left(\mathrm{R}^{2}=-11, P=0.58\right)$ or $\mathrm{Ba}\left(\mathrm{R}^{2}=0.02, P=0.92\right)$.

Three adult male and five adult female recaptures were evaluated for temporal trends in methylation, as well as one nestling recaptured as an adult female (Table 3). Two of the three adult male recaptures that had TerrGas presence in their territories had decreased methylation in the second year (Table 3). Adult male recaptures displayed decreased methylation in the second year, but adult female recaptures had increased methylation in subsequent years. The only nestling recaptured as an adult displayed the same trends as other adult female recaptures.

\section{DISCUSSION}

Our study detected at a molecular level differential methylation in a wild bird population relative to demographic characteristics and environmental influence of shale gas development 
despite a high amount of within-population variation (Table 1). Adult males and females were differentially methylated (Appendix Table 2), and nestlings were differentially methylated from females with methylation patterns similar to that of males (Appendix Table 3). Our study is the second for a wild bird population that suggests methylation varies with age. Humans have an epigenetic clock where methylation increases with age (Horvath 2013), but waterthrush generally displayed decreased methylation with age, similar to that found in a seabird at most age-related restriction sites (De Paoli-Iseppi et al. 2018). In addition to methylation varying with pollutant concentrations as previously seen in a wild bird population (Romano et al. 2016), our study is the first for a wild bird population to suggest a potential sex-specific epigenetic response to contaminants.

Adjacent, local wild bird populations can be differentially methylated due to living under different environmental conditions (McNew et al. 2017). Males in shale gas disturbed territories had fewer methylated restriction sites than males in undisturbed territories (Appendix Table 6) with unknown consequences on gene expression. Only one adult male recapture had no TerrGas disturbance each of the two years and had the same number of methylated restriction sites of the 10 identified as significant to TerrGas. The other two adult male recaptures had TerrGas disturbance each year and exhibited decreased methylation the following year among both TerrGas and age-related restriction sites (Table 3), consistent with overall population level results for adult males differentially methylated by TerrGas (Appendix Table 6). Sr and Ba were present in waterthrush feathers of both shale gas disturbed and undisturbed territories but was significantly higher in disturbed territories (Latta et al. 2015). Since heavy metals interfere with methyl transfer (Hala et al. 2014), evidence from our study suggests a strong possible link of males in shale gas disturbed areas having fewer methylated sites in response to direct exposure to contaminant sources. Only one age-related restriction site (i.e., 541) was shared with differentially methylated TerrGas restriction sites where there may be an interacting effect. Although Latta et al. (2015) did not trace the origin of the contaminants, the metals were hypothesized to have originated in the Marcellus Shale layer where they are known to be abundant (Entrekin et al. 2011; Chapman et al. 2012), and both surface waters and benthic aquatic prey were negatively affected by shale gas disturbance at our study site (Frantz et al. 2018a, 2018b). 
Females have a higher body condition index than males and can cope with a wider range of territory quality conditions (Latta et al. 2016). In our long-term study, males exhibited very high site fidelity returning to the same shale gas disturbed territories despite lower riparian habitat quality, but females in disturbed territories had a higher number of breeding attempts and were less likely to return (Frantz et al. 2019). Brood size alone can affect nestling DNA methylation (Sheldon et al. 2018), so prenatal stress from the increased number of breeding attempts could potentially affect differential methylation in waterthrush nestlings. Males arrive first on the breeding grounds to set up a territory (Mattsson et al. 2009) where females must select a nest site within the defended male's territory, so female capacity to handle environmental perturbation does not necessarily mean the ability to avoid disturbance with potential consequences to long-term population persistence. The contribution that differential methylation has on survivorship and fitness, at least for males, needs to be determined if shale gas disturbed areas are borderline "sink" habitats (Frantz et al. 2018a).

Our study adds to existing evidence that methylation varies with pollutant concentrations (Romano et al. 2016) but is the first to indicate a potential sex-specific epigenetic response to contaminants in a wild bird population. Adult females had an increased number of methylated sites with increasing $\mathrm{Sr}$ whereas adult males had fewer methylated sites with increasing $\mathrm{Sr}$ (Figure 1). Epigenetic responses to contaminants can be sex-specific such as in polar bears (Ursus maritimus) where males had mercury-related brain hypomethylation, but females did not (Pilsner et al. 2010). Interestingly, adult female recaptures had increased methylation the following year across all restriction sites and at age-related restriction sites when methylation decreased with age for the adult male recaptures (Table 3) and for adult males overall (Appendix Table 4); the trend for adult female recaptures was also opposite that seen when analyzing adult females overall (Appendix Table 5). As such, the differing methylation patterns seen in adult female recaptures compared to overall adult female methylation patterns may be a typical response to contaminants but masked by small sample size (5 of 49 adult females). Levels of oxidative stress are affected by heavy metals (Stauffer 2017), where oxidative stress is a component of aging in birds (Xia and Møller 2018). Contaminants can create an "epigenetic trap" where epigenetic machinery is hijacked and may produce a phenotype that is maladaptive or mismatched for the environment (O’Dea et al. 2016), a possibility at not just our study area but other shale play regions (Latta et al. 2015). 
DNA methylation is chiefly eliminated from germlines during gametogenesis and post fertilization but is not always complete (Wang et al. 2017). We did not detect differential methylation in nestlings between undisturbed and disturbed areas despite an expected weak signal if variability in methylation can establish over relatively short evolutionary time scales (Verhoeven et al. 2010). Adult waterthrush can provision nestlings with food items (i.e., terrestrial prey) that differ from what adults consume (Trevelline et al. 2016, 2018), which may buffer nestlings from any water-borne disturbances related to shale gas development. Because waterthrush nestlings typically disperse from their natal territory (Mattsson et al. 2009), our only return nestling was female and exhibited the same trend as the return adult females where methylation increased the following year (Table 3). Early environmental effects on a nestling's phenotype can be sex specific, and the environment experienced during early development may have a broader impact on the adult phenotype than that experienced later in life (Fresard et al. 2013). We should therefore caution drawing any conclusion that shale gas disturbance does not affect nestlings nor females from a lack of statistically significant differential methylation; nestlings that are males may be more susceptible, or females may be just as susceptible but exhibit a different methylation response to stressors (Figure 1).

No outlier restriction sites (i.e., loci) were identified as potentially under selection. While none were detected, our study identifies candidate restriction sites worthy of further attention. Given that we did see differentially methylated populations, these relationships may be complicated where only a few of these variable restriction sites may be ecologically important (Schrey et al. 2012). Methylation patterns are typically responsible for gene silencing (Li et al. 2011) but also can cause active transcription (Jones 2012). Epigenetic modifications are known to be involved in immune response (Gou et al. 2012), disease modulation (Luo et al. 2012a, 2012b), and may alter gene transcription from stress (Xu et al. 2012). Non-colonial, distributed bird species typically exhibit high gene flow (Barrowclough 1980; Avise 1994) which can both prevent and allow selection to occur. Factors that may explain a lack of selection include selection on restriction sites too weak to cause a "selective sweep" in the population without more time being involved, or too rare for selection to drive restriction sites to fixation without a certain number of generations since the environmental influence (e.g. Pritchard et al. 2010). Given the amount of within-population variability, higher statistical power may be necessary for 
detection (e.g., Schrey et al. 2012), which may also apply to the lack of population level differential methylation in females (15.6\% of sample size) in relation to shale gas development.

Our study is the first to our knowledge to relate shale gas development to a molecular level, epigenetic response in a wildlife population. We provide a genome-wide snapshot of differential methylation in response to demographic and environmental factors, despite the limitations of MS-AFLP (see Schrey et al. 2013), where additional techniques can further be incorporated to identify the function of the methylated restriction sites in question. Differential methylation could provide a short-lived means to adapt in a rapidly changing environment, but its effects on genetic variation could have lasting impacts (O'Dea et al. 2016). Methylation levels are tissue-specific ( $\mathrm{Li}$ et al. 2011), so the scope of epigenetic effects on waterthrush populations may be much broader. Most of the core breeding range of the waterthrush overlaps the Marcellus-Shale region (Sauer et al. 2017), meriting concern if there are potential long-term fitness and survival consequences from differential methylation between shale gas undisturbed and disturbed areas, especially when contaminants may further alter methylation (Nilsen et al. 2016).

\section{Funding}

Our research was funded by the West Virginia Division of Natural Resources (WVDNR), Appalachian Stewardship Foundation (ASF), West Virginia University (WVU), Eastern Bird Banding Association (EBBA), and the National Aviary's Avian Conservation Endowment. This work was also supported by the USDA National Institute of Food and Agriculture, Hatch project WVA00690.

\section{Competing Interests}

The authors do not have any conflicts of interest related to this work.

\section{ACKNOWLEDGMENTS}

West Virginia Division of Natural Resources (WVDNR) provided access to the study area and Wheeling Jesuit University provided access to field housing. We thank Jack Toriello, Robert (Blake) Hepner, Darin Blood, Jerry Kreiser, Steve Daniels, Jess Cosentino, Ashley Akers, Sara Crayton, and Celeste Rosencrance for assistance with collection of field and lab data. We thank members of the WVU Wild Genomics Lab, Aaron Schrey, and Andrea Liebl for assistance with lab protocols. This study was completed under the auspices of West Virginia University 
IACUC protocol \#04-0302, 07-0303. Any use of trade, firm, or product names is for descriptive purposes only and does not imply endorsement by the U.S. Government.

\section{LITERATURE CITED}

Askins, R.A., Lynch, J.F. \& Greenberg, R. 1990. Population declines in migratory birds in eastern North America. Current Ornithol. 7: 1-57.

Avise, J.C. 1994. Molecular Markers, Natural Selection, and Evolution. New York: Chapman and Hill.

Barrowclough, G.F. 1980. Gene flow, effective population sizes, and genetic variance components in birds. Evolution 34: 789-798.

Bossdorf, O., Richards, C.L., \& Pigliucci, M. 2008. Epigenetics for ecologists. Ecol. Lett. 11: 106-115.

Brittingham, M.C., Maloney, K.O., Farag, A.M., Harper, D.D., \& Bowen, Z.H. 2014. Ecological risks of shale oil and gas development to wildlife, aquatic resources and their habitats. Environ. Sci. Technol. 48: 11034-11047.

Burdge, G.C., \& Lillycrop, K.A. 2010. Nutrition, epigenetics, and developmental plasticity: implications for understanding human disease. Annu. Rev. Nutr. 30: 315-339.

Chapman, E.C., Capo, R.C., Stewart, B.W., Kirby, C.S., Hammack, R.W., Schroeder, K.T., \& Edenborn, H.M. 2012. Geochemical and strontium isotope characterization of produced waters from Marcellus shale natural gas extraction. Environ. Sci. Technol. 46: 3545-3553.

De Paoli-Iseppi, R., Deagle, B.E., Polanowski, A.M., M.M McMahon, C.R., Dickinson, J.L., Hindell, M.A., \& Jarman, S.N. 2018. Age estimation in a long-lived seabird (Ardenna tenuirostris) using DNA methylation-based biomarkers. Mol. Ecol. Resour. 10.111/17550998.12981.

DOE (Department of Energy). 2009. Modern shale gas development in the United States: a primer. Office of Fossil Energy and National Energy Technology Laboratory, U.S. Department of Energy, Washington, D.C.

Dowen, R.H., Pelizzola, M., Schmitz, R.J., Lister, R., Dowen, J.M., Nery, J.R., Dixon, J.E., \& Ecker, J.R. 2012. Widespread dynamic DNA methylation in response to biotic stress. PNAS 109: E2183-E2191.

EIA (Energy Information Administration). 2018. Annual energy outlook 2018 with projections to 2050. U.S. Department of Energy, Washington, D.C.

Entrekin, S., Evans-White, M., Johnson, B., \& Hagenbuch, E. 2011. Rapid expansion of natural gas development poses a threat to surface waters. Front. Ecol. Environ. 9: 503-511. 
Farwell, L.S., Wood, P.B., Sheehan, J., \& George, G.A. 2016. Shale gas development effects on the songbird community in a central Appalachian forest. Biol. Conserv. 201: 78-91.

Foll, M., \& Gaggiotti, O.E. 2008. A genome scan method to identify selected loci appropriate for both dominant and codominant markers: a Bayesian perspective. Genetics 180: 977-993.

Foust, C.M., Preite, V., Schrey, A.W., Alvarez, M., Robertson, M.H., Verhoeven, K.J.F., \& Richards, C.L. 2016. Genetic and epigenetic differences associated with environmental gradients in replicate populations of two salt marsh perennials. Mol. Ecol. 25: 1639-1652.

Fox, J., Weisberg, S., Adler, D., Bates, D., Baud-Bovy, G., Ellison, S., Firth, D., Friendly, M., Gorjanc, G., Graves, S., Heiberger, R., Laboissiere, R., Monette, G., Murdoch, D., Nilsson, H., Ogle, D., Ripley, B., Venables, W., Winsemius, D., Zeileis, A., \& R-Core. 2017. Package 'car'. Version 2.1-5. https://CRAN.R-project.org/package=car (accessed 2017 July 19).

Frantz, M.W., Wood, P.B., Sheehan, J., \& George, G. 2018a. Demographic response of a migratory songbird of conservation concern to shale gas development. Condor: Ornithological Applications 120: 265-282.

Frantz, M.W., Wood, P.B., Merovich, G.T. Jr. 2018b. Demographic characteristics of an avian predator, Louisiana Waterthrush (Parkesia motacilla), in response to its aquatic prey in a Central Appalachian USA watershed impacted by shale gas development. PLOS ONE 13: e0206077.

Frantz, M.W., Wood, P.B., Sheehan, J., \& George, G. 2019. Louisiana Waterthrush (Parkesia motacilla) survival and site fidelity in an area undergoing shale gas development. Wilson J. Ornithol. 131: 84-95.

Fresard, L., Morisson, M., Brun, J-M., Collin, A., Pain, B., Minvielle, F., \& Pitel, F. 2013. Epigenetics and phenotypic variability: some interesting insights from birds. Genet. Sel. Evol. 45: 16.

Gou, Z., Liu, R., Zhao, G., Zheng, M., Li, P., Wang, H., Zhu, Y., Chen, J., \& Wen, J. 2012. Epigenetic modification of TLRs in leukocytes is associated with increased susceptibility to Salmonella enteritidis in chickens. PLOS ONE 7: e33627.

Hala, D., Huggett, D.B., \& Burggren, W.W. 2014. Environmental stressors and the epigenome. Drug Discov. Today Technol. 12: e3-e8.

Herrera, C.M., \& Bazaga, P. 2011. Untangling individual variation in natural populations: ecological, genetic and epigenetic correlates of long-term inequality in herbivory. Mol. Ecol. 20: $1675-1688$.

Jacquet, J.B., Junod, A.N., Bugden, D., Wildermuth, G., Fergen, J.T., Jalbert, K., Rahm, B., Hagley, P., Brasier, K.J., Schafft, K., Glenna, L., Kelsey, T., Fershee, J., Kay, D.L., Stedman, 
R.C., \& Ladlee J. 2018. A decade of Marcellus shale: impacts to people, policy, and culture from 2008 to 2018 in the Greater Mid-Atlantic region of the United States. Extr. Ind. Soc. 5: 596-609.

Jeffreys, H. 1961. Theory of Probability. Oxford Classic Texts in the Physical Sciences. Oxford: Oxford University Press.

Jones, P.A. 2012. Functions of DNA methylation: islands, start sites, gene bodies and beyond. Nat. Rev. Genet. 13: 484-492.

Horvath, S. 2013. DNA methylation age of human tissues and cell types. Genome Biol. 14: R115.

Kargbo, D.M., Wilhem, R.G., \& Campbell, D.J. 2010. Natural gas plays in the Marcellus shale: challenges and potential opportunities. Environ. Sci. Technol. 44: 5679-5684.

Kleist, N.J., Guralnick, R.P., Cruz, A., Lowry, C.A., \& Francis, C.D. 2018. Chronic anthropogenic noise disrupts glucocorticoid signaling and has multiple effects on fitness in an avian community. PNAS 115: E648-E657.

Latta, S.C., Marshall, L.C., Frantz, M.W., \& Toms, J. 2015. Evidence from two shale regions that a riparian songbird accumulates metals associated with hydraulic fracturing. Ecosphere 6: 144.

Latta, S.C., Cabezas, S., Mejia, D.A., Paulino, M.M., Almonte, H., Miller-Butterworth, C.M., \& Bortolotti, G.R. 2016. Carry-over effects provide linkages across the annual cycle of a Neotropical migratory bird, the Louisiana Waterthrush Parkesia motacilla. Ibis 158: 395-406.

Li, Q., Li, N., Hu, X., Li, J., Du, Z., Chen, L., Yin, G., Duan, J., Zhang, H., Zhao, Y., Wang, J., \& Li, N. 2011. Genome-wide mapping of DNA methylation in chicken. PLOS ONE 6: e19428. Luo, J., Yu, Y., Chang, S., Tian, F., Zhang, H., \& Song, J. 2012a. DNA methylation fluctuation induced by virus infection differs between MD-resistant and -susceptible chickens. Front. Genet. 3: 20 .

Luo, J., Mitra, A., Tian, F., Chang, S., Zhang, H., Cui, K., Yu, Y., Zhao, K., \& Song, J. 2012 b. Histone methylation analysis and pathway predictions in chickens after MDV infection. PLOS ONE 7: e41849.

Mattsson, B.J., Master, T.L., Mulvihill, R.S., \& Robsinson, W.D. 2009. Louisiana Waterthrush (Parkesia motacilla). In Rodewald, P.G., (ed) The Birds of North America. Ithaca: Cornell Lab of Ornithology. https://doi.org/10.2173/bna.151 (accessed 2017 July 12).

Mattsson, B.J., \& Cooper, RJ. 2006. Louisiana waterthrushes (Seiurus motacilla) and habitat assessment as cost effective indicators of instream biotic integrity. Freshw. Biol. 51: 1941-1958. 
Mattsson, B.J., \& Cooper, R.J. 2009. Multi-scale analysis of the effects of subseasonal rainfall extremes on reproduction by an obligate riparian bird in urban and rural landscapes. $A u k 126$ : 64-76.

McNew, S.M., Beck, D., Sadler-Riggleman, I., Knutie, S.A., Koop, J.A.H., Clayton, D.H., Skinner, M.K. 2017. Epigenetic variation between urban and rural populations of Darwin's finches. BMC Evol. Biol. 17: 183.

MCOR (Marcellus Center for Outreach and Research). 2016. Unconventional wells drilled by year. http://www.marcellus.psu.edu/resources/images/tristate-static-2016.jpg (accessed 2017 July 12).

Mongelli, G.F. 2018. Challenges and opportunities of shale gas extraction via hydraulic fracturing. Journal of Material Sciences 6: 117-133.

Mulvihill, R.S., Newell, F.L., \& Latta, S.C. 2008. Effects of acidification on the breeding ecology of a stream-dependent songbird, the Louisiana Waterthrush (Seiurus motacilla). Freshw. Biol. 53: 2158-2169.

Nilsen, F.M., Parrott, B.B., Bowden, J.A., Kassim, B.L., Somerville, S.E., Bryan, T.A., Bryan, C.E., Lange, T.R., Delaney, J.P., Brunell, A.M., Long, S.E., \& Guillette, L.J. Jr. 2016. Global DNA methylation loss associated with mercury contamination and aging in the American alligator (Alligator mississippiensis). Sci. Total Environ. 545-546: 389-397.

O’Connell, T.R., Brooks, R.P., Laubscher, S.E., Mulvihill, R.S., \& Master, T.E. 2003. Using bioindicators to develop a calibrated index of regional ecological integrity for forested headwater ecosystems. Final report. University Park (PA): Penn State Cooperative Wetlands Center, Penn State University. U.S. Environmental Protection Agency, STAR Grants Program. Report No. 2003-01.

O’Dea, R.E., Noble, D.W.A., Johnson, S.L., Hesselson, D., \& Nakagawa, S. 2016. The role of non-genetic inheritance in evolutionary rescue: epigenetic buffering, heritable bet hedging and epigenetic traps. Environ. Epigenet. 2: dvv014.

Peakall, R., \& Smouse, P.E. 2006. GENALEX 6: genetic analysis in Excel. Population genetic software for teaching and research. Mol. Ecol. Notes 6: 288-295.

Peakall, R. \& Smouse, P.E. 2012. GenAlEx 6.5: genetic analysis in Excel. Population genetic software for teaching and research - an update. Bioinformatics 28: 2537-2539.

Pilsner, J.R., Lazarus, A.L., Nam, D-A., Letcher, R.J., Sonne, C., Dietz, R., \& Basu, N. 2010. Mercury-associated DNA hypomethylation in polar bear brains via the LUminometric

Methylation Assay: a sensitive method to study epigenetics in wildlife. Mol. Ecol. 19: 307-314.

Pritchard, J.K., Pickrell, J.K., \& Coop, G. 2010. The genetics of human adaptation: hard sweeps, soft sweeps, and polygenic adaptation. Curr. Biol. 20: R208-R215. 
Prosser, D.J., \& Brooks, R.P. 1998. A verified habitat suitability index for the Louisiana Waterthrush. J. Field Ornithol. 69: 288-298.

Pyle, P. 1997. Identification guide to North American birds, part 1: Columbidae to Ploceidae. Slate Creek Press, Bolinas, CA, USA.

Rando, O.J., \& Verstrepen, K.J. 2007. Timescales of genetic and epigenetic inheritance. Cell 128: 655-668.

R Development Core Team. 2014. R: a language and environment for statistical computing. R Foundation for Statistical Computing, Vienna, Austria.

Revelle, W. 2017. Package 'psych'. Version 1.7.5. https://CRAN.Rproject.org/package=psych (accessed 2017 July 19).

Reyna-López, G.E., Simpson, J., \& Ruiz-Herrera, J. 1997. Differences in DNA methylation patterns are detectable during the dimorphic transition of fungi by amplification of restriction polymorphisms. Mol. Gen. Genet. 253: 703-710.

Richards, E.J. 2006. Inherited epigenetic variation- revisiting soft inheritance. Nat. Rev. Genet. 7: 395-401.

Romano, A., De Giorgio, B., Parolini, M., Favero, C., Possenti, C.D., Iodice, S., Caprioli, M., Rubolini, D., Ambrosini, R., Gianfranceschi, L., Saino, N., Bollati, V. Methylation of the circadian Clock gene in the offspring of a free-living passerine bird increases with maternal and individual exposure to $\mathrm{PM}_{10}$. 2016. Environ. Pollut. 220 (Pt A): 29-37.

Sauer, J.R., Niven, D.K., Hines, J.E., Ziolkowski, D.J. Jr., Pardieck, K.L., Fallon, J.E., \& Link, W.A. 2017. The North American breeding bird survey, results and analysis 1966-2015. Version 2.07.2017. Laurel (MD): USGS Patuxent Wildlife Research Center. http://www.mbrpwrc.usgs.gov/bbs/ (accessed 2017 July 19).

Schrey, A.W., Coon, C.A.C., Grispo, M.T., Awad, M., Imboma, T., McCoy, E.D., Mushinsky, H.R., Richards, C.L., \& Martin, L.B. 2012. Epigenetic variation may compensate for decreased genetic variation with introductions: a case study using house sparrows on two continents. Genet. Res. Int. 2012: 1-7.

Schrey, A.W., Alvarez, M., Foust, C.M., Kilvitis, H.J., Lee, J.D., Liebl, A.L., Martin, L.B., Richards, C.L., \& Robertson, M. 2013. Ecological Epigenetics: beyond MS-AFLP. Integr. Comp. Biol. 53: 1-11.

Sheldon, E.L., Schrey, A.W., Ragsdale, A.K., \& Griffith, S.C. 2018. Brood size influences patterns of DNA methylation in wild Zebra Finches (Taeniopygia guttata). The Auk:

Ornithological Advances 135: 1113-1122. 
Stauffer, J., Panda, B., Eeva, T., Rainio, M., \& Ilmonen, P. 2017. Telomere damage and redox status alterations in free-living passerines exposed to metals. Sci Total Environ. 575: 841-848.

Sun, L., Miao, X., Cui, J., Deng, J., Wang, X., Wang, Y., Zhang, Y., Gao, S., \& Yang, K. 2018. Genome-wide high-resolution mapping of DNA methylation identifies epigenetic variation across different salt stress in Maize (Zea mays L.). Euphytica 214: 25.

Trevelline, B.K., Latta, S.C., Marshall, L.C., Nuttle, T., \& Porter, B.A. 2016. Molecular analysis of nestling diet in a long-distance Neotropical migrant, the Louisiana Waterthrush (Parkesia motacilla). The Auk: Ornithological Applications 133: 415-428.

Trevelline, B.K., Nuttle, T., Hoenig, B.D., Brouwer, N.L., Porter, B.A., \& Latta, S.C. 2018. DNA metabarcoding of nestling feces reveals provisioning of aquatic prey and resource partitioning among Neotropical migratory songbirds in a riparian habitat. Oecologia 187: 85-98.

United States Fish and Wildlife Service (USFWS). 2008. Birds of conservation concern 2008. Arlington (VA): United States Department of Interior, Fish and Wildlife Service, Division of Migratory Bird Management. http://www.fws.gov/migratorybirds (accessed 2015 Dec 24).

Verhoeven, K.J.F., Jansen, J.J., van Dijk, P.J., \& Biere, A. 2010. Stress-induced DNA methylation changes and their heritability in asexual dandelions. New Phytol. 185: 1108-1118.

Wang, Y., Liu, H., \& Sun, Z. 2017. Lamarck rises from his grave: parental environment-induced epigenetic inheritance in model organisms and humans. Biol. Rev. 92: 2084-2111.

Whitaker, J.M., Welsh, A.B., Hondorp, D.Q., Boase, J.C., Merovich, G.T., Welsh, S., \& Krueger, C. 2018. Variation in DNA methylation is associated with migratory phenotypes of lake sturgeon Acipenser fulvescens in the St. Clair River, MI, USA. J. Fish Biol. 93: 942-951.

Wood, P., Frantz, M., \& Becker, D. 2016. Louisiana Waterthrush and benthic macroinvertebrate response to shale gas development. J. Fish Wildl. Manag. 7: 423-433.

WVDEP (West Virginia Department of Environmental Protection) 2018. Office of Oil and Gas. https://tagis.dep.wv.gov/oog/ (accessed 31 March 2018).

Xia, C., \& Möller, A.P. 2018. Long-lived birds suffer less from oxidative stress. Avian Res. 9: 41.

Xu, P., Denbow, C.J., Meiri, N., \& Denbow, D.M. 2012. Fasting of 3-day-old chicks leads to changes in histone H3 methylation status. Physiol. Behav. 105: 276-282. 


\section{TABLES}

Table 1. Summary results of Analysis of Molecular Variance (AMOVA) performed on 100 methylation-sensitive amplified fragment-length polymorphism (MS-AFLP) restriction sites grouped by sex, adult female vs. nestling, age (second year [SY] vs. after second year [ASY]) and shale gas disturbance status (TerrGas), showing differential methylation $(P<0.10)$ on a population level.

\begin{tabular}{lcccccc} 
& df & $\begin{array}{c}\text { Sum of } \\
\text { squares }\end{array}$ & $\begin{array}{c}\text { Mean } \\
\text { squares }\end{array}$ & $\begin{array}{c}\% \\
\text { Variance }\end{array}$ & PhiPT & p value \\
\hline Male vs. Female & & & & & & \\
Among Populations & 1 & 46.810 & 46.810 & $2 \%$ & 0.022 & 0.000 \\
Within Populations & 154 & 2841.652 & 18.452 & $98 \%$ & & \\
$\quad$ Total & 155 & 2888.462 & & $100 \%$ & & \\
Female vs. Nestling & & & & & & \\
Among Populations & 1 & 50.090 & 50.090 & $2 \%$ & 0.023 & 0.000 \\
Within Populations & 206 & 3691.679 & 17.921 & $98 \%$ & & \\
$\quad$ Total & 207 & 3741.769 & & $100 \%$ & & \\
Male SY vs ASY & & & & & & \\
Among Populations & 1 & 26.645 & 26.645 & $2 \%$ & 0.023 & 0.013 \\
Within Populations & 99 & 1694.266 & 17.114 & $98 \%$ & & \\
$\quad$ Total & 100 & 1720.911 & & $100 \%$ & & \\
Female SY vs ASY & & & & & & \\
Among Populations & 1 & 34.066 & 34.066 & $3 \%$ & 0.032 & 0.017 \\
Within Populations & 46 & 961.288 & 20.898 & $97 \%$ & & \\
$\quad$ Total & 47 & 995.354 & & $100 \%$ & & \\
Male TerrGas & & & & & & \\
Among Populations & 1 & 21.469 & 21.469 & $1 \%$ & 0.005 & 0.088 \\
$\quad$ Within Populations & 93 & 1592.594 & 17.125 & $99 \%$ & & \\
Total & 94 & 1614.063 & & $100 \%$ & & \\
\hline
\end{tabular}


Table 2. Summary results of Analysis of Molecular Variance (AMOVA) performed on 100 methylation-sensitive amplified fragment-length polymorphism (MS-AFLP) restriction sites grouped by adult male vs. nestling and shale gas disturbance status (TerrGas and TerrRunoff), indicating no differential methylation $(P>0.10)$ on a population level.

\begin{tabular}{|c|c|c|c|c|c|c|}
\hline & df & $\begin{array}{l}\text { Sum of } \\
\text { squares }\end{array}$ & $\begin{array}{c}\text { Mean } \\
\text { squares }\end{array}$ & $\begin{array}{c}\% \\
\text { Variance }\end{array}$ & PhiPT & p value \\
\hline \multicolumn{7}{|l|}{ Male vs. Nestling } \\
\hline Among Populations & 1 & 19.073 & 19.073 & $0 \%$ & 0.001 & 0.218 \\
\hline Within Populations & 264 & 4477.168 & 16.959 & $100 \%$ & & \\
\hline Total & 265 & 4496.241 & & $100 \%$ & & \\
\hline \multicolumn{7}{|l|}{ Male TerrRunoff } \\
\hline Among Populations & 1 & 16.559 & 16.559 & $0 \%$ & -0.001 & 0.547 \\
\hline Within Populations & 93 & 1597.504 & 17.177 & $100 \%$ & & \\
\hline Total & 94 & 1614.063 & & $100 \%$ & & \\
\hline \multicolumn{7}{|l|}{ Female TerrGas } \\
\hline Among Populations & 1 & 19.153 & 19.153 & $0 \%$ & -0.006 & 0.701 \\
\hline Within Populations & 44 & 965.217 & 21.937 & $100 \%$ & & \\
\hline Total & 45 & 984.370 & & $100 \%$ & & \\
\hline \multicolumn{7}{|l|}{ Female TerrRunoff } \\
\hline Among Populations & 1 & 26.335 & 26.335 & $1 \%$ & 0.009 & 0.147 \\
\hline Within Populations & 44 & 958.034 & 21.774 & $99 \%$ & & \\
\hline Total & 45 & 984.370 & & $100 \%$ & & \\
\hline \multicolumn{7}{|l|}{ Nestling TerrGas } \\
\hline Among Populations & 1 & 18.719 & 18.719 & $0 \%$ & 0.001 & 0.240 \\
\hline Within Populations & 151 & 2556.223 & 16.929 & $100 \%$ & & \\
\hline Total & 152 & 2574.941 & & $100 \%$ & & \\
\hline \multicolumn{7}{|l|}{ Nestling TerrRunoff } \\
\hline Among Populations & 1 & 17.771 & 17.771 & $0 \%$ & 0.001 & 0.343 \\
\hline Within Populations & 151 & 2557.170 & 16.935 & $100 \%$ & & \\
\hline Total & 152 & 2574.941 & & $100 \%$ & & \\
\hline
\end{tabular}


Table 3. A summary of recaptures $(n=9)$ that were sampled from year to year to evaluate the degree to which an individual's methylated state was subject to change. All Sites indicates the total number of methylated sites across all restriction sites $(\mathrm{n}=100)$, while Male vs. Female $(n=39)$, Female vs. Nestling $(n=35)$, Male Age $(n=21)$, Female Age $(n=18)$, and TerrGas $(n=10)$ indicates the total number of methylated sites across restriction sites determined to be differentially methylated. TerrGas Presence and TerrRunoff Presence are the presence (1) or absence (0) of shale gas territory disturbance. The only nestling recapture was an adult female. Individuals with Strontium (Sr) and Barium (Ba) data from 2013 have Box-Cox transformed ppm values displayed as used in the Pearson correlations. NA = the data is not available. Data that is not applicable is indicated with "-" because differential methylation was not tested.

\begin{tabular}{|c|c|c|c|c|c|c|c|c|c|c|c|c|}
\hline ID & Year & Age & $\begin{array}{l}\text { TerrGas } \\
\text { Presence }\end{array}$ & $\begin{array}{c}\text { TerrRunoff } \\
\text { Presence }\end{array}$ & $\begin{array}{c}\text { All } \\
\text { Sites }\end{array}$ & $\begin{array}{c}\text { Male vs. } \\
\text { Female }\end{array}$ & $\begin{array}{c}\text { Female vs. } \\
\text { Nestling }\end{array}$ & $\begin{array}{c}\text { Male } \\
\text { Age }\end{array}$ & $\begin{array}{c}\text { Female } \\
\text { Age }\end{array}$ & $\begin{array}{l}\text { Terr } \\
\text { Gas }\end{array}$ & $\mathbf{S r}$ & $\mathbf{B a}$ \\
\hline \multicolumn{13}{|l|}{ Males } \\
\hline 12642 & 2013 & 3 & 0 & 0 & 24 & 5 & - & 3 & - & 3 & 1.22 & 1.07 \\
\hline 12642 & 2014 & 4 & 0 & 0 & 21 & 2 & - & 2 & - & 3 & NA & NA \\
\hline 12773 & 2014 & 3 & 1 & 0 & 28 & 6 & - & 2 & - & 1 & NA & NA \\
\hline 12773 & 2015 & 4 & 1 & 0 & 6 & 0 & - & 0 & - & 0 & NA & NA \\
\hline 12781 & 2014 & 3 & 1 & 0 & 19 & 5 & - & 4 & - & 2 & NA & NA \\
\hline 12781 & 2015 & 4 & 1 & 0 & 15 & 7 & - & 0 & - & 0 & NA & NA \\
\hline \multicolumn{13}{|c|}{ Females } \\
\hline 12634 & 2013 & 3 & 1 & 0 & 15 & 3 & 2 & - & 1 & - & 1.26 & 1.05 \\
\hline 12634 & 2014 & 4 & 1 & 0 & 48 & 16 & 17 & - & 8 & - & NA & NA \\
\hline 12634 & 2015 & 5 & 1 & 1 & 55 & 21 & 20 & - & 10 & - & NA & NA \\
\hline 12635 & 2013 & 3 & 1 & 1 & 16 & 3 & 4 & - & 2 & - & 1.38 & 1.07 \\
\hline 12635 & 2014 & 4 & 1 & 1 & 29 & 12 & 7 & - & 5 & - & NA & NA \\
\hline 12638 & 2013 & 3 & 0 & 1 & 20 & 5 & 3 & - & 3 & - & 1.36 & 1.08 \\
\hline 12638 & 2014 & 4 & 0 & 1 & 29 & 10 & 8 & - & 7 & - & NA & NA \\
\hline 12727 & 2013 & 3 & NA & NA & 13 & 3 & 1 & - & 0 & - & 1.35 & 1.09 \\
\hline 12727 & 2014 & 4 & 0 & 0 & 48 & 16 & 14 & - & 4 & - & NA & NA \\
\hline 12799 & 2013 & 3 & NA & NA & 12 & 2 & 1 & - & 1 & - & 1.44 & 1.16 \\
\hline 12799 & 2014 & 4 & 0 & 1 & 45 & 21 & 18 & - & 6 & - & NA & NA \\
\hline \multicolumn{13}{|c|}{ Nestlings } \\
\hline 12839 & 2014 & 1 & 0 & 1 & 14 & - & - & - & - & - & NA & NA \\
\hline 12839 & 2015 & 2 & 0 & 0 & 64 & - & - & - & - & - & NA & NA \\
\hline
\end{tabular}




\section{FIGURES}
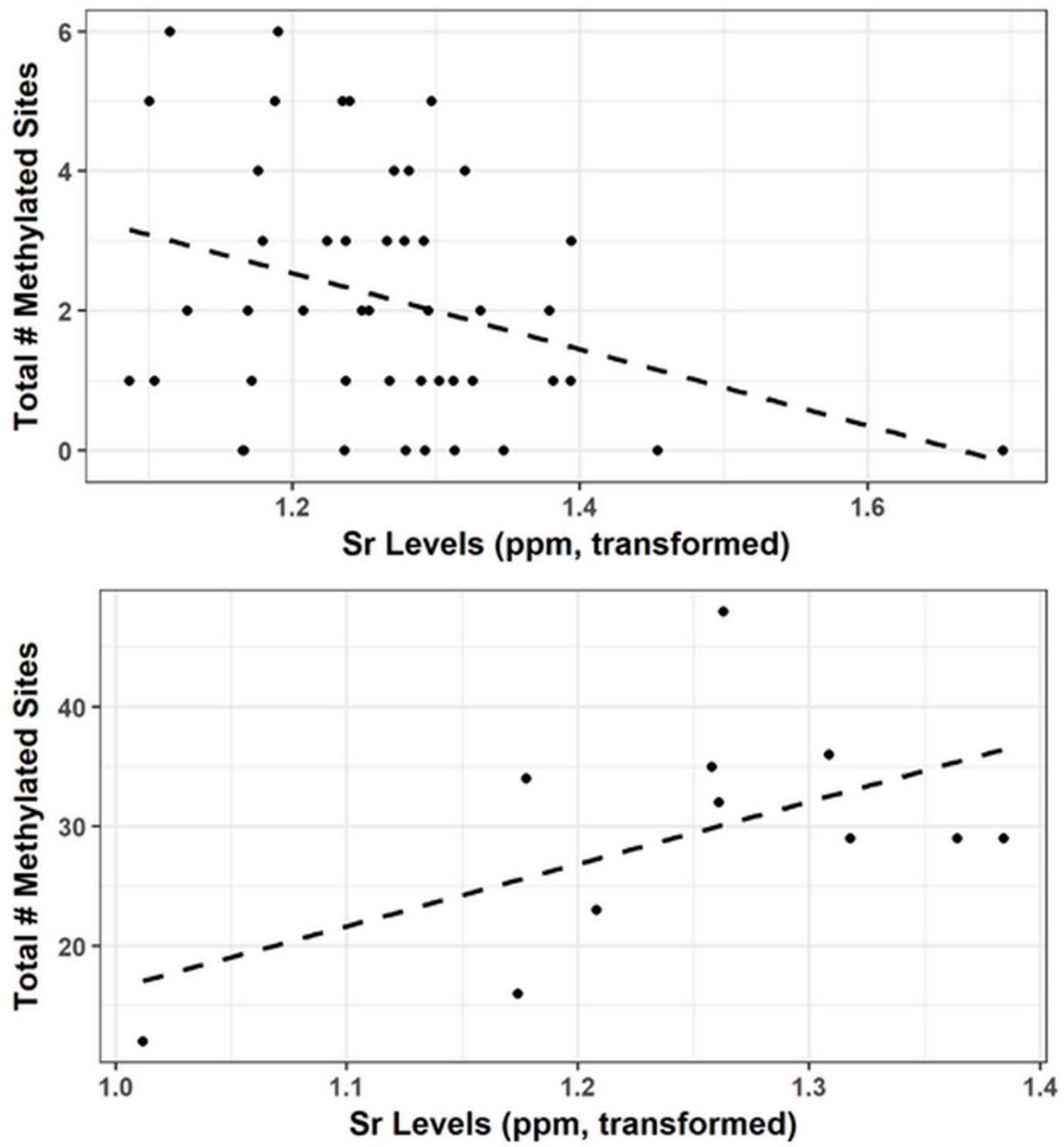

Figure 1. The number of methylated restriction sites identified as differentially methylated for TerrGas $(\mathrm{n}=10)$ vs. strontium $\left(\mathrm{Sr} ; \mathrm{R}^{2}=-32, P=0.03\right)$ for adult males (top panel) and the number of methylated restriction sites across all restriction sites $(\mathrm{n}=100)$ vs. strontium $\left(\mathrm{Sr} ; \mathrm{R}^{2}=\right.$ $0.55, P=0.08$ ) for adult females (bottom panel). 


\section{APPENDICES}

Appendix Table 1. Summary results indicating differential methylation $(P<0.10)$ on a restriction site (i.e., locus) level after performing Analysis of Molecular Variance (AMOVA) grouped by sex (male, $n=107$ vs. female, $n=49)$, adult females $(n=49)$ vs. nestlings $(n=159)$, male age (second year [SY], $\mathrm{n}=14$ vs. after second year [ASY], $\mathrm{n}=87$ ), female age $(\mathrm{SY}, \mathrm{n}=13$ vs. ASY, $n=35$ ), and TerrGas (undisturbed $n=46$, disturbed $n=49)$ for adult males $(n=95)$.

\begin{tabular}{|c|c|c|c|c|c|}
\hline Restriction Site & PhiPT & P value & Restriction Site & PhiPT & P value \\
\hline Male vs. Female & & & Female vs. Nestling & & \\
\hline 155 & 0.069 & 0.022 & 229 & 0.008 & 0.006 \\
\hline 222 & 0.055 & 0.031 & 290 & 0.066 & 0.016 \\
\hline 229 & 0.131 & 0.002 & 305 & 0.118 & 0.002 \\
\hline 305 & 0.042 & 0.061 & 322 & 0.060 & 0.020 \\
\hline 322 & 0.035 & 0.089 & 325 & 0.049 & 0.039 \\
\hline 324 & 0.047 & 0.039 & 350 & 0.139 & 0.001 \\
\hline 325 & 0.060 & 0.029 & 353 & 0.011 & 0.011 \\
\hline 328 & 0.050 & 0.052 & 355 & 0.045 & 0.054 \\
\hline 339 & 0.057 & 0.042 & 362 & 0.053 & 0.031 \\
\hline 350 & 0.089 & 0.009 & 367 & 0.139 & 0.001 \\
\hline 353 & 0.033 & 0.096 & 371 & 0.074 & 0.012 \\
\hline 366 & 0.067 & 0.018 & 375 & 0.120 & 0.002 \\
\hline 367 & 0.050 & 0.054 & 411 & 0.128 & 0.001 \\
\hline 371 & 0.202 & 0.000 & 417 & 0.029 & 0.097 \\
\hline 375 & 0.109 & 0.003 & 419 & 0.043 & 0.049 \\
\hline 400 & 0.039 & 0.075 & 425 & 0.062 & 0.024 \\
\hline 411 & 0.050 & 0.053 & 432 & 0.037 & 0.054 \\
\hline 419 & 0.069 & 0.020 & 437 & 0.084 & 0.009 \\
\hline 425 & 0.070 & 0.021 & 448 & 0.247 & 0.000 \\
\hline 437 & 0.058 & 0.039 & 451 & 0.053 & 0.031 \\
\hline 448 & 0.167 & 0.001 & 453 & 0.057 & 0.026 \\
\hline 453 & 0.047 & 0.041 & 455 & 0.117 & 0.001 \\
\hline 454 & 0.035 & 0.082 & 468 & 0.108 & 0.004 \\
\hline 455 & 0.124 & 0.002 & 483 & 0.060 & 0.020 \\
\hline 458 & 0.045 & 0.057 & 510 & 0.053 & 0.030 \\
\hline 468 & 0.057 & 0.034 & 521 & 0.081 & 0.010 \\
\hline 483 & 0.035 & 0.083 & 526 & 0.066 & 0.016 \\
\hline 510 & 0.064 & 0.024 & 532 & 0.112 & 0.003 \\
\hline 521 & 0.182 & 0.000 & 535 & 0.105 & 0.004 \\
\hline 526 & 0.102 & 0.006 & 536 & 0.094 & 0.005 \\
\hline 532 & 0.144 & 0.002 & 569 & 0.069 & 0.018 \\
\hline 535 & 0.047 & 0.048 & 575 & 0.084 & 0.010 \\
\hline 536 & 0.082 & 0.014 & 587 & 0.045 & 0.056 \\
\hline 541 & 0.051 & 0.058 & 589 & 0.053 & 0.033 \\
\hline 569 & 0.096 & 0.008 & 591 & 0.071 & 0.014 \\
\hline
\end{tabular}




\begin{tabular}{|c|c|c|c|c|c|}
\hline $\begin{array}{l}582 \\
587 \\
591 \\
\end{array}$ & $\begin{array}{c}0.07 \\
0.035 \\
0.041 \\
\end{array}$ & $\begin{array}{l}0.022 \\
0.090 \\
0.059\end{array}$ & & & \\
\hline Restriction Site & PhiPT & P value & Restriction Site & PhiPT & P value \\
\hline Male Age & & & Female Age & & \\
\hline 244 & 0.094 & 0.083 & 135 & 0.116 & 0.095 \\
\hline 319 & 0.165 & 0.027 & 144 & 0.189 & 0.050 \\
\hline 339 & 0.190 & 0.032 & 209 & 0.161 & 0.045 \\
\hline 340 & 0.088 & 0.093 & 290 & 0.154 & 0.081 \\
\hline 343 & 0.104 & 0.078 & 297 & 0.143 & 0.076 \\
\hline 347 & 0.141 & 0.040 & 305 & 0.126 & 0.097 \\
\hline 353 & 0.118 & 0.055 & 325 & 0.338 & 0.005 \\
\hline 362 & 0.098 & 0.072 & 340 & 0.263 & 0.015 \\
\hline 367 & 0.141 & 0.040 & 350 & 0.288 & 0.012 \\
\hline 376 & 0.208 & 0.015 & 368 & 0.167 & 0.048 \\
\hline 419 & 0.124 & 0.061 & 419 & 0.155 & 0.067 \\
\hline 425 & 0.230 & 0.020 & 453 & 0.155 & 0.063 \\
\hline 437 & 0.124 & 0.060 & 458 & 0.329 & 0.008 \\
\hline 451 & 0.072 & 0.100 & 468 & 0.288 & 0.013 \\
\hline 483 & 0.356 & 0.002 & 509 & 0.167 & 0.050 \\
\hline 484 & 0.226 & 0.012 & 532 & 0.200 & 0.042 \\
\hline 508 & 0.128 & 0.059 & 541 & 0.205 & 0.027 \\
\hline 532 & 0.225 & 0.017 & 569 & 0.116 & 0.092 \\
\hline 541 & 0.124 & 0.061 & & & \\
\hline 589 & 0.165 & 0.024 & & & \\
\hline 591 & 0.208 & 0.017 & & & \\
\hline Restriction Site & PhiPT & P value & & & \\
\hline \multicolumn{6}{|l|}{ Male TerrGas } \\
\hline 155 & 0.158 & 0.003 & & & \\
\hline 289 & 0.061 & 0.068 & & & \\
\hline 292 & 0.109 & 0.015 & & & \\
\hline 333 & 0.067 & 0.054 & & & \\
\hline 368 & 0.051 & 0.082 & & & \\
\hline 371 & 0.115 & 0.010 & & & \\
\hline 446 & 0.115 & 0.016 & & & \\
\hline 448 & 0.057 & 0.074 & & & \\
\hline 455 & 0.132 & 0.007 & & & \\
\hline 541 & 0.072 & 0.054 & & & \\
\hline
\end{tabular}


Appendix Table 2. Proportion (\%) of differential methylation between male and female individual restriction sites $(\mathrm{n}=39)$ that were statistically significant by sex (male, $n=107$ vs. female, $n=49$ ), and the collective proportion of differential methylation among all ( $n$ $=100)$ and just the statistically significant restriction sites.

\begin{tabular}{|c|c|c|c|c|c|c|c|c|c|c|c|c|c|c|}
\hline \multirow[t]{2}{*}{ Sex } & \multicolumn{2}{|c|}{ All Sites } & \multicolumn{2}{|c|}{ Sig. Sites } & \multicolumn{2}{|c|}{ Site 155} & \multicolumn{2}{|c|}{ Site 222} & \multicolumn{2}{|c|}{ Site 229} & \multicolumn{2}{|c|}{ Site 305} & \multicolumn{2}{|c|}{ Site 322} \\
\hline & Unmeth & Meth & Unmeth & Meth & Unmeth & Meth & Unmeth & Meth & Unmeth & Meth & Unmeth & Meth & Unmeth & Meth \\
\hline Female & 68.08 & 31.92 & 68.66 & 31.34 & 44.90 & 55.10 & 53.06 & 46.94 & 36.73 & 63.27 & 59.18 & 40.82 & 71.43 & 28.57 \\
\hline Male & 75.98 & 24.02 & 85.31 & 14.69 & 65.42 & 34.58 & 71.03 & 28.97 & 64.49 & 35.51 & 74.77 & 25.23 & 84.11 & 15.89 \\
\hline Sex & \multicolumn{2}{|c|}{ Site 324} & \multicolumn{2}{|c|}{ Site 325} & \multicolumn{2}{|c|}{ Site 328} & \multicolumn{2}{|c|}{ Site 339} & \multicolumn{2}{|c|}{ Site 350} & \multicolumn{2}{|c|}{ Site 353} & \multicolumn{2}{|c|}{ Site 366} \\
\hline & Unmeth & Meth & Unmeth & Meth & Unmeth & Meth & Unmeth & Meth & Unmeth & Meth & Unmeth & Meth & Unmeth & Meth \\
\hline Female & 67.35 & 32.65 & 69.39 & 30.61 & 69.39 & 30.61 & 77.55 & 22.45 & 67.35 & 32.65 & 69.39 & 30.61 & 67.35 & 32.65 \\
\hline Male & 82.24 & 17.76 & 85.05 & 14.95 & 84.11 & 15.89 & 90.65 & 9.35 & 85.98 & 14.02 & 82.24 & 17.76 & 84.11 & 15.89 \\
\hline Sex & \multicolumn{2}{|c|}{ Site 367} & \multicolumn{2}{|c|}{ Site 371} & \multicolumn{2}{|c|}{ Site 375} & \multicolumn{2}{|c|}{ Site 400} & \multicolumn{2}{|c|}{ Site 411} & \multicolumn{2}{|c|}{ Site 419} & \multicolumn{2}{|c|}{ Site 425} \\
\hline & Unmeth & Meth & Unmeth & Meth & Unmeth & Meth & Unmeth & Meth & Unmeth & Meth & Unmeth & Meth & Unmeth & Meth \\
\hline Female & 69.39 & 30.61 & 67.35 & 32.65 & 65.31 & 34.69 & 79.59 & 20.41 & 69.39 & 30.61 & 73.47 & 26.53 & 77.55 & 22.45 \\
\hline Male & 84.11 & 15.89 & 92.52 & 7.48 & 85.98 & 14.02 & 90.65 & 9.35 & 84.11 & 15.89 & 88.79 & 11.21 & 91.59 & 8.41 \\
\hline Sex & \multicolumn{2}{|c|}{ Site 437} & \multicolumn{2}{|c|}{ Site 448} & \multicolumn{2}{|c|}{ Site 453} & \multicolumn{2}{|c|}{ Site 454} & \multicolumn{2}{|c|}{ Site 455} & \multicolumn{2}{|c|}{ Site 458} & \multicolumn{2}{|c|}{ Site 468} \\
\hline & Unmeth & Meth & Unmeth & Meth & Unmeth & Meth & Unmeth & Meth & Unmeth & Meth & Unmeth & Meth & Unmeth & Meth \\
\hline Female & 73.47 & 26.53 & 53.06 & 46.94 & 73.47 & 26.53 & 77.55 & 22.45 & 69.39 & 30.61 & 81.63 & 18.37 & 67.35 & 32.65 \\
\hline Male & 87.85 & 12.15 & 81.31 & 18.69 & 86.92 & 13.08 & 88.79 & 11.21 & 89.72 & 10.28 & 92.52 & 7.48 & 83.18 & 16.82 \\
\hline Sex & \multicolumn{2}{|c|}{ Site 483} & Site 5 & & Site & & Site & 26 & Site 5 & & Site 5 & & Site & \\
\hline & Unmeth & Meth & Unmeth & Meth & Unmeth & Meth & Unmeth & Meth & Unmeth & Meth & Unmeth & Meth & Unmeth & Meth \\
\hline Female & 71.43 & 28.57 & 71.43 & 28.57 & 67.35 & 32.65 & 67.35 & 32.65 & 63.27 & 36.73 & 73.47 & 26.53 & 73.47 & 26.53 \\
\hline Male & 84.11 & 15.89 & 86.92 & 13.08 & 91.59 & 8.41 & 86.92 & 13.08 & 86.92 & 13.08 & 86.92 & 13.08 & 89.72 & 10.28 \\
\hline Sex & Site 5 & & Site 5 & & Site & & Site & & Site 5 & & Site 5 & & & \\
\hline & Unmeth & Meth & Unmeth & Meth & Unmeth & Meth & Unmeth & Meth & Unmeth & Meth & Unmeth & Meth & & \\
\hline Female & 75.51 & 24.49 & 65.31 & 34.69 & 73.47 & 26.53 & 77.55 & 22.45 & 77.55 & 22.45 & 69.39 & 30.61 & & \\
\hline Male & 88.79 & 11.21 & 85.05 & 14.95 & 94.39 & 5.61 & 91.59 & 8.41 & 88.79 & 11.21 & 83.18 & 16.82 & & \\
\hline
\end{tabular}


Appendix Table 3. Proportion (\%) of differential methylation between adult females vs. nestlings individual restriction sites $(\mathrm{n}=35)$ that were statistically significant by adult females $(n=49)$ vs. nestlings $(n=159)$, and the collective proportion of differential methylation among all $(\mathrm{n}=100)$ and just the statistically significant sites.

\begin{tabular}{|c|c|c|c|c|c|c|c|c|c|c|c|c|}
\hline \multirow[t]{2}{*}{ Group } & \multicolumn{2}{|c|}{ All Sites } & \multicolumn{2}{|c|}{ Sig. Sites } & \multicolumn{2}{|c|}{ Site 229} & \multicolumn{2}{|c|}{ Site 290} & \multicolumn{2}{|c|}{ Site 305} & \multicolumn{2}{|c|}{ Site 322} \\
\hline & Unmeth & Meth & Unmeth & Meth & Unmeth & Meth & Unmeth & Meth & Unmeth & Meth & Unmeth & Meth \\
\hline Female & 68.08 & 31.92 & 68.86 & 31.14 & 36.73 & 63.27 & 67.35 & 32.65 & 59.18 & 40.82 & 71.43 & 28.57 \\
\hline Nestling & 76.50 & 23.50 & 85.71 & 14.29 & 59.75 & 40.25 & 83.65 & 16.35 & 81.76 & 18.24 & 86.16 & 13.84 \\
\hline Group & \multicolumn{2}{|c|}{ Site 325} & \multicolumn{2}{|c|}{ Site 350} & \multicolumn{2}{|c|}{ Site 353} & \multicolumn{2}{|c|}{ Site 355} & \multicolumn{2}{|c|}{ Site 362} & \multicolumn{2}{|c|}{ Site 367} \\
\hline & Unmeth & Meth & Unmeth & Meth & Unmeth & Meth & Unmeth & Meth & Unmeth & Meth & Unmeth & Meth \\
\hline Female & 69.39 & 30.61 & 67.35 & 32.65 & 69.39 & 30.61 & 77.55 & 22.45 & 71.43 & 28.57 & 69.39 & 30.61 \\
\hline Nestling & 83.65 & 16.35 & 88.68 & 11.32 & 86.16 & 13.84 & 89.31 & 10.69 & 85.53 & 14.47 & 89.94 & 10.06 \\
\hline \multirow[t]{2}{*}{ Group } & \multicolumn{2}{|c|}{ Site 371} & \multicolumn{2}{|c|}{ Site 375} & \multicolumn{2}{|c|}{ Site 411} & \multicolumn{2}{|c|}{ Site 417} & \multicolumn{2}{|c|}{ Site 419} & \multicolumn{2}{|c|}{ Site 425} \\
\hline & Unmeth & Meth & Unmeth & Meth & Unmeth & Meth & Unmeth & Meth & Unmeth & Meth & Unmeth & Meth \\
\hline Female & 67.35 & 32.65 & 65.31 & 34.69 & 69.39 & 30.61 & 71.43 & 28.57 & 73.47 & 26.53 & 77.55 & 22.45 \\
\hline Nestling & 84.28 & 15.72 & 86.16 & 13.84 & 89.31 & 10.69 & 83.02 & 16.98 & 86.16 & 13.84 & 90.57 & 9.43 \\
\hline \multirow[t]{2}{*}{ Group } & \multicolumn{2}{|c|}{ Site 432} & \multicolumn{2}{|c|}{ Site 437} & \multicolumn{2}{|c|}{ Site 448} & \multicolumn{2}{|c|}{ Site 451} & \multicolumn{2}{|c|}{ Site 453} & \multicolumn{2}{|c|}{ Site 455} \\
\hline & Unmeth & Meth & Unmeth & Meth & Unmeth & Meth & Unmeth & Meth & Unmeth & Meth & Unmeth & Meth \\
\hline Female & 73.47 & 26.53 & 73.47 & 26.53 & 53.06 & 46.94 & 71.43 & 28.57 & 73.47 & 26.53 & 69.39 & 30.61 \\
\hline Nestling & 85.53 & 14.47 & 89.31 & 10.69 & 85.53 & 14.47 & 85.53 & 14.47 & 87.42 & 12.58 & 88.68 & 11.32 \\
\hline \multirow[t]{2}{*}{ Group } & \multicolumn{2}{|c|}{ Site 468} & Site 4 & & Site 5 & & Site & & Site & & Site 5 & \\
\hline & Unmeth & Meth & Unmeth & Meth & Unmeth & Meth & Unmeth & Meth & Unmeth & Meth & Unmeth & Meth \\
\hline Female & 67.35 & 32.65 & 71.43 & 28.57 & 71.43 & 28.57 & 67.35 & 32.65 & 67.35 & 32.65 & 63.27 & 36.73 \\
\hline Nestling & 86.79 & 13.21 & 86.16 & 13.84 & 85.53 & 14.47 & 84.91 & 15.09 & 83.65 & 16.35 & 84.28 & 15.72 \\
\hline Group & Site 5 & & Site 5 & & Site 5 & & Site & & Site & & Site 5 & \\
\hline & Unmeth & Meth & Unmeth & Meth & Unmeth & Meth & Unmeth & Meth & Unmeth & Meth & Unmeth & Meth \\
\hline Female & 73.47 & 26.53 & 73.47 & 26.53 & 65.31 & 34.69 & 73.47 & 26.53 & 77.55 & 22.45 & 71.43 & 28.57 \\
\hline Nestling & 90.57 & 9.43 & 89.94 & 10.06 & 82.39 & 17.61 & 89.31 & 10.69 & 89.31 & 10.69 & 85.53 & 14.47 \\
\hline Group & Site 5 & & & & & & & & & & & \\
\hline & Unmeth & Meth & & & & & & & & & & \\
\hline Female & 69.39 & 30.61 & & & & & & & & & & \\
\hline Nestling & 85.53 & 14.47 & & & & & & & & & & \\
\hline
\end{tabular}


Appendix Table 4. Proportion (\%) of differential methylation between male age (second year [SY], $\mathrm{n}=14$ vs. after second year [ASY], $\mathrm{n}=87$ ) individual restriction sites $(\mathrm{n}=21)$ that were statistically significant by male age $(\mathrm{n}=101)$, and the collective proportion of differential methylation among all $(n=100)$ and just the statistically significant sites.

\begin{tabular}{ccccccccccccc} 
Age & \multicolumn{2}{c}{ All Sites } & \multicolumn{2}{c}{ Sig. Sites } & \multicolumn{2}{c}{ Site 244 } & \multicolumn{2}{c}{ Site 319 } & \multicolumn{2}{c}{ Site 339 } & \multicolumn{2}{c}{ Site 340 } \\
\hline & Unmeth & Meth & Unmeth & Meth & Unmeth & Meth & Unmeth & Meth & Unmeth & Meth & Unmeth & Meth \\
SY & 69.57 & 30.43 & 58.84 & 41.16 & 35.71 & 64.29 & 50.00 & 50.00 & 71.43 & 28.57 & 57.14 & 42.86 \\
ASY & 76.95 & 23.05 & 84.23 & 15.77 & 63.44 & 36.56 & 80.65 & 19.35 & 93.55 & 6.45 & 79.57 & 20.43
\end{tabular}

\begin{tabular}{ccccccccccccc}
\hline Age & \multicolumn{2}{c}{ Site 343 } & \multicolumn{2}{c}{ Site 347 } & \multicolumn{2}{c}{ Site 353 } & \multicolumn{2}{c}{ Site 362 } & \multicolumn{2}{c}{ Site 367 } & \multicolumn{2}{c}{ Site 376 } \\
\hline & Unmeth & Meth & Unmeth & Meth & Unmeth & Meth & Unmeth & Meth & Unmeth & Meth & Unmeth & Meth \\
SY & 57.14 & 42.86 & 57.14 & 42.86 & 64.29 & 35.71 & 64.29 & 35.71 & 64.29 & 35.71 & 57.14 & 42.86 \\
ASY & 79.57 & 20.43 & 81.72 & 18.28 & 84.95 & 15.05 & 86.02 & 13.98 & 87.10 & 12.90 & 86.02 & 13.98
\end{tabular}

\begin{tabular}{|c|c|c|c|c|c|c|c|c|c|c|c|c|}
\hline \multirow[t]{2}{*}{ Age } & \multicolumn{2}{|c|}{ Site 419} & \multicolumn{2}{|c|}{ Site 425} & \multicolumn{2}{|c|}{ Site 437} & \multicolumn{2}{|c|}{ Site 451} & \multicolumn{2}{|c|}{ Site 483} & \multicolumn{2}{|c|}{ Site 484} \\
\hline & Unmeth & Meth & Unmeth & Meth & Unmeth & Meth & Unmeth & Meth & Unmeth & Meth & Unmeth & Meth \\
\hline SY & 71.43 & 28.57 & 71.43 & 28.57 & 71.43 & 28.57 & 57.14 & 42.86 & 50.00 & 50.00 & 50.00 & 50.00 \\
\hline ASY & 91.40 & 8.60 & 94.62 & 5.38 & 90.32 & 9.68 & 78.49 & 21.51 & 89.25 & 10.75 & 81.72 & 18.28 \\
\hline Age & \multicolumn{2}{|c|}{ Site 508} & \multicolumn{2}{|c|}{ Site 532} & \multicolumn{2}{|c|}{ Site 541} & \multicolumn{2}{|c|}{ Site 589} & \multicolumn{2}{|c|}{ Site 591} & & \\
\hline & Unmeth & Meth & Unmeth & Meth & Unmeth & Meth & Unmeth & Meth & Unmeth & Meth & & \\
\hline SY & 42.86 & 57.14 & 64.29 & 35.71 & 71.43 & 28.57 & 50.00 & 50.00 & 57.14 & 42.86 & & \\
\hline ASY & 72.04 & 27.96 & 90.32 & 9.68 & 91.40 & 8.60 & 79.57 & 20.43 & 87.10 & 12.90 & & \\
\hline
\end{tabular}


Appendix Table 5. Proportion (\%) of differential methylation between female age (second year [SY], $\mathrm{n}=13$ vs. after second year [ASY], $n=35)$ individual restriction sites $(n=18)$ that were statistically significant by female age $(n=48)$, and the collective proportion of differential methylation among all $(\mathrm{n}=100)$ and just the statistically significant sites.

\begin{tabular}{ccccccccccc} 
Age & \multicolumn{2}{c}{ All Sites } & \multicolumn{2}{c}{ Sig. Sites } & \multicolumn{2}{c}{ Site 135 } & \multicolumn{2}{c}{ Site 144 } & \multicolumn{2}{c}{ Site 209 } \\
\hline & Unmeth & Meth & Unmeth & Meth & Unmeth & Meth & Unmeth & Meth & Unmeth & Meth \\
SY & 63.15 & 36.85 & 52.14 & 47.86 & 46.15 & 53.85 & 84.62 & 15.38 & 38.46 & 61.54 \\
ASY & 70.80 & 29.20 & 77.94 & 22.06 & 74.29 & 25.71 & 48.57 & 51.43 & 71.43 & 28.57
\end{tabular}

\begin{tabular}{ccccccccccc}
\hline Age & \multicolumn{2}{c}{ Site 290 } & \multicolumn{2}{c}{ Site 297 } & \multicolumn{2}{c}{ Site 305 } & \multicolumn{2}{c}{ Site 325 } & \multicolumn{2}{c}{ Site 340 } \\
\hline & Unmeth & Meth & Unmeth & Meth & Unmeth & Meth & Unmeth & Meth & Unmeth & Meth \\
SY & 46.15 & 53.85 & 92.31 & 7.69 & 38.46 & 61.54 & 38.46 & 61.54 & 53.85 & 46.15 \\
ASY & 77.14 & 22.86 & 62.86 & 37.14 & 68.57 & 31.43 & 82.86 & 17.14 & 88.57 & 11.43
\end{tabular}

\begin{tabular}{|c|c|c|c|c|c|c|c|c|c|c|}
\hline Age & \multicolumn{2}{|c|}{ Site 350} & \multicolumn{2}{|c|}{ Site 368} & \multicolumn{2}{|c|}{ Site 419} & \multicolumn{2}{|c|}{ Site 453} & \multicolumn{2}{|c|}{ Site 458} \\
\hline & Unmeth & Meth & Unmeth & Meth & Unmeth & Meth & Unmeth & Meth & Unmeth & Meth \\
\hline SY & 38.46 & 61.54 & 61.54 & 38.46 & 53.85 & 46.15 & 53.85 & 46.15 & 53.85 & 46.15 \\
\hline ASY & 80.00 & 20.00 & 88.57 & 11.43 & 82.86 & 17.14 & 82.86 & 17.14 & 91.43 & 8.57 \\
\hline Age & \multicolumn{2}{|c|}{ Site 468} & \multicolumn{2}{|c|}{ Site 509} & \multicolumn{2}{|c|}{ Site 532} & \multicolumn{2}{|c|}{ Site 541} & \multicolumn{2}{|c|}{ Site 569} \\
\hline & Unmeth & Meth & Unmeth & Meth & Unmeth & Meth & Unmeth & Meth & Unmeth & Meth \\
\hline SY & 38.46 & 61.54 & 61.54 & 38.46 & 38.46 & 61.54 & 53.85 & 46.15 & 46.15 & 53.85 \\
\hline ASY & 80.00 & 20.00 & 88.57 & 11.43 & 74.29 & 25.71 & 85.71 & 14.29 & 74.29 & 25.71 \\
\hline
\end{tabular}


Appendix Table 6. Proportion (\%) of differential methylation between undisturbed $(n=46)$ and disturbed $(n=49)$ shale gas territory (TerrGas) individual restriction sites $(n=18)$ that were statistically significant for adult males $(n=95)$, and the collective proportion of differential methylation among all $(\mathrm{n}=100)$ and just the statistically significant restriction sites.

\begin{tabular}{|c|c|c|c|c|c|c|c|c|c|c|c|c|}
\hline Status & \multicolumn{2}{|c|}{ All Sites } & \multicolumn{2}{|c|}{ Sig. Sites } & \multicolumn{2}{|c|}{ Site 155} & \multicolumn{2}{|c|}{ Site 289} & \multicolumn{2}{|c|}{ Site 292} & \multicolumn{2}{|c|}{ Site 333} \\
\hline & Unmeth & Meth & Unmeth & Meth & Unmeth & Meth & Unmeth & Meth & Unmeth & Meth & Unmeth & Meth \\
\hline Undisturbed & 74.33 & 25.67 & 71.74 & 28.26 & 50.00 & 50.00 & 60.87 & 39.13 & 63.04 & 36.96 & 65.22 & 34.78 \\
\hline Disturbed & 77.02 & 22.98 & 87.55 & 12.45 & 79.59 & 20.41 & 79.59 & 20.41 & 85.71 & 14.29 & 83.67 & 16.33 \\
\hline Status & \multicolumn{2}{|c|}{ Site 368} & \multicolumn{2}{|c|}{ Site 371} & \multicolumn{2}{|c|}{ Site 446} & \multicolumn{2}{|c|}{ Site 448} & \multicolumn{2}{|c|}{ Site 455} & \multicolumn{2}{|c|}{ Site 541} \\
\hline & Unmeth & Meth & Unmeth & Meth & Unmeth & Meth & Unmeth & Meth & Unmeth & Meth & Unmeth & Meth \\
\hline Undisturbed & 78.26 & 21.74 & 86.96 & 13.04 & 65.22 & 34.78 & 71.74 & 28.26 & 80.43 & 19.57 & 95.65 & 4.35 \\
\hline Disturbed & 91.84 & 8.16 & 100.00 & 0.00 & 87.76 & 12.24 & 87.76 & 12.24 & 97.96 & 2.04 & 81.63 & 18.37 \\
\hline
\end{tabular}


Appendix Table 7. Results of BAYESCAN analysis on a restriction site (i.e., locus) level grouped by demographic parameter and shale gas disturbance status that was differentially methylated at a population level. $\mathrm{p}$ is the posterior probability for the selection model.

$\log 10(\mathrm{PO})$ is the logarithm of Posterior Odds to base 10 for the selection model. The estimated alpha coefficient indicates the strength and direction of selection. The averaged $F_{\text {st }}$ coefficient is calculated as the posterior mean.

\begin{tabular}{|c|c|c|c|c|}
\hline Restriction Site & $\mathbf{p}$ & $\log 10(P O)$ & alpha & $\mathbf{F}_{\text {st }}$ \\
\hline \multicolumn{5}{|l|}{ Male vs. Female } \\
\hline 155 & 0.077 & -1.076 & -0.005 & 0.076 \\
\hline 222 & 0.079 & -1.065 & -0.012 & 0.076 \\
\hline 229 & 0.077 & -1.080 & 0.014 & 0.078 \\
\hline 305 & 0.090 & -1.007 & -0.019 & 0.076 \\
\hline 322 & 0.092 & -0.993 & -0.023 & 0.075 \\
\hline 324 & 0.086 & -1.024 & -0.015 & 0.076 \\
\hline 325 & 0.083 & -1.042 & -0.012 & 0.076 \\
\hline 328 & 0.078 & -1.070 & -0.009 & 0.076 \\
\hline 339 & 0.084 & -1.040 & -0.010 & 0.076 \\
\hline 350 & 0.073 & -1.105 & -0.003 & 0.076 \\
\hline 353 & 0.080 & -1.063 & -0.023 & 0.075 \\
\hline 366 & 0.089 & -1.011 & -0.006 & 0.076 \\
\hline 367 & 0.082 & -1.048 & -0.013 & 0.076 \\
\hline 371 & 0.085 & -1.031 & 0.025 & 0.078 \\
\hline 375 & 0.082 & -1.047 & -0.004 & 0.077 \\
\hline 400 & 0.079 & -1.065 & -0.018 & 0.076 \\
\hline 411 & 0.081 & -1.057 & -0.014 & 0.076 \\
\hline 419 & 0.077 & -1.076 & -0.007 & 0.076 \\
\hline 425 & 0.083 & -1.043 & -0.015 & 0.076 \\
\hline 437 & 0.080 & -1.062 & -0.019 & 0.075 \\
\hline 448 & 0.076 & -1.082 & 0.013 & 0.077 \\
\hline 453 & 0.083 & -1.044 & -0.018 & 0.076 \\
\hline 454 & 0.080 & -1.058 & -0.022 & 0.075 \\
\hline 455 & 0.080 & -1.059 & 0.005 & 0.077 \\
\hline 458 & 0.079 & -1.067 & -0.018 & 0.075 \\
\hline 468 & 0.083 & -1.041 & -0.021 & 0.075 \\
\hline 483 & 0.079 & -1.064 & -0.016 & 0.076 \\
\hline 510 & 0.080 & -1.059 & -0.010 & 0.076 \\
\hline 521 & 0.073 & -1.105 & 0.017 & 0.078 \\
\hline 526 & 0.085 & -1.030 & -0.001 & 0.077 \\
\hline 532 & 0.081 & -1.054 & 0.011 & 0.077 \\
\hline 535 & 0.080 & -1.061 & -0.011 & 0.076 \\
\hline 536 & 0.089 & -1.012 & -0.003 & 0.077 \\
\hline 541 & 0.084 & -1.036 & -0.008 & 0.076 \\
\hline 569 & 0.074 & -1.095 & 0.004 & 0.077 \\
\hline 575 & 0.072 & -1.108 & 0.017 & 0.078 \\
\hline
\end{tabular}




\begin{tabular}{|c|c|c|c|c|}
\hline 582 & 0.080 & -1.058 & -0.016 & 0.076 \\
\hline 587 & 0.084 & -1.035 & -0.010 & 0.076 \\
\hline 591 & 0.081 & -1.055 & -0.017 & 0.076 \\
\hline Restriction Site & $\mathbf{p}$ & $\operatorname{Log10}(\mathrm{PO})$ & alpha & $\mathbf{F}_{\text {st }}$ \\
\hline \multicolumn{5}{|l|}{$\begin{array}{l}\text { Female vs. } \\
\text { Nestling }\end{array}$} \\
\hline 229 & 0.081 & -1.057 & -0.003 & 0.077 \\
\hline 290 & 0.082 & -1.047 & -0.012 & 0.076 \\
\hline 305 & 0.073 & -1.102 & 0.003 & 0.077 \\
\hline 322 & 0.083 & -1.041 & -0.016 & 0.076 \\
\hline 325 & 0.088 & -1.017 & -0.015 & 0.076 \\
\hline 350 & 0.080 & -1.063 & 0.007 & 0.077 \\
\hline 353 & 0.079 & -1.069 & -0.004 & 0.077 \\
\hline 355 & 0.084 & -1.036 & -0.017 & 0.076 \\
\hline 362 & 0.084 & -1.035 & -0.014 & 0.076 \\
\hline 367 & 0.080 & -1.059 & 0.003 & 0.077 \\
\hline 371 & 0.080 & -1.061 & -0.004 & 0.077 \\
\hline 375 & 0.073 & -1.102 & 0.000 & 0.076 \\
\hline 411 & 0.081 & -1.052 & 0.000 & 0.077 \\
\hline 417 & 0.086 & -1.028 & -0.023 & 0.075 \\
\hline 419 & 0.081 & -1.055 & -0.026 & 0.075 \\
\hline 425 & 0.086 & -1.028 & -0.014 & 0.076 \\
\hline 432 & 0.090 & -1.004 & -0.023 & 0.076 \\
\hline 437 & 0.082 & -1.050 & -0.009 & 0.076 \\
\hline 448 & 0.079 & -1.064 & 0.024 & 0.078 \\
\hline 451 & 0.079 & -1.064 & -0.015 & 0.076 \\
\hline 453 & 0.086 & -1.024 & -0.014 & 0.076 \\
\hline 455 & 0.080 & -1.058 & 0.001 & 0.077 \\
\hline 468 & 0.076 & -1.082 & -0.001 & 0.077 \\
\hline 483 & 0.083 & -1.041 & -0.013 & 0.076 \\
\hline 510 & 0.079 & -1.065 & -0.013 & 0.076 \\
\hline 521 & 0.081 & -1.052 & -0.006 & 0.076 \\
\hline 526 & 0.078 & -1.070 & -0.009 & 0.076 \\
\hline 532 & 0.077 & -1.077 & 0.002 & 0.077 \\
\hline 535 & 0.074 & -1.095 & -0.001 & 0.077 \\
\hline 536 & 0.079 & -1.068 & -0.003 & 0.076 \\
\hline 569 & 0.081 & -1.054 & -0.011 & 0.076 \\
\hline 575 & 0.079 & -1.069 & -0.005 & 0.076 \\
\hline 587 & 0.080 & -1.063 & -0.011 & 0.076 \\
\hline 589 & 0.088 & -1.013 & -0.017 & 0.076 \\
\hline 591 & 0.085 & -1.034 & -0.009 & 0.076 \\
\hline Restriction Site & $\mathbf{p}$ & $\log 10($ PO) & alpha & $\mathbf{F}_{\text {st }}$ \\
\hline \multicolumn{5}{|l|}{ Male Age } \\
\hline 244 & 0.079 & -1.069 & -0.015 & 0.129 \\
\hline 319 & 0.079 & -1.067 & -0.004 & 0.130 \\
\hline 339 & 0.089 & -1.010 & -0.002 & 0.131 \\
\hline
\end{tabular}




\begin{tabular}{|c|c|c|c|c|}
\hline 340 & 0.087 & -1.023 & -0.016 & 0.129 \\
\hline 343 & 0.081 & -1.056 & -0.012 & 0.130 \\
\hline 347 & 0.072 & -1.111 & -0.011 & 0.129 \\
\hline 353 & 0.082 & -1.047 & -0.018 & 0.129 \\
\hline 362 & 0.085 & -1.033 & -0.014 & 0.129 \\
\hline 367 & 0.078 & -1.071 & -0.010 & 0.130 \\
\hline 376 & 0.074 & -1.097 & 0.003 & 0.131 \\
\hline 419 & 0.084 & -1.040 & -0.013 & 0.130 \\
\hline 425 & 0.071 & -1.118 & -0.001 & 0.130 \\
\hline 437 & 0.085 & -1.032 & -0.012 & 0.130 \\
\hline 451 & 0.085 & -1.031 & -0.024 & 0.129 \\
\hline 483 & 0.077 & -1.081 & 0.012 & 0.132 \\
\hline 484 & 0.083 & -1.041 & -0.006 & 0.130 \\
\hline 508 & 0.083 & -1.042 & -0.014 & 0.129 \\
\hline 532 & 0.078 & -1.070 & 0.003 & 0.131 \\
\hline 541 & 0.078 & -1.073 & -0.010 & 0.130 \\
\hline 589 & 0.073 & -1.101 & -0.013 & 0.129 \\
\hline 591 & 0.072 & -1.110 & -0.001 & 0.130 \\
\hline Restriction Site & p & $\log 10(P O)$ & alpha & $\mathbf{F}_{\mathrm{st}}$ \\
\hline \multicolumn{5}{|l|}{ Female Age } \\
\hline 135 & 0.080 & -1.063 & -0.021 & 0.150 \\
\hline 144 & 0.080 & -1.059 & -0.014 & 0.151 \\
\hline 209 & 0.082 & -1.050 & -0.010 & 0.151 \\
\hline 290 & 0.081 & -1.056 & -0.013 & 0.151 \\
\hline 297 & 0.088 & -1.015 & -0.021 & 0.151 \\
\hline 305 & 0.078 & -1.070 & -0.016 & 0.151 \\
\hline 325 & 0.074 & -1.097 & 0.006 & 0.153 \\
\hline 340 & 0.076 & -1.084 & -0.001 & 0.152 \\
\hline 350 & 0.081 & -1.057 & 0.003 & 0.152 \\
\hline 368 & 0.078 & -1.075 & -0.011 & 0.151 \\
\hline 419 & 0.081 & -1.055 & -0.012 & 0.151 \\
\hline 543 & 0.081 & -1.055 & -0.018 & 0.150 \\
\hline 458 & 0.082 & -1.049 & 0.004 & 0.153 \\
\hline 468 & 0.075 & -1.089 & -0.001 & 0.152 \\
\hline 509 & 0.079 & -1.064 & -0.008 & 0.152 \\
\hline 532 & 0.079 & -1.068 & -0.003 & 0.152 \\
\hline 541 & 0.081 & -1.054 & -0.005 & 0.152 \\
\hline 569 & 0.078 & -1.070 & -0.022 & 0.150 \\
\hline Restriction Site & $\mathbf{p}$ & $\log 10(P O)$ & alpha & $\mathbf{F}_{\mathrm{st}}$ \\
\hline \multicolumn{5}{|l|}{ Male TerrGas } \\
\hline 155 & 0.083 & -1.044 & -0.009 & 0.147 \\
\hline 289 & 0.081 & -1.052 & -0.023 & 0.146 \\
\hline 292 & 0.085 & -1.030 & -0.017 & 0.146 \\
\hline 333 & 0.088 & -1.018 & -0.027 & 0.145 \\
\hline 368 & 0.081 & -1.054 & -0.019 & 0.146 \\
\hline 371 & 0.090 & -1.003 & 0.020 & 0.151 \\
\hline
\end{tabular}




\begin{tabular}{llccc}
446 & 0.078 & -1.075 & -0.010 & 0.147 \\
448 & 0.081 & -1.052 & -0.028 & 0.145 \\
455 & 0.076 & -1.087 & 0.003 & 0.148 \\
541 & 0.087 & -1.020 & -0.016 & 0.147 \\
\hline
\end{tabular}

